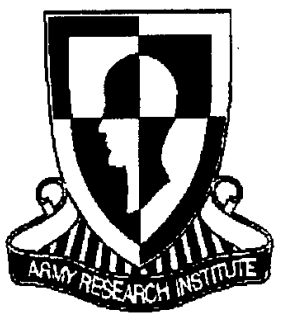

Research Product 98-07

\title{
Direct and Lead Units in Execution of Battle (Battlefield Function 20) as Accomplished by a Heavy Brigade Volume 1: Function Analysis
}
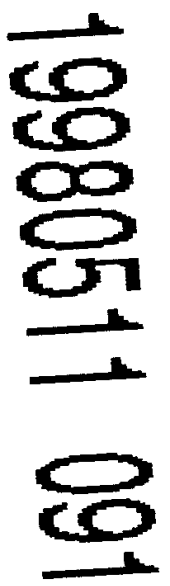

Kent E. Harrison and Terry P. Bartkoski PRC, Inc.

Charles Getz

BDM Federal, Inc.

Dorothy L. Finley and Kathleen A. Quinkert

U.S. Army Research Institute

January 1998

Armored Forces Research Unit

U.S. Army Research Institute for the Behavioral and Social Sciences 


\section{REPORT DOCUMENTATION PAGE}

\begin{tabular}{l|l}
$\begin{array}{l}\text { 1. REPORT DATE (dd-mm-y) } \\
\text { January } 1998\end{array}$ & $\begin{array}{l}\text { 2. REPORT TYPE } \\
\text { Final }\end{array}$
\end{tabular}

\section{TITLE AND SUBTITLE}

Direct and Lead Units in Execution of Battle (Battlefield Function 20) as Accomplished by a Heavy Brigade Volume 1: Function Analysis

\section{6. $A \cup T H O R(S)$}

Kent E. Harrison (PRC), Terry P. Bartkoski (PRC), Charles Getz (BDM), Dorothy L. Finley (ARI), and Kathleen A. Quinkert (ARI)
7. PERFORMING ORGANIZATION NAME(S) AND ADDRESS(ES)

BDM Federal, Inc. $\quad$ PRC, Inc.

1801 Randolph Road, S.E. 1500 PRC Drive

Albuquerque, NM 87106 McLean, VA 22102
U.S. Army Research Institute for the Behavioral and Social Sciences

ATTN: TAPC-ARI-IK

2423 Morande Street

Fort Knox. KY 40121
9. SPONSORING/MONITORING AGENCY NAME(S) AND ADDRESS(ES)

U.S. Army Research Institute for the Behavioral and Social Sciences

ATTN: TAPC-ARI-IK

5001 Eisenhower Avenue

Alexandria VA 22333-5600

12. DISTRIBUTION/AVAILABILITY STATEMENT

Approved for public release; distribution is unlimited.
3. DATES COVERED (from. . . to)

July 1995 - July 1997

5a. CONTRACT OR GRANT NUMBER

MDA 903-92-D-0075

5b. PROGRAM ELEMENT NUMBER

0602785A

5c. PROJECT NUMBER

A791

5d. TASK NUMBER

2228

5e. WORK UNIT NUMBER

R03

8. PERFORMING ORGANIZATION REPORT NUMBER
10. MONITOR ACRONYM

ARI

11. MONITOR REPORT NUMBER

Research Product 98-07

\section{SUPPLEMENTARY NOTES}

Kathleen A. Quinkert, Contracting Officer's Representative

14. ABSTRACT (Maximum 200 words):

The purpose of the overall research program was to document the synchronization required by command and control tasks performed within the armored brigade, to include combat support and combat service support units. The immediate application of the documentation was to support developers of staff training in two related projects: Battle Staff Training System and Staff Group

Trainer. The documentation was also intended to assist with the planning and execution of collective training.

The documentation approach was to apply function analysis (FA) techniques for battlefield functions (BFs) in the Command and Control battlefield operating system. Thirteen FAs were developed for the brigade headquarters and four supporting units: direct support field artillery battalion, engineer battalion, forward support battalion, and air defense artillery battery. The FAs were revised through a formative evaluation process that included internal review and successive external reviews by combat training centers, proponent agencies, and a review council representing potential users of the FAs. The final products include the FAs, a user's guide, and assessment packages for the BFs. This report provides the FA and user's guide for BF20 as performed by a heavy brigade headquarters.

15. SUBJECT TERMS

Structured Training Staff Training Multiechelon Training Training Strategy

Functions Analysis of Functions Command and Control

\begin{tabular}{|c|c|c|c|c|c|}
\hline $\begin{array}{l}\text { 16. REPORT } \\
\text { Unclassified }\end{array}$ & $\begin{array}{l}\text { 17. ABSTRACT } \\
\text { Unclassified }\end{array}$ & $\begin{array}{l}\text { 18. THIS PAGE } \\
\text { Unclassified }\end{array}$ & $\begin{array}{l}\text { 19. LIMITATION OF } \\
\text { ABSTRACT } \\
\text { Unlimited }\end{array}$ & $\begin{array}{l}\text { 20. NUMBER } \\
\text { OF PAGES } \\
488\end{array}$ & $\begin{array}{l}\text { 21. RESPONSIBLE PERSON } \\
\text { (Name and Telephone Number) } \\
\text { Kathleen A. Quinkert } \\
(502) 624-6928 / 3450\end{array}$ \\
\hline
\end{tabular}




\title{
Direct and Lead Units in Execution of Battle (Battlefield Function 20) as Accomplished by a Heavy Brigade Volume 1: Function Analysis
}

\author{
Kent E. Harrison and Terry P. Bartkoski \\ PRC, Inc.
}

\author{
Charles Getz \\ BDM Federal, Inc.
}

\section{Dorothy L. Finley and Kathleen A. Quinkert \\ U.S. Army Research Institute}

\section{Armored Forces Research Unit \\ Barbara A. Black, Chief}

U.S. Army Research Institute for the Behavioral and Social Sciences 5001 Eisenhower Avenue, Alexandria, Virginia 22333-5600

January 1998 
One of the goals for the U.S. Army Research Institute for the Behavioral and Social Sciences (ARI) is to facilitate the development of training strategies that will serve the needs of the combined arms team today and into the 21 st century. The indispensable foundations, the cornerstones, for meeting this goal are solid information and data bases. One such base is a set of comprehensive descriptions of how soldiers accomplish their missions. Many task descriptions have been developed where the focus is on activities within a particular Battlefield Operating System (BOS); these are often further narrowed to one BOS element within one echelon. What have been lacking are function analyses along with task descriptions that have a broader BOS perspective; one which focuses not only on intra-BOS relationships, but also the relationships of that BOS with other BOSs in accomplishing the overall mission. It is this latter perspective which is needed, for example, to define training requirements and strategies for combined arms operations.

The function analysis described in this report is a product of one of three efforts conducted under the ARI project, "Innovative Tools and Techniques for Brigade and Below Staff Training (ITTBBST)." The work in this part of ITTBBST is the fifth in a series of ARI projects directed at analyzing the vertical and horizontal synchronization required by combined arms operations. All of the projects have analyzed functions, previously labeled "critical combat functions (CCFs)" and now labeled "battlefield functions (BFs)." The previous projects analyzed: all BFs performed by a heavy battalion task force; a sample of seven BFs performed by an armored brigade; and the integration of fire support BFs as performed by an armored brigade and at echelons higher than brigade. The research in this project analyzed BFs in the Command and Control BOS. Separate coordinated analyses of these BFs were performed for the armored brigade headquarters and four types of supporting units.

The analyses developed in the project have been used in the development of staff training in related projects within the ITTBBST program. In addition, U.S. Army Training and Doctrine Command (TRADOC) representatives have identified a variety of applications by TRADOC training and other developers as well as potentials for collective training management.

ZITA M. SIMUTIS

Technical Director 
This analysis has benefited from considerable dedicated effort on the part of many persons. The efforts of a few of these many persons are specifically and gratefully acknowledged here. An especially key person was MG (Ret) Lon E. Maggart, Commanding General of the U.S. Army Armor Center (USAARMC). Prior to and during the conduct of this effort, he contributed greatly to definition of training needs and concepts in support of Force XXI. He saw that battlefield functional analyses could provide a valuable foundation for Force XXI training development efforts; hence, MG (Ret) Maggart strongly backed these efforts.

COL G. Patrick Ritter and LTC Marvin K. Decker, acting in accordance and agreement with MG (Ret) Maggart's vision, vigorously pursued battlefield function analysis efforts and persevered in ensuring their application to Force XXI training developments. COL Ritter, Director of Directorate of Training Development and Doctrine (DTDD) at USAARMC, and LTC Decker, Chief of DTDD's Force XXI Training Program office, ensured implementation of necessary actions, and the participation of military subject matter experts and potential users of function analysis products as needed to assure quality outcomes.

Among many participants in performing the analyses themselves, and validating their integrity and validity, were members of the Battle Command Training Program, U.S. Army Command and General Staff College, TRADOC Program Integration Office-Army Battle Command System, DTDD at USAARMC, Joint Readiness Training Center (JRTC), and Operations Group at the National Training Center (NTC). Final recommendations and approval of these analyses were provided by proponents and users constituting the Force XXI Review Council. Members of the Review Council included: COL G. Patrick Ritter and LTC Marvin K. Decker, U.S. Army Armor School (USAARMC); LTC James R. Harrison, U.S. Army Armor School (USAARMS); LTC Larry Newman, U.S. Army Air Defense Artillery School; LTC David M. Annen, U.S. Army Field Artillery School; COL Philip Federle, U.S. Army Engineer School; LTC Roger F. Murtie, National Training Center; LTC Gilbert Pearsall, Joint Readiness Training Center; COL Roger W. Jones, TRADOC Program Integration Office-Army Battle Command System; and COL Robert J. Fulcher, 29th Infantry Regiment.

The research for and preparation of this report benefited immeasurably from the assistance provided by members of the U.S. Army Research Institute. Specifically, the authors would like to acknowledge Ms. Dorothy Finley for serving as a peer reviewer for the product. She offered constructive comments that have improved both the content and style of the report. Also, special recognition is given to Ms. May Throne, a Consortium Research Fellow from the University of Louisville assigned to Fort Knox, and Ms. Lori Cracknell. Their never ending efforts to assist in the formal production of this report will not soon be forgotten.

Finally, a large debt of gratitude is owned to BG (Ret) Bill Mullen for guidance and support on this product. He provided the program management that ensured this product is well "synched" with past products as well as the Army of the future. His continual attention to details have provided the Army with a truly unique document. 
DIRECT AND LEAD UNITS IN EXECUTION OF BATTLE (BATTLEFIELD FUNCTION

20) AS ACCOMPLISHED BY A HEAVY BRIGADE VOLUME 1: FUNCTION ANALYSIS

CONTENTS

Page

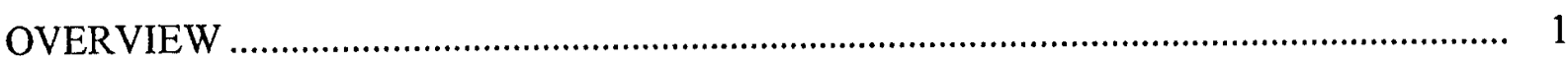

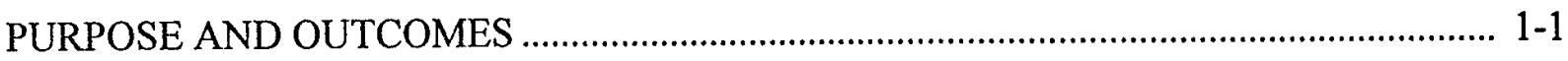

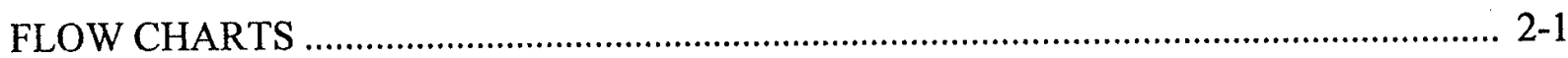

TASK LINKAGES TO OTHER BFs/UNITS ………….................................................... 3-1

KEY PARTICIPANTS BY TASK …….......................................................................... 4-1

KEY INPUTS AND OUTPUTS ..................................................................................... 5-1

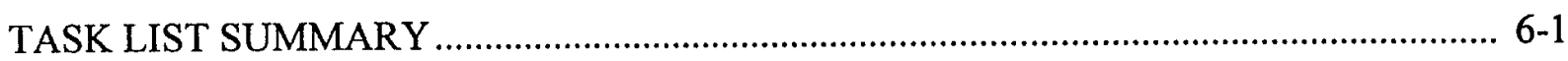

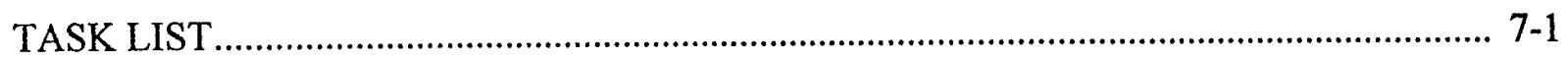

TASKS ORGANIZED BY OUTCOMES ……………...................................................... 8-1

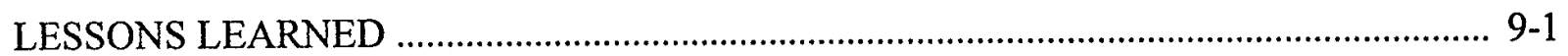

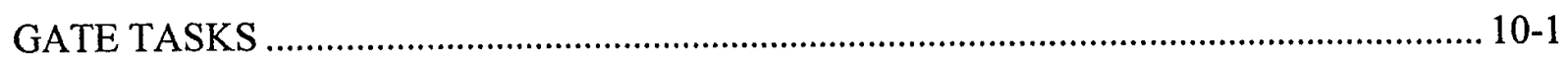

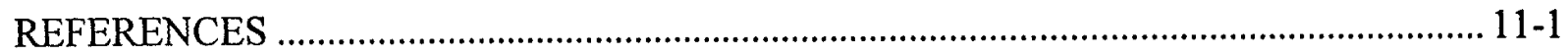

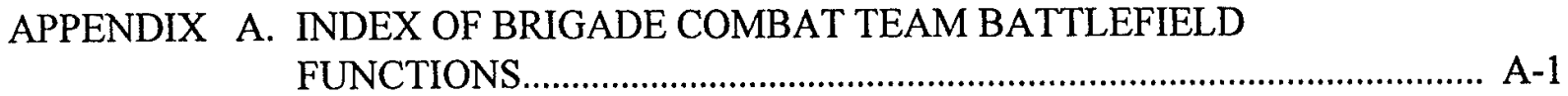

B. STRUCTURE OF BATTLEFIELD FUNCTIONS RELEVANT TO
BRIGADE OPERATIONS .................................................................. B-1

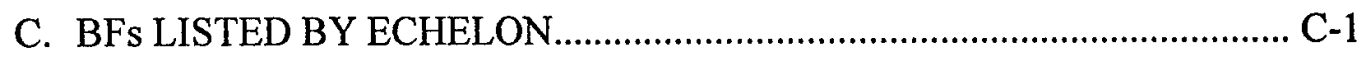

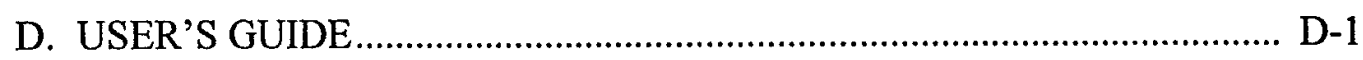

E. ACRONYMS AND ABBREVIATIONS …………................................... E-1 


\section{LIST OF FIGURES}

Figure 1. Depiction of a task contributing to the accomplishment of another task.

2. Depiction of the relationship between tasks and subtasks..................................... 2-2

3. Depiction of placement of the box reflecting information input and output........... 2-2

D-1. Assessment worksheet for heavy brigade performance of BF 18 ...................... D-7

D-2. Overview of tasks by outcomes for BF 18 FA ................................................ D-8

D-3. Example of supporting tasks extracted from the Task List of BF 18 FA.............. D-9

D-4. Excerpt from References component of BF 18 FA ............................................ D-9

D-5. Excerpt from Lessons Learned Integrated into the TASK List component of

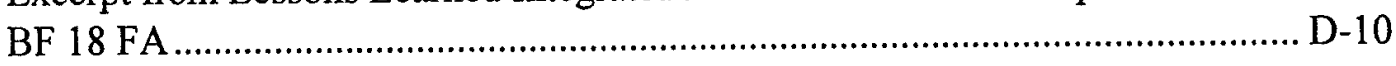

D-6. Excerpt from Key Participants by Task component of BF 18.......................... D-10

D-7. Excerpt from Key Inputs and Outputs component of BF 18 FA........................ D-12

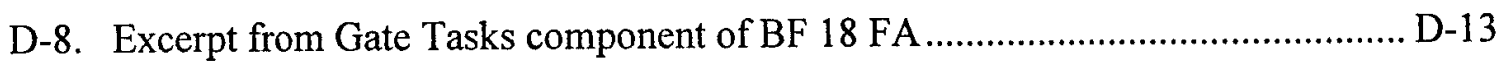

D-9. Extract from CATS for battalion task force ………………………………..... D-14 


\section{OVERVIEW}

The results of the Army Research Institute's (ARI) examination of battlefield functions (BFs) relevant to a heavy (armored or mechanized) brigade combat team's combined arms operations are in two volumes. Volume 1, Function Analysis, identifies and describes various components necessary to accomplish the function. The components were selected based on their relevance to a unit trainer's interests. Volume 2, Assessment Package, is an assessment aid. It describes performance measures based on the purpose, outcomes, and tasks supporting the outcomes identified in the Function Analysis (Volume 1).

This overview provides the user with necessary and relevant information concerning the analysis of BF 20, Direct and Lead Units in Execution of Battle, as performed by a brigade. Participants and organizational structure identified in this analysis are based on table of organization and equipment (TO\&E) 87042L100, dated 10/05/95, and augmented (special staff additions) by Field Manual (FM) 71-3, January 1996.

This function analysis (FA), Direct and Lead Units in the Execution of Battle (BF 20), is a product of the process of developing a training strategy for the brigade. It is the third of three BFs (Plan, Prepare, Execute) which compose the command and control (C2) battlefield operating system (BOS). The analysis reflects all the tasks, participants, products, and processes required by the brigade to achieve the outcomes necessary for the commander to direct and lead his brigade during the execution phase of a battle.

A battlefield function is defined as processes or activities occurring over time that must be performed to accomplish a mission(s) or supporting critical tasks. It provides task integration, combined arms interaction, and inter-Battlefield Operating Systems (BOSs) linkages. ${ }^{1}$

Synchronization, the process of massing the effects of combat power at the specific place and time chosen by the commander, starts in the planning phase (BF 18) when the brigade commander first visualizes and then articulates his intent and concept of the operation to his staff and subordinate/supporting commanders. Synchronization continues into the preparation phase (BF 19) with the rehearsals, other preparations for battle and refinements of the original operations plan. In the execution phase of the battle the brigade commander must make timely decisions based upon the rapidly changing situation. He will be the center of multiple cycles of monitoring, planning, and directing as he and his brigade react to change in mission, enemy, terrain, troops, and time (METT-T).

Synchronization of BFs provides commanders at tactical echelons with a definable outcome that materially effects the battle. Without this synchronization, it is doubtful that a commander's concept and intent will be achieved.

1 The term "Battlefield Function (BF)" was designated by the U.S. Army Training and Doctrine Command (TRADOC) in September 1996 to replace "Critical Combat Function (CCF)". At the same time, the term was redefined. TRADOC also renamed "task analysis" (TA) to "function analysis" (FA). 
The analysis identifies the critical tasks and subtasks undertaken by the brigade commander, his staff, and the brigade subordinate/supporting commanders. It reflects the continuation of the activities undertaken in performing BFs 18 and 19 , as well as those tasks unique to fighting the brigade deep, close, and rear battles. For the purpose of the analysis, the function is depicted as beginning when the enemy or the brigade attacks and ends after the battle, when the brigade consolidates, reorganizes, and is prepared for the next mission.

The brigade commander must ensure that his staff and subordinate/supporting commanders provide him with information that allows him to update his estimate of the situation in the context of time-distance relationships and the capability to achieve the endstates envisioned as necessary to accomplish the brigade mission. He must focus on these desired endstates in spite of the intense tempo of the battle. He must winnow out information that may clutter his thought processes.

The military decision-making process (MDMP) outlined in the 1993 publication of FM 101-5, Command and Control for Commanders and Staff "Draft," is the basis of the processes described in this function analysis. At the time of writing this analysis (August - December 1996), the Command and General Staff College, proponent for FM 101-5, Command and Control for Commanders and Staff, was in the process of rewriting the draft manual. This function analysis recognizes the decision by the Commanding General, Combined Arms Center, that there is only one MDMP and that commanders in the field will have to modify the single process based on situation constraints. The authors have coordinated continuously with the Command and General Staff College to ensure that the doctrine reflected in this analysis is accurate and current. However, information reflected in the recently published FM 101-5 (31 May 1997) will most likely require minor modification of this analysis. The currency of this analysis will also be affected by changes to unit capabilities, such as the additional technology (e.g., information systems), now in different stages of fielding. The MDMP performed under time constraints has been addressed for each task. Although these procedures can be used under any planning circumstances, they most commonly would be used by the battalion commander and staff when time for planning is short (such as when faced with the need to issue a fragmentary order (FRAGO) during the battle). As will be seen, the portrayal of the performance of the MDMP under time constraints does not omit steps, but instead recommends procedures to reduce the time required to conduct planning.

This analysis also reflects current and emerging Army doctrine based on FM 71-3, The Armored and Mechanized Infantry Brigade, January 1996, and its portrayal of the decision-making process. The currency of this analysis will be affected by changes to unit capabilities, such as the additional technology (e.g., information systems), now in different stages of fielding.

Based on experience and intuition, the brigade commander assigns missions, prioritizes and allocates resources, selects the critical times and places to act, and decides when and how to make adjustments during the battle. Normally, during the battle he uses the military decision-making process (MDMP) in a time-constrained environment. 
He plans for and rehearses actions for the eventuality that his brigade tactical command post (TAC CP) or he become casualties or are out of contact, so that the brigade will continue the fight without interruption or loss of momentum. He and the brigade staff also ensure that the brigade can quickly transition from the present battle into readiness for the next mission.

This analysis includes the leading and motivation of soldiers and units, both vital components of battle command. A characteristic of this analysis is the identification of tasks that are performed in battlefield conditions of high stress, time constraints, and the rapidly changing situation coupled with the need to act faster than the enemy. The brigade commander must be able to swiftly assess the situation based on a synthesis of information he has received, make quick, sound decisions, and rapidly disseminate those decisions to generate speed and efficiency relative to the tempo of the combat. He must be able to receive, evaluate, and learn from information received. He must communicate to those who assist him with the information to be used in the planning process that modifies or changes his previous orders for the tasking of subordinate/supporting commanders. Once deciding on a course of action, he must direct and lead the brigade in the accomplishment of the mission. There is no universally appropriate single sequence of steps that leads to success. Battle command is tactical judgment and effective decision-making combined with leadership. The commander's ability to command and control is extended by tailoring the composition of the brigade command posts.

An effort was made to identify specific task titles taken directly from the appropriate Army Training and Evaluation Program - Mission Training Plans (ARTEP-MTP). The wording of each task in this analysis is sometimes a direct quote from MTP. Generally, however, the wording of the tasks is an integration of tasks and requirements derived from ARTEP-MTPs, applicable Field Manuals (FMs), and other related documents. Those tasks not taken from the ARTEP-MTPs are: a) derived titles that may apply only to a part of an ARTEP-MTP subtasks or some other element of the ARTEP-MTP; b) multiple subtasks from several different, but related, tasks; c) tasks that are not directly stated in the ARTEP-MTP, but are implied by other tasks or requirements in an applicable FM or other related document; d) tasks derived from Center for Army Lessons Learned publications; e) tasks developed during coordination visits with TRADOC proponent schools, FORSCOM units, and the Combat Training Centers; or, f) performance requirements considered necessary based on experience of the analyst. 


\section{PURPOSE AND OUTCOMES}

This component identifies what the battlefield function (BF) is supposed to accomplish overall, which we term as the purpose. This component also identifies the endstates or bottom line results necessary to achieve the purpose, which we term outcomes. As a consequence, this component of the analysis defines the endstates that performance of the tasks will accomplish.

\section{PURPOSE}

To accomplish the brigade's assigned mission within the division and corps commander's intents.

\section{OUTCOMES}

1. Brigade command posts (CPs) maintain continuous communications with higher, adjacent, and subordinate headquarters.

2. The brigade commander, staff, and other key individuals within the heavy brigade receive, evaluate, and process timely and accurate battlefield information.

3. Tactically sound recommendations are developed and critical information is communicated by the heavy brigade staff and others within the brigade.

4. Sound (feasible, suitable, acceptable) decisions are made by the brigade commander and others within the heavy brigade.

5. Affected units and personnel receive relevant direction, changes, and refinements to the plan in time to perform troop leading procedures and execute coordinated and synchronized actions.

6. The brigade staff ensures that the brigade commander's guidance and orders are executed and that all relevant actions are coordinated with higher, adjacent, and subordinate headquarters. 
7. Subordinate leaders demonstrate an understanding of the critical elements of their own mission and missionessential tasks, the brigade mission, and the brigade commander's intent.

8. Soldiers and units are motivated, disciplined, and maintain unit cohesion.

9. The brigade command and control capability is effective, survives, and is prepared for the next mission. 


\section{FLOW CHARTS}

This component provides a graphical/pictorial description of BF tasks as they are sequenced within the framework of tactical battle phases (e.g., planning, preparation, execution). The purposes of this component are: to describe the flow of tasks during each battle phase; to describe vertical task linkages (to higher and lower echelon units) and horizontal task linkages (to other BF tasks for the echelon being analyzed); and to depict information input and output which affect each task. Although the sequencing of tasks throughout each battle phase is intended to reflect the flow of tasks, tasks may be performed concurrently or may overlap with preceding or subsequent tasks.

Each echelon is described by the echelon on the left of the flow chart; a horizontal line depicts the flow of tasks by sequence, reading left to right. The horizontal line for the echelon being analyzed is thicker than all other echelon horizontal lines.

Tasks from the BF task list are applied to the echelon line in the sequence in which they occur. The tasks are depicted in a task box. Inside and to the upper left of each task box is placed the task number of the appropriate task as listed in the task list.

The linkages of tasks, both vertically and horizontally, are depicted with lines. Arrowheads are placed on lines to depict linkages or interaction with other tasks. The linkage or interaction between these tasks is detailed in the task list.

Figure 1 illustrates the battalion (Bn) or battalion task force (Bn TF) task contributing to or otherwise supporting the brigade (Bde) task.

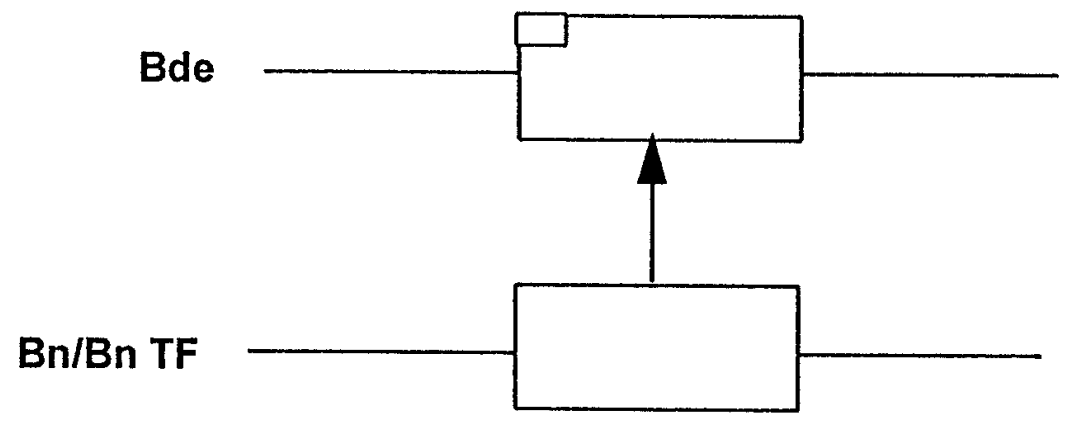

Figure 1. Depiction of a task contributing to the accomplishment of another task. 
Lines with no arrowheads reflect a task and its subordinate (sub)tasks. Figure 2 illustrates this association.

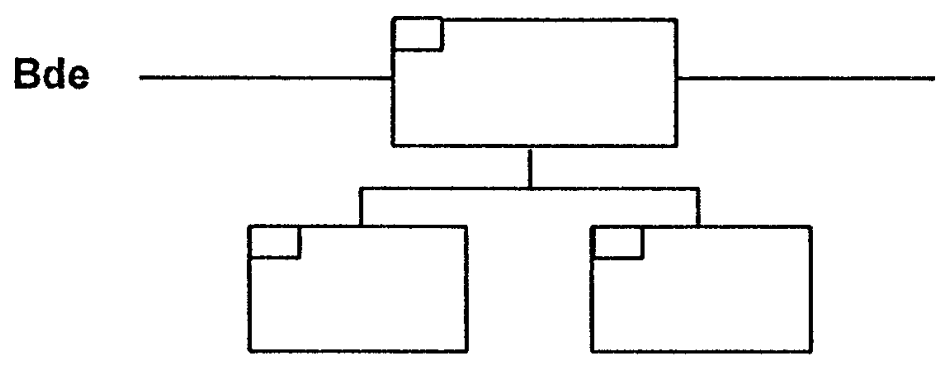

Figure 2. Depiction of the relationship between tasks and subtasks.

Inputs and/or outputs, as contained in the "Key Inputs and Outputs" component (section 5) of this BF function analysis (FA), are also reflected on the flow charts. The relevant input and/or output letter listed in the "Key Inputs and Outputs" component is listed in a box on the outside upper right of the task. Relevant information input for each task is depicted to demonstrate information which is required to perform the task; output information is that which is produced as a result of performing the task. Figure 3 illustrates how information input and output are depicted.

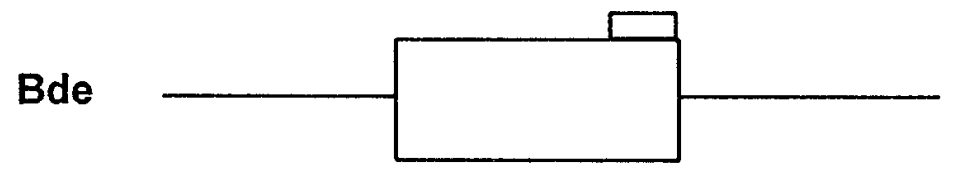

Figure 3. Depiction of placement of the box reflecting information input and output. 


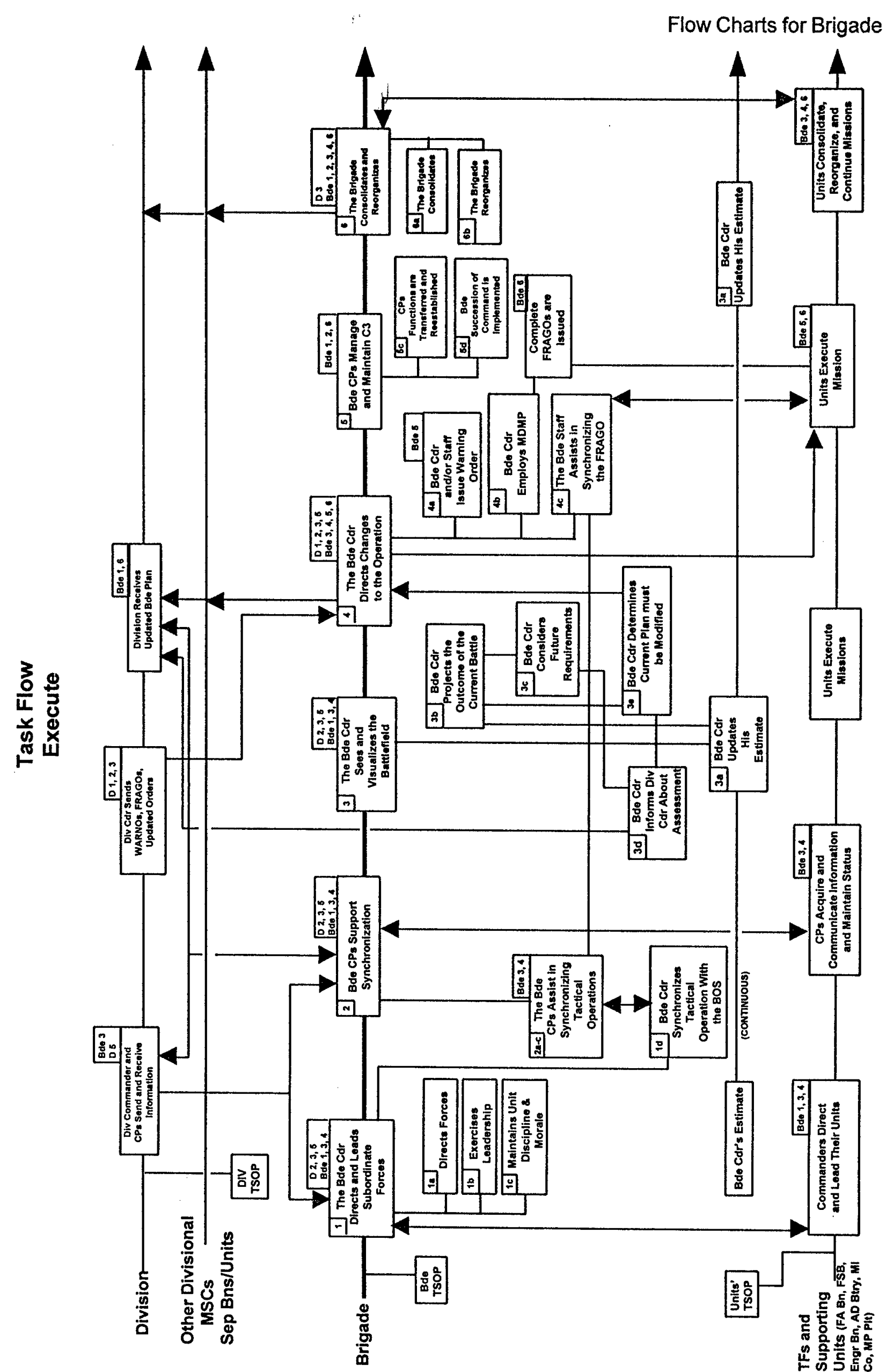




\section{TASK LINKAGES TO OTHER BFs/UNITS}

This component links the tasks performed as a part of this function with the tasks performed in other BFs or by other units. The purpose of this component is to allow the trainer or training developer to incorporate related tasks and participants into a training exercise for this BF. Tasks which link to this analysis have been extrapolated for BFs/type units for which function analyses (FAs) have not been accomplished. For tasks extracted from published BF FAs, the task number is provided.

\section{TASKS}

1. The brigade commander directs and leads subordinate forces.

\section{LINKS TO OTHER BFs/UNITS}

Division BF 8.

- $\quad$ The division artillery (DIVARTY) conducts counterfire operations.

Division BF 11.

- The division conducts psychological operations (PSYOP).

Division BF 20.

- The division commander conducts briefbacks with major subordinate command (MSC) commanders.

Division BF 26.

- The division plans deception operations.

Brigade BF 10.

- The combat and electronic warfare and intelligence (CEWI) battalion conducts electronic warfare (EW) operations.

Brigade BF 15, Task 24.

- The brigade targeting team monitors, coordinates, and synchronizes the employment of indirect fires.

Field Artillery (FA) Bn BF 20, Task 1.

- $\quad$ The direct support (DS) FA Bn commander (Cdr) directs and leads subordinate forces.

Engineer (ENGR) Bn BF 20, Task 1.

- The engineer battalion commander directs and leads subordinate forces. 
TF BF 20, Task 4.

- $\quad$ TF commanders directs and leads subordinate forces.

TF BF 20, Task 1. a. 8) a) (2).

- $\quad \mathrm{TF}$ commander or $\mathrm{S} 3$ personally perform coordination with adjacent/forward battalions on brigade command net.

Forward Support Bn (FSB) BF 20, Task 1.

- The FSB commander directs and leads subordinate forces.

2. Brigade command posts support synchronization by acquiring, evaluating, and communicating information.
Division BF 19.

- $\quad$ Adjacent maneuver brigades dispatch liaison officers (LNOs) to the brigade.

Division BF 20.

- Division units operating adjacent to brigades coordinate with the brigade headquarters (HQ) and subordinate units.

FA Bn BF 20, Task 2.

- The DS FA Bn Cdr, with staff assistance, commands, controls, and synchronizes the FA cannon battalion fire support operations.

ENGR Bn BF 20, Task 2.

- Engineer battalion CPs provide communication and control.

TF BF 20, Task 1.

- TF CPs acquire and communicate information and maintain status.

FSB BF 20, Task 2.

- $\quad$ FSB CP supports synchronization by acquiring, evaluating, and communicating information.

Air Defense Artillery (ADA) BF 16, Task 15.

- The brigade and the ADA battery 
acquire, evaluate, and communicate $\mathrm{AD}$ information.

3. The brigade commander sees and visualizes the battlefield.
Division BF 20.

- The division conducts a fragmentary order (FRAGO) briefing.

- The division publishes operations plans (OPLANs).

- The division commander provides guidance on follow-on missions and future operations to the brigade commander.

Brigade BF 15, Task 30.

- The brigade commander visualizes the battlefield.

FA Bn BF 20, Task 2. a. 8).

- The Bde fire support coordinator (FSCOORD), Bde fire support officer (FSO), and Bde fire support element (FSE) section obtain fire support information related to synchronizing fire support for the brigade.

ENGR Bn BF 20, Task 2. c.

- The engineer battalion commander and staff communicate information.

TF BF 20, Task 1. a. 8) a) (2).

- $\quad T F$ commander or operations and training officer (S3) personally perform coordination with adjacent/forward battalions on brigade command net.

TF BF 2, Task 3 .

- Conduct reconnaissance and surveillance (R\&S).

FSB BF 20, Task 2. c.

- The FSB CPs and staff communicate information necessary to ensure a synchronized brigade battle. 
DS Military Intelligence Company (MI Co)

BF 2.

- The MI Co interrogation team interrogates enemy prisoners of war (EPW) and provides information to the brigade $\mathrm{S} 2$.

- $\quad$ The unmanned aerial vehicle (UAV) platoon leader ensures UAV mission operations.

4. The brigade commander directs changes to the operation or plan.

Division BF 20.

- The LNOs to division and to/from adjacent units provide the brigade FRAGO to their respective HQ.

FA Bn BF 20, Task 3. d. 4).

- The DS FA Bn Cdr assesses the impact of new FRAGOs from Bde.

FA Bn BF 20, Task 4. c. 12).

- The DS FA Bn Cdr approves FRAGOs and directs members of his staff to issue FRAGOs based on his approval or in compliance with his guidance.

ENGR Bn BF 20, Task 3. d.

- The engineer battalion commander informs the supported maneuver brigade commander of the results of his assessment.

ENGR Bn BF 20, Task 4. e.

- The engineer battalion commander approves FRAGOs and directs members of the staff to issue FRAGOs based on his approval or in compliance with his guidance.

TF BF 20, Task 2.

- Assess situation, the TF commander visualizes the battlefield. 
TF BF 20, Task 3.

- Determine actions, the TF commander directs changes to the operation or plan.

FSB BF 20, Task 3. d.

- The FSB commander informs the division support command (DISCOM) and brigade commanders of the results of his battalion assessment.

FSB BF 20, Task 4. b. 12).

- The FSB commander approves and directs issuance of the FRAGO.

5. Brigade command posts manage and maintain command, control, and communications.
Division BF 18.

- The division signal battalion establishes the division area communications system.

Division BF 15.

- $\quad$ The DIVARTY establishes tactical fire direction system (TACFIRE)/ advanced field artillery tactical data system (AFATDS) network.

Brigade BF 25.

- The brigade provides operations security (OPSEC).

Brigade BF 24.

- The engineer battalion provides survivability position construction support for brigade CPs.

Air Defense (AD) Battery BF 16, Task 15. a.

- Brigade CPs and AD battery tactical operations center (TOC) receive $\mathrm{AD}$ information.

AD Battery BF 16, Task 17. d.

- $\quad$ ADA battery elements engage enemy aircraft.. 


\section{DS MI Co BF 2.}

- The DS MI Co commander establishes all source analysis system (ASAS) in support of the brigade $\mathrm{S} 2$.

6. The brigade consolidates and reorganizes
Division BF 31.

- The division G-4 and DISCOM support weapons system replacement operations (WSRO).

Brigade BF 31.

- $\quad$ The brigade supply/logistics officer (S4), adjutant/personnel officer (S1), and the FSB maintain weapons systems and equipment.

ENGR Bn BF 20, Task 6. a.

- The engineer battalion supports brigade consolidation with engineer operations.

TF BF 20, Task 6.

- $\quad$ TF consolidates and reorganizes.

FSB BF 20, Task 6. a.

- The FSB assists the brigade in consolidation and/or reorganization. 


\section{KEY PARTICIPANTS BY TASK}

This component identifies the training audience for training events for the related tasks. It is based on the appropriate echelon/type unit table of organization and equipment (TO\&E) and includes special staff (as per appropriate doctrinal reference) critical for the task accomplishment. The purpose of this component is to help commanders and trainers to identify the training audience required for a training event.

\section{TASKS}

1. The brigade commander directs subordinate forces.

2. Brigade command posts support synchronization by acquiring, evaluating, and communicating information.

3. The brigade commander sees and visualizes the battlefield.

\section{PARTICIPANTS}

Brigade Commander (Bde Cdr), Bde Command Sergeant Major (CSM), Bde Executive Officer (XO), Bde S3, Bde S3 Air, Bde S2, Bde S4, Bde Fire Support Coordinator (FSCOORD), Bde Direct Support (DS) Engineer (Engr) Battalion (Bn) Cdr, Bde USAF Air Support Officer (ALO), Bde Air Defense Officer (ADO), Bde Chemical Officer (CMLO), Task Force (TF) Cdrs

Bde Cdr, Bde CSM, Bde XO, Bde S1, Bde S1 section, Bde S2, Bde S2 section, Bde DS Military Intelligence (MI) Company (Co), Bde S3, Bde S3 Air, Bde Army Air Command and Control (A2C2) element, Bde S3 section, Bde S4, Bde S4 section, Bde civilian and military operations (S5), Bde FSCOORD, Bde Fire Support (FSO), Bde Fire Support Element (FSE), Bde Targeting Officer, Bde Assistant Brigade Engineer (ABE), Bde ABE section, Bde Signal officer (SO), Bde Signal Support section, Bde CMLO, Bde Nuclear, Biological, Chemical (NBC) section, Forward Support Battalion (FSB) support operations section, Bde Surgeon, Bde ALO, Bde Army Aviation Liaison Officer (AVLO), Bde Naval Gunfire Liaison Officer (NGLO), Bde ADO, Bde Military Police (MP) Platoon (Plt) Leader (Ldr), Bde Headquarters and Headquarters Company (HHC) Cdr

Bde Cdr, Bde XO, Bde S1, Bde S1 Section, Bde S2, Bde intelligence (S2) Section, Bde 
4. The brigade commander directs changes to the operation or plan.

5. Brigade command posts manage and maintain command, control, and communications.
6. The brigade consolidates and reorganizes.
S3, Bde S3 Section, Bde S4, Bde S4

Section, Bde S5, Bde Signal Support section, Bde NBC section, Bde FSCOORD/FSO/FSE section, Bde ABE section, FSB Cdr, Bde ALO, Bde AVLO, Bde ADO, Task Force (TF) Cdrs, Division (Div) $\mathrm{Cdr}$

Bde Cdr, Bde XO, Bde S1, Bde S2, Bde S3, Bde S4, Bde S5, Bde FSO, Bde ABE, FSB Cdr, Bde ALO, Bde AVLO, Bde ADO.

Bde Cdr, Bde XO, Bde S1, Bde S1 section, Bde S2, Bde S2 section, Bde DS MI Co, Bde S3, Bde S3 Air, Bde A2C2 element, Bde $\mathrm{S} 3$ section, Bde $\mathrm{S} 4$, Bde $\mathrm{S} 4$ section, Bde S5, Bde FSO, Bde FSE, Bde targeting team, Bde ABE, Bde ABE section, Bde SO, Bde Signal Support section, Bde CMLO, Bde NBC section, FSB support operations section, Bde ALO, Bde AVLO, Bde NGLO, Bde ADALO, Bde MP Plt Ldr, Bde HHC Cdr, Liaison Officers (LNO), Bde Battle Captains, Bde Command Posts (CP) Information managers, Bde Radio net operators

Bde Cdr, Bde CSM, Bde XO, Bde S1, Bde S1 section, Bde S2, Bde S2 section, Bde S3, Bde $\mathrm{S} 3$ section, Bde $\mathrm{S} 4$, Bde $\mathrm{S} 4$ section, Bde S5, Bde FSCOORD, Bde FSO, Bde FSE, Bde ABE, Bde SO, Bde CMLO, FSB $\mathrm{Cdr}$ /support operations section, Bde Surgeon, Bde ALO, Bde AVLO, Bde NGLO, Bde ADO, Bde HHC Cdr, Subordinate and supporting unit Cdrs and staff 


\section{KEY INPUTS AND OUTPUTS}

This component identifies critical input information required by participants to successfully accomplish the BF. Where information results from the performance of the BF tasks, BF information output will be identified. One BF's information output normally is provided as another BF's input. Critical input and output information is organized by the specific part of the doctrinal product or the means used to communicate the information. The orders' content reflected below is based on information obtained during the revision of the 1993 draft of FM 101-5. The orders outlines have been expanded to facilitate development of material to support unit training. The source of critical information identified is specific only to the BF echelon and function being analyzed, and is not intended to reflect all the information the product may contain. The purpose of this component is to identify information required to drive a training exercise for this $\mathrm{BF}$ and to establish standards for measuring the performance of $\mathrm{BF}$ tasks resulting in information output.

\section{KEY INPUTS}

\section{D - 1 DIVISION WARNING ORDER (WARNO)}

a. HEADING

1) References: maps, charts, and other relevant documents.

2) Time zone used throughout the order.

3) Task organization.

b. SITUATION

1) Enemy forces. Include significant changes of information.

2) Friendly forces.

a) Corps mission.

b) Corps commander's intent.

c) Corps concept of operation.

d) Missions of units to the immediate left and right of the division.

e) Missions of other units with a significant bearing on the division.

3) Attachments and detachments. 


\section{c. MISSION}

\section{d. EXECUTION}

Intent of the division commander (if available).

1) Concept of operation (when available).

2) Tasks to maneuver units (when available).
a) Tasks to units for execution.
b) Movement to be initiated (time).
c) Reconnaissance to be initiated (time).
d) Security to be in place (time).

3) Tasks to combat support units (when available).

4) Coordinating instructions.
a) Commander's critical information requirements (CCIR).
b) Risk guidance.
c) Deception guidance.
d) Timeline.
e) Guidance on orders and rehearsals.
f) Orders group meeting (attendees, location, and time) (when applicable).
g) Earliest time of movement and amount of notice.

\section{e. SERVICE SUPPORT}

1) Special equipment: Identify requirements and coordinate transfer to using units. 
2) Transportation: Identify requirements and coordinate for prepositioning of assets.

f. COMMAND AND SIGNAL

1) Command. Chain of command if different from division standing operating procedures (SOP).

2) Signal. Identify current signal operating instructions (SOI) and prepositioning of assets to support the operation.

g. ACKNOWLEDGE (Statement directing acknowledgment of receipt and understanding.)

D - 2 DIVISION OPERATIONS ORDER (OPORD)

a. HEADING

1) References. (Maps, charts, DATUM, and other related documents needed to understand the order).

2) Task Organization.

b. SITUATION

1) Enemy forces.

a) Description of the enemy to brigade level.

b) Enemy most probable course of action (COA).

c) Enemy most dangerous (to the division) COA.

d) Assessment of terrorist activities directed against the division.

2) Friendly forces.

a) Echelons above corps (EAC) mission.

b) EAC commander's intent.

c) EAC concept of operation. 
d) Corps mission.

e) Corps commander's intent.

f) Corps concept of operation.

g) Missions of units to the immediate left and right of the division.

h) Missions of other units with a significant bearing on the division.

3) Attachments and detachments.

c. MISSION

d. EXECUTION

Intent of the division commander.

1) Concept of operation (by phase if required).

a) Maneuver.

b) Fire Support.

(1) Main effort.

(2) Priority of fires.

c) Mobility and Survivability.

(1) Priority of support.

(2) Priority of mobility and survivability assets as appropriate for GS units.

(3) Designation of authority to emplace obstacles.

d) Air Defense.

(1) Priority of air defense.

(2) $\mathrm{AD}$ weapons status. 
(3) $\mathrm{AD}$ warning status.

e) Command and Control Warfare (C2W).

2) Tasks to maneuver units.

a) Infantry.

b) Armor.

c) Cavalry.

d) Aviation.

3) Tasks to combat support units.

a) Fires.

(1) Air support.

(a) Close air support (CAS) sorties allocation.

(b) Tactical air reconnaissance sorties allocation.

(2) Chemical support. (Priorities of reconnaissance, decontamination, and smoke.)

(3) Field artillery support.

(a) General. (Priorities for counterfire or interdiction.)

(b) Organization for combat.

(4) Naval surface fires (NSF).

(5) Fire support coordinating instructions.

b) Mobility and Survivability.

(1) Engineer (and engineer overlay).

(2) Nuclear, biological, and chemical (NBC) operations. 
c) Air Defense.

(1) Organization for combat.

(2) Missions.

(3) Priorities for protection.

d) $\mathrm{C} 2 \mathrm{~W}$.

(1) Functional and support roles of attached MI units.

(2) Deception.

(3) Electronic warfare (EW).

(4) Psychological warfare.

(5) Unmanned aerial vehicle (UAV).

4) Coordinating instructions.

a) Time or condition when the division OPORD becomes effective.

b) $\mathrm{CCIR}$

(1) Priority intelligence requirements (PIR) (if not addressed in Annex B [Intelligence]).

(2) Essential elements of friendly information (EEFI) (if not addressed in Annex B [Intelligence]).

(3) Friendly forces information requirements (FFIR) (if not addressed in Annex B [Intelligence]).

c) Risk reduction control measures.

(1) Antiterrorist actions.

(2) Mission-oriented protective posture (MOPP).

(3) Operational exposure guidance (OEG). 
(4) Vehicle recognition signals.

(5) Fratricide prevention measures.

d) Rules of engagement (ROE).

e) Environmental considerations.

f) Any other coordinating instructions or additional instructions.

\section{e. SERVICE SUPPORT}

1) Support concept.

a) Synopsis of the division support command (DISCOM) mission.

b) DISCOM headquarters and/or division support area locations.

c) The corps support command (COSCOM) support priorities and where the division fits into those priorities.

d) The division commander's priorities of support.

e) COSCOM units supporting the division.

f) Significant and/or unusual combat service support (CSS) issues that might impact the overall division operation.

g) Any significant CSS risks.

h) Support requirements in the functional areas of manning, arming, fueling, fixing, and moving.

2) Material and services.

3) Medical evacuation (MEDEVAC) and hospitalization.

4) Personnel.

5) Civil-military cooperation. 
6) Miscellaneous.

f. COMMAND AND SIGNAL

1) Command.

a) Map coordinates for division CP locations.

b) Chain of command if different from division SOP.

2) Signal.

a) Signal instructions.

b) Identification of current SOI.

c) Required division reports, formats, and times due (if different from tactical standing operating procedures (TSOP)).

g. ACKNOWLEDGE

h. ANNEXES:

1) A-Task organization

2) B-Intelligence

a) SITUATION

(1) Enemy.

(a) Terrain.

(b) Weather.

(c) Enemy capabilities and/or activities.

$1 \quad$ Known and templated locations and activities of enemy units to brigade level.

$2 \quad$ Significant enemy maneuver and other functional area capabilities that 
impact on accomplishment of division functions.

$3 \quad$ Expected employment of enemy assets based on most probable enemy course of action.

(2) Friendly situation.

(3) Attachments and detachments.

b) MISSION

c) EXECUTION

(1) Concept of intelligence support to support the overall division operation.

(2) Tasks to subordinate units. (Detailed intelligence acquisition tasks by unit.)

(3) Multidisciplined counterintelligence (CI). (Special operational instructions having $\mathrm{CI}$ aspects.)

(4) Coordinating instructions.

(a) Intelligence requirements and their priority.

(b) Intelligence acquisition.

1 Requests to corps, EAC, adjacent, and cooperating units (for intelligence information).

2 Requests for information from other units not organic or attached.

(c) Measures for handling personnel, documents, and material.

1 Enemy prisoners of war (EPW), deserters, repatriates, civilian inhabitants of area, and other persons. 

a Special handling and segregation instructions.
b Location of EPW collection points.

2 Captured documents. (Special instructions for handling and processing from time of capture to receipt by specified division intelligence personnel [if different from TSOP].)

3 Captured material. (Specially designated items or categories of enemy material required for examination; specific instructions for their processing and disposition [if different from TSOP].)

(d) Documents or equipment required.

(Description of the conditions under which subordinate units can obtain or request documents or equipment, such as air photographs and maps [if different from TSOP].)

(e) Distribution of intelligence products.

1 Periods that routine reports and distribution cover.

2 Distribution of special intelligence products.

d) SERVICE SUPPORT

e) COMMAND AND SIGNAL

f) APPENDICES:

(1) Appendix 1 - Intelligence Estimate.

Tab 1 Situation Overlay. 
(2) Appendix 2 - Reconnaissance and Surveillance.

(3) Appendix 3 - Signals Intelligence.

(4) Appendix 4 - Multidisciplined CI Estimate.

3) C-Operation Overlay

4) D-Fire Support

a) SITUATION

(1) Enemy.

(a) Description of enemy fire support and $\mathrm{AD}$ assets up to corps and down to battalion.

(b) Enemy capabilities and/or activities.

1 Enemy rocket, cannon, and missile artillery.

2 Numbers of possible enemy CAS and attack helicopter sorties by day.

3 Number, type, yield, and delivery means of enemy NBC weapons available to the committed force.

(2) Friendly situation.

(a) Corps concept of fires.

(b) Adjacent units' concepts of fires.

(c) Supporting air and naval forces.

(3) Attachments and detachments.

b) MISSION

c) EXECUTION 
(1) Concept of fires to support the division commander's concept and priority of fire support.

(2) Air support.

(a) Division commander's intent for use of air power.

(b) Air interdiction (AI) operations.

(c) CAS operations.

(d) Electronic combat (EC) operations.

(e) Reconnaissance and surveillance (R\&S) operations.

(f) Miscellaneous.

$1 \quad$ Air tasking order (ATO) effective time period.

2 Deadlines for submission of AI, CAS, $\mathrm{R} \& \mathrm{~S}$, and $\mathrm{EC}$ requests.

$3 \quad$ Mission request numbering system as it relates to the target numbering system.

$4 \quad$ JSEAD taskings.

$5 \quad$ Essential A2C2 measures.

(3) Field artillery support.

(a) Concept for use of cannon, rocket, and missile artillery in support of close, deep, and rear operations.

(b) Artillery organization for combat.

(c) Allocation of ammunition.

(d) Miscellaneous. 
1 Changes to the targeting numbering system.

$2 \quad$ Use of pulse repetition frequency (PRF) codes.

3 Positioning restrictions.

(4) NSF.

(a) Concept for use of NSF support.

(b) NSF organization and relationships of ship to units (DS, general support (GS)).

(c) Miscellaneous.

1 Trajectory limitations or minimum safe distances.

2 Frequency allocations.

(5) Chemical support.

(6) Offensive EW support. (Concept for use of EW (jamming) in close and deep operations.)

(7) Target acquisition.

(a) Employment and allocation of FA targetacquisition systems and IEW assets.

(b) Specific target-acquisition tasks, the observation matrix, fire support execution matrix, and radar deployment order.

(8) Coordinating instructions.

(a) Deep operations boundary.

(b) Targeting products.

1 Target-selection standards matrix. 
2 High-payoff target list (HPTL).

3 Attack-guidance matrix (AGM).

(c) Fire support coordination measures (FSCMs).

(d) Time of execution of program of fires relative to $\mathrm{H}$-Hour.

(e) ROE.

d) SERVICE SUPPORT

(1) Location of ammunition transfer points (ATPs) and ammunition supply points (ASPs).

(2) Controlled supply rate (CSR).

e) COMMAND AND SIGNAL

f) APPENDICES:

(1) Appendix 1 - Air Support.

(2) Appendix 2 - Field Artillery.

(3) Appendix 3 - Naval Surface Fires.

5) E-Mobility and Survivability

a) SITUATION

(1) Enemy.

(a) Terrain.

(b) Weather.

(c) Enemy engineer capabilities and/or activities.

$1 \quad$ Known and templated locations and activities of enemy engineer units to battalion level. 
2 Significant enemy maneuver and engineer capabilities that impact division engineer operations.

3 Expected employment of enemy engineer assets based on most probable enemy course of action.

(2) Friendly situation.

(3) Attachments and detachments.

b) MISSION

c) EXECUTION

(1) Scheme of mobility and survivability operations to support the overall division operation, by phase and in priority.

(2) Tasks to subordinate units.

(3) Coordinating instructions.

(a) ROE for engineer units.

(b) Reference to supporting appendices.

d) SERVICE SUPPORT

(1) Command-regulated classes of supply.

(2) Supply distribution plan.

(3) Transportation.

(4) Combat health support.

(5) Host Nation.

(a) Type, location, facilities, assets, and support available. 
(b) Procedures for requesting and acquiring host nation $(\mathrm{HN})$ support.

(c) Limitations and restrictions on $\mathrm{HN}$ support.

e) COMMAND AND SIGNAL

f) APPENDICES:

(1) Appendix 1 - Engineer.

(a) Scheme of engineer operations to support the overall division operation. The engineer main effort by mission and unit for each phase of the operation. Corps level missions that impact the division.

1 Obstacles. (The details of the countermobility effort. Identification of obstacle belts to support division deep, close, and rear operations. Identification, prioritization, and assignment of responsibilities for corps and division directed and reserve targets execution criteria for reserve targets.)

2 Situational obstacles. (Concept for employing situational obstacles to support the division plan. Division planned and executed obstacles. Division planned and brigade executed obstacles. Division resourced and brigade planned and executed obstacles. Criteria for each type of obstacle with designation of HQ maintaining authority to use scatterable mines [SCATMINEs]; restrictions on duration [by belt].)

(b) Tasks to subordinate units.

(c) Coordinating instructions. 
1 Times or events at which obstacle belts become effective.

2 Division PIR to be considered by subordinate engineer staffs and that PIR must be reported.

3 Mission reports required.

$4 \quad$ Explanation of engineer work lines.

\section{(d) SERVICE SUPPORT}

\section{(e) COMMAND AND SIGNAL}

(2) Appendix 2 - Environmental Considerations.

(a) Operational effect on environment versus military advantage.

(b) Coordinating instructions.

1 Certification of local water sources.

2 Solid waste and liquid waste management.

3 Medical waste.

$4 \quad$ Hazardous waste management.

$5 \quad$ Flora and fauna protection.

6 Archeological and historical preservation.

(d) SERVICE SUPPORT

(e) COMMAND AND SIGNAL (Responsibility for initial environmental considerations guidance. Point of contact, for processing requested waivers to environmental governing standards, responsibility for coordinating and issuing 
guidance on disposal of hazardous material and wastes.)

(3) Appendix 3 - Nuclear, Biological, and Chemical (NBC) Operations.

(a) Scheme of NBC defense operations to support the overall division operation.

(b) Tasks to subordinate units.

(c) Coordinating instructions.

1 MOPP level guidance.

$2 \quad$ Automatic masking criteria.

$3 \quad$ Troop safety criteria.

$4 \quad$ Decontamination site locations.

5 Medical facilities and locations for treating chemical casualties.

6 Turn-in points for chemical/biological samples.

$1 \quad$ List of civilian and military facilities whose destruction could create militarily significant NBC hazards.

$8 \quad$ OEG guidance (if applicable).

2 Procedures for limiting electromagnetic pulse (EMP) effects.

(d) SERVICE SUPPORT

(Procedures for handling contaminated casualties. Information on availability and locations of field expedient decontamination supplies, materials, and decontaminants.)

(e) COMMAND AND SIGNAL

(NBC warning and reporting system.) 
(f) Tabs:

1 Tab 1- NBC Defense.

2 Tab 2 - Smoke operations.

6) F-Air Defense

a) SITUATION

(1) Enemy.

(a) Terrain. Most likely routes of enemy ingress and egress.

(b) Weather.

(c) Enemy air capabilities and/or activities.

1 Air threat data. (Air-capable enemy organizations including platforms by number and type. Enemy aircraft with all weather capabilities and limitations.)

2 Additional air threat information. (Air threat information not covered in the intelligence annex. Specific air threat considerations: sortie rate, subordination of air elements to ground units, ordnance peculiarities, target preferences, tactics, and recent significant activities.)

3. Pattern of use of air avenues of approach.

(2) Friendly situation. (Description of how the air defense plan integrates with division plans.)

(3) Attachments and detachments.

b) MISSION 


\section{c) EXECUTION}

(1) Scheme of ADA support to the overall division operation. (Includes the division commanders intent, objectives, and priorities.)

(2) Tasks to subordinate units. (Command and support relationships and priority of protection.)

(3) Coordinating instructions.

(a) Air defense warning (ADW) and $\mathrm{ADW}$ authority.

(b) Specific orders and requests (SOR) plan.

(c) Weapons control status (WCS) and WCS authority.

(d) Hostile criteria.

(e) ROE.

(f) Passive air defense.

(g) Combined arms for air defense.

(h) Early warning.

\section{d) SERVICE SUPPORT}

e) COMMAND AND SIGNAL

(IFF code edition and book number.)

7) G-Command and Control Warfare (C2W)
a) SITUATION
b) MISSION
c) EXECUTION 
(1) Scheme of support for $\mathrm{C} 2 \mathrm{~W}$ to the overall division operation.

(a) Military deception.

(b) EW.

(c) OPSEC.

(d) PSYOP.

(e) Physical destruction.

(2) $\mathrm{C} 2 \mathrm{~W}$ tasks. (Exercise of coordinating authority for $\mathrm{C} 2 \mathrm{~W}$ operations. Division commander's C2W objectives and guidelines for accomplishment. Joint restricted fire list [JRFL] to support operations.)

d) SERVICE SUPPORT

e) COMMAND AND SIGNAL

f) APPENDICES:

(1) Appendix 1- Electronic Warfare.

(2) Appendix 2 - Operations Security.

(3) Appendix 3 - Deception.

(4) Appendix 4 - PSYOP.

8) H-Signal Operations (SO)

a) SITUATION

(1) Enemy.

(a) Terrain. (All critical aspects that will impact on employment of $\mathrm{C} 2$ communications systems.) 
(b) Enemy capabilities and/or activities. (Significant enemy EW capabilities that impact C2 systems.)

(2) Friendly situation. (Primary communications gateways providing connectivity to corps, brigades and adjacent units. Critical communications measures required to counter expected enemy EW capabilities and protect $\mathrm{C} 2$ systems. External communication assets that will augment the division signal support.)

b) MISSION

c) EXECUTION

(1) Concept of signal support to support the overall division operation. (Primary and back-up systems supporting critical $\mathrm{C} 2$ networks. Plan for extending $\mathrm{C} 2$ systems through each phase of the division operation. Critical links between tactical and strategic communications systems [if applicable]. Signal support priorities.)

(2) Tasks to subordinate units. (Tasks to specific maneuver and signal support units not contained in the five paragraphs of the division OPORD. Detailed Army battle command system (ABCS) control procedures.)

(3) Coordinating instructions. (Key times or events critical to information system and network control procedures.)

d) SERVICE SUPPORT

e) COMMAND AND SIGNAL (C2 systems control [SYSCON] hierarchy for common user network. Local area network control procedures for network administration and/or management.)

9) I-Provost Marshal (PM)

a) SITUATION 
b) MISSION

c) EXECUTION

(1) Scheme of provost marshal operations to support the overall division operation.

(a) Maneuver and mobility support. (Battlefield circulation control [BCC] plan. Route R\&S. Main supply route [MSR] traffic control. Straggler control. Refugee control. Intelligence collecting and reporting.)

(b) Area security. (Rear area protection plan, to include base defense. Security of critical assets. Base response force [Levels I, II, III]. Counterincursion. Air ground defense. Terrorism counteraction. Area damage control $[\mathrm{ADC}]$. NBC detection and reporting.)

(c) Internment and resettlement operations. EPW holding areas. EPW operations.

(d) Law and order operations. (Maintenance of law and order in rear area forward to maneuver units' rear boundaries).

(2) Tasks to subordinate units.

(3) Coordinating instructions. (Refer to Annex K [Rear Operations]. Coordination/cooperation among adjacent and other units. Civilian $\mathrm{HN}$ agencies which are required to complete the mission. Actions pertaining to rear area force protection that expand or differ from the division TSOP.)

d) SERVICE SUPPORT

e) COMMAND AND SIGNAL

10) J-Civil-Military Operations (CMO) 
a) Scheme of operation for civil-military support to the overall division operation.

b) Tasks to subordinate units.

c) Coordinating instructions.

d) Signal. (Reporting functions for units and CMO activities. special operations forces (SOF) [if appropriate] specific communications procedures to support CMO.)

11) K-Rear Operations

a) SITUATION

b) MISSION

c) EXECUTION

(1) Scheme of rear area operations to support the overall division operation. (Support for the brigade deep, and close operations by executing rear operations.)

(a) Terrain management.

(b) Security. (Tactical combat force (TCF), response force, and reaction force.

Counterreconnaisance plan. CI tasks to assist in threat reduction, location, and identification. Plan for integrating $\mathrm{HN}$, multinational, or joint forces support.)

(c) Sustainment. Monitoring of sustainment operations within the division. Identify positioning of support assets and critical CSS facilities and movements that require priority protection. Plan for establishment of forward supply points.)

(d) Movements. (Monitoring of administrative and tactical movements in the rear area. Identification critical choke points that require sustained engineer support. Plan for routing of sustainment on MSRs to ensure no 
interference with movement of tactical units. Plan for tracking of all units moving through the rear area.)

(2) Tasks to subordinate units.

(a) Tactical combat force (TCF).

(b) Military police. Response force. (Establishment of traffic control points.)

(c) Base/base clusters. Reaction force. (Establishment of LP/OPs. Patrols.)

(3) Coordinating instructions. (Establishment of operations centers. Reaction forces. Liaison with the rear CP. Terrain management, coordination. Base defense plans.)

\section{d) SERVICE SUPPORT}

e) COMMAND AND SIGNAL (Location of rear operations commander. Chain of command for the rear CP. Base and base cluster commanders and chain of command. Deconfliction of chain of command with chain of support. Alternate rear CP location.)

12) L-Service Support

a) SITUATION (see base OPORD)

b) MISSION (see base OPORD)

c) EXECUTION

(1) Scheme of service support operations to support the overall division operation.

(2) Tasks to subordinate units.

(3) Coordinating instructions.

d) SERVICE SUPPORT 
(1) Material and Services.

(a) Supply. (Information by class of supply. Supply cycle [as appropriate] plan and procedures by class of supply.)

(b) Transportation. (Land, sea, and air [as applicable]. Facility locations, traffic control, regulation measures, MSRs and alternate supply routes (ASRs), transportation critical shortages, and essential data not provided elsewhere.)

1 Road movement table.

2 Traffic circulation.

(c) Services. (Construction. clothing exchange and bath (CEB) and laundry. Mortuary affairs. Identification of services available; designation and location of units providing services.)

(d) Labor.

(e) Maintenance. (Aircraft, ground vehicle and other equipment and watercraft maintenance. Priority of maintenance, location of facilities and collecting points, repair time limits at each level of maintenance, and evacuation procedures.)

(2) MEDEVAC. (Evacuation. Hospitalization. Plan for collection, medical treatment, MEDEVAC policy, and hospitalization of sick, injured, or wounded US and joint forces soldiers, EPW, and civilians [as appropriate]. Requirements for combat health support (CHS) logistics, combat stress management, preventive medicine, dental services, and veterinary services.)

(3) Personnel. (Unit strength maintenance. Morale. Plans for unit strength maintenance, personnel management, morale development and maintenance, 
discipline, law and order, headquarters management, and religious support.)

(4) Civil-military cooperation. (if not addressed in Annex J, [Civil-Military Operations]).

e) COMMAND AND SIGNAL

f) APPENDICES:

(1) Appendix 1- Service Support Matrix.

(2) Appendix 2 - Service Support Overlay.

(3) Appendix 3 - Traffic Circulation and Control.

Tab 1 Traffic Circulation (Overlay).

Tab 2 Road Movement Table.

(4) Appendix 4 - Personnel.

(5) Appendix 5 - Legal.

Tab 1 ROE

6) Appendix 6 - Religious Support.

13) M-Army Airspace Command and Control (A2C2)

a) SITUATION

(1) Enemy capability and activity. (Known and templated enemy ADA locations and enemy air corridors. Significant enemy maneuver capabilities that affect $\mathrm{A} 2 \mathrm{C} 2$ operations such as radio combat capabilities.)

(2) Friendly situation. (Additional airspace users including Air Force, Navy, Marine, allies, coalition forces. ADA, FA, and UAV that effect the division scheme of maneuver.)

b) MISSION 
c) EXECUTION

(1) Concept of $\mathrm{A} 2 \mathrm{C} 2$ support to the overall division operation.

(2) Tasks to subordinate units.

(3) Coordinating instructions.

(a) All ADA warnings, weapons control status, and ROE.

(b) Rules for in-flight procedures if different from the aviation procedures guide.

(c) Description of liaison procedures.

(d) Hostile and friendly aircraft in the division area of interest.

(e) Routes and corridors (minimum risk routes, low level transit routes [LLTRs], standard use routes, UAV operating areas, restricted operations zones [ROZs], air forces' routes, coordination requirements).

(f) Fire support coordination measures that affect airspace users.

d) SERVICE SUPPORT

e) COMMAND AND SIGNAL

i. DISTRIBUTION

D - 3 DIVISION FRAGMENTARY ORDER (FRAGO)

a. HEADING

b. SITUATION

1) Enemy forces. 
a) Description of the enemy to brigade or regiment level.

b) Enemy most probable course of action.

c) Enemy course of action (COA) most dangerous (to the division) COA.

2) Friendly forces.
a) EAC mission.
b) EAC commander's intent.
c) EAC concept of operation.
d) Corps mission.
e) Corps commander's intent.
f) Corps concept of operation.
g) Missions of units to the immediate left and right of the division.
h) Missions of other units with a significant bearing on the division.

3) Attachments and detachments.

c. MISSION

d. EXECUTION

Intent of the division commander.

1) Concept of operation.

a) Maneuver.

b) Fire Support.
(1) Main effort.
(2) Priority of fires. 
c) Mobility and Survivability.

(l) Priority of support.

(2) Priority of mobility and survivability assets as appropriate for GS units.

(3) Designation of authority to emplace obstacles.

d) Air Defense.

(1) Priority of air defense.

(2) AD weapons status.

(3) $\mathrm{AD}$ warning status.

e) Command and Control Warfare.

2) Tasks to maneuver units.
a) Infantry.
b) Armor.
c) Cavalry.
d) Aviation.

3) Tasks to combat support units.

a) Fires.

(1) Air support.

(a) CAS sorties allocation.

(b) Tactical air reconnaissance sorties allocation.

(2) Chemical support. (Priorities of reconnaissance, decontamination, and smoke.)

(3) Field artillery support. 
(a) General. (Priorities for counterfire or interdiction.)

(b) Organization for combat.

(4) Naval surface fires (NSF).

(5) Fire support coordinating instructions.

b) Mobility and Survivability.

(1) Engineer (and engineer overlay).

(2) Nuclear, biological, and chemical (NBC) operations.

c) Air Defense.

(1) Organization for combat.

(2) Missions.

(3) Priorities for protection.

d) Command and Control Warfare.

(1) Functional and support roles of attached MI units.

(2) Deception.

(3) Electronic warfare.

(4) Psychological warfare.

(5) Unmanned aerial vehicle.

4) Coordinating instructions.

a) Time or condition when the division FRAGO becomes effective.

b) CCIR - Changes from existing division order. 
(1) PIR (if not addressed in changes to Annex B [ntelligence]).

(2) EEFI (if not addressed in changes to Annex B [Intelligence]).

(3) FFIR (if not addressed in changes to Annex B [Intelligence]).

c) Risk reduction control measures that have changed.

d) Rules of engagement changes.

e) Environmental considerations changes.

f) Any other coordinating instructions that changed from the existing division order or additional instructions

\section{e. SERVICE SUPPORT}

1) Support concept.

a) Synopsis of the DISCOM mission.

b) DISCOM headquarters and/or division support area locations.

c) The COSCOM support priorities and where the division fits into those priorities.

d) The division commanders priorities of support.

e) COSCOM units supporting the division.

f) Significant and/or unusual CSS issues that might impact the overall division operation.

g) Any significant CSS risks.

h) Support requirements in the functional areas of manning, arming, fueling, fixing, and moving.

2) Material and services. 
3) Medical evacuation and hospitalization.

4) Personnel.

5) Civil-military cooperation.

6) Miscellaneous.

f. COMMAND AND SIGNAL

1) Command.

a) Map coordinates for division CP locations.

b) Chain of command if different from division SOP.

2) Signal.

a) Signal instructions.

b) Identification of current SOI.

c) Required division reports, formats, and times due.

g. ACKNOWLEDGE

h. ANNEXES

i. DISTRIBUTION

D - 4 DIVISION TACTICAL STANDARD OPERATING PROCEDURE (TSOP)

a. Battle command procedures.

b. Control procedures.

c. Tactical movements procedures.

d. Assembly area occupation procedures.

e. Other tactical operations procedures.

f. Air defense procedures. 
g. $\mathrm{A} 2 \mathrm{C} 2$ procedures.

h. Signal procedures.

i. Intelligence and security procedures.

j. NBC procedures.

k. Engineer procedures.

1. Fire support procedures.

m. Army aviation procedures.

n. Procedures for attachments and detachments.

o. Logistics procedures.

p. Personnel procedures.

q. Military police procedures.

r. CMO procedures.

s. Host nation support procedures.

t. Aerial resupply procedures.

\section{D - 5 \\ GUIDANCE FROM THE DIVISION COMMANDER AND STAFF}

a. Division commander's, assistant division commander's (ADC's), or G3's oral or written guidance.

b. Operational situation reports (OPSITREPs).

c. Periodic personnel report (PPREPT).

d. Periodic intelligence report (PERINTREP).

e. Periodic operation report (PEROPRPT).

f. Air defense procedures.

1) ADWs. 
2) Local ADWs (LADWs).

3) WCS/guidance.

4) Hostile aircraft criteria.

5) ROE.

g. Periodic civil affairs report (PERCARPT).

h. As required reports, e.g.:

1) NBC reports.

2) Bridge report.

3) Crossing report.

4) Meaconing, intrusion, jamming, and interference (MIJ) report.

5) Minefield report.

6) Patrol report.

7) EPW or captured material report.

8) Route reconnaissance report.

9) Severe weather warning report.

\section{Bde - 1 BRIGADE OPERATIONS ORDER (OPORD)}

a. HEADING

1) References. (Maps, charts, DATUM, and other related documents needed to understand the order.)

2) Task organization.

b. SITUATION

1) Enemy forces.

a) Description of the enemy to battalion level.

b) Enemy course of action most probable. 
c) Enemy most dangerous (to the brigade) course of action.

d) Assessment of terrorist activities directed against the brigade.

2) Friendly forces.

a) Corps mission.

b) Corps commander's intent.

c) Corps concept of operation.

d) Division mission.

e) Division commander's intent.

f) Division concept of operation.

g) Missions of units to the immediate left and right of the brigade.

h) Missions of other units with a significant bearing on the brigade's accomplishment of its mission.

3) Attachments and detachments.

c. MISSION

\section{d. EXECUTION}

Intent of the brigade commander.

1) Concept of operation (by phase if required).

a) Maneuver.

b) Fire Support.

(1) Main effort.

(2) Priority of fires.

c) Mobility and Survivability. 
(1) Priority of support.

(2) Priority of mobility and survivability assets as appropriate for GS units.

(3) Designation of authority to emplace obstacles.

d) Air Defense.

(1) Priority of air defense.

(2) $\mathrm{AD}$ weapons status.

(3) $\mathrm{AD}$ warning status.

e) Command and Control Warfare.

2) Tasks to maneuver units.
a) Infantry.
b) Armor.
c) Cavalry.
d) Aviation.

3) Tasks to combat support units.

a) Fires.

(1) Air support.

(a) CAS sorties allocation.

(b) Tactical air reconnaissance sorties allocation.

(2) Chemical support. (Priorities of reconnaissance, decontamination, and smoke.)

(3) Field artillery support. 
(a) General. (Priorities for counterfire or interdiction.)

(b) Organization for combat.

(4) NSF.

(5) Fire support coordinating instructions.

b) Mobility and Survivability.

(1) Engineer (and engineer overlay).

(2) NBC operations.

c) Air Defense.

(1) Organization for combat.

(2) Missions.

(3) Priorities for protection.

d) $\quad$ C2W.

(1) Functional and support roles of attached MI units.

(2) Deception.

(3) EW.

(4) Psychological warfare.

(5) UAV.

4) Coordinating instructions.

a) Time or condition when the brigade OPORD becomes effective.

b) CCIR.

(1) PIR (if not addressed in Annex B [Intelligence]). 
(2) EEFI (if not addressed in Annex B [Intelligence]).

(3) FFIR (if not addressed in Annex B [Intelligence]).

c) Risk reduction control measures.

(1) Antiterrorist actions.

(2) MOPP.

(3) OEG.

(4) Vehicle recognition signals.

(5) Fratricide prevention measures.

d) ROE.

e) Environmental considerations.

f) Any other coordinating instructions or additional instructions.

e. SERVICE SUPPORT

1) Support concept.

a) Synopsis of the FSB mission.

b) FSB headquarters and/or brigade support area locations.

c) The DISCOM support priorities and where the brigade fits into those priorities.

d) The brigade commander's priorities of support.

e) DISCOM units in addition to FSB supporting the brigade.

f) Significant and/or unusual CSS issues that might impact the overall brigade operation.

g) Any significant CSS risks. 
h) Support requirements in the functional areas of manning, arming, fueling, fixing, and moving.

(2) Material and services.

3) MEDEVAC and hospitalization.

4) Personnel.

5) Civil-military cooperation.

6) Miscellaneous.

\section{f. COMMAND AND SIGNAL}

1) Command.
a) Map coordinates for brigade $\mathrm{CP}$ locations.
b) Chain of command if different from brigade SOP.

2) Signal.
a) Signal instructions.
b) Identification of current SOI.
c) Required brigade reports, formats, and times due (if different from TSOP).

g. ACKNOWLEDGE

h. ANNEXES:

1) A-Task organization.

2) B-Intelligence.

a) SITUATION

(1) Enemy.

(a) Terrain. 
(b) Weather.

(c) Enemy capabilities and/or activities.

1 Known and templated locations and activities of enemy units to battalion level.

$2 \quad$ Significant enemy maneuver and other functional area capabilities that impact on accomplishment of brigade functions.

3 Expected employment of enemy assets based on most probable enemy course of action.

(2) Friendly situation.

(3) Attachments and detachments.

\section{b) MISSION}

c) EXECUTION

(1) Concept of intelligence support to support the overall brigade operation.

(2) Tasks to subordinate units. (Detailed intelligence acquisition tasks, by unit.)

(3) Multidisciplined CI. (Special operational instructions having CI aspects.)

(4) Coordinating instructions.

(a) Intelligence requirements and their priority.

(b) Intelligence acquisition.

1 Requests to division, corps, adjacent, and cooperating units (for intelligence information). 
2 Requests for information from other units not organic or attached.

(c) Measures for handling personnel, documents, and material.

1 Enemy prisoners of war (EPW), deserters, repatriates, civilian inhabitants in the area, and other persons.
a $\quad$ Special handling and segregation instructions.
b Locations of EPW collection points.

$2 \quad$ Captured documents. (Special instructions for handling and processing from time of capture to receipt by specified brigade intelligence personnel [if different from TSOP].)

3 Captured material. (Specially designated items or categories of enemy material required for examination; specific instructions for their processing and disposition [if different from TSOP].)

(d) Documents or equipment required. (Description of the conditions under which subordinate units can obtain or request documents or equipment, such as air photographs and maps [if different from TSOP].)

(e) Distribution of intelligence products.

1 Periods that routine reports and distribution cover. 
2 Distribution of special intelligence products.

d) SERVICE SUPPORT

e) COMMAND AND SIGNAL

f) APPENDICES:

(1) Appendix 1 - Intelligence Estimate.

Tab 1 Situation Overlay.

(2) Appendix 2 - Reconnaissance and Surveillance.

(3) Appendix 3 - Signals Intelligence.

(4) Appendix 4 - Multidisciplined CI Estimate.

3) C-Operation Overlay.

4) D-Fire Support.

a) SITUATION

(1) Enemy.

(a) Description of enemy fire support and $\mathrm{AD}$ assets up to division and down to battery/company.

(b) Enemy capabilities and/or activities.

1 Enemy rocket, cannon, and missile artillery.

$2 \quad$ Numbers of possible enemy CAS and attack helicopter sorties by day.

$3 \quad$ Number, type, yield, and delivery means of enemy NBC weapons available to the committed force.

(2) Friendly situation. 
(a) Division's concept of fires.

(b) Adjacent units' concepts of fires.

(c) Supporting air and naval forces.

(3) Attachments and detachments.

b) MISSION

c) EXECUTION

(1) Concept of fires to support the brigade commander's concept and priority of fire support.

(2) Air support.

(a) Brigade commander's intent for use of air power.

(b) AI operations.

(c) CAS operations.

(d) EC operations.

(e) $R \& S$ operations.

(f) Miscellaneous.

$1 \quad$ ATO effective time period.

2 Deadlines for submission of AI, CAS, $\mathrm{R} \& \mathrm{~S}$, and $\mathrm{EC}$ requests.

$3 \quad$ Mission request numbering system as it relates to the target numbering system.

$4 \quad$ Joint suppression of enemy air defenses (JSEAD) taskings.

$5 \quad$ Essential A2C2 measures. 
(3) Field artillery support.

(a) Concept for use of cannon, rocket, and missile artillery in support of close, deep, and rear operations.

(b) Artillery organization for combat.

(c) Allocation of ammunition.

(d) Miscellaneous.

1 Changes to the targeting numbering system.

2 Use of PRF codes.

$3 \quad$ Positioning restrictions.

(4) NSF.

(a) Concept for use of NSF support.

(b) NSF organization and relationships of ships to units (DS, GS).

(c) Miscellaneous.

1 Trajectory limitations or minimum safe distances.

$2 \quad$ Frequency allocations.

(5) Chemical support.

(6) Offensive EW support. (Concept for use of EW [jamming] in close and deep operations.)

(7) Target acquisition.

(a) Employment and allocation of FA targetacquisition systems and IEW assets. 
(b) Specific target-acquisition tasks, the observation matrix, fire support execution matrix, and radar deployment order.

(8) Coordinating instructions.

(a) Deep operations boundary.

(b) Targeting products.

1 Target-selection standards matrix.

2 HPTL.

3 AGM.

(c) FSCMs.

(d) Time of execution of program of fires relative to H-Hour.

(e) ROE.

d) SERVICE SUPPORT

(1) Location of ATPs and ASPs.

(2) CSR.

e) COMMAND AND SIGNAL

f) APPENDICES:

(1) Appendix 1 - Air Support.

(2) Appendix 2 - Field Artillery.

(3) Appendix 3 - Naval Surface Fires.

5) E-Mobility and Survivability.

a) SITUATION

(1) Enemy. 
(a) Terrain.

(b) Weather.

(c) Enemy engineer capabilities and/or activities.

$1 \quad$ Known and templated locations and activities of enemy engineer units to company level.

$\underline{2} \quad$ Significant enemy maneuver and engineer capabilities that impact brigade engineer operations.

3 Expected employment of enemy engineer assets based on most probable enemy course of action.

(2) Friendly situation.

(3) Attachments and detachments.

b) MISSION

c) EXECUTION

(1) Scheme of mobility and survivability operations to support the overall brigade operation, by phase and in priority.

(2) Tasks to subordinate units.

(3) Coordinating instructions.

(a) ROE for engineer units.

(b) Reference to supporting appendices.

d) SERVICE SUPPORT

(1) Command regulated classes of supply.

(2) Supply distribution plan. 
(3) Transportation.

(4) Combat health support (CHS).

(5) Host nation (HN).

(a) Type, location, facilities, assets, and support available.

(b) Procedures for requesting and acquiring $\mathrm{HN}$ support.

(c) Limitations and restrictions on $\mathrm{HN}$ support.

e) COMMAND AND SIGNAL

f) APPENDICES:

(1) Appendix 1 - Engineer.

(a) Scheme of engineer operations to support the overall brigade operation. The engineer main effort by mission and unit for each phase of the operation. Division level missions that impact the brigade.

1 Obstacles. (The details of the countermobility effort. Identifications of obstacle belts to support brigade deep, close and rear operations. Identification, prioritization, and assignment of responsibilities for division and brigade directed and reserve targets. Execution criteria for reserve targets.)

2 Situational obstacles. (Concept for employing situational obstacles to support the brigade plan. Brigade planned and executed obstacles. Brigade planned and battalion/TF executed obstacles. Brigade resourced and battalion/TF planned 
and executed obstacles. Criteria for each type of obstacle with designation of HQ maintaining authority to use SCATMINEs; restrictions on duration [by belt].)

(b) Tasks to subordinate units.

(c) Coordinating instructions.

1 Times or events at which obstacle belts become effective.

$2 \quad$ Brigade PIR to be considered by subordinate engineer staff or PIR that must be reported.

$3 \quad$ Mission reports required.

$4 \quad$ Explanation of engineer work lines.

(g) Service support

(h) Command and signal

(2) Appendix 2 - Environmental Considerations.

(a) Operational effect on environment versus military advantage.

(b) Coordinating instructions.

1 Certification of local water sources.

$2 \quad$ Solid waste and liquid waste management.

3 Medical waste.

$4 \quad$ Hazardous waste management.

$5 \quad$ Flora and fauna protection. 

6 Archeological and historical preservation.

(c) SERVICE SUPPORT

(d) COMMAND AND SIGNAL

(Responsibility for initial environmental considerations guidance. Point of contact for processing requested waivers to environmental governing standards, and instructions for responsible for coordinating and issuing on disposal of hazardous material and wastes.)

(3) Appendix 3 - Nuclear, Biological, and Chemical (NBC) Operations.

(a) Scheme of NBC defense operations to support the overall brigade operation.

(b) Tasks to subordinate units.

(c) Coordinating instructions.

1 MOPP level guidance.

$\underline{2} \quad$ Automatic masking criteria.

$3 \quad$ Troop safety criteria.

4 Decontamination site locations.

5 Medical facilities and locations for treating chemical casualties.

6 Turn-in points for chemical and biological samples.

$1 \quad$ List of civilian and military facilities whose destruction could create militarily significant NBC hazards.

8 OEG guidance (if applicable). 
2 Procedures for limiting EMP effects.

(d) SERVICE SUPPORT

(Procedures for handling contaminated casualties. Information on availability and locations of field expedient decontamination supplies, materials, and decontaminants.)

(e) COMMAND AND SIGNAL

(NBC warning and reporting system.)

(f) Tabs:

1 Tab 1- NBC Defense.

$2 \quad$ Tab 2 - Smoke operations.

6) F-Air Defense

a) SITUATION

(1) Enemy.

(a) Terrain. (Most likely route of enemy ingress and egress.)

(b) Weather.

(c) Enemy air capabilities and/or activities.

1 Air threat data. (Air-capable enemy organizations including platforms by number and type. Enemy aircraft with all weather capabilities and limitations.)

$2 \quad$ Additional air threat information. (Air threat information not covered in the intelligence annex. Specific air threat considerations: sortie rate, subordination of air elements to ground units, ordnance peculiarities, target preferences, tactics, and recent significant activities.) 
3 Patterns of use of air avenues of approach.

(2) Friendly situation. (Description of how the air defense plan integrates with division plans.)

(3) Attachments and detachments.

b) MISSION

c) EXECUTION

(1) Scheme of ADA support to the overall brigade operation. (Includes the brigade commanders intent, objectives, and priorities.)

(2) Tasks to subordinate units. (Command and support relationships and priority of protection.)

(3) Coordinating instructions.

(a) $\mathrm{ADW}$ and $\mathrm{ADW}$ authority.

(b) Specific orders and requests (SOR) plan.

(c) WCS and WCS authority.

(d) Hostile criteria.

(e) ROE.

(f) Passive air defense.

(g) Combined arms for air defense.

(h) Early warning.

d) SERVICE SUPPORT

e) COMMAND AND SIGNAL (IFF code edition and book number.)

7) G-Command and Control Warfare (C2W) 
a) SITUATION

b) MISSION

c) EXECUTION

(1) Scheme of support for $\mathrm{C} 2 \mathrm{~W}$ to the overall brigade operation.

(a) Military deception.

(b) EW.

(c) OPSEC.

(d) PSYOP.

(e) Physical destruction.

(2) $\mathrm{C} 2 \mathrm{~W}$ tasks. (Exercise of coordinating authority for $\mathrm{C} 2 \mathrm{~W}$ operations. Division commander's $\mathrm{C} 2 \mathrm{~W}$ objectives and guidelines for accomplishment. JRFL to support operations.)

d) SERVICE SUPPORT

e) COMMAND AND SIGNAL

f) APPENDICES:

(1) Appendix 1-Electronic Warfare.

(2) Appendix 2 - Operations Security.

(3) Appendix 3 - Deception.

(4) Appendix 4 - PSYOP.

8) H-Signal Operations (SO)

a) SITUATION

(1) Enemy. 
(a) Terrain. (All critical aspects that will impact on employment of $\mathrm{C} 2$ communications systems.)

(b) Enemy capabilities and/or activities. (Significant enemy EW capabilities that impact $\mathrm{C} 2$ systems.)

(2) Friendly situation. (Primary communications gateways providing connectivity to division, battalion/TFs, and adjacent units. Critical communications measures required to counter expected enemy EW capabilities and protect $\mathrm{C} 2$ systems. External communication assets that will augment the brigade's signal support.)

b) MISSION

c) EXECUTION

(1) Concept of signal support to support the overall brigade operation. (Primary and back-up systems supporting critical $\mathrm{C} 2$ networks. Plan for extending C2 systems through each phase of the brigade operation. Critical links between tactical and strategic communications systems [if applicable]. Signal support priorities.)

(2) Tasks to subordinate units. (Tasks to specific maneuver and signal support units not contained in the five paragraphs of the brigade OPORD. Detailed $\mathrm{ABCS}$ control procedures.)

(3) Coordinating instructions. (Key times or events critical to information system and network control procedures.)

d) SERVICE SUPPORT

e) COMMAND AND SIGNAL (C2 SYSCON hierarchy for common user network. Local area network control procedures for network administration and/or management.) 
9) I-Provost Marshal (PM)

a) SITUATION

b) MISSION

c) EXECUTION

(1) Scheme of provost marshal operations to support the overall brigade operation.

(a) Maneuver and mobility support. (BCC plan. Route R\&S. MSR traffic control. Straggler control. Refugee control. Intelligence collecting and reporting.)

(b) Area security. (Rear area protection plan, to include base defense. Security of critical assets. Base response force [Levels I, II, III]. Counterincursion. Air ground defense. Terrorism counteraction. Area damage control. NBC detection and reporting.)

(c) Internment and resettlement operations.

(d) EPW holding areas. EPW operations.

(e) Law and order operations. (Maintenance of law and order in rear area forward to maneuver units' rear boundaries.)

(2) Tasks to subordinate units.

(3) Coordinating instructions. (Refer to Annex K [Rear Operations]. Coordination/cooperation among adjacent and other units. Civilian $\mathrm{HN}$ agencies which are required to complete the mission. Actions pertaining to rear area force protection that expand or differ from the brigade TSOP.)

d) SERVICE SUPPORT

e) COMMAND AND SIGNAL 
10) J-Civil-Military Operations (CMO)

a) Scheme of operation for civil-military support to the overall brigade operation.

b) Tasks to subordinate units.

c) Coordinating instructions.

d) Signal. (Reporting functions for units and CMO activities. SOF [if appropriate] specific communications procedures to support CMO.)

11) K-Rear Operations

a) SITUATION

b) MISSION

c) EXECUTION

(1) Scheme of rear area operations to support the overall brigade operation. Support for the brigade deep, and close operations by executing rear operations.

(a) Terrain management.

(b) Security. (TCF, response force, and reaction force. Counterreconnaisance plan. CI tasks to assist in threat reduction, location, and identification. Plan for integrating $\mathrm{HN}$, multinational, or joint forces support.)

(c) Sustainment. (Monitoring of sustainment operations within the brigade. Positioning of support assets and critical CSS facilities and movements that require priority protection. Plan for establishment of forward supply points.)

(d) Movements. (Monitoring of administrative and tactical movements in the rear area. Identification of critical choke points that 
require sustained engineer support. Plan for routing of sustainment on MSRs to ensure no interference with movement of tactical units. Plan for tracking of all units moving through the rear area.)

(2) Tasks to subordinate units.

(a) Tactical combat force.

(b) Response force.

(c) Military police. (Establishment of traffic control points.)

(d) Base/base clusters. Reaction force. (Establishment of LPs and OPs. Patrols.)

(3) Coordinating instructions. (Establishment of operations centers. Reaction forces. Liaison with the rear $\mathrm{CP}$. Terrain management, coordination. Base defense plans.)

\section{d) SERVICE SUPPORT}

e) COMMAND AND SIGNAL

(Location of rear operations commander. Chain of command for the rear CP. Base and base cluster commanders and chain of command. Deconfliction of chain of command with chain of support. Alternate rear $\mathrm{CP}$ location.)

12) L-Service Support

a) SITUATION (see base OPORD)

b) MISSION (see base OPORD)

c) EXECUTION

(1) Scheme of service support operations to support the overall brigade operation.

(2) Tasks to subordinate units. 
(3) Coordinating instructions.

\section{d) SERVICE SUPPORT}

(1) Material and Services.

(a) Supply. (Information by class of supply. Supply cycle [as appropriate], plan, and procedures by class of supply.)

(b) Transportation. (Land, sea, and air [as applicable]. Facility locations, traffic control, regulation measures, MSRs and ASRs, transportation critical shortages, and essential data not provided elsewhere.)

1 Road movement tables.

$2 \quad$ Traffic circulation.

(c) Services. (Construction. Clothing exchange and bath [CEB] and laundry. Mortuary affairs. Identification of services available; designation and location of units providing services.)

(d) Labor.

(e) Maintenance. (Aircraft, ground vehicles and other equipment and watercraft maintenance. Priority of maintenance, location of facilities and collecting points, repair time limits at each level of maintenance, and evacuation procedures.)

(2) MEDEVAC. (Evacuation. Hospitalization. Plan for collection, medical treatment, MEDEVAC policy, and hospitalization of sick, injured, or wounded US and joint forces soldiers, EPW, and civilians [as appropriate]. Requirements for CHS logistics, combat stress management, preventive medicine, dental services, and veterinary services.) 
(3) Personnel. (Unit strength maintenance. Morale. Plans for unit strength maintenance, personnel management, morale development and maintenance, discipline, law and order, headquarters management, and religious support.)

(4) Civil-military cooperation. (if not addressed in Annex J, [Civil-Military Operations]).

e) COMMAND AND SIGNAL

f) APPENDICES:

(1) Appendix 1- Service Support Matrix.

(2) Appendix 2 - Service Support Overlay.

(3) Appendix 3 - Traffic Circulation and Control.

Tab 1 Traffic Circulation (Overlay).

Tab 2 Road Movement Table.

(4) Appendix 4 - Personnel.

(5) Appendix 5 - Legal.

Tab 1 ROE

(6) Appendix 6 - Religious Support.

13) M-Army Airspace Command and Control (A2C2)

a) SITUATION

(1) Enemy Capability and activity. (Known and templated enemy ADA locations and enemy air corridors. Significant enemy maneuver capabilities that affect $\mathrm{A} 2 \mathrm{C} 2$ operations such as radio combat capabilities.)

(2) Friendly situation. (Additional airspace users including Air Force, Navy, Marine, allies, coalition 
forces. ADA, FA, and UAV that affect the scheme of maneuver.)

b) MISSION

c) EXECUTION

(1) Concept of $\mathrm{A} 2 \mathrm{C} 2$ support to the overall brigade operation.

(2) Tasks to subordinate units.

(3) Coordinating instructions.

(a) All ADA warnings, WCS, and ROE.

(b) Rules for in-flight procedures if different from the aviation procedures guide.

(c) Description of liaison procedures.

(d) Hostile and friendly aircraft in the brigade area of interest.

(e) Routes and corridors. (Minimum risk routes, LLTRs, standard use routes, UAV operating areas, ROZs, air forces' routes, coordination requirements).

(f) Fire support coordination measures that effect airspace users.

d) SERVICE SUPPORT

e) COMMAND AND SIGNAL

i. DISTRIBUTION

Bde - 2 BRIGADE TACTICAL STANDING OPERATING PROCEDURE (TSOP) (Provides for compliance with Army regulations and conformance with Joint/Army doctrine)

a. Battle command procedures. 
1) Succession of command.

2) Alternate command posts (CPs).

3) Displacement of CPs.

4) CP security.

5) Orders and plans.

6) $\mathrm{CP}$ organization layout shifts.

7) CP communications.

8) Reports.

9) Designation and duties of battle captain.

b. Control procedures.

1) Liaison officer (LNO) procedures.

2) Brevity codes.

3) Terrain index reference system.

4) Recognition techniques.

5) Signals.

6) Alarms and warnings.

7) Readiness conditions.

8) Fixed call signs.

c. Tactical movement procedures.

d. Assembly area occupation procedures.

e. Other tactical operations procedures.

1) Link-up operations. 
2) Relief-in-place.

3) Forward passage of lines.

4) Rearward passage of lines.

5) River crossing.

f. Air defense procedures.

1) Air defense warnings.

2) Local air defense warnings.

3) Weapons control status/guidance.

4) Hostile aircraft criteria.

5) ROE.

g. $\mathrm{A} 2 \mathrm{C} 2$ procedures.

1) Organization as required:

a) Brigade S3 Air (chairman).

b) FSO/FSCOORD.

c) Assistant division air defense officer (ADALO).

d) AVLO.

e) NGLO.

f) Brigade S2

g) Brigade Marine air officer (from the air and naval gunfire liaison company [ANGLICO]).

h) Brigade ALO.

2) Conduct. (Meets as required to deconflict artillery fires and air operations.) 
3) Functions:

a) Deconflict brigade airspace for all users.

b) Establish, confirm, and coordinate airspace control measures, such as:

(1) Air routes for ingress and egress synchronization (CAS, UAV).

(2) Identification of flight times and artillery firing times to separate by time.

(3) Designation of airspace coordination areas/boxes.

(4) Identification of fire support coordination times (nofly/no-fire times).

h. Signal procedures.

i. Intelligence and security procedures.

1) General guidance.

2) Named area of interest (NAI)/targeted area of interest (TAI) procedures.

3) Document security.

4) Personnel security.

5) EPW procedures.

6) Captured document and equipment procedures.

7) Battle damage assessment (BDA) procedures.

j. NBC procedures.

1) MOPP guidance.

2) Required NBC teams.

3) Alarms and warnings. 
4) Reporting and marking procedures.

k. Engineer procedures.

1) Priorities for support.

2) Countermobility procedures.

3) SCATMINEs.

4) Mobility operations.

5) Standard obstacles.

1. Fire support procedures.

1) Target numbering.

2) Laser code assignments.

m. Targeting team procedures.

1) Organization. (Bde CDR, XO, S3, S2, FSCOORD, FSO, Targeting Officer, S3 Air, DS MI CO Cdr, DS FA Bn S3 \& S2, other staff representatives, including the ALO, Marine air officer, CMLO, $\mathrm{ADO}, \mathrm{NGLO}$, engineer, Army aviation LNO as required.)

2) Conduct. (Agenda, meeting times.)

3) Functions.

a) Develop the HPTL.

b) Develop the attack guidance.

c) Establish Target Selection Standards (TSS) (TSS=high payoff targets (HPT)+timeliness+accuracy).

d) Nominate targets to higher HQ.

e) Develop and synchronize the R\&S plan.

f) Synchronize maneuver and fire support. 
g) Integrate counter-mobility, mobility, and survivability operations.

h) Receive and evaluate BDA.

i) Monitor fire support systems and ammunition.

j) Develop/synchronize the R\&S plan with the fire support plan.

4) Responsibilities by staff position. (e.g., XO is chairman)

n. Army aviation procedures.

1) Priorities.

2) Supported unit responsibilities.

3) Landing zone (LZ) and pickup zone (PZ) selection and preparation.

o. Procedures for attachments and detachments.

p. Logistics procedures.

1) Reports.

2) Reorganization and reconstitution.

3) Supply.

4) Services.

5) Transportation.

6) Refueling on the move (ROM).

7) Aerial resupply procedures.

q. Personnel procedures.

1) Reports.

2) Replacement operations.

3) Casualty reporting. 
4) Postal.

5) Finance.

6) Health service support (HSS).

7) MEDEVAC.

8) Legal.

9) Public affairs.

10) Religious.

r. Military police (MP) procedures.

s. $\quad$ CMO procedures.

t. HN support procedures.

Bde - 3 GUIDANCE AND INFORMATION FROM THE BRIGADE COMMANDER AND STAFF

a. Oral orders and guidance from the brigade commander, $\mathrm{XO}$, and S3.

b. Operations reports.

c. Intelligence reports.

d. Logistics reports.

e. Personnel reports.

f. As required reports, e.g.:

1) Bridge report.

2) Crossing report.

3) МПЛ report.

4) Minefield report.

5) Patrol report. 
6) EPW or captured material report.

7) Route reconnaissance report.

8) Severe weather warning report.

g. NBC reports.

Bde - 4 REPORTS AND INFORMATION FROM BRIGADE ELEMENTS AND OTHER UNITS

a. Oral and written reports from subordinate and supporting commanders (e.g., SITREPs).

b. Operations reports (including spot reports).

c. Intelligence reports.

d. Logistics reports.

e. Personnel reports.

f. Reports as required by TSOP, e.g.:

1) NBC report.

2) Bridge report.

3) Crossing report.

4) MIJI report.

5) Minefield reports.

6) Patrol report.

7) EPW or captured material report.

8) Route reconnaissance report.

9) Severe weather warning report.

10) Aerial resupply requests.

11) Closing report.

12) MEDEVAC request. 
13) Sensitive items report.

\section{KEY OUTPUTS}

\section{Bde - 5 BRIGADE WARNING ORDER (WARNO)}

a. HEADING

1) References. (Maps, charts, and other relevant documents.)

2) Time zone used throughout the order:

3) Task organization:

b. SITUATION

1) Enemy forces. (Include significant changes of information.)

2) Friendly forces.

a) Division mission.

b) Division commander's intent.

c) Division concept of operation.

d) Missions of units to the immediate left and right.

e) Missions of other units with a significant bearing on the brigade.

3) Attachments and detachments.

c. MISSION of the brigade

d. EXECUTION

Intent of the brigade commander (if available).

1) Concept of operation (when available).

2) Tasks to maneuver units (when available).

a) Tasks to units for execution. 
b) Movement to be initiated (time).

c) Reconnaissance to be initiated (time).

d) Security to be in place (time).

3) Tasks to combat support units (when available).

4) Coordinating instructions.

a) $\mathrm{CCIR}$.

b) Risk guidance.

c) Deception guidance.

d) Timeline.

e) Guidance on orders and rehearsals.

f) Orders group meeting (attendees, location, and time) (when applicable).

g) Earliest time of movement and degree of notice.

e. SERVICE SUPPORT

1) Special equipment. (Identification of requirements and coordination instructions for transfer to using units.)

2) Transportation. (Identification of requirements and coordination for pre-positioning of assets.)

f. COMMAND AND SIGNAL

1) Command. (Chain of command if different from the brigade SOP.)

2) Signal. (Identification of current SOI and prepositioning of assets to support the operation.)

g. ACKNOWLEDGE (Statement directing acknowledgment of receipt and understanding.)

Bde - 6 BRIGADE FRAGMENTARY ORDER (FRAGO) 


\section{a. HEADING \\ b. SITUATION}

1) Enemy forces.

a) Description of the enemy to battalion level.

b) Enemy most probable course of action.

c) Enemy most dangerous (to the brigade) course of action.

2) Friendly forces.

a) Corps mission.

b) Corps commander's intent.

c) Corps concept of operation.

d) Division mission.

e) Division commander's intent.

f) Division concept of operation.

g) Missions of units to the immediate left and right of the brigade .

h) Missions of other units with a significant bearing on the brigade.

3) Attachments and detachments.

c. MISSION

d. EXECUTION

Intent of the brigade commander.

1) Concept of operation.

a) Maneuver. 
b) Fire Support.

(1) Main effort.

(2) Priority of fires.

c) Mobility and Survivability.

(1) Priority of support.

(2) Priority of mobility and survivability aspects as appropriate for GS units.

(3) Designation of authority to emplace obstacles.

d) Air Defense.

(1) Priority of air defense.

(2) $\mathrm{AD}$ weapons status.

(3) $\mathrm{AD}$ warning status.

e) Command and Control Warfare.

2) Tasks to maneuver units.
a) Infantry.
b) Armor.
c) Cavalry.
d) Aviation.

3) Tasks to combat support units.

a) Fires.

(1) Air support.

(a) CAS sorties allocation. 
(b) Tactical air reconnaissance sorties allocation.

(2) Chemical support. (Priorities of reconnaissance, decontamination, and smoke.)

(3) Field artillery support.

(a) General. (Priorities for counterfire or interdiction.)

(b) Organization for combat.

(4) NSF.

(5) Fire support coordinating instructions.

b) Mobility and Survivability.

(1) Engineer. (and engineer overlay)

(2) NBC operations.

c) Air Defense.

(1) Organization for combat.

(2) Missions.

(3) Priorities for protection.

d) Command and Control Warfare.

(1) Function and support roles of attached MI units.

(2) Deception.

(3) EW.

(4) Psychological warfare.

(5) Unmanned aerial vehicle.

(4) Coordinating instructions. 
a) Time or condition when the brigade FRAGO becomes effective.

b) CCIR - Changes from existing brigade order.

(1) PIR (if not addressed in changes to Annex B [Intelligence]).

(2) EEFI (if not addressed in changes to Annex B [Intelligence]).

(3) FFIR (if not addressed in changes to Annex B [ntelligence]).

c) Risk reduction control measures that have changed.

d) Rules of engagement changes.

e) Environmental considerations changes.

f) Any other coordinating instructions that changed from the existing brigade order or additional instructions

\section{e. SERVICE SUPPORT}

1) Support concept.

a) Synopsis of the FSB mission.

b) FSB headquarters and/or brigade support area locations.

c) The DISCOM support priorities and where the brigade fits into those priorities.

d) The brigade commander's priorities of support.

e) Units in the DISCOM supporting the brigade.

f) Significant and/or unusual CSS issues that might impact the overall brigade operation.

g) Any significant CSS risks. 
h) Support requirements in the functional areas of manning, arming, fueling, fixing, and moving.

2) Material and services.

3) Medical evacuation and hospitalization.

4) Personnel.

5) Civil-military cooperation.

6) Miscellaneous.

\section{f. COMMAND AND SIGNAL}

1) Command.
a) Map coordinates for brigade $\mathrm{CP}$ locations.
b) Chain of command if different from brigade SOP.

2) Signal.
a) Signal instructions.
b) Identify current SOI.
c) Required brigade reports, formats, and times due.
g. ACKNOWLEDGE
h. ANNEXES
i. DISTRIBUTION 


\section{TASK LIST SUMMARY}

This component provides a summary of the first level of tasks on the task list.

1. The brigade commander directs and leads subordinate forces.

2. Brigade command posts support synchronization by acquiring, evaluating, and communicating information.

3. The brigade commander sees and visualizes the battlefield.

4. The brigade commander directs changes to the operation or plan.

5. Brigade command posts manage and maintain command, control, and communications.

6. The brigade consolidates and reorganizes. 


\section{TASK LIST}

The purpose of this component is to identify, organize, and list in logical sequence all of the tasks and subtasks necessary to perform this function. Normally, the primary participants responsible for performing the task are identified. The tasks were extracted from the appropriate doctrinal publications and sources. The specific sources of reference for each task and subtask are shown in brackets [] following the task.

In many instances, the wording of the task has been changed from the text found in the Army Training and Evaluation Program - Mission Training Plan (ARTEP-MTP) or Field Manual (FM) to add clarity, context, or meaning. The references allow the user to refer to the original source material for further detail and context, if desired.

For tasks selected from an ARTEP-MTP, the task number has been expanded with a slash ( $/$ to identify the subtask and standard reflected in the ARTEP-MTP task. To illustrate: a task referenced as [ARTEP 71-3-MTP, 71-3-4001/4c] was derived from ARTEP 71-3-MTP, the Mission Training Plan for the Heavy Brigade Command Group and Staff, and identifies brigade S4 section task "71-3-4001, Conduct Logistical Planning," subtask "4," "Prepares plans and orders," standard or sub-element "c."

For tasks derived from an FM, the FM number and page number have been provided as a reference. For example, the reference for a task, "The brigade commander demonstrates understanding of mission and higher commander's intent during confirmation briefing to the division commander" would be [FM 101-5, p. 1-9].

Some tasks and subtasks needed to define the function are not contained in ARTEP-MTPs, nor can they be derived from FMs. Tasks and subtasks were identified to fill such gaps and were developed during coordination visits with various U.S. Army Training and Doctrine Command (TRADOC) schools, Forces Command (FORSCOM) units, and Combat Training Center (CTCs). These tasks are listed as field notes [FN] and are annotated with their source. For example, tasks identified by CSS Observer-Controllers (OCs) at the National Training Center (NTC) would be referenced as [FN-NTC CSS OCs]. Still other tasks and subtasks were identified based on review of newsletters and other documents published by the Center for Army Lessons Learned (CALL), which capture lessons learned from Army units relevant to doctrine, tactics, techniques, and procedures (DTTP). Tasks derived from CALL publications are referenced as Lessons Learned [LL] with the appropriate document and page number provided. For example, a task extracted from CALL Newsletter 95-6, "National Training Center's 'Fighting with Fires"' is referenced as [LLCALL Newsletter 95-6, p. 16].

In some cases, the analysis of the BF resulted in the identification of tasks for which no doctrinal references could be determined. Such tasks were selected based on author experience and a careful study of relevant doctrine. These tasks are referenced as author notes [AN].

Full references for all the source material are listed in the reference section. 
1. The brigade commander directs and leads subordinate forces. [FM 71-3, pp. 3-2 - 3-4; FM 101-5, pp. 1-4 - 1-5; Battle Command Techniques and Procedures, Chap 1, 2, 4; Battle Command, pp. 12-14, 34-37]

a. The brigade commander directs subordinate forces. [FM 71-3, p. 3-4; FM 101-5, pp. 1-4 - 1-5]

1) The brigade commander takes actions to ensure that subordinate leaders have a clear understanding of his intent and concept. Actions include: [FM 101-5, Chap 1, 4; Battle Command Techniques and Procedures, Chap 2, 4; Battle Command, pp. 10-32]

a) Meeting with subordinate commanders and leaders to receive information and issue directions. [FM 101-5, pp. 4-53, 4-59 - 4-60]

b) Listening to cross-talk on brigade command nets.

c) Evaluating reports from subordinates for understanding of his intent, concept of operations, and their missions.

d) Confirmation briefs and backbriefs by subordinate commanders. [AN]

e) Rehearsals. [AN]

2) The brigade commander positions himself where he can best direct and lead, observe the battlefield, and synchronize operations: [FM 71-3, pp. 3-2 - 34; FM 101-5, Chap 1, 2, 3; FM 7-20; Battle Command Techniques and Procedures, Chap 2, 3, 4; ST 22-102, pp. 4-14 - 4-15]

a) Ensures that people and equipment needed for him to move about the battlefield are organized and prepared to move on short notice.

b) Selects positions that enable communications with:

(1) Division commander and assistant division commander for maneuver (ADC-M).

(2) Brigade subordinate commanders.

(3) Main CP.

(4) Adjacent units (main $\mathrm{CP}$ may be given this task). 
c) Selects positions that provide protection for the brigade commander and the tactical (TAC) $\mathrm{CP}$ against direct and indirect fires.

d) Selects positions that minimize chance that he will become decisively engaged and lose freedom of movement.

e) Selects locations at decisive points in the battle using as criteria:

(1) Proximity to the main effort.

(2) Event or location where the brigade can exploit enemy weaknesses.

(3) Proximity to places that he anticipates his personal intervention, at a precise time, will be necessary to synchronize maneuver and/or indirect fires or other elements of combat power.

(4) Capability to command through the depth of the battlefield (close, deep, and rear battles).

(5) Capability to see the battlefield and enhance overall visualization of the battle.

(6) Non-interference with the exercise of initiative, judgment, and efforts of subordinates.

(7) Enhance capability to conduct necessary face-to-face coordination and guidance in the operational area.

(8) Enhance the capability for redundant $\mathrm{C} 2$ in high risk situations.

(9) Non-interference of brigade command, control, communications, and intelligence ( $\mathrm{C} 3 \mathrm{I}$ ) activities of the brigade CSM, S3, or other key leaders.

3) The brigade commander directs the execution of the battle: [FM 71-3, Chap 3, 4, 5, FM 101-5, Chap 1, 4, App D, E; Battle Command Techniques and Procedures, Chap 3, 4; Battle Command, pp. 10-16, 32-37; FM 71-123, Chap 3, 4, 5, 6]

a) Allows plan to be executed unless there is significant change to mission, enemy, terrain, troops, and time available (METT-T). 
b) Issues timely FRAGOs (refer to Task 4) to:

(1) Modify OPORD or create new OPORD.

(2) Change priorities:

(a) Main effort.

(b) Fire support.

(c) CSS.

(d) ADA support.

(e) Engineer support.

(3) Commit reserve.

(4) Reorganize task forces.

c) Intervenes personally if required to:

(1) Direct maneuver.

(2) Coordinate fires with the FSCOORD or brigade targeting team.

d) Diverts, in coordination with the brigade targeting team, CAS from a preplanned target to a more critical target.

e) Requests additional resources and assets from division.

f) Provides guidance as appropriate to commanders and to brigade staff.

g) Ensures continuous mutual support among units.

h) Ensures continuity of command throughout the brigade.

4) The brigade commander uses his staff to assist him in directing and monitoring the battlefield. [FM 101-5, Chap 1, 3; FM 71-3, Chap 1, 2, 3; Battle Command Techniques and Procedures, Chap 2, 4] 
a) Directs the brigade $\mathrm{XO}$ to function as the brigade information manager.

b) Directs the brigade $\mathrm{XO}$ to act as supervisor of the brigade main $\mathrm{CP}$.

c) Specifies the composition of the TAC CP.

d) Provides the brigade S3 guidance as to the manner in which the S3 will operate in conjunction with the commander to direct tactical operations.

e) Provides guidance to staff officers if they are to operate in a manner other than governed by SOP or usual practices.

f) Provides guidance to the brigade FSCOORD and the engineer battalion commander on how to operate in conjunction with the brigade commander to synchronize and direct the brigade battle.

g) Exchanges information with the brigade staff.

h) Takes steps to identify indicators of diminishing effectiveness of the brigade staff. [LL-CALL Newsletter No. 90-8, p. 25]

b. The brigade commander exercises leadership during the execution of the brigade battle by: [FM 101-5, Chap 1, 4; FM 71-3, Chap 3; Battle Command Techniques and Procedures, Chap 1, 2, 3, 4; Battle Command, pp. 10-13, 32-37]

1) Being professionally competent.

2) Inspiring soldiers with the will to win.

3) Sharing the hardships and dangers of his soldiers.

4) Demonstrating both mental and physical stamina.

5) Displaying physical and moral courage (making the difficult choices and decisions).

6) Issuing timely, clear, concise guidance and orders to provide the brigade subordinate commanders purpose, direction, and motivation.

7) Maintaining his perspective and focus on the brigade mission, regardless of the turmoil surrounding him. 
8) Demonstrating flexibility to quickly adjust to rapidly changing situations to accomplish the mission.

9) Visualizing and thinking in dimensions of time and space regarding the consequences of actions.

10) Visualizing follow-on brigade missions.

11) Providing subordinate commanders with a vision of future operations.

12) Establishing and reinforcing an attitude of teamwork throughout the brigade.

13) Fostering and encouraging initiative in subordinate leaders.

14) Delegating authority whenever appropriate.

15) Providing accurate, objective reports to the division commander/ADC-M.

16) Getting needed rest.

17) Learning from mistakes. [LL-CALL Newsletter 90-8, p. 26]

c. The brigade commander maintains unit discipline and morale by: [FM 101-5, Chap 1; Battle Command Techniques and Procedures, Chap 4; Battle Command, pp. 1013; ST 22-102, Chap 4]

1) Keeping the soldiers informed of the current situation.

2) Making personal contact with soldiers.

3) Sharing the hardships and dangers that his soldiers face.

4) Reassuring subordinates in a calm manner.

5) Ensuring that soldiers have the opportunity to rest, eat, and otherwise refit as conditions permit.

6) Acting decisively.

7) Giving precise, simple, easy-to-understand orders.

8) Checking to see that his orders are carried out. 
9) Ensuring that the brigade subordinate commanders and other supporting elements cross-talk on the brigade command or operations and intelligence (O\&I) nets to:

a) Coordinate actions and activities.

b) Exchange information.

c) Assist each other as possible.

d) Integrate and synchronize activities.

e) Prevent fratricide.

f) Keep everyone updated on the current situation.

g) Allow the brigade commander and his staff to anticipate upcoming requirements.

10) Observing subordinate commanders and units for indications of degradation in performance.

11) Monitoring himself and the subordinate commanders for degradation of leadership ability based upon physical and/or mental stress or exhaustion:

a) Self monitoring of own physical and mental state.

b) Ensuring that subordinate commanders have and execute a rest schedule for themselves, their staffs, and their subordinate commanders.

12) Ensuring that CSS operations which contribute to morale are conducted as conditions permit.

13) Recognizing unit and individual achievement and performance during the battle.

14) Using the brigade CSM's assistance to maintain unit discipline and morale.

15) Using the brigade $\mathrm{XO}$ or brigade $\mathrm{S} 3$ to monitor the brigade commander's condition and recommending rest periods. 
d. The brigade commander synchronizes tactical operations. [FM 101-5, Chap 1, 5, 6; Battle Command, pp. 42-45, Battle Command Techniques and Procedures, Chap 2, 4; FM 71-123, Chap 3, 4, 5, 6; ST 22-102, p. 4-10 - 4-12]

1) The brigade commander synchronizes tactical operations by using the following techniques to employ maneuver and fires at required times or places in order to accomplish the commander's intent and concept of operations.

a) Maintaining a current revised estimate of the situation.

b) Maintaining communications with key elements.

c) Continuously focusing combat power at decisive points.

d) Continuously monitoring and using decision support aids:

(1) Using the decision support template (DST) and synchronization matrix to aid timing of maneuver.

(2) Using the DST and synchronization matrix to order execution of fires, movement, and/or maneuver of subordinate elements.

(3) Using the DST to execute pre-planned tactical decisions to shift fires and/or forces.

(4) Using the fire support execution matrix (FSEM) to aid in the execution of fire support.

(5) Using the FSEM, DST, and synchronization matrix to aid in timing and target selection.

(6) Ordering resupply based on critical events reflected on the synchronization matrix.

e) Deciding when to issue a change/modification/replacement of existing order.

2) The brigade commander, assisted by the brigade staff, integrates and coordinates combat power, considering factors associated with each battlefield operating system; factors include: [TRADOC Pamphlet 11-9, Chap 7, App D; FM 101-5, Chap 1, 3, 4, App A, B, C, D, E, F, J; Battle 
Command Techniques and Procedures, Chap 1, 2, 3, 4, 6; Battle Command, pp. 10-39]

a) Maneuver: [Battle Command Techniques and Procedures, Chap 3; FM 71-3, Chap 4, 5, 6; FM 71-123, Chap 2, 3, 4, 5, 6, App A]

(1) Movement:

(a) Brigade movements are conducted in accordance with the order (e.g., checkpoints are met on time) so that units are on time and at the right place to achieve intended results.

(b) Units are required to maintain orientation, security, and mutual support.

(2) Maneuver:

(a) Depth is achieved by the disposition of forces, obstacles, and fires.

(b) The battlefield is shaped to mass fires on the enemy.

(c) Agility is achieved by the rapid shifting of combat power to a place where it can be most effectively employed against the enemy force.

(d) Initiative is achieved by forcing the enemy into a continuous reactive state.

(e) Synchronization is achieved by integrating and massing friendly combat power at the right place and time to achieve the intended purpose.

(f) With the brigade S2 and brigade S3, reviews the DST to ensure that decisions can be made in a timely manner.

(g) Brigade reserve is committed as necessary to gain/retain initiative and accomplish commander's intent. 
(h) Commitment of attack helicopter assists is synchronized with fire support and maneuver to achieve brigade commander's intent.

b) Fire support: [FM 6-20; Battle Command Techniques and Procedures, Chap 6; FM 6-71; FM 71-123, Chap 2, 3, 4, 5, 6]

(1) Manages, in conjunction with the brigade FSCOORD, execution of fire support by exception.

(2) Monitors, in conjunction with the brigade FSCOORD, fire support, ensuring that it is executed according to plan and that it achieves the desired results.

(3) In conjunction with brigade ALO, directs diversion of immediate CAS attack based on requirements to influence the current battle.

(4) Exercises overall control of fire support through FRAGOs to change priorities and missions/tasks for supporting fire support systems.

(5) As required, orders massing and shifting of fires to support the brigade's maneuver.

(6) Monitors, in conjunction with the brigade FSCOORD, repositioning of DS FA battalion elements and determines alternative means to compensate for unavailable means of fire support.

(7) Monitors BDA to appraise results of the fire support plan in terms of achieving the desired effects.

(8) Determines deep attack requirements.

(9) Monitors establishment and implementation of airspace coordination areas (ACAs).

(10) Monitors suppression of enemy air defenses (SEAD) in support of operations.

c) Mobility and survivability: [FM 71-3, Chap 4, 5, 6; Battle

Command Techniques and Procedures, Chap 8] 
(1) Provides execution criteria or orders execution of the obstacle plan.

(2) In the attack, controls, in conjunction with the brigade engineer, the critical actions of a brigade breach of an obstacle by:

(a) Directing brigade fire and maneuver.

(b) Using smoke, direct fires, and indirect fires on the enemy positions to deny observation.

(c) Using fires, direct and indirect, to destroy or suppress the enemy.

(d) Using fires to isolate the point of penetration.

(e) Providing security on the far side of the obstacle at the breach site.

(f) Ensuring that the brigade maintains the momentum of the attack including during passage through gaps in obstacles.

(g) Massing fires.

(h) Ensuring that unit integrity is maintained.

(3) Controls, in conjunction with the brigade engineer, the critical aspects of the defense by:

(a) Ensuring that gaps and lanes in friendly obstacles are closed in accordance with prearranged signals and/or events that support the brigade scheme of maneuver.

(b) Ensuring that survivability positions are constructed.

(c) Massing fires.

(d) Moving or maneuvering in a timely manner.

(e) Employing family of scatterable mines (FASCAM). 
(4) In conjunction with the brigade engineer, ensures that engineer units are employed or postured to accomplish intended missions.

(5) In conjunction with the brigade FSCOORD, ensures that firing of FASCAM does not interfere with the capability to execute indirect fires required to support maneuver.

(6) Verifies that the brigade is prepared for a possible NBC strike.

(7) In conjunction with the brigade CMLO, directs MOPP levels.

(8) Monitors OPSEC and force protection.

d) Command and control: [FM 101-5, Chap 5; FM 71-3, Chap 3, 4, 5, 6; FM 71-123, Chap 1, 2, 3, 4, 5, 6; Battle Command Techniques and Procedures, Chap 4]

(1) Positions himself where he can best command and control the tactical operation (METT-T dependent) and:

(a) Maintains control of the battle through his subordinate commanders.

(b) Ensures that clear responsibility for the close battle is maintained.

(c) When appropriate, hands over the battle, in terms of fire support, to his TF commanders for the close battle.

(d) Shifts his location as needed to maintain the capability of directly influencing action at critical DPs.

(e) Changes CCIR as required to meet his information needs.

(2) Continuously synchronizes and masses combat power against enemy forces by: 
(a) Using decision support aids and updating them as necessary.

(b) Cueing pre-planned decisions to shift fires and/or forces.

(c) Focusing combat power at decisive points.

(d) Retaining the initiative throughout the battle.

(e) Lifting and shifting direct and indirect fires.

(f) Repositioning and/or reorienting brigade forces.

(g) Conducting counter attacks rapidly and effectively.

(h) Changing priorities.

(3) Maintains continuous control of subordinate elements by:

(a) Maintaining communications with all elements.

(b) Monitoring the situation throughout the battlefield.

(c) Providing guidance as appropriate.

(d) Integrating the brigade's effort.

(e) Monitoring combat capabilities of all subordinate elements.

(f) Monitors risk factors associated with the battle.

(4) Ensures that brigade orders are timely and responsive to the changing tactical situation by:

(a) Being decisive.

(b) Maintaining continuous communications with key leaders and all brigade CPs.

(c) Using decision aids that have been develop (e.g., DST). 
(d) Maintaining an accurate commander's estimate.

(5) Makes checks that ensure that the soldiers' personal readiness is maintained by:

(a) Ensuring that leaders keep soldiers informed.

(b) Ensuring that sleep plans are enforced.

(c) Ensuring that soldiers receive food, mail, responsive repair or replacement of equipment, and effective medical treatment.

e) Intelligence: [FM 71-3, pp. 2-4 - 2-6; FM 101-5, Chap 6; Battle Command, pp. 39-42; FM 71-123, Chap 1, 2, 3, 4, 5, 6]

(1) Is continuously aware of enemy situation, capabilities, and intentions throughout the brigade deep, close, and rear battle area.

(2) In conjunction with brigade $\mathrm{S} 2$, continuously monitors intelligence reporting to be sure that changes to the enemy situation are being detected, evaluated, and reported.

(3) Continuously monitors BDA to appraise results of the battle in terms of enemy destruction and achieving the desired effects against the enemy throughout the battlefield (deep and close battles).

(4) In conjunction with the brigade $S 2$, ensures that the employment timing and targeting of collection and jamming assets are synchronized with the scheme of maneuver and concept of operation.

(5) In conjunction with brigade S2, reviews the PIR to ensure that they reflect current intelligence needs.

(6) In conjunction with the brigade S2 and brigade S3, ensures adequate $\mathrm{R} \& \mathrm{~S}$ assets are available to provide required intelligence information.

(7) Incorporate critical information from modified combined obstacle overlay $(\mathrm{MCOO})$ into operations. 
f) Air defense: [FM 71-3, p. 2-7; FM 71-123, Chap 1, 2, 3, 4, 5, 6; FM 101-5, Chap 6; Battle Command Techniques and Procedures, pp. 7-1 $-7-4]$

(1) Continuously assesses the brigade's vulnerability to enemy air and prioritizes air defense missions based on current METT-T.

(2) In conjunction with brigade ADO, ensures that air defense protection is in place at critical times and locations where other combat power is being synchronized.

g) CSS: [FM 71-3, pp. 2-8 - 2-9; FM 101-5, Chap 6; Battle Command Techniques and Procedures, pp. 9-1 - 9-26; FM 71-123, Chap 1, 2, 3, $4,5,6]$

(1) In conjunction with the brigade $\mathrm{S} 4$, ensures that critical supplies (e.g., special munitions, medical) are available to support application of combat power.

(2) In conjunction with the brigade S4, directs replacement and resupply priorities consistent with the main effort.

(3) Monitors system for the treatment and evacuation of casualties.

(4) In conjunction with brigade CMLO and brigade $\mathrm{S} 4$ ensures that NBC decontamination capabilities are ready for use.

(5) Ensures that critical weapons systems are available.

2. Brigade command posts support synchronization by acquiring, evaluating, and communicating information. [FM 101-5, pp. 5-5 - 5-15]

a. The brigade CPs acquire information. [TRADOC Pam 11-9, Chap 7, App D; FM 71-3, Chap 2; FM 34-130, Chap 2; FM 101-5, p. 3-84, Chap 4, 6, App A, C; Battle Command Techniques and Procedures, Chap 2, 3, 4, 5]

1) The brigade staff members, operating out of $\mathrm{CPs}$, directed by the brigade commander or brigade SOP, obtain information during the execution of the battle that: [FM 101-5, p. 3-84]

a) Is critical in assisting the brigade commander to synchronize the execution of the brigade battle. [FM 101-5, pp. 6-33, 6-34] 
b) Provides information that focuses on critical information requirements (CCIR, other) for the commander. [LL- Combat Training Centers (CTCs) Bulletin No. 94-1, p. 5; FM 101-5, pp. 6-8, 6-11, 6-16, and C-4]

(1) Minimum critical information (MCI) that should be tracked in the brigade TOCs (both friendly and enemy forces) includes: [LL-CALL News from the Front!, Apr 94]

(a) Relative combat power.

(b) Unit/systems/activity/locations.

(c) Obstacle overlays.

(d) Decision and execution tools (e.g., DST, execution matrixes).

(e) Task organization.

(f) Key personnel status.

(2) Information boards are updated continuously. [LL-CALL News from the Front!, Apr 94]

(3) There is a designated individual to track MCI. [LL-CALL News from the Front!, Apr 94]

(4) Formal shift change briefs are conducted in the TOCs. [LLCALL News from the Front!, Apr 94]

(5) There is a "significant activities" board in the TOC and it is used to share information. [LL-CALL News from the Front!, Apr 94]

c) Resolves or reduces, if possible, given the time available, all uncertainties as to: [LL-CALL Newsletter No. 90-8, p. 25]

(1) Enemy status and responses.

(2) Friendly capabilities and successes.

(3) Terrain conditions and weather. 
d) Uncertainties that cannot be resolved are addressed as planning unknowns; contingency planning is conducted for the most likely branches. [LL-CALL Newsletter No. 90-8, p. 25]

2) The brigade CSM obtains information on matters such as: [FM 71-3, pp. 35 - 3-6; FM 101-5, pp. 3-70 - 3-71]

a) Morale, discipline, and adherence to standards by brigade soldiers.

b) Brigade capability to sustain combat operations.

c) Viability of CSS systems.

d) Welfare of brigade soldiers.

e) Topics requested by the brigade commander.

f) Brigade casualty evacuation system.

3) The brigade $\mathrm{XO}$ manages the acquisition, flow, and exchange of information to, from, and within the brigade main CP. [FM 101-5, pp. 6-2, 6-11, 6-34; ARTEP 71-3-MTP, Task 71-3-0001]

a) Ensures that the brigade staff maintains a combined arms perspective. [LL-CALL Newsletter No. 90-8, p. 25]

b) Facilitates brigade staff coordination. [LL-CALL Newsletter No. 90-8, p. 25]

(1) Uses backbriefs.

(2) Uses rehearsals.

(3) Facilitates brigade staff visits and follow ups with other staff and supporting/subordinate units as appropriate.

c) Remains open to opposing opinions and assures that the brigade staff has good reasons for rejecting contrary information. [LL-CALL Newsletter No. 90-8, p. 25]

d) Watches for waning concentration and automatic behavior within the brigade staff and takes corrective action when spotted. [LL-CALL Newsletter No. 90-8, p. 25] 
e) The brigade $\mathrm{XO}$, as chief of the targeting team, convenes the brigade targeting team as necessary, to ensure full coordination and integration of targeting related information. [FN - Force XXI Review Panel]

f) Ensures that brigade TOC personnel are trained in all aspects of the TOC operation. [LL-CALL Bulletin No. 1-86]

g) Ensures that: [LL-CALL Bulletin No. 1-86]

(1) All brigade TOC personnel understand the commander's concept and intent and what is supposed to happen at TAIs and NAIs.

(2) Brigade TOC supervisory personnel are able to make basic tactical decisions, based on the situation, in the absence (for whatever the reason) of key leaders.

(3) The brigade staff personnel remain focused on CCIR information.

h) Confirms that all brigade supporting and subordinate units are on proper radio nets. $[\mathrm{AN}]$

i) Queries the brigade staff on the capabilities of the brigade. [AN]

j) Informs the brigade commander of subordinate and supporting unit capabilities. [AN]

k) Identifies and informs the brigade commander of problems needing the brigade commander's attention. [AN]

1) Ensures coordination of information vital to synchronizing the battle.

m) Continuously monitors and controls terrain usage in the brigade area of operations (AO). [FN - Force XXI Review Panel]

n) The brigade XO obtains information related to:

(1) Revised CCIR from the brigade commander.

(2) Critical CSS matters.

(3) Synchronizing brigade operations. 
(4) Impending division operations.

4) The $\mathrm{S} 2$ section obtains intelligence information. [FM 101-5, pp. C-7, C-8; FM 34-130, Chap 2]

a) The brigade $\mathrm{S} 2$ section obtains information from: [ARTEP 71-3MTP, Tasks 71-3-2007/1, 2; 2004/2; 2003; 2006/1; 2004; 2002/3; FM 101-5, App L]

(1) Higher headquarters.

(2) Brigade commander and $\mathrm{S} 3$ in the brigade TAC CP.

(3) Subordinate units:

(a) Maneuver TFs.

(b) Supporting engineer, artillery, and FSBs

(c) Military Police (MP) platoon.

(d) Air defense battery.

(4) Adjacent units.

(5) Brigade $\mathrm{XO}$ and other brigade staff sections.

(6) MI battalion or DS MI company.

(7) Eavesdropping on division, adjacent, or subordinate unit command and O\&I nets.

(8) Debriefing patrols and other R\&S elements.

(9) Interrogation of EPW and deserters.

(10) ASAS.

(11) LNOs from/to higher, adjacent, and supporting units.

(12) Aerial photographs.

(13) Civilian population. 
(14) UAVs.

(15) TerraBase terrain analysis team.

(16) Artillery forward observers.

(17) Special operations forces; division and corps long range surveillance units (LRSUs).

b) The brigade $\mathrm{S} 2$ coordinates information concerns related to synchronizing the execution of the battle to include:

(1) Information related to NAIs and TAIs.

(2) Information related to the enemy, terrain, and weather:

[ARTEP 71-3-MTP, Tasks 71-3-2003; 2005/2; 2006/3]

(a) PIR.

(b) Dispositions (confirmed and suspected).

(c) Composition.

(d) Activity in deep, close, and rear areas.

(e) Intentions.

(f) Reactions to friendly battle techniques.

(g) Actions triggered by friendly actions or events.

(h) Adherence to or deviation from postulated enemy COA.

(i) Losses based on observer reports, other sources.

(j) Use of EW.

(k) Use of NBC.

(l) Capabilities.

(m) Enemy prisoners of war. 
(3) Information related to the brigade's capability to continue collection of intelligence information:

(a) Status of NAI coverage.

(b) Strength, location, and capability of brigade and TF R\&S elements.

(c) Status of requests for aerial reconnaissance and other external support.

(d) ASAS status.

(e) DS MI company strength, location, and capability to continue support.

(f) Updating of MCOO.

(4) Information related to targeting (e.g., HPT, BDA, and other targeting information).

(5) Monitoring, in coordination with the brigade S3, the R\&S taskings and execution. [AN]

(6) Deconflicting, as necessary, in coordination with the brigade FSE, taskings to elements capable of observation and control of fires and intelligence gathering.

5) The brigade $\mathrm{S} 3$ section obtains operations information (e.g., changes to METT-T and unit status). [FM 101-5, pp. C-8, C-9; ARTEP 71-3-MTP, Task 71-3-3001/1]

a) The brigade $\mathrm{S} 3$ section obtains information from:

(1) Higher headquarters.

(2) Brigade commander.

(3) Subordinate units:

(a) Maneuver TFs.

(b) Supporting engineer, artillery, and FSBs. 
(c) MP platoon.

(d) Air defense battery.

(4) Adjacent units.

(5) The brigade XO and other brigade staff officers and sections at the main $\mathrm{CP}$.

(6) LNOs.

(7) Eavesdropping on subordinate and adjacent units' command nets.

(8) ALO, based on pilot reports.

(9) Special operations forces; division and corps LRSU.

b) The brigade $\mathrm{S} 3$ section in conjunction with the brigade $\mathrm{XO}$, and the brigade $\mathrm{S} 3$ in the TAC CP, coordinate information concerns related to synchronizing the execution of the battle to include: [ARTEP 713-MTP, Tasks 71-3-3003/1, 2, 3; 3014/1; 3003/2, 3; FM 101-5, App A]

(1) Direction from the brigade commander.

(a) Changes to mission concept or details of the plan.

(b) Requirements for information to assist him in synchronizing the battle.

(2) FRAGOs/WARNOs from division headquarters.

(3) Changes to division or adjacent unit situations which necessitate changes to brigade OPSEC posture.

(4) Division and corps units and systems operating within and requiring terrain in the brigade $\mathrm{AO}$.

(5) Information relating to determining effectiveness of brigade OPSEC measures.

(6) Subordinate units' situation reports (SITREPs) and graphics. 
(a) Enemy contact.

(b) Current and projected strength and combat power.

(c) Status of task organization.

(d) OPSEC reports.

(e) Results of security operations.

(7) Requests for resources from subordinate units based on synchronization requirements.

(8) Recommendations from subordinate commanders (TFs, DS FA, engineer, FSB, ADA battery) on changes to the brigade scheme of maneuver based on their current and projected operational status.

(9) Information about adjusted maneuver plans from subordinate units.

(10) Information required for confirming, refining, or changing the DST.

(11) Updates from the brigade S1 and S4.

(a) Personnel status.

(b) Vehicle, weapons systems, and equipment status.

(c) Status of supply (Classes (CLs) I, III and V).

(d) Casualty evacuation.

(e) Capability for emergency resupply.

(f) Status of key leaders and critical military occupational specialties (MOSs).

(12) Updates from the brigade S5 on CMO information.

(a) Civilian population movement on brigade lines of communication (LOCs). 
(b) Civilian population centers.

(c) ROE.

(13) Updates from the brigade FSCOORD on employment and status of fire support assets.

(14) Updates from the brigade engineer on status of mobility/ counter-mobility/survivability (M/CM/S) actions and unit status.

(15) Updates from the brigade ALO on CAS employment and status of CAS requests.

(16) Updates from the brigade AVLO on status and employment of attack, assault, and cargo helicopter units.

(17) Updates from the brigade SO on the status of brigade communications links and systems.

(18) Updates from the brigade CMLO on the status and employment of chemical units.

(19) Updates from the brigade ADALO on the status and employment of $\mathrm{AD}$ assets.

(20) Information necessary to deconflict terrain requirements and projected locations for external and/or supporting units operating in the brigade area. [FM 101-5, Chap 3]

(21) Updates from the brigade S2 on:

(a) The enemy situation to include update BDA on enemy.

(b) Implementation of the R\&S plan and confirmation of NAIs. [AN]

(c) Status of intelligence collection assets.

(22) Updates on status of FSB operations.

(a) Critical problems with support. 
(b) Integrity of brigade support area (BSA) and rear area security.

6) The brigade $\mathrm{S} 3 \mathrm{Air}$, as chief of the $\mathrm{A} 2 \mathrm{C} 2$ element, obtains information from the S2, FSE, ADO, AVLO, NGLO, and Marine air officer concerning airspace use. [ARTEP 71-3-MTP, Task 71-3-3012]

a) The brigade operations and training officer - air operations (S3 Air) obtains information from:

(1) The brigade $\mathrm{S} 2$.

(2) The brigade FSE.

(3) The brigade ADO.

(4) The brigade AVLO.

(5) The brigade ALO.

(6) The brigade NGLO.

b) The brigade $\mathrm{S} 3 \mathrm{Air}$ coordinates $\mathrm{A} 2 \mathrm{C} 2$ information necessary to synchronize the execution of the battle to include:

(1) Changes to $\mathrm{A} 2 \mathrm{C} 2$ measures.

(2) Division use of brigade airspace.

(3) Adequacy of airspace control authority (ACA).

7) The brigade NBC section obtains information concerning friendly and enemy NBC status. [ARTEP 71-3-MTP, Tasks 71-3-0001; 0002, 0005/1]

a) The brigade NBC section obtains information from:

(1) Subordinate units.

(2) Brigade $\mathrm{S} 4$.

(3) Division CMLO.

(4) Brigade S2. 
(5) Brigade targeting team.

(6) Brigade commander.

(7) Subordinate units' CMLOs.

(8) Brigade AVLO.

(9) Brigade ALO.

(10) Brigade NGLO.

(11) Brigade ADO.

(12) Brigade ABE.

(13) Brigade S3 Air.

(14) NBC reconnaissance elements.

b) The brigade NBC section coordinates NBC information concerns related to synchronizing the execution of the battle to include:

(1) Division NBC warning and reporting system (WRS) updates.

(2) Changes from the brigade commander's guidance and mission concept and, requirements for information.

(3) Status and location of decontamination and reconnaissance assets.

(4) Reports from NBC reconnaissance elements.

(5) NBC monitoring and surveillance reports.

(6) Information from the brigade $\mathrm{S} 2$ and intelligence section which confirms or refutes estimate of NBC threat and requirements.

(7) Changes to brigade, supporting, and subordinate units' operations in terms of decontamination requirements and timelines. 
8) The brigade engineer, $\mathrm{ABE}$, and $\mathrm{ABE}$ section obtain mobility, countermobility and survivability mission information. [FM 5-71-3, Chap 2; ARTEP 71-3-MTP, Tasks 1-3-8001/1, 2; 8003]

a) The brigade engineer, $\mathrm{ABE}$, and $\mathrm{ABE}$ section obtain information from:

(1) Division engineer.

(2) Engineer brigade main $\mathrm{CP}$.

(3) Brigade S2.

(4) Brigade CMLO.

(5) Brigade commander and S3 in the TAC CP.

(6) Subordinate units.

(a) Engineer companies supporting TFs.

(b) TFs.

(c) Attached combat, combat service (CS), and CSS units.

(d) FSO or fire support teams (FISTs) assigned to the engineer battalion.

(7) Brigade XO, brigade FSO, and brigade targeting team.

(8) Brigade S1/S4, FSB support operations officer in the brigade rear $\mathrm{CP}$.

(9) Engineer battalion TOC.

b) The brigade $\mathrm{ABE}$ section coordinates mobility, countermobility, and survivability information concerns related to synchronizing the execution of the battle to include:

(1) Changes from the brigade commander to guidance and mission concept and requirements for information. 
(2) Reports from the engineer battalion representative or TF engineer about regarding status of equipment.

(a) Armed combat earthmovers (ACEs) and other digging assets.

(b) Armed vehicle launched bridges (AVLBs).

(c) Mine clearing line charges (MICLICs).

(d) Mine clearing blades and rollers.

(e) Cleared lanes marking systems (CLAMS).

(f) Grizzly.

(3) Countermobility status:

(a) Obstacle/barrier status to include engineer capability to achieve its purpose against the enemy, with obstacle/barrier coverage by fires and responsibilities clearly defined.

(b) Status on Class IV (construction and barrier material) and $\mathrm{V}$ materials and special equipment.

(c) Updates on capability to emplace obstacles to include number, classification by type of obstacle, and time requirements.

(d) Updates on readiness to employ FASCAM from the brigade FSO. [ARTEP 71-3-MTP, Task 71-3-8003]

(e) Updates on the capability of maneuver task forces to emplace obstacles and barriers. [AN]

(f) Updates status of security and control of obstacles from maneuver TFs. [AN]

(4) Survivability position status:

(a) Survivability position construction status and adherence timelines from engineers and subordinate units. 
(b) Status of receipt of survivability materials from TF S4s.

(5) Mobility status:

(a) Updates on availability of engineer materials from engineer battalion $\mathrm{S4}$.

(b) Updates on availability of engineer systems from engineer companies.

(c) Updates on availability of mobility equipment organic to brigade maneuver units (e.g., plows, rollers, breach kits) from TF S4s.

(d) Reports from engineer reconnaissance units and TF scouts on terrain and enemy obstacles.

(6) Task organization status from engineer and TFs, including adherence to directed timelines.

(7) Intelligence information on weather, terrain, and other information which confirms or refutes estimates of engineer requirements.

(8) Changes to brigade and TF maneuver operations in terms of $\mathrm{M} / \mathrm{CM} / \mathrm{S}$ :

(a) FASCAM targets.

(b) Completion of obstacles.

(c) Previously unreported obstacles.

(d) Status of M/CM/S capabilities.

(9) Monitors close operations and posts key activities and locations to engineer journal and situation map (SITMAP). [AN]

(10) Provides additional engineer support to the close fight from the engineer battalion resources, as directed by the command group. [AN] 
(11) Monitors engineer tasks begin done in support of the brigade rear area and posts the status to the engineer journal and SITMAP. [AN]

(12) Assists the brigade staff in the main $\mathrm{CP}$ with the execution of countermobility support to planned brigade deep operations. [AN]

(13) Identifies options for SCATMINE employment not previously planned and coordinates with the brigade FSO and brigade $\mathrm{S} 2$ to determine suitability, feasibility, and acceptability. [AN]

9) The brigade AVLO obtains information about friendly air capabilities and plans. [ARTEP 71-3-MTP, Task 71-3-7001; ARTEP 1-100-MTP, Tasks $01-4-1311 ; 1322]$

a) The brigade AVLO acquires information from:

(1) Division ALO.

(2) Brigade FSO/FSE.

(3) Brigade S2.

(4) Brigade targeting and $\mathrm{A} 2 \mathrm{C} 2$ teams.

(5) Brigade commander.

(6) Subordinate units' ALOs/FACs.

(7) Subordinate units' S3 Air/S3s.

(8) Brigade ALO.

(9) Brigade NGLO.

(10) Brigade S3.

(11) Brigade S3 Air.

(12) Brigade ADO. 
(13) Aviation brigade S3.

(14) Brigade ABE.

(15) DS FA battalion S3.

b) The brigade AVLO coordinates air information concerns related to synchronizing the execution of the battle to include:

(1) Changes from the brigade commander to guidance and mission concept and requirements for information.

(2) Updated status from the aviation brigade on helicopter availability, support capability, and plans.

(3) Intelligence information.

(a) Enemy $\mathrm{ADA}$ weapons and electronics capabilities.

(b) Enemy ground to air capability.

(c) Enemy air to air capability.

(d) Confirmation or refutation of predicted weather constraints.

(4) Information from the brigade FSO on SEAD, ACAs, fires, and laser support required for Army aviation operations.

(5) Information from the brigade S3 and S3 Air on the concept for employment of Army aviation and desired effects.

(6) Updates from the division $\mathrm{CP}$ or aviation brigade on aviation activities in the brigade sector (e.g., ingress or egress routes and times of use before/after a deep attack).

(7) Status from the ALO on CAS flight operations.

(a) Times.

(b) Locations.

(c) Routes. 
(8) Changes to brigade, supporting, and subordinate units' plans in terms of target locations and timelines.

(9) Integration of information during targeting and $\mathrm{A} 2 \mathrm{C} 2$ team meetings. [AN]

10) The FSCOORD, brigade FSO, brigade targeting officer, and FSE section obtain fire support information. [FM 6-20, pp. 2-22, 2-23; FM 6-20-40, Chap 4; ARTEP 71-3-MTP, Task 71-3-9002/1b, 3; 9003/1a; 9004/1a]

a) The brigade FSO/FSE monitors calls-for-fire from TF FSOs and retransmits the requests, if necessary, to support execution of the scheme of maneuver.

b) The brigade FSCOORD, FSO, and FSE section obtain information from:

(1) Division FSE.

(2) Division artillery TOC.

(3) Brigade S2, DS MI company targeting officer.

(4) Brigade targeting and $\mathrm{A} 2 \mathrm{C} 2$ teams.

(5) Brigade commander.

(6) Subordinate unit FSOs, FISTs, combat observation lasing teams (COLTs), and supporting arms liaison teams (SALTs) (if assigned).

(7) DS FA battalion S3.

(8) Brigade ALO.

(9) Brigade NGLO (if assigned).

(10) Brigade AVLO.

(11) Brigade ADO.

(12) Brigade ABE.

(13) Brigade S3 Air. 
c) The brigade FSCOORD, FSO, targeting officer, and FSE coordinate fire support information concerns related to synchronizing the execution of the battle to include:

(1) Enemy capabilities to attack the brigade with indirect fires.

(2) Status of field artillery from the DS FA battalion S3 and mortars from TF S3(s).

(a) Current and projected locations of units.

(b) Current and projected unit weapons status.

(c) Current and projected ammunition status.

(d) Planned repositioning of artillery and mortar units in terms of locations and time.

(3) Status of target acquisition assets and current operations.

(4) Status of field artillery units from division artillery/division FSE.

(a) Organization for combat (including GS, general support-reinforcing [GSR] FA).

(b) Locations and status of GS and GSR batteries, and platoons.

(c) Status and locations of counter fire radars.

(d) Status and timing of meteorological support.

(e) Division or corps directed FSCMs.

(f) SALTs.

(5) Status of task organization, personnel, and equipment from TF FSOs.

(a) COLTs.

(b) FISTs, SALTs. 


\section{(c) Mortars.}

(6) Bottom-up target refinements from TF FSOs for:

(a) Maneuver TFs, to include scout platoons, COLTs, and other observers; obstacle locations.

(b) Final protective fires.

(c) Fire support coordination and control measures.

(7) Information from ALO and AVLO.

(a) Timing of operations and status for Army aviation (from AVLO).

(b) Availability of and times for CAS support.

(c) Status of availability, capability of tactical air control party (TACP) to coordinate and execute CAS from ALO.

(d) Suppression of enemy air defenses (SEAD) requirements in terms of times, locations, and control measures to support brigade operations or division directed operations in brigade sector.

(8) Availability and locations of EW assets from the brigade S2 and DS MI company commander.

(9) Information necessary to refine indirect fires coverage of obstacles, and adjustments to FASCAM employment from the brigade engineer or $\mathrm{ABE}$.

(10) Fire support requirements from the brigade S4 and FSB commander to support the BSA and rear area operations.

(11) $\mathrm{A} 2 \mathrm{C} 2$ information from the brigade $\mathrm{S} 3 \mathrm{Air}$ and $\mathrm{A} 2 \mathrm{C} 2$ team meetings.

(12) BDA on enemy, particularly about HPT. 
(13) Intelligence or operational information on the TACFIRE nets.

(14) Reports changes in FSCMs to division artillery. [AN]

(15) Reports changes in FSCMs to the division FSE. [AN]

(16) Coordinates planning and implementation of suppression of enemy air defense. [AN]

(17) Coordinates with the task force FSOs in SEAD zone to plan mortar targets. [AN]

(18) Disseminates FRAGOs to artillery units. [AN]

11) The ALO obtains information about friendly air capabilities and plans. [FM 6-20-40, Chap 2, p. A-9; FM 6-20-50, p. C-7; FM 71-3, Chap 3]

a) The brigade $\mathrm{ALO}$ acquires and receives information from:

(1) Division TACP.

(2) Brigade FSO/FSE.

(3) Brigade S2.

(4) Brigade targeting team.

(5) Brigade commander.

(6) Subordinate unit ALOs/TACP, SALTs.

(7) Marine air officer from brigade air/NGF platoon, ANGLICO (if assigned).

(8) Subordinate unit S3s.

(9) Corps air support operations center (ASOC).

(10) Brigade TACP liaison team.

(11) Brigade $\mathrm{S} 3$. 
(12) Brigade ABE.

(13) Brigade ADO.

(14) Aviation brigade CP.

(15) Brigade S3 Air.

b) The brigade ALO coordinates CAS information concerns related to synchronizing the execution of the battle to include:

(1) Updated ATO information from the division ALO concerning CAS support status (e.g., times, routes).

(2) Capabilities of Marine/Navy air (CAS) from the Marine air officer, brigade air/NGF platoon, ANGLICO.

(3) Changes to the brigade commander's guidance and mission concept and, requirements or information.

(4) Intelligence information from ALO and ANGLICO channels.

(a) Enemy ADA weapons capabilities and electronics signatures.

(b) Enemy ground to air threat.

(c) Enemy air to air threat.

(d) Enemy ground activities.

(5) Information from the brigade S2 and intelligence section which confirms or refutes estimate of weather constraints and enemy ADA capabilities.

(6) Information from the brigade FSO on SEAD, ACAs, fires, and lazing support requirements for CAS operations.

(7) Status from the brigade S3, brigade S3 Air, and AVLO on concept for employment of joint air attack team (JAAT) and desired effects.

(8) Status from the AVLO on helicopter operations. 
(9) Changes to brigade, supporting, and subordinate units' plans in terms of projected locations and timelines.

12) The NGLO obtains information about requirements for NSF and capabilities of ships that provide NSF. [FM 71-3, pp. 7-13 - 7-14; FM 6-20-40, p. A-26; FM 6-20-50, pp. C-25 - C-28]

a) The brigade NGLO acquires and receives information from:

(1) Division naval gunfire officer (NGO).

(2) Brigade FSO/FSE.

(3) Brigade S2.

(4) Brigade targeting team.

(5) Brigade commander and $\mathrm{S} 3$ in the TAC CP.

(6) Subordinate unit ALOs/TACP.

(7) Subordinate unit S3s.

(8) Brigade ALO, Marine air officer.

(9) SALT.

(10) US Navy ships in DS.

(11) Brigade $\mathrm{S} 3$ section in the main $\mathrm{CP}$.

(12) Brigade $\mathrm{ABE}$.

(13) Brigade ADO.

(14) Aviation brigade CP.

(15) Brigade S3 Air (A2C2 team).

b) The brigade NGLO coordinates information concerns related to synchronizing the execution of the battle to include: 
(1) Status of ships in DS role, and availability and times for GS NSFs from the division NGLO.

(2) Targeting information from the brigade FSE and TF SALT teams.

(3) Mission timelines from the brigade FSE.

(4) Fire support coordination and control measures from the brigade FSE.

(5) $\mathrm{A} 2 \mathrm{C} 2$ information from the brigade $\mathrm{A} 2 \mathrm{C} 2$ team.

13) The brigade $\mathrm{ADO}$ obtains information on air defense requirements and resources. [ARTEP 71-3-MTP, Task 71-3-6001/1]

a) The brigade $\mathrm{ADO}$ obtains information from:

(1) Division CPs.

(2) Brigade AVLO.

(3) Brigade $\mathrm{S}$.

(4) Brigade targeting and $\mathrm{A} 2 \mathrm{C} 2$ teams.

(5) Brigade commander or brigade $\mathrm{S} 3$ in the TAC CP.

(6) Subordinate unit FSOs.

(7) Brigade S3 Air.

(8) Brigade ALO, Marine air officer.

(10) ADA battalion commander and S3.

(11) ADA platoons under TF's control.

(12) Adjacent units.

b) The brigade $\mathrm{ADO}$ coordinates air defense information concerns related to synchronizing the execution of the battle to include: 
(1) Disposition of $\mathrm{ADA}$ assets from the ADA battalion commander and battalion ADA elements.

(2) Changes from the brigade commander to guidance and mission concept and requirements for information.

(3) ADA weapons systems and ammunition status from supporting ADA elements.

(4) Intelligence information which confirms or refutes estimate of ADA requirements.

(5) Weapons control status from the area air defense commander.

(6) Air defense warning system updates from the ADA battalion and division $\mathrm{CP}$.

(7) Changes or additions to tactical aircraft or Army aviation routes and schedules through the brigade sector.

(8) $\mathrm{A} 2 \mathrm{C} 2$ updates from the division $\mathrm{ACofS}$, operations and plans (G3) A2C2 section.

(9) Changes in positions or priorities of designated brigade assets to be defended.

(10) Changes to brigade, supporting, and subordinate units' operations based on $\mathrm{AD}$ capabilities and timelines.

(11) Warns brigade staff and command of imminent enemy air attacks. [AN]

(12) Logs engagement reports and decrement missile counts that includes: [AN]

(a) Type of aircraft engaged.

1 Location.

2 Time.

(b) Type of damage inflicted. 
(c) Unit engaging.

(d) Type and number of weapons expended.

14) The MP platoon leader obtains information: [ARTEP 71-3-MTP, Task 713-1201/1]

a) The MP platoon leader acquires and receives information from:

(1) Brigade $\mathrm{XO}$ and $\mathrm{S} 3$ section in the main $\mathrm{CP}$.

(2) MP company commander.

(3) Brigade S2.

(4) Brigade S5.

(5) FSB support operations officer.

(6) Brigade $\mathrm{S} 1 / \mathrm{S} 4$ in the rear $\mathrm{CP}$.

(7) Brigade $\mathrm{S} 3$ in the TAC CP.

b) The brigade MP platoon leader coordinates information concerns related to synchronizing the execution of the battle to include:

(1) Changes from brigade commander to guidance, mission concept, and requirements for information.

(2) Status of supporting MP units.

(3) Intelligence information from the brigade S2 and intelligence section regarding expected EPW numbers.

(4) Information from the brigade S4 about logistical support for EPW holding areas (transportation, supplies, equipment, and medical).

(5) Information from brigade $\mathrm{S} 5$ about $\mathrm{HN}$ military and civilian requirements and status.

(6) Changes from brigade $\mathrm{S} 3$ or brigade $\mathrm{XO}$ regarding priorities for MP support for: 
(a) Straggler and refugee control.

(b) Traffic control.

(c) EPW operations.

(d) Security operations.

15) The Bde SO and communications section obtain information concerning brigade communications requirements and capabilities. [ARTEP 71-3MTP, Tasks 71-3-1101/1; 1102/1, 4]

a) The Bde $\mathrm{SO}$ and communications section obtain information from:

(1) Assistant division signal officer.

(2) Division signal battalion CP.

(3) Brigade S2.

(4) Brigade CPs.

(5) Brigade commander and brigade $\mathrm{S} 3$ in the TAC CP.

(6) Subordinate unit:

(a) CPs.

(b) Signal officers.

(7) Brigade S3 Air.

(8) Brigade S3 section.

(9) Brigade HHC commander.

b) The Bde SO and communications section coordinate communications and electronics $(\mathrm{CE})$ information concerns related to synchronizing the execution of the battle to include:

(1) Status of communications links from brigade CPs to division and other MSC CPs. 
(2) Changes from the brigade commander to guidance and mission concept and requirements for information.

(3) Disposition and status of communications assets from the assistant division signal officer and signal battalion $\mathrm{S} 3$.

(4) Updates from subordinate units on communications status.

(a) Status of communications links from brigade CPs.

(b) Equipment (secure and non-secure).

(c) SOIs.

(d) Availability of subordinate unit communications personnel and equipment.

(5) Intelligence information:

(a) Which updates estimate of communications requirements.

(b) Updates enemy electronic and communication capabilities.

(6) Status reports from retransmission stations.

(a) Positioning.

(b) Equipment serviceability and capability.

(c) Communication ranges and dead spaces.

(7) Information from the brigade $\mathrm{XO}, \mathrm{S} 4$, and $\mathrm{S} 3$ about changes to proposed brigade $\mathrm{CP}$ locations and projected timelines.

(8) Changes to brigade, supporting, and subordinate units' plans in terms of projected locations and timelines.

16) The brigade $S 1$ section obtains personnel information. [ARTEP 71-3-MTP, Tasks 71-3-1001/1, 2; 1002/1, 3, 4; 1004/1; 1008/1; FM 101-5, pp. C-5; FM 71-3, pp. 8-5, 8-6, 8-17, 8-24; FM 71-3, Chap 8]

a) The brigade $\mathrm{S} 1$ section obtains information from: 
(1) Division G1/adjutant general (AG).

(2) Brigade commander and $\mathrm{S} 3$ in the TAC CP.

(3) Subordinate units:

(a) Maneuver TFs.

(b) Supporting engineer, artillery, and FSBs.

(c) MP platoon.

(d) Air defense battery.

(e) Brigade $\mathrm{HHC}$ commander.

(4) Adjacent units.

(5) Brigade S5.

(6) FSB medical company.

(7) Brigade surgeon.

(8) MP platoon leader.

(9) Division Judge Advocate General (JAG).

(10) Division PM.

(11) Division inspector general (IG).

(12) Rear CP liaison officer to the brigade main CP.

(13) Brigade, subordinate, and adjacent units' communications nets (eavesdropping).

b) The brigade $\mathrm{S} 1$ section coordinates personnel information concerns related to synchronizing the execution of the battle to include:

(1) Changes from the brigade commander to guidance, mission concept, priorities, and requirements for information. 
(2) Information from the brigade $\mathrm{S} 2$ and $\mathrm{S} 2$ section which confirms or refutes estimates of personnel situation and casualty estimates.

(3) Personnel status from subordinate and supporting units.

(a) Personnel strength reports (PSRs).

(b) Critical MOS/grade shortages.

(c) AWOLs.

(d) Casualty feeder reports.

(e) Key leader and MOS status.

(4) Personnel information from division ACofS, personnel (G1)/AG.

(a) Availability of replacements and replacement operations (WSRO).

(b) Postal services.

(c) Morale, welfare, recreation (MWR) support.

(5) Morale and discipline indicators from division and brigade special staff officers.

(a) Disciplinary rates from Staff Judge Advocate (SJA).

(b) Straggler and crime rates from PM.

(c) Sick call and stress casualties from brigade surgeon.

(d) Complaints information from the IG.

(e) Leader and soldier concerns from the chaplain.

(6) FSB support capabilities from the FSB support operations center.

(7) Information from the MP platoon leader concerning EPW processing and evacuation requirements. 
(8) Information from the brigade S5 concerning civil-military operations (CMO) support requirements.

(9) Changes to brigade, supporting, and subordinate unit plans in terms of projected locations and times.

(10) Continually tracks the tactical situation to focus attention on the forces in contact. [AN]

(11) Monitors the administrative and logistics net for casualty reports from task force S1s. [AN]

(12) Informs the brigade command and operations group when task force combat strength or total brigade combat strength or total brigade combat power falls below benchmark. [AN]

(13) Updates personnel status to division G1 routinely or when total brigade strength falls below benchmark. [AN]

(14) Monitors MEDEVACs and number of brigade casualties at each echelon of medical support through division. [AN]

(15) Monitors mass casualty plans requirement. [AN]

(16) Continually tracks EPW (numbers and locations, back through the brigade support area). [AN]

17) The brigade $\mathrm{S} 4$ and $\mathrm{S} 4$ section obtain logistics information. [ARTEP 71-3MTP, Tasks 71-3-4001/1, 3; 4002; 4003; FM 101-5, p. C-9; FM 71-3, pp. 8$5,8-17,8-24]$

a) The brigade $\mathrm{S} 4$ section acquires and receives information from:

(1) Division ACofS, logistics (G4).

(2) Brigade commander and CSM.

(3) Subordinate units:

(a) Maneuver TFs. 
(b) Supporting engineer, artillery and fire support measures (FSMs).

(c) MP platoon.

(d) Air defense battery.

(e) Bde HHC Cdr.

(4) Adjacent units.

(5) Brigade S5.

(6) MP platoon leader.

(7) DISCOM.

(8) Brigade S2.

(9) Brigade S3 section and S3 Air.

(10) Rear CP liaison officer to the brigade main CP.

(11) Brigade, subordinate, and adjacent units' communications nets (eavesdropping).

(12) Brigade XO.

b) The brigade $\mathrm{S} 4$ coordinates logistics information concerns related to synchronizing the execution of the battle to include:

(1) Changes from the brigade commander to guidance, mission concept, priorities, and information requirements.

(2) Intelligence information from the brigade S2 and S2 section which confirms or refutes estimates of the logistical situation.

(3) Logistics reports from subordinate and supporting units.

(a) Status of supplies by class.

(b) Equipment readiness. 
(c) Task organization and status of CSS elements:

1 FSB.

2 Field trains command post (FTCPs).

3 Combat trains command post (CTCPs).

$4 \quad$ Status of critical CSS personnel.

(d) Prestocked/cached supplies status.

(4) Maintenance, transportation and supply updates from the division G4 and FSB support operations center (including plans for WSRO).

(5) Availability of air transportation assets from the brigade S3 Air.

(6) Information from the MP platoon leader concerning EPW status and support requirements.

(7) Information from the S5 concerning availability of host nation assets and $\mathrm{CMO}$ support requirements.

(8) Changes to brigade, supporting, and subordinate unit plans in terms of projected locations and times of displacement.

(9) Coordinates the execution of refuel requirements by exchanging information regarding who, what, where, and when with the FSB commander and task forces. [AN]

(10) Reacts to critical losses by cross-leveling critical personnel replacement and personnel. [AN]

(11) Performs a situational CSS estimate and presents an information summary when friendly losses start to impact on combat effectiveness. [AN]

(12) Coordinates with the brigade S1 and FSB commander to determine brigade's combat strength. [AN] 
18) The brigade surgeon obtains information. [ARTEP 71-3-MTP, Tasks 71-3$1301 / 2,3 ; 1302 / 1 b]$

a) The brigade surgeon obtains information from:

(1) Division medical supply officer.

(2) Division surgeon.

(3) Brigade commander and $\mathrm{S} 3$ at the TAC CP.

(4) Brigade XO or brigade S4.

(5) Brigade S2.

(6) TF medical platoon leaders.

(7) FSB staff.

(8) Main support battalion (MSB).

(9) Division medical operations center (DMOC).

b) The brigade surgeon coordinates medical information concerns related to synchronizing the execution of the battle to include:

(1) Information from the brigade S2 and S2 section which confirms or refutes estimates of projected casualties.

(2) Changes from the brigade commander to guidance, mission concept, priorities, and information requirements.

(3) Medical updates and aerial medical evacuation capabilities from the division surgeon.

(4) Class VIII (medical material) supply updates from the division medical supply officer.

(5) Additional medical support capability from the MSB and corps.

(6) Subordinate and supporting unit medical support status.

(a) Positioning and readiness of medical assets. 
(b) Capability to receive, triage, and evacuate casualties.

(c) Requirements for support.

(7) Changes to brigade, subordinate, and supporting unit plans in terms of projected locations and times of displacement.

19) The brigade S5 (or designated substitute) obtains information about the CMO situation related to synchronizing the battle. [FM 101-5, p. C-9; ARTEP 71-3-MTP, Task 71-3-5001, 5003, 5004]

a) The brigade $\mathrm{S} 5$ obtains information on $\mathrm{CMO}$ requirements and resources, from: [ARTEP 71-3-MTP, Task 71-3-5001/1, 2; 5003/1; $5004 / 1]$

(1) Higher headquarters.

(2) Brigade commander.

(3) Civilian authorities.

(4) MP units.

(5) Adjacent units.

(6) Brigade $\mathrm{XO}$ and brigade $\mathrm{S} 4$.

b) The brigade $\mathrm{S} 5$ coordinates $\mathrm{CMO}$ information concerns related to synchronizing the execution of the battle to include:

(1) Status of $\mathrm{CMO}$ support required for current brigade operations.

(2) Information from subordinate commanders on whether the situation with civilians will interfere with military operations in their sectors.

(3) Status of and potential problems with refugees and civilians on critical brigade LOCs.

20) The FSB commander and support operations center obtain CSS information: [FM 63-20, Chap 3, 5, 6; FM 71-3, pp. 8-5, 8-6, 8-17, 8-18, 8-25] 
a) The FSB commander and staff obtain information from:

(1) Division G4.

(2) Brigade commander and $\mathrm{S} 3$ in the TAC CP.

(3) Brigade units:

(a) Maneuver TFs.

(b) Supporting engineer and artillery battalions.

(c) MP platoon.

(d) Air defense battery.

(e) Brigade HHC commander.

(4) FSB companies.

(5) Adjacent units.

(6) Brigade S5.

(7) Division material management center (DMMC).

(8) DISCOM commander.

(9) Division medical operations center (DMOC).

(10) Brigade S2.

(11) Brigade S3 Air.

(12) MSB.

(13) Brigade S1 and S4.

(14) Brigade XO.

(15) Brigade, subordinate, and adjacent units' communications nets (eavesdropping). 
b) The FSB commander and staff coordinate CSS information concerns related to synchronizing the execution of battle to include:

(1) Changes from the brigade commander to guidance, mission, concept, priorities, and information requirements.

(2) Information from the brigade S2 and S2 section which confirms or refutes estimates of the CSS situation.

(3) Changes to guidance, priorities, and requirements from the DISCOM commander.

(a) CSS task organization.

(b) Tasks to provide CSS support to division and corps units.

(4) Information from the MSB regarding backup CSS support.

(5) Information from the DMMC concerning supply and maintenance management support.

(6) Information from supported units regarding their requirements.

(a) Maintenance and recovery of weapons systems and equipment.

(b) Resupply requirements.

(7) Information from all organizations in the BSA (for defense and terrain management).

21) The brigade HHC commander obtains information necessary to support the main and tactical CPs. [ARTEP 71-3-MTP, Task 71-3-1501]

a) The brigade $\mathrm{HHC}$ commander obtains information from:

(1) Brigade commander and CSM.

(2) Brigade XO.

(3) Brigade $\mathrm{S} 1 / \mathrm{S} 4$. 
(4) Brigade S3.

(5) Brigade S2.

(6) Brigade CPs.

b) The brigade HHC commander coordinates information concerns related to synchronizing the execution of the battle to include:

(1) Obtains information from the brigade S2 and S2 section which confirms or refutes enemy threat to the main $\mathrm{CP}$.

(2) Obtains changes to brigade commander guidance, mission concept and information requirements from the brigade XO.

(3) Obtains anticipated movement times and projected locations for the main and TAC CPS from the brigade XO and S3.

(4) Obtains information from attachments/supporting agencies concerning space, supply, and support requirements.

b. The brigade CPs and staff sections evaluate acquired information, update products, and maintain status. [FM 63-20, Chap 3, 6; FM 101-5, Chap 6]

1) The brigade $\mathrm{XO}$ maintains the timeline of brigade operations based on newly acquired information.

a) Evaluates the quality and timelines of information being acquired in meeting the information needs.

b) Updates his guidance to the staff on information shortfalls.

c) Evaluates extent of preparation versus desired endstate/remaining time.

d) Convenes targeting and $\mathrm{A} 2 \mathrm{C} 2$ cells as required.

2) The brigade CSM: [AN]

a) Evaluates brigade combat preparations and special concerns of the brigade commander.

b) Updates the brigade commander on his observations. 
c) Evaluates extent of preparation versus desired endstate/time.

3) The brigade $S 2$ section evaluates intelligence information and updates products: [ARTEP 71-3-MTP, Tasks 71-3-2002, 2003, 2005, 2006]

a) The $\mathrm{S} 2$ section evaluates intelligence information: [ARTEP 71-3MTP, Tasks 71-3-2002/1; 2003/1, 2; 2004/1;2005]

(1) Impact of changes to guidance/direction and information.

(2) Comparison of desired brigade endstates with current intelligence situation, trends, and intelligence preparation of the battlefield (IPB).

(3) Information which:

(a) Identifies answers to brigade commander's CCIR, $\mathrm{PIR}$, and information requirements (IR).

(b) Confirms or refutes IPB information relative to achieving the commander's intent (e.g., NAIs and TAIs).

(c) Identifies enemy:

1 Composition.

2 Disposition.

3 Location.

$4 \quad$ Strength (losses) and present capabilities.

5 Indications of possible enemy intent.

6 Enemy reaction to friendly operations.

$1 \quad$ Adherence to or deviation from postulated enemy COA.

(d) Permits comparison of known enemy activity with previously projected enemy COAs.

(e) Permits development of BDAs. 
(4) Determines whether R\&S plan/operations continue to meet brigade commander's intent.

(a) Positioning of assets to collect PIR and IR.

(b) Positioning of assets to maintain constant observation of NAIs and TAIs.

(c) Positioning of assets to detect and track HPTs, provide observation for attack of HPTs, and provide BDA on HPT following attack.

(5) Indicators of enemy intentions:

(a) NBC weapons usage or activity as prelude to offensive operations.

(b) Presence of reconnaissance forces as prelude to attack.

(c) Presence and massing of maneuver forces as indicator of initiation of offensive operations.

(d) Increase in fighter activity and massing of transport fixed wing aircraft as indicators of airborne assault or start of offensive operations.

(e) Meaconing, interference, jamming, interception (MIJI) and other changes in enemy electromagnetic activity as prelude to offensive operations.

(f) Conduct of counter-reconnaissance operations as an indicator of defense.

(g) Field artillery and rocket unit activity.

1 Offensive indicators.

2 Defensive indicators.

(h) Presence and nature of activity of engineer units.

1 Offensive indicators. 
2 Defensive indicators.

(i) Increase of enemy helicopter activity as indication of air assault operations.

(6) The brigade $\mathrm{S} 2$ and the intelligence cell:

(a) Identify changes to current projections of enemy COAs.

(b) Perform BDA.

(c) Deduce possible future enemy COAs.

(d) Conduct a hasty analysis of enemy intentions with the intelligence analyst at the TAC CP.

b) The brigade $S 2$ evaluates changes in situation which should lead to convening the targeting and/or $\mathrm{A} 2 \mathrm{C} 2$ teams and recommends to the brigade XO or brigade $\mathrm{S} 3$ air that the teams meet if necessary.

c) The brigade $\mathrm{S} 2$ section updates intelligence products, including: [ARTEP 71-3-MTP, Tasks 71-3-2003/2; 2006/2, 3]

(1) Revised intelligence estimate (may or may not be in written form).

(2) Situation template (SIT TEMP).

(3) Event template.

(4) Modified combined obstacle overlay (MCOO), in coordination with the brigade $\mathrm{S} 3$, brigade engineer section and $\mathrm{NBC}$ section.

(5) Intelligence portion of the DST.

(6) R\&S plan.

(7) Intelligence database.

(8) Intelligence overlays and graphics. 
(9) Enemy order of battle (OB).

(10) Brigade intelligence summaries (INTSUMs).

(11) Intelligence journal/log.

4) The brigade $\mathrm{S} 3$ operating in the TAC $\mathrm{CP}$ and the brigade $\mathrm{S} 3$ section evaluate operational information and update products: [ARTEP 71-3-MTP, Task 713-3003]

a) The $\mathrm{S} 3$ and $\mathrm{S} 3$ section evaluate operations information to ensure synchronization. [ARTEP 71-3-MTP, Task 71-3-3003/1, 3]

(1) Changes to guidance/direction and information.

(2) Information which confirms or refutes IPB information which may affect achieving the commander's intent.

(3) Desired brigade endstates with what is possible based on current brigade operations, maneuver plan, and trends.

(a) Maneuver units status.

(b) Fire support status.

(c) $\quad \mathrm{M} / \mathrm{CM} / \mathrm{S}$ support status.

(d) CSS status.

(e) Air defense status.

(f) Enemy situation and projected COA.

(4) Impact of changes to the brigade maneuver operations on subordinate units' maneuver operations.

(5) Changes to adjacent unit operations which might affect brigade operations.

(6) Brigade OPSEC based on information received from division and internal brigade sources.

(7) Changes to $\mathrm{A} 2 \mathrm{C} 2$ plan. 
(8) Changes to targeting products.

b) The brigade $\mathrm{S} 3$ section evaluates changes in situation which should lead to convening the targeting and/or $\mathrm{A} 2 \mathrm{C} 2$ teams and recommends to the brigade XO or brigade S3 Air that the teams meet if necessary.

c) The brigade $\mathrm{S} 3$, operating in the TAC CP, and the brigade $\mathrm{S} 3$ section, in coordination with the brigade $\mathrm{XO}$, update operations products. [ARTEP 71-3-MTP, Task 71-3-3003]

(1) Decision tools (e.g., the DST), in conjunction with the brigade $\mathrm{S} 2$, brigade $\mathrm{XO}$, and brigade commander.

(2) Synchronization and execution tools.

(3) The operations overlay for brigade, division, and adjacent units.

(4) Revised operations estimate (may or may not be in written form).

(5) Brigade status boards and charts which record combat power.

(6) Timeline of brigade operations.

(7) Current operations and intelligence map.

(8) NBC map.

(9) SIT TEMP overlay.

(10) Event template overlay.

(11) CSS overlay and support matrix.

(12) Plans map with overlay for future operations.

(13) FSE map with FS overlay and FSEM.

(14) TACP map and CAS status with assistance of ALO and brigade TACP.

(15) Brigade operations journal/log. 
(16) Assists brigade $\mathrm{S} 2$ and $\mathrm{ABE}$ in updating $\mathrm{MCOO}$.

(17) Updates terrain management plan/overlay.

d) The brigade $\mathrm{S} 3 \mathrm{Air}$, as chief of the $\mathrm{A} 2 \mathrm{C} 2$ team, convenes the brigade $\mathrm{A} 2 \mathrm{C} 2$ team as required to ensure full coordination and integration of $\mathrm{A} 2 \mathrm{C} 2$ related information. [AN]

5) The brigade NBC section evaluates $\mathrm{NBC}$ information and updates products. [ARTEP 71-3-MTP, Tasks 71-3-4-0003, 0004, 0007, 0017]

a) The brigade NBC section evaluates information. [ARTEP 71-3MTP, Tasks 71-3-4-0004, 0007]

(1) Changes to guidance/direction and information.

(2) Desired brigade endstates with what is possible based on current NBC situation and trends.

(3) Information which confirms or refutes IPB information relative to achieving the brigade commander's intent.

(4) Answers to intelligence queries about enemy NBC capabilities.

(5) Brigade decontamination capabilities.

(6) Adjustments to subordinate units operations which affect brigade NBC plans.

(7) Changes to the division's defensive NBC capabilities.

b) The brigade NBC section updates NBC products. [ARTEP 71-3MTP, Tasks 3-4-0003; 0017]

(1) Revised NBC estimate (may or may not be in written form).

(2) MOPP analysis.

(3) Enemy NBC capabilities.

(4) NBC equipment and supplies inventories.

(5) NBC overlays and graphics. 
(6) Contaminated areas portion of $\mathrm{MCOO}$ (provided to S2).

6) The brigade $\mathrm{ABE}$ section evaluates $\mathrm{M} / \mathrm{CM} / \mathrm{S}$ information and updates products. [ARTEP 71-3-MTP, Tasks 71-3-8001, 8005]

a) The brigade $\mathrm{ABE}$ section evaluates information. [ARTEP 71-3MTP, Task 71-3-8005]

(1) Changes to guidance/direction.

(2) Desired brigade endstates with what is possible based on current $\mathrm{M} / \mathrm{CM} / \mathrm{S}$ situation and trends.

(3) Progress on engineer tasks compared to timelines and required endstates.

(4) Information which confirms or refutes IPB information relative to achieving the brigade commander's intent.

(5) Answers to intelligence queries which alter initial enemy engineer capabilities and assessment.

(a) Changes to enemy mobility capabilities to determine impact on brigade countermobility and survivability plans.

(b) Changes to enemy countermobility actions or capabilities to determine impact on brigade mobility plan and task organization.

(c) Changes to enemy survivability measures or capabilities to determine impact on brigade mobility, direct fire, and indirect fire plans (through coordination with brigade S3 and FSO).

(6) Changes in operations versus plans by subordinate units.

(7) Estimates of mobility based on differences in terrain from initial IPB or the effect of current weather on the terrain.

(8) Adequacy of Class IV and V barrier material to support operations. 
b) The brigade $\mathrm{ABE}$ determines if evaluated information would require convening the brigade targeting team and recommends to the brigade $\mathrm{XO}$ that the team meets, if necessary.

c) The brigade $\mathrm{ABE}$ section updates engineer products. [ARTEP 71-3MTP, Task 71-3-8001]

(1) Revised engineer estimate (may or may not be in written form).

(2) Priorities and schedules for engineer effort.

(3) Survivability position and obstacle graphics.

(4) Engineer timelines.

(5) FASCAM employment plan in coordination with the brigade FSO.

(6) $\mathrm{MCOO}$ (in coordination with (ICW) brigade S2, brigade S3 section and brigade CMLO).

7) The brigade AVLO evaluates aviation information and updates products. [ARTEP 71-3-MTP, Tasks 71-3-7001/3; ARTEP 1-100-MTP, Tasks 01-4$1311,1322]$

a) The brigade AVLO evaluates information. [ARTEP 71-3-MTP, Task 71-3-7001/3; ARTEP 1-100-MTP, Tasks 01-4-1311, 1322]

(1) Changes to guidance/direction and information.

(2) Desired brigade endstates with what is possible based on current aviation situation, trends, and allocated Army aviation support for brigade mission.

(3) Information which confirms or refutes IPB information relative to achieving the brigade commander's intent.

(4) Answers to intelligence queries which alter initial assessment of enemy air and air defense capabilities, objective area or engagement areas, and targets.

(5) Information which impacts on Army aviation employment, and CAS operations. 
(a) Adjustments to fire support plans which affect Army aviation employment plans.

(b) Changes to weather.

(c) Changes to enemy ADA capabilities.

(d) Changes to Army aviation employment under control of the division and the aviation brigade.

b) The brigade AVLO determines if evaluated information would require convening the brigade targeting team and recommends to the brigade XO that the team meets if necessary.

c) The brigade AVLO updates Army aviation products. [ARTEP 71-3MTP, Task 71-3-7001/3; ARTEP 1-100-MTP, Tasks 01-4-1311, 1322]

(1) Revised aviation estimate (may or may not be in written form).

(2) Provides input to revision of ACAs.

(3) Army aviation plan.

(4) SEAD and indirect fire support plans (with brigade FSO).

8) The brigade FSCOORD, brigade FSO, brigade targeting officer and brigade FSE section, and NGLO evaluate fire support information and update products. [ARTEP 71-3-MTP, Tasks 71-3-9001, 9002]

a) The brigade FSCOORD, brigade FSO, brigade targeting officer, FSE section, and NGLO evaluate information to determine:

[ARTEP 71-3-MTP, Task 71-3-9001/2,3]

(1) Retargeting requirements. [AN]

(2) Changes to fire support guidance/direction to include AGM, observer plan, target acquisition and surveillance plan, and HPTL.

(3) Current fire support capability to support brigade operations and implement the FS plan. 
(4) Changes to the brigade fire support plan which require synchronization with TFs' fire support plans.

(5) Changes to FA task organization and locations, GS and GSR FA units, or NSF ships.

(6) Required actions based on new information that results from changes in enemy, terrain, or weather.

(7) Changes to FASCAM requirements in coordination with the brigade $\mathrm{ABE}$.

(8) Refinements to the fire support plan based on Army aviation and CAS requirements.

(9) Permissive and restrictive fire measures which may be required.

(10) Effects of indirect fires on enemy; impact on potential future operations.

(11) Availability of CAS and Army aviation; possible targets.

(12) Changes to ACAs.

(13) SEAD plan.

b) The brigade FSCOORD or FSO evaluates changes in situation which should lead to convening the targeting and/or $\mathrm{A} 2 \mathrm{C} 2$ teams and recommends to the brigade $\mathrm{XO}$ or brigade $\mathrm{S} 3$ air that the teams meet if necessary.

c) The brigade FSCOORD, FSO, targeting officer, and FSE section update fire support products. [ARTEP 71-3-MTP, Task 71-3-9002]

(1) Revised fire support estimates (may or may not be in written form) to include:

(a) Status of firing elements.

(b) Displacement of artillery units throughout the AO.

(c) Fire support plan. 
(d) Observation plan.

(e) Dispositions, status, and activities of fire support assets under brigade control.

(2) FSEM.

(3) Target lists.

(4) HPT list.

(5) Fire support graphics.

(6) Priority targets.

(7) FSCMs to include ACAs.

(8) SEAD plan.

(9) AGM.

9) The brigade ALO, in conjunction with the Marine air officer, and the brigade TACP, evaluates CAS information and updates products. [FM 1015, p. 6-45]

a) The brigade $\mathrm{ALO}$ evaluates information in coordination with the Marine air officer (if assigned) and brigade TACP. [FM 101-5, p. 645]

(1) Changes to guidance/direction and information.

(2) Changes to ATO.

(3) Desired brigade endstates with what is possible based on current CAS situation, trends, and allocated CAS support from the ATO.

(4) Information which confirms or refutes IPB information which may affect achieving the brigade commander's intent.

(5) Answers to intelligence queries which alter initial assessment of enemy air and air defense capabilities as well as CAS targets. 
(6) Information which impacts on planned ACAs, CAS employment, and integration with Army aviation operations.

(7) Changes to weather.

(8) Changes to enemy ADA capabilities.

(9) Adjustments to the brigade plan and the Army aviation employment.

(10) Availability of CAS.

(11) Changes to SEAD plans.

b) The brigade ALO evaluates changes in situation which should lead to convening the targeting and/or $\mathrm{A} 2 \mathrm{C} 2$ teams and recommends to the brigade XO or brigade $\mathrm{S} 3$ Air that the teams meet if necessary.

c) The brigade ALO, in coordination with the Marine air officer, and brigade TACP, updates CAS products. [FM 6-20-40, Chap 2]

(1) Revised CAS estimate (may or may not be in written form).

(2) Target lists for preplanned CAS.

(3) Updates input for SEAD and indirect fire support plans (with brigade FSO).

10) The brigade ADALO evaluates air defense information and updates products. [ARTEP 71-3-MTP, Tasks 71-3-6001, 6002]

a) The brigade ADALO evaluates information. [ARTEP 71-3-MTP, Task 71-3-6001/1]

(1) Changes to guidance/direction and information.

(2) Desired brigade endstates with what is possible based on current ADA situation and trends.

(3) Information which confirms or refutes IPB and may affect achieving the brigade commander's intent.

(4) Answers to intelligence queries about enemy air capabilities. 
(5) Friendly air (CAS, Army aviation).

(6) Adjustments to subordinate unit operations.

(7) Changes to locations and $\mathrm{AD}$ coverage by divisional $\mathrm{AD}$ assets.

(8) Continually compares the high- to medium-altitude air defense (HIMAD) coverage with the position of the maneuver faces.

(9) Plots and maintains airspace control measures and effective times within the brigade $\mathrm{AO}:$ [AN]

(a) Restricted operation areas.

(b) Standard-use Army, United States Air Force (USAF), United States Navy (USN), United States Marine Corps (USMC) aircraft flight routes.

(c) Weapons-free zones.

(d) Planned FA FS fires.

(e) Air assault operations.

(f) Major aviation operations.

(10) Changes to the brigade air picture and division early warning status. [AN]

(11) Coordinates with the brigade $\mathrm{XO}$ and brigade $\mathrm{S} 3$ to adjust air defense coverage by reallocating fire units. [AN]

b) The brigade ADALO evaluates changes in situation which should lead to convening the targeting and/or $\mathrm{A} 2 \mathrm{C} 2$ teams and recommends to the brigade XO or brigade $\mathrm{S} 3$ Air that the teams meet if necessary.

c) The brigade ADALO updates air defense products. [ARTEP 71-3MTP, Task 71-3-6001/3; 6002/1d] 
(1) Revised air defense estimate (may or may not be in written form).

(2) Graphics of air defense high- to medium-altitude air defense (HIMAD) coverage and location of ADA battery assets.

(3) Graphics of friendly air corridors.

(4) Graphics of probable enemy air routes into the brigade area.

(5) Brigade weapons control and air defense warning status.

d) The brigade ADALO monitors air picture and early warning, alerting brigade elements as necessary.

11) The MP platoon leader evaluates information and updates products. [ARTEP 71-3-MTP, Tasks 71-3-1201/1; 1202/1]

a) The MP platoon leader evaluates information. [ARTEP 71-3-MTP, Tasks 71-3-1201/1; 1202/1]

(1) Changes to guidance/direction and information.

(2) Desired endstates with what is possible based on current MP situation and trends.

(3) Answers to intelligence queries.

(4) Updated status of EPW demands and assessment of capability to continue the mission. [AN]

(5) Assessment to continue to support traffic control mission. [AN]

b) The MP platoon leader updates MP products. [ARTEP 71-3-MTP, Task 71-3-1201/1]

(1) Revised estimates (may or may not be in written form).

(2) Straggler/refugee control plans.

(3) Traffic control plans.

(4) EPW/CI plan. 
12) The brigade communications section evaluates information and updates brigade communication products. [ARTEP 71-3-MTP, Tasks 71-3-1102, 1103]

a) The brigade communications section evaluates information. [ARTEP 71-3-MTP, Task 71-3-1103/3]

(1) Changes to guidance/direction and information.

(2) Desired brigade endstates with what is possible based on current communication situation and trends.

(3) Information which confirms or refutes IPB information relative to achieving the brigade commander's intent.

(4) Answers to intelligence queries about enemy electronic and communications capabilities.

(5) Adjustments to brigade CPs' locations, and subordinate unit operations and locations.

(6) Results of communications checks.

b) The brigade communications section updates communications products. [ARTEP 71-3-MTP, Task 71-3-1102/2,3]

(1) Revised signal estimates (may or may not be in written form).

(2) Communications network overlay, area coverage overlay, and dead space overlay.

(3) SOIs.

13) All brigade CSS officers (brigade S1, brigade S4, and brigade surgeon) and FSB commander evaluate CSS information and update products. [FM 6320, Chap 3, 6; ARTEP 71-3-MTP, Tasks 71-3-1002; 1003; 1004; 1008; $1009 ; 4001 ; 4002 ; 4003 ; 1301]$

a) The brigade CSS officers and sections evaluate information. 
(1) Desired brigade endstate compared with current and projected personnel, maintenance, transportation, medical, and supply status.

(a) Adequacy of CSS for the brigade main effort.

(b) Adequacy of CSS for the brigade secondary effort.

(2) Information which confirms or refutes EEFI and other IPB information.

(3) Answers to intelligence queries which alter initial assessment of enemy CSS capabilities.

(4) Adjustments to subordinate and supporting units' operations.

(5) Additional requirements for medical treatment and evacuation.

(6) Forecast of future sustainment levels based on known resupply of critical Class III and $\mathrm{V}$ requirements.

(7) Requirements for emergency resupply of units engaged in the close battle.

(8) Enemy activity.

(9) Status of the brigade LOCs.

b) The brigade CSS officers update CSS products.

(1) The brigade $\mathrm{S} 1$ section updates personnel information. [ARTEP 71-3-MTP, Tasks 71-3-1002/1, 3; 1003/1; 1004/2; $1008 ; 1009]$

(a) Revised personnel services estimate (may or may not be in written form).

(b) Personnel status of subordinate and supported units.

(c) Casualty feeder reports.

(d) Personnel priorities as directed by the brigade commander. 
(e) Updates medical evacuation status on administration and logistics operation center (ALOC) map overlay. [AN]

(2) The brigade S4 section updates logistical information. [ARTEP 71-3-MTP, Tasks 71-3-4001; 4002; 4003]

(a) Maintenance, supply, and transportation portions of revised logistics estimates (may or may not be in written form).

(b) Supply:

1 Percent fill of combat basic loads.

2 Configuration and location of immediate and emergency resupply (Class III and V) loads and push packages.

$3 \quad$ Adequacy of CSS supply assets.

$4 \quad$ Supply priorities as directed by the brigade commander.

$5 \quad$ Establishment and fill of stock piles and caches.

6 Capability for emergency resupply.

(c) Maintenance:

$1 \quad$ Number and type of equipment systems on hand and operational.

2 Systems non-mission capable and repairable.

3 Projections for repair and return of fighting vehicles and other essential equipment.

$4 \quad$ On-hand Class IX (repair parts and components), authorized stockage list (ASL) and prescribed load list (PLL) stockage levels. 
$5 \quad$ Maintenance priorities and guidelines as directed by the brigade commander.

6 Status of the combat vehicles in the maintenance float pool. [AN]

(d) Transportation:

$1 \quad$ Schedules and priorities.

2 Status of supplies, equipment, and materials requiring transport.

$3 \quad$ Availability of ground transport assets.

$4 \quad$ Availability of air transport assets.

5 Status of logistics packages (LOGPACs) and refuel-on-the-move (ROM) capability.

6 Transportation recovery and back-haul plans.

$1 \quad$ MSR and ASR traffic and route conditions.

(3) The brigade surgeon updates medical information. [ARTEP 71-3-MTP, Task 71-3-1301/3]

(a) MEDEVAC capabilities.

(b) Class VIII stocks and resupply activities.

(c) Reinforcement and reconstitution of medical assets.

(d) Disposition and capability of brigade medical assets compared to tactical situation and plans.

(e) Medical priorities as directed by the brigade commander.

(4) The FSB commander and FSB support operations center update CSS information. [FM 63-20, Chap 3, 5, 6] 
(a) Tasks to subordinate units to support the brigade's current and future operations.

(b) Tasks to subordinate units to support division and corps units operating in the brigade sector.

(c) Rear area security plans:

1 Threat (Levels I, II and III) from brigade S2.

$2 \quad$ Base and base cluster defense plans integrated with brigade security plans.

3 Forces available for local security operations and reaction force.

$4 \quad$ Aviation and indirect fire support.

$5 \quad$ Communications capabilities.

(d) Update/validate support matrix and CSS overlay.

14) The brigade $\mathrm{S} 5$ evaluates $\mathrm{CMO}$ information and updates products. [ARTEP 71-3-MTP, Task 71-3-5001]

a) The brigade S5 evaluates newly obtained information to determine:

(1) Changes to guidance and direction.

(2) The impact of the civilian population on the activities and mission of the brigade.

(3) The impact of enemy activity on the civilian population and resources/facilities.

(4) The impact of brigade combat activities on the civilian population.

(5) Desired brigade endstates compared with what is possible based on the CMO situation and trends.

b) The brigade $\mathrm{S} 5$ determines requirements and actions to assist in the acquisition of local resources, facilities, and support. [ARTEP 713-MTP, Task 71-3-5003] 
c) The brigade $\mathrm{S} 5$ determines coordination requirements to mitigate local population interference with US military operations. [ARTEP 71-3-MTP, Task 71-3-5004]

d) The brigade S5 updates the CMO plan to provide guidance and direction for dealing with the civilian population on termination of operations. [AN]

e) The brigade S5 section updates the CMO "running estimate" to support the brigade's operations (may or may not be in written form). [AN]

15) The HHC commander evaluates information to determine:

a) Capability to move, secure, and support the main and TAC CPs.

b) Requirements to move, secure, and support the main and TAC CPs.

16) The brigade CPs maintain status. [FM 71-3, pp. 3-20 - 3-25]

a) The brigade commander and brigade $\mathrm{S} 3$ in the command group/TAC CP maintains status and information to include: [FM 71-3, pp. 3-20 $-3-25]$

(1) Information which supports the commander's CCIR.

(2) Current and projected combat power status of subordinate units (e.g., green-amber-red).

(3) Current operations and intelligence map.

(a) Operations overlay (brigade, higher, and adjacent units).

(b) Intelligence overlay.

(c) SIT TEMP overlay.

(d) Event template overlay.

(e) Modified combined obstacle overlay.

(f) Fire support overlay. 
(g) Decision support tools (e.g., DST).

(h) Synchronization and execution tools (e.g., matrixes, operations schedule (OPSCHED), checklists).

(4) Status of key communications links.

(5) Information required to serve as alternate main $\mathrm{CP}$.

b) The brigade $\mathrm{XO}$ ensures that the main $\mathrm{CP}$ maintains status and information including: [FM 71-3, pp. 3-20 - 3-25]

(1) Current operations and intelligence map.

(a) Operations overlay (brigade, higher, and adjacent units).

(b) Intelligence overlay.

(c) SIT TEMP overlay.

(d) Event template.

(e) $\mathrm{MCOO}$.

(f) NBC overlay.

(g) CSS overlay.

(h) Terrain management status.

(2) CSS overlays and information per brigade SOP.

(3) Intelligence information from division and higher headquarters.

(4) Disposition of collection assets.

(5) Information on external units conducting R\&S and security operations to prevent fratricide.

(6) Disposition and status of patrols and other R\&S and security forces. 
(7) Status of operations so as to ensure compliance with stated mission timelines.

(8) Current and projected combat power status of subordinate units (e.g., green-amber-red).

(9) Status on task organization (into the brigade, within the brigade, and detachments out of the brigade).

(a) R\&S and security forces.

(b) TFs.

(c) Fire support systems.

(d) Engineer assets.

(e) GSR and other radar systems.

(f) $\quad \mathrm{ADA}$ assets.

(10) Obstacle and survivability position construction and progress as compared to timelines.

(11) Utilization of engineer assets and materials as compared to timelines.

(12) Decision support tools (e.g., DST).

(13) Plans map (with overlays for future operations).

(14) Synchronization and execution tools (e.g., FSEM, OPSCHEDs, checklists).

(15) Journals/logs.

(16) Status of key communications links to include retransmission capability.

c) The brigade $\mathrm{S} 1$ or $\mathrm{S} 4$ at the brigade rear $\mathrm{CP}$ ensures that status is maintained and that information includes: [FM 71-3, pp. 3-20 - 325] 
(1) Current operations and intelligence map.

(a) Operations overlay (brigade, higher, and adjacent units).

(b) Rear operations, security, and threat overlay.

(c) Intelligence overlay.

(d) SIT TEMP overlay.

(e) Event template overlay.

(f) $\mathrm{MCOO}$.

(g) Fire support overlay.

(2) Decision support tools (e.g. DST).

(3) CSS SITMAP and overlays.

(a) LOCs, MSR and ASR.

(b) CSS locations, current and projected.

(c) Decontamination sites.

(4) Synchronization and execution tools (e.g., matrixes, OPSCHEDs, checklists).

(5) BSA security plans.

(6) CSS staff journal.

(7) Current and projected personnel and equipment status.
(a) Personnel strength.
(b) Operational equipment strength.
(c) Status of supplies.
(d) Casualties. 
(e) Replacement personnel status/location.

(f) Damaged and non-mission-capable vehicles and equipment.

(8) Location and evacuation of EPW and their equipment.

(9) Location and evacuation of displaced persons.

(10) Status of key communications links.

(11) Identification and location of CSS units operating in brigade rear to include non-brigade units/elements.

c. The brigade $\mathrm{CPs}$ and staff communicate information necessary to conduct a synchronized brigade battle. [FM 6-20-40, p. 26; FM 6-20-50, App C; FM 71-3, Chap 3, 8, App H; FM 71-123, Chap 1; FM 101-5, Chap 5, 6, App A, B, L; ARTEP 1-100-MTP; ARTEP 3-117-40-MTP; ARTEP 71-3-MTP; FN-NTC]

1) All CPs and staff members disseminate information. [FM 71-3, pp. 3-20 $3-25]$

a) Timely recommendations to the commander on critical synchronization actions.

b) Critical information needed to:

(1) Coordinate brigade synchronization.

(2) Monitor the situation.

(3) Keep higher and adjacent headquarters informed.

(4) Influence their areas of responsibility.

c) All staff officers remain alert for and ensure that critical information they receive is passed as soon as it is received to other staff officers who require the information.

2) The brigade $S 2$ and $S 2$ section assist the brigade commander to synchronize the battle by communicating the enemy's situation, evaluations of enemy capabilities, BDA, and analyses of PIR, IR, and routine information. 
3) The brigade $\mathrm{S} 3$ in the TAC CP and $\mathrm{S} 3$ section assist the brigade commander to synchronize the battle by communicating: [ARTEP 71-3-MTP, Tasks 713-3003/2, 3; LL-CALL Bulletin No. 95-4, Chap 1]

a) Updated products, e.g.:

(1) WARNOs/FRAGOs.

(2) Coordinating instructions.

(3) Reports of the brigade situation.

(4) Evaluations of brigade status.

(5) DST information.

(6) Synchronization/execution matrix.

b) Information regarding requirements for use of terrain in the brigade area that will impact on current operations.

c) Information to adjacent units to coordinate: [ARTEP 71-3-MTP, Task $71-3-3003 / 3 c]$

(1) Zones of attack or axes of advance, objectives, bypass criteria, and actions on contact.

(2) Battle handover location, criteria, and time or event at which handover is complete.

(3) Checkpoints, coordination points, phase lines, and contact points.

(4) Direct and indirect fire plans, control measures, and restrictive fire lines.

d) Mission information from other staff members (internal and external) which impacts on the concept of operation and synchronization of combat power.

(1) Disposition and location of brigade combat power.

(2) Brigade activities. 
(3) Brigade capabilities.

(4) Status of personnel and equipment.

(5) Intentions of the brigade.

(6) Unit boundaries.

(7) Current situation.

e) Information on future operations.

f) Significant changes to enemy situation.

g) Answers to CCIR.

h) Recommendations to the brigade S3 (from S3 section), XO, or commander concerning shifts of main effort and synchronization of combat power.

4) The brigade CMLO and NBC section assist the brigade commander to synchronize the battle by communicating: [FM 101-5, App A; ARTEP 3117-40-MTP, Tasks 3-4-0007; 0009; 0016]

a) The brigade NBC situation and analysis of CCIR, IR, and critical information.

b) The brigade CMLO coordinates with the division CMLO and supporting decontamination units to confirm and organize deliberate decontamination plans and preparations. [ARTEP 3-117-40-MTP, Task 3-4-0005]

c) Recommendations to the brigade $\mathrm{S} 3, \mathrm{XO}$, or commander concerning critical NBC related actions.

5) The $\mathrm{ABE}$ section assists the brigade commander to synchronize the battle by communicating: [FM 101-5, App A; ARTEP 71-3-MTP, Task 71-38005/2]

a) The brigade engineer situation, analysis of CCIR, IR, and critical information to other brigade staff sections and external headquarters/staff officers. 
b) Current status of M/CM/S operations. [ARTEP 71-3-MTP, Task 71$3-8005 / 1]$

(1) Mobility operations. [ARTEP 71-3-MTP, Task 71-3$8005 / 1]$

(a) Sufficient engineer obstacle (natural and man-made) breaching equipment has been allocated to and coordinated with maneuver forces to ensure maintaining brigade momentum.

(b) Smoke and suppressive fires have been planned at critical breaching sites.

(c) MSRs and ASRs can be maintained allowing the brigade to sustain combat operations.

(2) Countermobility operations: [ARTEP 71-3-MTP, Task 713-8002/2]

(a) Obstacles support the brigade scheme of maneuver and subordinate unit tactical plans, reinforce engagement areas, and are tied in to other obstacles and terrain.

(b) All obstacles are covered by observation, direct fires, and indirect fires.

(c) Control measures are established.

(d) Existing obstacle locations and types are recorded, including lanes and passage points.

(e) Obstacle security is maintained by the unit responsible for the obstacle.

(f) Obstacles will not conflict or inhibit future mobility requirements for brigade operations. [AN]

(g) Criteria for FASCAM employment is accurate and understood.

(3) Current status of types and locations of required survivability positions: [ARTEP 71-3-MTP, Task 71-3-8002] 
(a) Position construction is based on priority (including positions for security force units).

(b) Locations are jointly sited by:

1 Maneuver commanders (responsible for site selection).

$\underline{2} \quad$ Engineer leader (responsible for providing equipment, material, expertise, and for preparation to standard of vehicle positions).

c) The $\mathrm{ABE}$ section coordinates with brigade units, TF engineers, and engineer battalion (as applicable) to ensure that $\mathrm{M} / \mathrm{CM} / \mathrm{S}$ operations are in accordance with the brigade order. [ARTEP 71-3-MTP, Task $71-3-8005 / 1]$

d) The brigade engineer section communicates with adjacent units and the assistant division engineer. [ARTEP 71-3-MTP, Task 71-38005/1]

(1) To exchange information on obstacle status, type, and location.

(2) To ensure that division-directed obstacle requirements are satisfied.

(3) To exchange information on mobility plans (brigade, division).

e) Recommendations to the brigade $\mathrm{S} 3, \mathrm{XO}$ or commander concerning critical mobility, countermobility, and survivability actions.

6) The AVLO assists the brigade commander to synchronize the battle by communicating: [ARTEP 71-3-MTP, Task 71-3-7001/3; ARTEP 1-100MTP, Tasks 01-4-1311, 1322]

a) The Army aviation situation to other brigade staff sections and external headquarters/staff officers.

b) Time on station for attack helicopters for specific missions. 
c) Recommendations to the brigade $\mathrm{S} 3, \mathrm{XO}$, or commander concerning employment of Army aviation assets.

7) The brigade FSCOORD, FSO, targeting officer, FSE, and NGLO assist the brigade commander to synchronize the battle by communicating: [FM 1015, App A; ARTEP 71-3-MTP, Task 71-3-9002/2, 3; FM 71-3, pp. 7-13 - 7 14; FM 6-20-40, p. A-26; FM 6-20-50, pp. C-25 - C-28]

a) Brigade fire support situation and analysis of CCIR, IR, and routine information.

b) Brigade FSO and FSE section communicate with adjacent and higher FSEs and DS FA battalion headquarters (and NGLO communicates with DS and GS NSF ships) to: [ARTEP 71-3-MTP, Task 71-3-9002/2]

(1) Ensure that planned brigade fire support will not interfere with other fire support systems, will not disrupt adjacent unit operations, and will not jeopardize troop safety.

(2) Ensure that fire support information and products (target lists, FSEM, CAS requests, and ATO) are exchanged and refined.

c) The brigade FSO and FSE section communicate with the brigade S3 and TF FSOs to verify: [ARTEP 71-3-MTP, Task 71-3-3001/2]

(1) Control measures delineating mutual boundaries.

(a) Directed by division.

(b) Internal boundaries (TFs, scouts, security forces).

(2) Air space control measures.

(3) FSCMs.

(4) Signals and conditions under which restrictive measures will be emplaced or lifted.

(5) Locations.

d) Intelligence information received through artillery or naval channels. 
e) The targeting team communicates results of attacks on targets, assessments of results, and recommendations of changes to the fire support plan and attack means.

f) Recommendations to the brigade $\mathrm{S} 3, \mathrm{XO}$, or commander concerning critical fire support matters.

8) The ALO, Marine air officer, and brigade TACP assist the brigade commander to synchronize the battle by communicating: [FM 101-5, App A]

a) CAS situation and routine information to other brigade staff sections and external headquarters/staff officers.

b) Time on station for CAS sorties in support of specific targets.

c) Intelligence information received through air operations channels.

d) Recommendations to the brigade $\mathrm{S} 3, \mathrm{XO}$, or commander concerning CAS employment.

9) The Marine air officer and NGLO assist the brigade commander to synchronize the battle by communicating naval air and NSF situation to brigade staff sections and external (to include maritime) headquarters/staff officers and make recommendations to the brigade $\mathrm{S} 3, \mathrm{XO}$, or commander as necessary concerning naval air support and NSF. [FM 101-5, App A; ARTEP 71-3-MTP, Task 71-3-9002/2, 3]

10) The $\mathrm{ADO}$ assists the brigade commander to synchronize the battle by communicating: [FM 101-5, App A; ARTEP 71-3-MTP, Task 71-3-6001/1, 6002]

a) Changes in HIMAD coverage to the brigade $\mathrm{XO}$ and brigade $\mathrm{S} 3$.

b) The brigade air picture, ADA situation and analysis of CCIR, IR, and routine information.

c) The $\mathrm{ADO}$ communicates with adjacent units and $\mathrm{ADA}$ battalion headquarters. [ARTEP 71-3-MTP, Task 71-3-6002/2, 3]

(1) To confirm scheme of maneuver, identification, friend or foe (IFF) codes, and $\mathrm{AD}$ weapons area coverage. 
(2) To confirm weapons control status with higher and adjacent units.

(3) To confirm events and reporting systems which will cause the brigade to upgrade weapons control status.

d) Warning of imminent enemy air attacks (early warning).

e) Updates the brigade S2 and air defense battalion S2 on: [AN]

(1) Type of aircraft engaged.

(a) Location.

(b) Time.

(2) Type of damage inflicted.

(3) Routes, tactics used by enemy air.

f) Recommendations to the brigade $\mathrm{S} 3, \mathrm{XO}$, or commander concerning air defense matters.

11) The MP platoon leader assists the brigade commander to synchronize the battle by communicating brigade MP situation and critical information to other brigade staff sections and external headquarters and makes recommendations to the brigade $\mathrm{S} 3, \mathrm{XO}$, or commander as necessary about traffic control, handling of EPW, and other assigned missions. [FM 101-5, App A; ARTEP 71-3-MTP, Task 71-3-1201/1]

12) The Bde $\mathrm{SO}$ and section assists the brigade commander to synchronize the battle by communicating: [FM 101-5, App A; ARTEP 71-3-MTP, Task 71$3-1102 / 4]$

a) Brigade communications situation and critical information to other brigade staff sections and external headquarters.

b) The brigade communications section communicates with adjacent units and signal battalion headquarters. [ARTEP 71-3-MTP, Task $71-3-1102 / 4]$

(1) To confirm allocation and locations of signal assets and capabilities. 
(2) To acquire signal equipment to supplement brigade CPs and subordinate units which require special communications equipment.

c) Recommendations to the brigade $\mathrm{S} 3, \mathrm{XO}$, or commander concerning critical communication actions.

13) The brigade rear $\mathrm{CP}$ (S1 and S4 officers and sections), FSB commander, and support operations officer assist the brigade commander to synchronize the battle by communicating: [FM 101-5, App A]

a) Critical Class III, IV, and V supplies status that will affect the current battle.

b) Brigade CSS staff communicates with brigade staff and brigade units:

(1) To identify additional requests for support.

(a) Transportation assets.

(b) Medical augmentation.

(c) Maintenance support for vehicles and weapons systems and for recovery of damaged vehicles or return of repaired vehicles.

(2) To coordinate the transportation of supplies and cargo to brigade units.

(3) To coordinate routine, emergency, and critical resupply operations (e.g., delivery times, types and quantities of supplies required.)

(4) For receiving and processing replacements.

(5) To track evacuation of personnel and casualties.

(6) To process awards, decorations, promotions, and legal actions.

(7) For security and protection of CSS units operating forward. 
c) Inform the brigade $\mathrm{S} 3, \mathrm{XO}$, or commander of serious capability losses and provide recommendations for provision of CSS. [AN]

d) Inform higher headquarters (G4, WSRO officer) when combat personnel or equipment losses reach a point where assistance is needed. $[\mathrm{AN}]$

14) The brigade $S 5$ assists the brigade commander to synchronize the battle by communicating: [FM 101-5, App A; ARTEP 71-3-MTP, Task 71-3$5001 / 2]$

a) CMO situation and analysis of CCIR, IR, and routine information.

b) Civilian activity impact on LOC congestion that will affect synchronization.

c) Recommendations to the brigade $\mathrm{S} 3, \mathrm{XO}$, or commander concerning operational actions based on $\mathrm{CMO}$ situation.

3. The brigade commander sees and visualizes the battlefield. [FM 100-5, p. 1-8]

a. The brigade commander updates his estimate according to his assessment of new information for purpose of more clearly seeing the battlefield, based on what he has observed and what he has been told. The updated estimate is based on information related to: [FM 101-5, Chap 1, 3, 4; Battle Command Techniques and Procedures, Chap 2, 4; Battle Command, pp. 10-14 and pp. 22-24; FM 34-130, Chap 1, 2, 4; FM 71-100, Chap 1, 3, App 4]

1) Friendly situation:

a) The present friendly situation based on his personal observation.

b) The present friendly situation based upon reports from:

(1) Division commanding general (CG), ADC-M, or G3.

(2) TF and other subordinate commanders.

(3) Brigade XO and brigade staff officers.

(4) Brigade S3, FSCOORD, and ALO.

c) The present friendly situation in terms of: 
(1) The brigade commander's CCIR. [FM 101-5, pp. 4-47/48, 6-8/9]

(2) The brigade commander's need for information based on his visualization of current and future desired endstates.

(3) Anticipated flow of the battle (e.g., changes in battle phasing).

(4) Changes in location of brigade combat power.

(5) The impact of past activities on brigade units, particularly those fighting the close battle.

(6) The current operations of brigade units and their ability to modify or change their plans.

(7) Changes in combat power of brigade units relative to the accomplishment of current and future missions relative to:

(a) Capabilities, strengths, and weaknesses of subordinate commanders.

(b) Capabilities, strengths, and weaknesses of subordinate units in terms of:

1 Weapon systems and equipment.

2 Personnel.

$3 \quad$ Supplies.

(8) Status of brigade reserve.

(9) Adjacent units.

(a) Situation:

1 Locations.

2 Activities.

3 Combat power. 
(b) Intentions and future plans.

(10) Status of training.

d) Time:

(1) The amount of time available and the amount of time required for:

(a) The brigade and its subordinate units to move or accomplish all assigned tasks.

(b) A planned event or required action to occur.

(2) The amount of time available and the amount of time required to plan and coordinate missions.

2) Mission:

a) The division and corps commander's intentions and concepts.

b) The brigade mission, in terms of:

(1) Present concept of operation (maneuver and fires).

(2) Comparison of the present plan to the current situation.

3) Characteristics of the $\mathrm{AO}$ :

a) Weather:

(1) Visibility (fog and cloud cover).

(2) Light data.

(3) Precipitation

(4) Temperature and humidity.

(5) Wind speed.

b) Terrain: 
(1) The impact on the brigade units, the enemy's ability to maneuver, and the capability to apply combat power relating to the brigade mission.

(2) The effects of terrain in relation to:

(a) Observation and fire.

(b) Enemy and friendly obstacles.

(c) Obscurants (smoke, etc.).

(d) Electromagnetic measures.

c) Other pertinent factors:

(1) Safety and accident prevention.

(2) Civilian infrastructures that affect brigade operations, such as communications, or transportation systems, noncombatant locations, or activity.

4) Enemy situation:

a) Dispositions.

b) Composition.

c) Strength, to include committed forces, reinforcements, artillery, air, $\mathrm{EW}$, air defense, anti-tank, and NBC.

d) Capabilities.

e) Recent and present activities.

f) Peculiarities and weaknesses.

g) Enemy capabilities, apparent intentions, and possible COAs.

5) Combat power relevant to the enemy:

a) Maneuver units.

b) Supporting fires. 
c) Leadership.

6) The battlefield operating systems (BOSs):

a) Intelligence.

(1) Is the $R \& S$ plan still valid?

(2) Are brigade collection assets still capable of providing required information about the enemy?

(3) Are PIR/IR still valid?

b) Maneuver.

(1) Does the brigade have the combat power to accomplish the mission in accordance with commander's intent?

(2) Does repositioning criteria and planned movement ensure that the mission can be achieved as designated?

(3) Are in-depth and on-order defensive positions prepared and do they meet the plan requirements and commander's intent?

(4) Does the scheme of maneuver gain the positional advantages to achieve this intent and the designated endstate (including contingencies, branches and sequels)?

(5) Does the employment criteria and events for the use of reserves achieve the mission?

(6) Have reconnaissance and back-briefs confirmed the initial decision on where the brigade will accept decisive engagement?

(7) Is the main effort properly resourced to accomplish the mission?

c) Fire support.

(1) Have fire plans been adjusted based on new enemy and terrain information? 
(2) Have fire plans and sector sketches been developed and modified to ensure that fires can be massed as designated by the commander?

(3) Have direct and indirect fire coordination measures been disseminated and confirmed by subordinate commanders?

(4) Have boundaries and other control measures been disseminated and confirmed by subordinate commanders?

(5) Are direct and indirect fire plans synchronized and integrated with all other combat multipliers, including physical tie-in between brigade units and units on the brigade's flanks?

(6) Do fire support priorities adequately weight the main effort?

(7) Do fires adequately support brigade R\&S and counterreconnaissance forces?

(8) Are target acquisition assets in place or projected to be in place in time?

(9) Have target lists been updated by the brigade FSO and TF FSOs, and are they synchronized with changes to the brigade or TF scheme of maneuver?

(10) Are fire support assets positioned and prepared to support the operation?

(11) Has responsibility been assigned for firing critical targets and are observers in position?

d) Command and control.

(1) Are key communications links within the brigade operational?

(2) Do current and projected locations of $\mathrm{CPs}$ provide for continuous command and control?

(3) Are CCIR being adequately answered?

(4) Are leaders and units motivated and capable of continued operations? 
(5) Is the succession of command clear and ready to be implemented?

(6) Have risk factors been accurately identified and understood?

e) Mobility and survivability.

(1) Are obstacles in place or projected to be in place in time?

(2) Are obstacles observed and covered by fires and responsibility properly assigned?

(3) Do the obstacles shape the battlefield in accordance with commander's intent?

(4) Are plans for clearing lanes in friendly obstacles adequate to support brigade maneuver?

(5) Can the brigade conduct obstacle breaching as designated in the plan?

(6) Is there new information which might require changes to the point of penetration or breach?

(7) Are there sufficient mobility assets (mine plows/blades) for the breach element?

(8) Are fighting and survivability positions adequate to ensure mission accomplishment?

(9) Is there adequate construction material and is it being delivered on time?

(10) Are there any modifications to FASCAM employment plans required by the engineer and FSCOORD/brigade FSO based on new information?

f) Air defense.

(1) Does ADA coverage ensure support of adjusted priorities, concept of the operation, and commander's intent? 
(2) Have modifications to the weapons control status been made based on changes to the enemy air threat?

(3) Are air defense assets adequate and positioned and capable of protecting the brigade now and during mission execution?

g) Combat service support.

(1) Is there a need to adjust CSS priorities based on new information?

(2) Are supplies adequate to support the operation and are they being delivered to brigade units on time?

(3) Are prestocked cache positions secured?

(4) Are there sufficient transportation assets available and operational to support the operation?

(5) Does the status of personnel fill enable brigade units to accomplish their missions and tasks?

(6) Does the state of morale in the brigade support mission accomplishment?

(7) Is the current and projected state of maintenance of equipment in the brigade adequate to support mission accomplishment?

(8) Are medical personnel, supplies, and equipment available and positioned to support the concept of the operation?

b. The brigade commander projects current battle endstates now necessary to achieve his intent based on his evaluation of the current plan and brigade situation by considering factors associated with each BOS: [FM 101-5, Chap 4; FM 34-130, Chap 1, 2, 3; Battle Command Techniques and Procedures, Chap 2, 4; Battle Command, pp. 38-45; FM 34-8, Chap 1, 2, App C]

1) Intelligence:

a) Disposition of enemy forces, to include follow-on, reserve, or uncommitted forces.

b) Composition and combat strength of enemy forces. 
c) "Will to fight" of enemy forces.

d) Enemy's capabilities and possible COAs.

e) Enemy's capability to continue operations at the conclusion of the current battle.

f) Enemy's limitations and exploitable weaknesses.

g) Terrain conditions and considerations.

h) Weather conditions.

i) Capability of brigade reconnaissance elements to provide continuous $\mathrm{R} \& \mathrm{~S}$ for the force.

j) Availability, position, and mission of brigade, division or higher headquarters intelligence collection assets.

2) Maneuver:

a) Combat strength of the brigade's maneuver forces.

b) Location of brigade maneuver forces including follow-on, reserve, or uncommitted units.

c) The terrain responsibility and orientation of subordinate units.

d) Brigade task organization.

e) Force ratios and combat power in comparison to the enemy.

f) Capabilities of division elements and adjacent units.

3) Command and control:

a) Status of unit morale, cohesion, and capability to continue operations.

b) Status and effectiveness of the brigade command, control, and communications (C3) system. 
c) Status of brigade C2 capability to achieve and maintain initiative, agility, flexibility, and depth.

d) Status of synchronization and "progress" of current battle.

e) Adequacy of CCIR.

4) Fire support:

a) Strength, availability, and positions of all fire support assets:

(1) Artillery.

(2) Mortars.

(3) CAS, TACP.

(4) EW.

(5) NSFs.

(6) FIST, FSO, COLTs, SALTs.

(7) Radars.

b) FS units' capabilities to support brigade operations.

c) Priorities.

5) Air defense:

a) Brigade friendly air status.

b) Enemy air threat.

c) Strength, availability, and position of $\mathrm{AD}$ assets.

d) Status of the air defense C2 system.

e) Status of early warning system.

f) Priorities.

6) Mobility/countermobility/survivability: 
a) Engineer assets and CL IV/V supplies available to support $\mathrm{M} / \mathrm{MCM} / \mathrm{S}$ operations.

b) Task organization of engineer assets as compared to maneuver units.

c) Engineer unit capabilities, positions, and missions.

d) Location and status of task force organic M/CM/S equipment.

e) Capability and disposition of supporting NBC reconnaissance, smoke and decontamination units.

7) Combat service support:

a) Operational capability of the subordinate units' CSS system.

b) Availability of all classes of supply.

c) Operational and support capability of the FSB.

d) Capability of the medical support system.

c. The brigade commander anticipates requirements and actions based on his projection of the outcome of the current battle. [FM 101-5, Chap 1, 2, 4, 5, App C, D, E; Battle Command Techniques and Procedures, Chap 2, 4]

1) The brigade commander bases anticipated future requirements and actions on:

a) The brigade on order or be prepared mission(s).

b) His understanding of the higher commander's intent.

c) His projection of the outcome of the current battle.

d) His assessment of what the enemy will do at the end of the current battle.

e) His assessment of risk.

f) Subordinate units' capabilities. 
g) Existing brigade contingency plans or war gamed branches and sequels to the current operation.

2) The brigade commander develops information to assist him in determining future requirements and actions by:

a) Communicating with his higher headquarters to ensure that he knows and understands future division plans.

b) Soliciting input from the senior leadership within the brigade, e.g., brigade $\mathrm{XO}$ and $\mathrm{S} 3$, subordinate $\mathrm{TF}$, and battalion commanders.

3) The brigade commander defines requirements and actions based on BOS factors:

a) Intelligence BOS:

(1) Adjustments necessary to the PIR.

(2) Additional intelligence collection assets needed.

(3) Mission changes required for intelligence collection assets.

b) Maneuver BOS:

(1) Missions appropriate for all maneuver forces.

(2) Repositioning or reorientation required for maneuver units at the end of the current battle.

(3) Mission changes required for the brigade maneuver reserve.

(4) Direction or guidance given to subordinate commanders to reduce ambiguity for future operations.

(5) Changes necessary in the maneuver scheme to shape the current battle so as to be better postured for the on order mission.

(6) Impact of adjacent unit dispositions, strength, activities, capabilities, and missions on projected brigade operations.

(7) Additional maneuver combat power required. 
c) Fire support BOS:

(1) Changes required to the fire support priorities and plan.

(2) Additional fire support assets needed.

(3) Requirements to reposition fire support assets.

(4) Adjacent units' capabilities to support.

(5) Retargeting of HPT.

d) Command and control BOS:

(1) Required adjustments in brigade C2.

(2) Additional communications capability required.

(3) Impact of time on future actions.

(4) Adjustments necessary to $\mathrm{C} 2$ graphics.

(5) Adjustments necessary to the DST and other operational matrices.

(6) Redefined CCIR.

(7) Redefined risk assessment.

e) Air defense BOS:

(1) Adjustments to the $\mathrm{AD}$ priorities.

(2) Repositioning requirements for $\mathrm{AD}$ assets.

(3) Additional AD assets needed.

f) Mobility and survivability BOS:

(1) Additional M/CM/S assets required.

(2) Adjustments to the mobility tasks required.

(3) Countermobility tasks required. 
(4) Survivability tasks required.

(5) MOPP status.

(6) Decontamination requirement.

(7) Force protection requirements.

g) Combat service support BOS:

(1) Additional CSS units required.

(2) Adjustments necessary in the positioning of logistics support units and nodes.

(3) Additional supplies by class of supply required.

(4) Additional personnel needed by MOS.

(5) Additional equipment, vehicles, and weapons systems required.

d. The brigade commander informs the division commander of the results of his brigade assessment. [AN]

1) The brigade commander's projection of the current battle indicates that the division commander's intent cannot be met.

2) The brigade must receive additional combat power to achieve the division commander's intent.

3) The brigade can accomplish the mission.

e. The brigade commander decides whether the current plan needs to be changed. [FM 101-5, Chap 4, 7, App H, J; Battle Command Techniques and Procedures, Chap 2, $4,5]$

1) The brigade commander uses his staff to test the validity of his ideas. [LLCall Newsletter, No 90-8, p. 24]

2) The brigade commander decides the current plan will achieve his intent and the brigade mission and continues to direct brigade battle execution. [FM $101-5$, p. 4-48] 
3) The brigade commander decides the plan must be modified. [FM 101-5, p. 4-48]

a) The brigade commander bases his decision to initiate a FRAGO by considering: (See Task 4.b.11 for description of how to develop and issue this FRAGO) [FM 101-5, pp. 1-14 - 1-16]

(1) Whether COAs previously developed can be modified and developed as the new plan.

(2) Time available to develop, coordinate, and implement a new plan.

(3) Subordinate units' time to complete new preparation requirements under the new plan and task organization.

(4) The brigade staff's ability to continue to monitor and direct current brigade activities while meeting new planning requirements.

(5) Whether the FS assets can support the COA considered.

(6) Reevaluating the present brigade $\mathrm{M} / \mathrm{CM} / \mathrm{S}$ situation and determining what can be done to support the COA considered.

(7) CSS units' capabilities to support the brigade.

(8) Whether the brigade can be supported by available $\mathrm{AD}$ assets.

(9) Preplanned CAS availability and joint air attack team (JAAT) requirements for the contemplated modification.

(10) Whether a new DST and FSEM can be developed to incorporate the modification.

(11) Whether the brigade's communication system can support the modified brigade COA.

(12) Time required to plan and prepare for new mission based on current mission timelines and staff's abilities. 
(13) Ability of the brigade to respond to the new situation based on current tactical posture and situation.

(a) Maneuver forces available to respond without impacting brigade ability to perform the current mission.

(b) Availability of CS, CSS, and supplies to support the new situation without impacting on support necessary for the current mission.

(14) Whether staff has time to plan and coordinate new missions.

(15) Impact of diverting key staff members from synchronizing the current mission to planning for a new mission.

b) The brigade commander determines how to modify the military decision-making process (MDMP) based on complexity, potential probable confusion on the battlefield, and time available. [FM 1015, Chap 4]

(1) The brigade commander determines staff availability, the magnitude of change to the plan, and the amount of time available before execution.

(2) The brigade commander decides where to conduct the decision-making process (DMP) and actions required to produce and disseminate the FRAGO.

4. The brigade commander directs changes to the operation or plan. [FM 71-123, pp. 138; FM 101-5, pp. 1-4 - 1-15]

a. The brigade commander and/or staff issue WARNOs to alert staff members and subordinate elements that the plan will be changed. WARNOs may include: [FM 101-5, p. 4-55; LL-CALL Newsletter No. 93-3, p. 3]

1) The enemy situation and events.

2) The corps and/or division mission(s).

3) The corps and/or division commander's intent(s).

4) The earliest time of movement or degree of notice the commander can provide to the main body. 
5) Orders for repositioning units, preliminary direct action against the enemy (e.g., fires, reconnaissance, surveillance, and observation).

6) Service support instructions, any special equipment necessary, regrouping of transportation, or preliminary moves to assembly areas.

7) The rendezvous point or time for assembly of an orders group; whether commanders or representatives are to attend; and time needed for issuing written orders.

b. The brigade commander employs the MDMP in a time-constrained environment. (Time available may be as brief as seconds or minutes.) [FM 71-3, App I; FM 1015, pp. 4-41 - 4-60]

1) When planning changes to current orders or planning for a new mission during the execution phase of the current battle, the brigade commander must:

a) Consider use of existing decision products and synchronization tools in use during the current mission as reference points from which modifications are made. Products and tools include:

(1) Weather analysis.

(2) Terrain analysis.

(3) Enemy order of battle and updated IPB products.

(4) Current revised staff estimates.

(a) Brigade capabilities.

(b) Constraints.

(5) PIR, EEFI, and FFIR requested by the commander.

(6) Decision support tools (e.g., DST).

(7) Synchronization and execution tools (e.g., FSEM, OPSCHEDs, checklists). 
b) The brigade commander and staff must simultaneously monitor, plan, and direct all aspects of brigade operations (e.g., execution of the current mission; development of changes to the current plan).

c) Anticipate the outcome of the current fight and begin considering future requirements and actions.

d) Recognize similarities and/or differences between the initial plan and new requirements.

e) Assess friendly force posture, enemy probable actions and postures, and battlespace.

f) Modify existing branches and sequels to meet new requirements.

g) Future requirements for deep, close, and rear battle areas.

h) Key leader and staff availability and location.

i) The amount of time available for planning and rehearsal.

j) Extent of reconnaissance effort necessary to obtain critical information.

2) The brigade commander conducts a quick mission analysis by:

a) Analyzing the division and corps commander's intents.

b) Determining the brigade's stated mission and required endstate to accomplish that mission.

c) Comparing the desired endstate for the brigade to the enemy situation.

d) Deciding whether the brigade has the assets and resources to execute the new mission.

e) Identifying time critical tasks (shifting units, resupply, and requesting additional resources).

f) Conducting a map reconnaissance or if possible a brief physical reconnaissance (by air).

g) Establishing a time schedule using backward planning. 
h) Deciding the brigade task organization.

3) The brigade commander completes an update of his estimate.

a) Mission:

(1) Identifies specified and implied tasks which his brigade must accomplish.

(2) Appraises whether the who, what, where, when, and why of the "new" brigade plan support the corps and division commander's intents.

b) Enemy:

(1) Determines the enemy's strength, location, disposition, activity, equipment, capability, and intentions.

(2) Identifies which limited number of enemy COA the brigade must defeat.

c) Terrain and weather: information on observation and fields of fire, cover and concealment, obstacles, key terrain, avenues of approach (OCOKA), vegetation, soil type, hydrology conditions, visibility, climatic conditions, and visibility.

d) Troops: the commander determines the status of the brigade's and TFs' combat power in terms of capability relative to the mission by considering:

(1) Capabilities, strengths, and weaknesses of subordinate commanders and units.

(2) Weapon systems and equipment.

(3) Disposition.

(4) Supplies.

(5) Troop rest and morale. 
e) Time: the commander determines the time available for planning, preparing, and executing the operation for both enemy and friendly forces.

4) The brigade commander quickly develops a revised concept and/or COA which is based on:

a) His mission analysis.

b) His updated commanders analysis.

c) BOS specific information from selected staff members.

d) Information available in products developed during the initial mission DMP.

5) The brigade commander describes his revised concept and COA to his staff. [FM 101-5, pp. 4-48, 4-49]

a) The commander develops and explicitly expresses:

(1) Brigade commander's intent and desired endstate.

(2) Concept of operations.

(a) Major components of maneuver.

(b) Integration of combat multipliers.

(c) Critical points and center of gravity.

(d) Sketch of the initial concept of the operation. [LLCALL Newsletter No. 93-3, p. 9]

(3) Enemy $\mathrm{COA}(\mathrm{s})$ to be considered.

(4) CCIR.

(5) Limitations.

(6) Risks.

b) If time is available, the brigade staff: 
(1) Develops details on COA provided by the commander.

(2) Develops branches and sequels to the selected COA which adhere to the commander's guidance.

6) The brigade commander performs a brief, but comprehensive, analysis of selected COA. The commander performs the analysis by himself or with staff assistance. [FM 71-3, App I; FM 101-5, pp. 4-51]

a) Suitability factors:

(1) New concept accomplishes the brigade mission.

(2) New concept meets the division and corps commander's intents.

(3) The plan accomplishes his intent for the brigade's endstate relative to the intended endstate for the enemy.

(4) The brigade can maintain the initiative by forcing the enemy to react to the new brigade COA.

b) Feasibility factors:

(1) There is time available to execute the plan(s) as designed.

(a) Duration of events.

(b) Time and distance factors for maneuver and fires.

(2) There is sufficient ground and air space to accomplish the plan(s) as designed.

(a) Roads and terrain support the plan.

(b) Depth of action.

(3) The brigade has the means to execute the plan(s) as designed.

(a) Brigade combat power versus the enemy (force ratios). 
(b) Special equipment and personnel to accomplish the mission (e.g., bridging equipment, mine clearing, Army aviation, CAS).

(4) Impact on on-going actions.

(5) Impact on subordinate units and combat multipliers.

(6) Requirements to alter task organization.

c) Acceptability: can be conducted within acceptable costs/risks.

7) The brigade commander quickly compares $\mathrm{COA}$ (if more than one).

8) The brigade commander selects a COA and:

a) Announces his decision to key brigade staff members.

b) Ensures that he or a staff member documents the selected COA for use in preparing and issuing orders.

9) The brigade commander conducts mission risk assessment to ensure that conditions most likely to cause mission failure and accidents (including fratricide) have been mitigated.

a) Brigade units have not been tasked beyond their capabilities.

b) Procedural and positive risk-reduction control measures have been implemented, for example:

(1) Situation is understood by brigade members.

(2) Procedures governing destruction or engagement of targets are clear.

(3) Target identification and responsibilities are clear.

(4) SOPs are consistent with doctrine and are adhered to.

(5) Control measures are flexible enough to not interfere with operations and are firm enough to prevent fratricide, civilian casualties, and collateral damage. 
(6) Doctrinally correct terminology is applied to all control measures (e.g., fire support coordination lines [FSCLs], and restrictive fire lines [RFLs]).

(7) ROE are clear.

10) The brigade commander reviews his current CCIR to determine: [FM 1015, pp. 4-47 - 4-48]

a) Validity of CCIR.

b) New CCIR required to provide him with the information needed to make decisions about the plan.

11) The brigade commander prepares or directs preparation of a FRAGO. [FM 101-5, App H; ARTEP 71-3-MTP, Task 71-3-3010]

a) The brigade commander, during battle execution, may prepare the FRAGO himself.

(1) The FRAGO must be documented by the main $\mathrm{CP}$ so that the staff can conduct necessary coordination and integration activities, and for recording the FRAGO in the brigade operations journal/log.

(2) The brigade staff members collocated with the brigade commander, (e.g., at the TAC CP) may assist in FRAGO preparation.

b) The brigade commander may direct the FRAGO be prepared by the brigade staff.

(1) The brigade XO manages and supervises internal and external coordination by the staff to prepare a synchronized FRAGO. [ARTEP 71-3-MTP, Task 71-3-0001]

(2) The brigade $\mathrm{XO}$ directs the brigade staff backbriefs to the brigade commander based on his guidance and: [LL-CALL Newsletter No 93-3, p. 9]

(a) The brigade $\mathrm{XO}$ develops a preparation timeline. [LL-CALL Newsletter No. 93-3, p. 12] 
(b) The brigade XO refines the timeline by listing tasks to be accomplished during preparation and the person responsible to complete the task. [LL-CALL Newsletter No. 93-3, p. 12]

(c) The brigade $\mathrm{XO}$ ensures that the brigade staff uses the timeline to track the progression of preparation. [LL-CALL Newsletter No. 93-3, p. 12]

(d) The brigade $\mathrm{S} 3$ section organizes reproduction by centralizing collection of the portions of the order and its production. [LL-CALL Newsletter No. 93-3, p. 27]

(e) The brigade $\mathrm{XO}$ selects an area to reproduce the order that will not interfere with the staff's work. [LL-CALL Newsletter No. 93-3, p. 27]

(f) The brigade $\mathrm{S} 3$ section uses a mimeograph or a photocopier to speed reproduction of order text. [LLCALL Newsletter No. 93-3, p. 27]

(g) The brigade $\mathrm{S} 3$ section uses a photocopier to reproduce graphics. [LL-CALL Newsletter No. 93-3, p. 27]

(3) The brigade XO directs the brigade staff as it takes prompt action to accomplish the guidance given by the commander. Actions include:

(a) Publish refinements to orders, annexes, and synchronization products.

(b) Initiate requests to higher and adjacent units for additional support.

(c) Coordinate receipt of additional support.

(4) The brigade $\mathrm{XO}$ directs the brigade staff in preparing FRAGOs reflecting changes to the current plan for the brigade commander's approval. FRAGO preparations include: [FM 101-5, App H; ARTEP 71-3-MTP, Task 71-33010] 
(a) Graphics and control measures for the operation.

(b) DST and synchronization matrix.

(c) Fire support plan, FSEM, FSCM, AGM, and quick fire plan.

(d) Communications plan.

(e) CSS plan with support matrix.

12) The brigade commander approves and directs issuance of the FRAGO. [FM 101-5, p. 4-49, 4-59 - 4-60; App H; ARTEP 71-3-MTP, Task 71-3-3010]

a) The brigade commander will normally, in the execution phase, approve and issue the FRAGO from the TAC CP (personally or by the $S 3$ ).

(1) Oral.

(2) Other.

b) If the FRAGO has been prepared by the staff at the main $\mathrm{CP}$, the brigade commander may direct the brigade $\mathrm{XO}$ to approve and issue the FRAGO.

c) Mandatory elements of the FRAGO are:

(1) 1. Situation. (Include any changes to the existing order.)

(2) 2. Mission. (List the new mission.)

(3) 3. Execution:

(a) Intent:

(b) a. Concept of operations.

(c) b. Tasks to subordinate units.

(d) c. Coordinating instructions. (Include the statement, "The current overlay remains in effect" or "See change one to Annex C, Operations Overlay.") 
(Mark any changes to control measures on the overlay.) (As time permits, issue a new overlay.)

(4) 4. Service support. (Include any changes to existing order or the statement, "no change to OPORD xx.")

(5) 5. Command and signal. (Include any changes to existing order or the statement, "no change to OPORD xx.")

13) As soon as possible, and as needed, appropriate supporting plans and decisions are developed and distributed, including:

a) DST and synchronization matrix.

b) Fire support plan, FSEM, FSCM.

14) The brigade commander conducts a confirmation brief in person or by electronic means with key brigade leaders. [LL-CALL Newsletter No. 90-8, p. 25]

15) The brigade $\mathrm{XO}$ conducts a confirmation brief with the brigade staff at the main and rear CPs. [LL-CALL Newsletter No. 90-8, p. 25]

16) Brigade key leaders and all subordinate commanders, if possible, are able to hear each others' confirmation briefs. This ensures:

a) Common understanding of the entire plan and the roles of each unit.

b) Agility in execution; i.e., the ability to react quicker than the enemy.

c) Direct personal coordination, which enhances synchronization of the plan.

d) Continuity of command, so that if the brigade commander becomes combat ineffective, the subordinate commanders will share the same view of the commander's intent.

c. The brigade $\mathrm{XO}$ directs the brigade staff as it coordinates internally and with higher, adjacent, and supporting elements to coordinate the FRAGO. [FM 101-5, App B]

1) The brigade $\mathrm{XO}$ directs the brigade staff to inform brigade elements of outdated/preempted orders, execution products and annexes containing information that has been superseded by the current FRAGO. 
2) The brigade $\mathrm{XO}$, at the main $\mathrm{CP}$, analyzes the current FRAGO in light of current division, adjacent, and supporting unit OPORDs to preclude conflict.

3) The brigade $\mathrm{XO}$ ensures that the brigade staff understands how the commander wants to synchronize the battle; staff members perform necessary coordination. (See brigade BF 20, Task 2. a, b and c; Task 4. b. 11) b) (1) and (2)).

4) The brigade $\mathrm{XO}$ directs LNOs to communicate the FRAGO and the brigade commander's intent to their respective headquarters.

d. The brigade $\mathrm{XO}$ supervises the staff actions necessary to assist the brigade commander to synchronize the current battle. (See brigade BF 20, Task 2. a, b and c).

5. Brigade command posts manage and maintain command, control, and communications. [FM 71-123, pp. 1-43 - 1-46; FM 71-3, Chap 3; FM 101-5, Chap 5, 7, App B, Battle Command Techniques and Procedures, Chap 4]

a. The brigade $\mathrm{XO}$ manages the means of communicating information for all brigade CPs. [FM 71-3, Chap 3, 8; FM 71-123, Chap 1; FM 101-5, Chap 6, App B, L]

1) The brigade commander appoints an "information manager" from the staff (usually the brigade $\mathrm{XO}$ ) to: [FM 101-5, 6-2, App B]

a) Facilitate the flow of information and communication of information from staff members and subordinate units.

b) Outline and monitor the performance and responsibilities of the staff in processing mission information, preparation status, and the commander's information requirements.

c) Ensure that the brigade CCIR is used to focus the staff as it manages all information.

d) Establish and enforce timelines.

2) The brigade commander or XO employs a "battle captain" to manage the operations of the main $\mathrm{CP}$ and the operations section when the $\mathrm{XO}$ is not available. [LL-CTC Bulletin No. 94-1, p. 5]

a) Coordinates and integrates staff activities for short periods.

b) Initiates staff action as directed by the commander, $\mathrm{XO}$, and $\mathrm{S} 3$. 
c) Performs as brigade operations OIC.

3) The brigade XO directs staff meetings to: [ARTEP 71-3-MTP, Task 71-30001]

a) Ensure that each staff officer disseminates information which is relevant to the entire staff.

b) Appraise completeness of information.

c) Identify information gaps and directs actions to fill them.

d) Initiate staff planning as part of an accelerated decision process.

e) Coordinate brigade targeting team's actions.

4) The brigade $\mathrm{XO}$ ensures that $\mathrm{LNO}$ provide information to the brigade commander and staff and to the HQ they represent. [FM 101-5, App L]

a) Responses to specific questions asked of LNO.

b) Unit locations, activities, capabilities, status, and intentions.

c) Coordination problems.

(1) Inability to reach/meet with specific people or staff positions.

(2) Receipt of information which invalidates or should change estimates and plans.

5) Radio net operators at all brigade CPs eavesdrop on lower and adjacent unit command and O\&I nets for information. [FN-NTC O/C]

6) The information manager at each brigade $\mathrm{CP}$ ensures that information on the situation is communicated between staff officers during shift changes. [FM 101-5, pp. 5-7 - 5-8; AN]

a) Enemy activities.

b) Status of subordinate units.

c) On-going staff actions which must be monitored, tracked, and completed. 
d) Timelines and suspenses which must be met.

e) Planning for future missions.

7) The radio net operators at all brigade CPs communicate routine information per brigade SOP. [FM 101-5, p. 6-5]

8) The brigade $\mathrm{S} 3$ manages communications for the command group and TAC CP and: [FM 71-3, Chap 3; FM 71-123, Chap 1]

a) Facilitates control and coordination for the commander through communication with subordinate, adjacent, and supporting elements.

b) Passes processed information and keeps the commander updated on new information through concise, consolidated updates.

c) Operates and monitors communications nets.

(1) Brigade command.

(2) Brigade O\&I.

(3) Division command.

(4) Division O\&I.

(5) Fire support nets (digital and voice).

(6) Division and brigade high frequency (HF) voice nets (on call).

(7) Air Force coordination nets (frequency modulated [FM], HF, ultra high frequency [UHF], very high frequency [VHF]).

d) The brigade commander communicates with:

(1) Division commander and the ADCs (O and M).

(2) Subordinate battalion/TFs' commander, XO, or S3.

(3) Brigade XO.

(4) Brigade FSCOORD. 
(5) Brigade engineer.

(6) Brigade ALO.

e) The brigade $\mathrm{S} 3$ communicates with:

(1) Brigade commander if not at the TAC CP.

(2) Brigade main CP.

(3) Subordinate battalions.

(4) Division G3.

9) The brigade $\mathrm{XO}$ at the main $\mathrm{CP}$ manages communications and: [FM 71-3, Chap 3; FM 71-123, Chap 1; ARTEP 71-3-MTP, Task 71-3-0001]

a) Maintains communications with the brigade command group and TAC.

b) Manages communications networks and maintains communications linking the brigade main $\mathrm{CP}$ to division $\mathrm{CP}$, adjacent headquarters, and brigade subordinate units.

c) Maintains communications between the brigade main CP, the BSA, base clusters, or other units in support of rear area operations.

d) Manages communications networks in support of counter reconnaissance and $\mathrm{R} \& \mathrm{~S}$ operations in order to maintain reporting linkages for critical sources of information.

e) Maintains a digitized LAN and wide-area network (WAN) to support battlefield computer systems.

f) Ensures that main CP staff members operate and monitor communications nets.

(1) Brigade command net control station (NCS).

(a) Communicates to subordinates the commander cannot reach. 
(b) Disseminates critical new information quickly to the commander, staff, and subordinate/supporting headquarters.

(2) Division command.

(3) Fire support nets (digital and voice).

(4) Brigade O\&I (NCS).

(5) Division O\&I.

(6) Brigade administrative/logistics (A/L).

(7) USAF coordination nets.

(8) Division early warning net and air defense data.

(9) Engineer net.

(10) MCS.

(11) Division EW net.

(12) Air defense battery net.

e) The brigade $\mathrm{S} 3$ section at the brigade main $\mathrm{CP}$ communicates and coordinates with:

(1) Division headquarters.

(2) Adjacent units.

f) The brigade $\mathrm{S} 2$ and $\mathrm{S} 2$ section communicates with: [ARTEP 71-3MTP, Task 71-3-2006; FM 101-5, App A]

(1) Brigade commander.

(2) Division ACofS, intelligence (G2).

(3) Subordinate/supporting unit S2s.

(4) Brigade TAC CP. 
(5) Brigade rear $\mathrm{CP}$.

(6) Adjacent unit headquarters in support of their collection efforts.

(7) ASAS.

(8) DS MI company.

g) The brigade $\mathrm{S} 3$ and $\mathrm{S} 3$ section communicate with: [ARTEP 71-3MTP, Tasks 71-3-3003/3c, 3008/4; FM 101-5, App A]

(1) Brigade XO.

(2) Brigade staff.

(3) Subordinate and supporting units.

(4) Brigade rear $\mathrm{CP}$.

(5) Division main CP.

(6) Division TAC CP.

h) The brigade $\mathrm{S} 3 \mathrm{Air}$, as $\mathrm{A} 2 \mathrm{C} 2$ team chief, communicates with:

(1) Members of $\mathrm{A} 2 \mathrm{C} 2$ team.

(2) Brigade TAC.

(3) Division G3 (A2C2 section).

i) The brigade NBC section communicates with: [AN]

(1) Division CMLO.

(2) Brigade subordinate commanders and leaders.

(3) Supporting NBC units (e.g., decontamination, reconnaissance).

(4) TF CMLOs.

(5) Brigade staff officers who need the information. 
(6) NBC section manages the nuclear, biological, and chemical warning system (NBCWRS) for the brigade through coordination and communication with external headquarters (division, and adjacent units).

j) The brigade $\mathrm{ABE}$ section communicates with: [FM 101-5, App A; AN]

(1) Engineer brigade commander.

(2) Assistant division engineer.

(3) Brigade staff officers who need the information.

(4) Adjacent units.

(5) Engineer battalion main $\mathrm{CP}$.

(6) Brigade TAC.

k) The brigade AVLO communicates with: [FM 101-5, App A; AN]

(1) Division G3 (A2C2 section).

(2) Aviation brigade main $\mathrm{CP}$.

(3) Battalion and brigade ALOs (re. Army aviation integration with USAF operations).

(4) Brigade subordinate commanders and leaders.

(5) Brigade FSO.

(6) Brigade S3 and S3 Air.

(7) Other members of brigade $\mathrm{A} 2 \mathrm{C} 2$ element.

(8) Brigade staff officers who need the information.

l) The brigade FSO and FSE section communicate with:

(1) Brigade engineer. 
(2) Brigade $\mathrm{S} 2$.

(3) Brigade $\mathrm{S} 3$.

(4) Division artillery.

(5) Division FSE.

(6) DS FA battalion S3.

(7) Subordinate TF FSOs.

(8) ALO and AVLO.

(9) FSB Cdr (for rear operations).

(10) Brigade staff officers who need the information.

(11) Brigade NGLO.

(12) FSCOORD.

(13) COLTs.

m) The USAF ALO communicates with: [FM 101-5, App A; AN]

(1) USAF headquarters.

(2) Division ALO.

(3) Subordinate commanders and their ALOs.

(4) Brigade FSO.

(5) Brigade S3 and S3 Air.

(6) Other members of brigade $\mathrm{A} 2 \mathrm{C} 2$ element.

(7) Brigade staff officers who need the information.

(8) Tactical air control party (TACP).

(9) Marine air officer. 
n) The brigade air and naval gunfire liaison team (Marine air officer and NGLO) communicates with: [AN]

(1) The division NGO (division main fire support call) and NALO (division TACP).

(2) Subordinate SALT teams.

(3) Brigade FSO and FSE, and TF FSEs.

(4) Brigade ALO and TACP.

(5) Supporting ships providing NSF.

(6) Navy/Marine aircraft.

o) The ADALO communicates with: [FM 101-5, App A; AN]

(1) Air defense battalion commander.

(2) Brigade subordinate commanders and leaders.

(3) ADA battery commander and subordinate $\mathrm{ADA}$ platoon leaders.

(4) Other members of brigade $\mathrm{A} 2 \mathrm{C} 2$ element.

(5) Brigade staff officers who need the information.

(6) ADALO maintains air defense early warning net with division and higher air defense headquarters, $A D$ units/teams/weapons within the brigade combat team, and all subordinate units.

p) The MP platoon leader communicates with: [FM 101-5, App A; $\mathrm{AN}]$

(1) MP company commander.

(2) FSB commander.

(3) Brigade staff officers who need the information.

(4) Brigade XO and brigade S3. 
q) The brigade communications section communicates with: [FM 1015, App A; AN]

(1) Assistant division signal officer.

(2) Signal battalion commander.

(3) Brigade subordinate commanders and leaders.

(4) Brigade staff officers who need the information.

r) The brigade $\mathrm{S} 5$ communicates with: [FM 101-5, App A]

(1) The division ACofS, civil affairs (G5).

(2) Brigade subordinate commanders and leaders.

(3) Brigade staff officers who need the information.

s) The Brigade HHC commander communicates with:

(1) Brigade XO.

(2) Bde SO.

(3) MP platoon leader.

(4) Brigade rear $\mathrm{CP}$.

(5) Brigade $\mathrm{S} 3$ section.

(6) Brigade CSM.

10) The brigade S1/S4 section ensures that the rear command post: [FM 71-3, Chap 3, 8; ARTEP 71-3-MTP, Tasks 71-3-1012; 4004; FM 101-5, App A; $\mathrm{AN}]$

a) Collocates with the FSB command post in the BSA.

b) Monitors the tactical situation and maintains communications capability to ensure that the rear $\mathrm{CP}$ is prepared to assume duties of the brigade main $\mathrm{CP}$. 
c) Maintains communications with the brigade main $\mathrm{CP}$, the FSB CP, and the division rear $\mathrm{CP}$.

d) Acts as NCS for the brigade admin/log net.

e) Operates on and monitors communications nets:

(1) Brigade command.

(2) Brigade admin/log.

(3) Division admin/log.

(4) FSB - if not collocated.

(5) Expands communications when/if it becomes the main $\mathrm{CP}$ in an emergency.

f) Manages CSS information required to:

(1) Sustain current deep, close, and rear operations.

(2) Forecast future CSS requirements.

(3) Conduct detailed CSS planning.

g) The brigade S1 communicates and coordinates with:

(1) Brigade XO.

(2) Brigade support cell.

(3) Brigade S3 (if necessary).

(4) Brigade current operations and plans cells.

(5) Division G1/AG, SJA, and surgeon.

(6) Brigade FSB CP.

(7) Rear area security units.

(8) TF S1s. 
h) The brigade $\mathrm{S} 4$ communicates and coordinates with:

(1) Brigade XO.

(2) Brigade support cell.

(3) Division G4.

(4) DISCOM and MSB staffs.

(5) FSB, support operations section.

(6) TF S4s.

(7) Brigade S3 (if necessary).

(8) $\mathrm{ADC}(\mathrm{S})$.

(9) Brigade subordinate and supporting commanders and leaders.

(10) Brigade staff officers who need the information.

(11) Brigade HHC commander.

(12) Brigade commander or brigade $\mathrm{S} 3$ in the TAC CP.

(13) Brigade CSM.

(14) ADO.

(15) Adjacent units.

b. The information managers at each of the brigade CPs maintains command, control, and communications throughout the battle. [FM 101-5, pp. 5-1 - 5-14; AN]

1) The brigade commander or $\mathrm{S} 3$ repositions TAC $\mathrm{CP}$ as necessary to maintain $\mathrm{C} 3$ with brigade subordinate leaders, division command group, commanders of adjacent units, and main $\mathrm{CP}$.

2) The brigade $\mathrm{XO}$ repositions the brigade main $\mathrm{CP}$ as necessary to:

a) Maintain $\mathrm{C} 3$ with brigade command group and $\mathrm{TAC} \mathrm{CP}$, brigade subordinate units' $\mathrm{CPs}$, division main $\mathrm{CP}$, and adjacent units' $\mathrm{CPs}$. 
b) Preclude destruction of main $\mathrm{CP}$ C3 capabilities.

3) The brigade $\mathrm{S} 1$ or $\mathrm{S} 4$ repositions the rear $\mathrm{CP}$ in order to:

a) Maintain continuity of CSS support for the brigade forces.

b) Preclude destruction of CSS C3 capabilities.

c) Maintain collocation and operational capability with the FSB.

4) The brigade CPs take actions to survive, employ: [FM 71-123, p. 1-47; FM 101-5, pp. 7-18 - 7-20; LL-CTC Bulletin 95-4, Chap 5] (Also see brigade BF 25 for a complete discussion of OPSEC)

a) OPSEC measures.

(1) Use of terrain for cover and concealment.

(2) Selected routes which reduce detection by the enemy.

(3) Camouflaged positions.

(4) Avoidance of target reference points.

(5) Use of electronic counter measures (ECM).

b) Security forces to: [FM 71-123, p. 1-47]

(1) Provide early warning, through the use of listening posts/observation posts (LP/OP) and patrols.

(2) Provide perimeter protection.

(3) React immediately.

c) Planning for deliberate and hasty repositioning. [FM 71-123, p. 148; FM 101-5, p. 7-20]

d) Engineer support to dig in $\mathrm{CP}$ positions. [AN]

5) The Bde SO monitors COMSEC throughout the brigade combat team; directs action as required to correct deficiencies. 
6) The brigade $\mathrm{S} 3$ monitors OPSEC throughout the brigade combat team; directs action as required to correct deficiencies.

c. The brigade reestablishes $\mathrm{C} 3$ operations in the event of $\mathrm{CP}$ loss or destruction. [FM 101-5, Chap 5, App B; FM 71-3, Chap 3, App H; Battle Command Techniques and Procedures, Chap 4]

1) The brigade $\mathrm{XO}$ reestablishes $\mathrm{C} 3$ operations in the event of the loss of the brigade TAC CP: [FM 71-3, Chap 3; FM 71-123, Chap 1, Battle Command Techniques and Procedures, Chap 4]

a) If communications are functioning, a preselected code word is transmitted by any member of the TAC CP, over the brigade command net indicating that the TAC CP is out of action.

b) If the $\mathrm{TAC} \mathrm{CP}$ is unable to communicate any message after being put out of action, the brigade $\mathrm{XO}$ at the main $\mathrm{CP}$, based upon a prearranged procedure, assumes that being out of contact means that the TAC CP is out of action.

c) The survivors of the TAC $\mathrm{CP}$ move to a preselected assembly point.

d) At first opportunity the ranking survivor informs the brigade main $\mathrm{CP}$ of the status of the:

(1) Brigade commander.

(2) Brigade S3.

(3) S2 representative.

(4) FSCOORD/FSO, and NGLO.

(5) ALO.

(6) Other key staff personnel.

(7) Survivors and their condition.

e) The brigade $\mathrm{XO}$ at the brigade main $\mathrm{CP}$ assumes control of the close battle by:

(1) Maintaining communications with forward elements. 
(2) Synchronizing combat, CS, and CSS activities in support of the close battle.

(3) Maintaining the current situation of the entire brigade battle area.

(4) Informing the division main $\mathrm{CP}$ of the loss of the brigade $\mathrm{TAC} \mathrm{CP}$ and the status of the brigade commander and key brigade staff members who were at the TAC CP.

(5) Notifying all brigade elements that the main $\mathrm{CP}$ or a preselected TF CP is now controlling the entire brigade battle area.

(6) Ensuring that all brigade units send all reports to the brigade main $\mathrm{CP}$.

(7) Notifying all adjacent units that the brigade main is now in charge of all brigade activities and to send all message traffic to the main.

f) The brigade $\mathrm{XO}$ located at the brigade main $\mathrm{CP}$ does the following:

(1) If the brigade commander is killed, captured, or evacuated, the XO initiates the pre-prepared plan of succession of brigade command.

(2) Notifies the division commander who is assuming command of the brigade, as per the plan, and provides a situation report.

(3) Ensures that the main $\mathrm{CP}$ assumes the responsibility for directing the close battle while maintaining its normal functions.

(4) Assumes the responsibilities of commanding the brigade until:

(a) The succession plan can be implemented if he is not the successor.

(b) The designated new brigade commander can assume command. 
(5) Ensures that the brigade main CP executes the brigade battle activities within the previous commander's intent if still valid.

(6) Completes the assumption of the brigade TAC CPs functions quickly (less than 15 minutes after determining the loss) and efficiently to ensure no loss of brigade momentum.

(7) If the brigade $\mathrm{XO}$ is not to be the long-term brigade commander, he prepares the staff for a smooth transition to the new commander.

(8) Reconstitutes a brigade TAC CP in terms of personnel and equipment.

(a) If necessary, selects replacements, with the assistance of the brigade $\mathrm{S} 1$, from among brigade personnel to replace those staff members lost when the TAC CP was destroyed.

(b) If necessary, allocates equipment from main $\mathrm{CP}$ and from TFs.

g) The brigade commander, should he survive or is not at the TAC CP when it is destroyed, may elect to:

(1) Establish a small assault $\mathrm{CP}$ with the communication equipment and personnel available and retain control to fight the close battle.

(2) Move to the closest TF CP and establish a new TAC CP and continue to fight the close battle.

(3) Move back to the brigade main CP and fight the close battle from that location.

2) The brigade commander or brigade $S 3$ ensures that appropriate actions are taken in the event of the loss of the brigade main CP: [FM 71-3, Chap 3, App H; FM 71-123, Chap 1; Battle Command Techniques and Procedures, Chap 4]

a) The surviving elements of the brigade main $\mathrm{CP}$ inform the brigade commander and key leaders on the command net using a code word that the main CP is out of action and unable to perform its functions. 
b) Based upon a plan or brigade SOP, the surviving cells:

(1) Move to a preselected location and attempt to regenerate main $\mathrm{CP}$ capabilities and to assume their functions.

(2) Move to the alternate main $\mathrm{CP}$ to assist the new $\mathrm{CP}$ in assuming some of the main's functions.

c) The brigade commander or brigade $\mathrm{S} 3$ ensures, upon confirmation that the main $\mathrm{CP}$ is out of action, that functions are transferred. Function transfer might include:

(1) The brigade TAC CP, which continues to fight the close battle and assumes the main $\mathrm{CP}$ functions of:

(a) Fighting the deep battle.

(b) Developing intelligence.

(c) Monitoring and coordinating the rear battle.

(d) Serving as the synchronization point for the entire brigade battlefield.

(e) Allocating brigade resources.

(f) Maintaining continuous communication with the forward elements, the brigade rear $\mathrm{CP}$, division, or other higher headquarters.

(g) Performs A2C2 functions for the entire brigade battle area.

(h) Requesting additional personnel from the brigade $\mathrm{S} 1$ at the rear $\mathrm{CP}$.

(i) Planning for future operations.

(2) The $\mathrm{CP}$ designated in the brigade TSOP assumes the following main $\mathrm{CP}$ responsibilities:

(a) The brigade command center and maintenance of communications with division and adjacent units. 
(b) Liaison with:

1 Brigade subordinate and supporting units.

2 Division and adjacent units.

(c) Synchronization of CS and CSS for the close and rear battle areas.

(d) Fighting the rear battle.

(e) Monitoring the close battle.

(f) Providing situation reports to division main CP.

(g) Ensures that all main CP functions are quickly assumed by the rear $\mathrm{CP}$.

(h) Reconstitutes main CP functional cells of headquarters, current operations, plans, intelligence, FS, and CSS from assets within the brigade or with help from division.

(3) The direct support artillery battalion assumes the function of the FSE until one can be reconstituted.

(4) The engineer battalion $\mathrm{CP}$ assumes the functions of the brigade engineer until he can be replaced.

(6) The air defense artillery battery assumes the functions of the brigade ADALO until he can be replaced.

3) The brigade $\mathrm{XO}$ ensures that appropriate actions are taken if the brigade rear CP is lost: [FM 71-3, Chap 3, App H; FM 71-123, Chap 1; Battle Command Techniques and Procedures, Chap 4]

a) The $\mathrm{CP}$ designated in the brigade TSOP assumes the functions of the brigade rear $\mathrm{CP}$ to include:

(1) Sustainment of all brigade units with priority to those units fighting the close battle.

(2) Transportation support of all brigade units with priority to forward elements. 
(3) Protection of support facilities and LOCs.

(4) Management of terrain in the BSA.

b) The brigade XO takes measures to reconstitute and reestablish the brigade rear $\mathrm{CP}$ by requesting replacement personnel and equipment.

d. The brigade commander or brigade $\mathrm{XO}$ ensures that the brigade succession of command is implemented in accordance with the brigade plan or TSOP. [FM 1015, Chap 5; FM 71-3, App H; Battle Command Techniques and Procedures, Chap 4; CTC Bulletin No 94-1, p. 19]

1) The brigade $\mathrm{XO}$, as soon as it is confirmed that the brigade commander is incapacitated or out of contact, assumes command of the brigade and does the following: [FM 71-3, App H; Battle Command Techniques and Procedures, Chap 4]

a) Notifies the division commander, ADC-M, G-1, and G-3.

b) Informs forward elements that he has assumed command until further notice.

2) If the $\mathrm{XO}$ is the designated commander he:

a) Assumes command when the situation allows.

b) Moves when feasible to the brigade TAC or main $\mathrm{CP}$ where he takes command and informs division and the brigade subordinate elements.

3) If the $\mathrm{XO}$ is not the designated commander:

a) The XO does the following:

(1) Continues his duties at the brigade main CP.

(2) Prepares to publish an assumption of command order.

(3) Ensures that key personnel at division are informed of the assumption of command by the senior TF commander. 
b) Based upon his knowledge of the previous brigade commander's intent, and the missions given to brigade elements, the designated commander can also:

(1) Designate his present TAC CP as the new brigade TAC CP and assume command.

(2) Move back to his battalion CP; transfer control of his battalion to his XO and the TAC CP; and use his coordinating staff, battalion, and TAC CP resources to fight the brigade close battle until there is a lull in the situation.

(3) Inform the brigade XO that he has assumed control of the brigade close battle.

(4) Notify division and all brigade subordinate units that he has assumed command and to send all traffic to his present $\mathrm{CP}$.

4) When division is notified of the loss of the brigade commander, the division commander may select a new brigade commander from outside the brigade. The brigade $\mathrm{XO}$ will:

a) Implement the succession plan until the new brigade commander arrives.

b) Set up a series of briefings from each of the functional cells at the main $\mathrm{CP}$ to quickly update the new commander.

c) If necessary regenerate a brigade $\mathrm{TAC} \mathrm{CP}$ and:

(1) Tasks the brigade S1 to obtain replacements for key brigade staff personnel.

(2) Tasks the brigade S4 to replace lost or damaged equipment, particularly that for $\mathrm{C} 3 \mathrm{I}$ and vehicles for a TAC CP.

d) Orders the brigade $\mathrm{S} 1$ and $\mathrm{S} 4$ to move from the brigade rear $\mathrm{CP}$ to brief the new commander.

e) Ensure that all brigade elements are informed of the assumption of command.

f) Notify all adjacent units of the assumption of command. 
g) Publish an assumption of command order.

6. The brigade consolidates and reorganizes. [FM 71-3, pp. 8-23 - 8-26; FM 7-30, p. 9-6, App H; FM 71-123, Chap 2, 5; FM 100-9, Chap 4; FM 71-100, Chap 1, App A; Battle Command Techniques and Procedures, Chap 3; FM 101-5, Chap 4]

a. The brigade commander directs the brigade consolidation. [FM 101-5, Chap 4; FM 71-3, Chap 8, App H; Battle Command Techniques and Procedures]

1) The brigade commander initiates the decision-making process for the next mission in order to rapidly transition from the current operation to the next and directs the brigade TFs and other combat units to prepare for follow-on operations by:

a) Establishing an all-around defense to repel any enemy activity including:

(1) Employment of hasty obstacles.

(2) The positioning of appropriate weapons systems to cover enemy avenues of approach into the unit area.

(3) Development of a fire support plan (quick fire plan) that covers the entire unit sector and fills any gaps among adjacent units.

(4) Preparation of hasty protective positions.

(5) Coordination with friendly units on the flanks.

(6) The positioning of security elements to ensure as much early warning as possible.

(7) Ensuring that all subordinate commanders are briefed on updated brigade orders.

(8) Ensuring that units are prepared to move on short notice.

b) Actively conducting reconnaissance in order to:

(1) Find and establish contact with enemy forces.

(2) Determine enemy COAs and intentions. 
(3) Determine status and condition of enemy units.

(4) Monitor and report on build up or reinforcement of enemy units.

(5) Monitor and report any enemy movement.

c) Initiating sustainment functions using existing unit resources to:

(1) Replace key personnel and cross level personnel to crew weapons systems and other essential capabilities.

(2) Ensure that vehicles and individual and crew served weapons are serviced and maintained. Repair deadlined or combat damaged equipment using repair parts available. Evacuate irreparable equipment to designated collection or repair points.

(3) Resupply ammunition from existing stocks and redistribute ammunition among units.

(4) Distribute fuel from existing stocks to both ground and aviation systems.

(5) Request additional transportation assets as required.

(6) Secure internal LOCs and coordinate security for routes among adjacent units.

(7) Evacuate POWs and captured enemy equipment.

d) Subordinate brigade unit commanders submit estimates of their units situation and capabilities.

2) The brigade commander directs the brigade staff to assist in the brigade consolidation: [FM 101-5, Chap 4; Battle Command Techniques and Procedures, Chap 2, 3; FM 71-3, App H]

a) The brigade $\mathrm{XO}$ ensures that the brigade staff, to include the special staff, provides information in their respective areas with respect to current METT-T.

b) The brigade XO directs the brigade coordinating and special staff in accomplishing the following: 
(1) The brigade XO:

(a) Alerts the brigade staff to start preparing for the consolidation and reorganization brief by: [AN]

1 Directing staff estimates of the brigade's post-battle situation.

2 Obtains current disposition and locations of brigade units.

3 Obtains estimate of strength and equipment status and capabilities of units.

$4 \quad$ Obtains current intelligence and estimate of enemy intent from the division G-2.

(b) Supervises the staff preparation of orders for follow on missions.

(c) Directs and supervises the refurbishment of brigade units in preparation of the next mission.

(d) Keeps the commander informed on the activities of adjacent units.

(e) Ensures that the command has the current CCIR.

(f) Continues to monitor all activities in the brigade deep battle area and supervises the activities in the brigade rear battle area.

(2) The brigade $\mathrm{S} 2$ and $\mathrm{S} 2$ section:

(a) Continues to update the intelligence estimate.

(b) Directs brigade reconnaissance and surveillance elements to:

1 Find enemy locations.

$2 \quad$ Determine enemy capabilities. 
(c) Assists in the preparation of brigade operations orders and/or FRAGOs.

(d) Keeps the brigade commander and staff informed of any change in the enemy situation.

(e) Ensures that the brigade MI company is prepared for the next mission.

(f) Continues with the assistance of the MI company to execute the brigade EW plan.

(g) Identifies locations, status, and missions of brigade collection assets. [AN]

(h) Identifies immediate collection needs and locations of NAIs. [AN]

(i) Coordinates collection needs and assists with the S3's consolidation and reorganization plan and activities. [AN]

(j) Briefs the brigade commander and staff on the current enemy activities, $R \& S$ requirements and assets, and makes appropriate recommendations. [AN]

(3) The brigade S3:

(a) Continues to monitor the current situation.

(b) Prepares the order or FRAGO for the next mission based upon the brigade commander's guidance.

(c) Maintains communications with division leadership and staff.

(d) Focuses upon synchronizing the new brigade deep, close, and rear battle areas.

(e) Ensures that the brigade XO is aware of the brigade commander's guidance, intent, and desired endstate of upcoming engagements. 
(f) Together with the brigade S2 and FSCOORD, revises the FS plan to support continuing operations.

(g) Together with the brigade ALO, NGLO, and the brigade AVLO, plans for pre-planned CAS and JAAT missions in the deep and close battle areas.

(h) Coordinates and directs brigade $\mathrm{ADO}$ and $\mathrm{ABE}$ on continuing operations.

(i) Refits the brigade TAC CP.

(j) Monitors refit and resupply operations of brigade TFs and other brigade command and support units.

(k) Monitors status of brigade units, to company level.

(l) Monitors OPSEC.

(m) Contacts battalion/task force S3s to gather information to check the possibility of exploitation of boundaries by enemy. [AN]

(n) Contacts brigade $\mathrm{S} 1$ and brigade $\mathrm{S} 4$ to confirm combat power and command and control status reported by each unit. [AN]

(o) Contacts the brigade S2 and subordinate units to ensure that bypassed enemy units are destroyed. [AN]

(p) Contacts subordinate unit S3s to determine resource needs of their task forces. [AN]

(q) Contacts the G3 to coordinate follow-on mission. [AN]

(r) Requests an update on current division tactical situation from the G3. [AN]

(s) Requests additional information concerning future mission and intent from the G3. [AN] 
(t) Exchanges information with the adjacent brigade S3s and updates them on overall tactical situation, status, location, and intent of forces. [AN]

(u) Informs adjacent brigade S3s of control areas. [AN]

(v) Briefs the brigade commander on his recommendations. [AN]

(4) The brigade ABE addresses: [AN]

(a) Requesting the status of equipment and personnel from subordinate engineer units. [AN]

(b) Developing mobility, countermobility and survivability estimates. [AN]

(c) Coordinating with the brigade S4 to determine quantity and location of obstacle materials. [AN]

(d) Informing the division engineer of changing mission requirements and problems. [AN]

(e) Recommending changes to the engineer task organization based on the situation. [AN]

(f) Informing the brigade commander and staff of the current engineer capability. [AN]

(g) Plans for employment of FASCAM.

(5) The brigade FSO addresses: [AN]

(a) Contacting subordinate fire support units to determine status of the following: operational and repairable howitzers, fire support teams, COLTs, battery locations, and radar status. [AN]

(b) Adjusting fire support assets due to losses. [AN] 
(c) Informing the brigade FSCOORD, division fire support element, and division artillery of fire support status. [AN]

(d) Coordinating with the brigade $\mathrm{S} 3$ to determine the consolidation and reorganization of the maneuver task forces. [AN]

(e) Coordinating with the brigade FSCOORD on requirements to implement the brigade commander's guidance. [AN]

(f) Informing the field artillery battalion $\mathrm{S} 3$ of the brigade commander's guidance. [AN]

(g) Conducting a hasty analysis of the current fire support situation. [AN]

(h) Monitoring the recovery and maintenance projections and Class V resupply for supporting FA units. [AN]

(i) Adjusting priorities of fires. [AN]

(j) Informing the brigade commander and staff of the current capability of fire support. [AN]

(6) The brigade $\mathrm{ADO}$ addresses: [AN]

(a) Requesting status updates from air defense assets. [AN]

(b) Providing a summarized status to the air defense battalion $\mathrm{S} 3$ and assistant division air defense officer (ADADO). [AN]

(c) Informing the brigade commander and staff of the current air defense capability. [AN]

(d) Assessing and adjusting air defense protection and priorities. 
(7) The brigade S1 addresses:

(a) Allocation of replacement personnel presently in the BSA to TFs based upon brigade commander's direction or recommendation of the brigade $\mathrm{S} 3$.

(b) Replacement of key leaders lost during previous operations.

(c) Fill of leadership positions down to platoon level.

(d) Replacement of key members of the brigade staff with personnel from within the brigade or from higher headquarters.

(e) Contacting subordinate unit S1s for personnel updates: killed in action (KIA), wounded in action (WIA), missing in action (MIA), return to duty (RTD), critical MOS shortages, and critical position shortages. [AN]

(f) Obtaining updates from the brigade surgeon. [AN]

(g) Tracking the status of KIA, to include the transportation of recovered remains. [AN]

(h) Monitoring status of EPWs. [AN]

1 Contacts the MP platoon leader for updates on the number of EPWs captured, the number needing medical assistance, and other concerns.

$2 \quad$ Contacts each unit S1 for updates on EPWs.

(i) Completing the consolidation of the brigade personnel status report and personnel losses report and submitting to the division G1. [AN]

(j) Providing an update on the personnel status to the brigade commander and staff. [AN] 
(8) The brigade S4, together with the FSB commander, regenerates brigade combat power by providing support well forward and addressing:

(a) The number and type of support units and resources.

(b) The brigade commander's priorities.

(c) Relevant consumption factors.

(d) Providing necessary transportation to brigade units to accomplish brigade directed tasks during continuation of the mission.

(e) Critical weapons systems.

1 Capable.

$2 \quad$ Non capable.

(f) Threat to CSS units in general and those moving into the forward battle areas in particular.

(g) Contingency plans if selected LOCs are impassable, if the enemy situation in the brigade area of operations changes, or stocks on hand do not meet requirements.

(h) Coordinates with task force S4s, FSB commander, and the direct maintenance team to conduct battle damage assessment. [AN]

(i) Determines the relative combat power of combat units. [AN]

(j) Coordinates with the FSB commander to replace expended materials. [AN]

(k) Provides status updates to the FSB commander from maintenance support teams in the tasks forces, the task force field trains in the brigade support area, and from ambulances in the field. [AN] 
(1) Exchanges information with FSB commander on maintenance, resupply activities, availability of parts, cross-leveling efforts, and evacuation of vehicles to brigade support area. [AN]

(m) Contacts the brigade S1 periodically for personnel status reports. [AN]

(n) Contacts the division G4 and division support command elements to report current status and expedite needed assistance. [AN]

(o) Checks with the brigade $\mathrm{S} 3$ periodically for updates on the tactical situation or follow-on mission. [AN]

(p) Provides logistics and maintenance information to the command group. [AN]

(9) The surgeon addresses:

(a) Treatment and evacuation of casualties.

(b) Positioning and reconstitution of medical assets.

(10) The brigade S5 addresses:

(a) Refugee control issues.

(b) Information on noncombatant activity in the brigade $\mathrm{AO}$ and other local population situations.

(11) The brigade's supporting units, to include artillery, engineers, MI, ADA, MP, and FSB, prepare for continuing operations.

b. The brigade commander directs brigade reorganization. [FM 71-123, Chap 2, 8; FM 71-3, Chap 1, 2, 7, 8, App H; Battle Command Techniques and Procedures, Chap 3, 9]

1) The brigade commander directs reorganization of brigade units: [FM 71123, Chap 2, 6; FM 71-3, Chap 8, App H; Battle Command Techniques and Procedures, Chap 3, 9] 
a) Refit of C3I equipment.

b) Cross leveling or replacement of personnel.

c) Replacement of personnel, supplies, and equipment based upon command priorities, references, and resources.

d) Conduct of essential training.

e) Reallocation of terrain responsibilities.

2) The brigade commander directs the brigade staff under the supervision of the brigade XO to prepare a FRAGO that includes: [FM 101-5, Chap 4; FM 71-3, Chap 8, App H; Battle Command Techniques and Procedures, Chap 9]

a) Personnel replacement (brigade S1).

b) Intelligence collection efforts (brigade S2).

c) Maneuver plan (brigade S2, brigade S3, brigade engineer, brigade FSO, brigade ADO, brigade S4, brigade FSB commander, and brigade ALO and brigade AVLO).

d) Security and reconnaissance (brigade S2, brigade S3, brigade FSO).

e) Fire support (brigade S3, brigade FSO, brigade ALO, brigade $\mathrm{ADO}$ ).

f) Engineer support (brigade $S 2$, brigade $S 3$, brigade $A B E$ ).

g) Air defense support (ADO/ADALO).

h) Supply (brigade S4, brigade FSB commander).

i) Medical support (brigade S1, brigade S4, brigade surgeon).

j) Maintenance support (brigade S4, brigade FSB commander, brigade maintenance officer).

k) Guidance on minimum manning levels for major weapon systems.

3) The brigade $\mathrm{XO}$ and brigade staff conduct reorganization activities: [FM 71-3, Chap 8, App H; Battle Command Techniques and Procedures, Chap 8]

a) The brigade $\mathrm{XO}$ : [AN] 
(1) Directs the staff as they coordinate and prepare the FRAGO.

(2) Coordinates with the brigade S3 and division G3 about the type/time/place of the follow on mission.

(3) Reviews WARNOs before they are disseminated to the Task Forces.

(4) Coordinates with the brigade commander for review and approval of the FRAGO.

b) The brigade $\mathrm{S} 3$ determines if weapon system replacement is required and determines the priority of issue.

(1) Informs higher headquarters of requirements.

(2) Coordinates with the brigade $\mathrm{S} 4$ for submission of requests to higher headquarters.

(3) Plans for training of new weapons systems crews. [AN]

c) The brigade S1: [AN]

(1) Coordinates with the brigade S4 and FSB commander to implement WSRO. [AN]

(2) Identifies the sources of manning for WSRO equipment. [AN]

(3) Obtains updates on the status of medical personnel, casualty evacuation, and medical facilities operability. [AN]

(4) Obtains updates from unit S1s. [AN]

(5) Obtains updates from the brigade surgeon. [AN]

(6) Makes recommendations to the brigade commander for reorganization or reconstitution of the brigade based on strength. [AN]

(7) Submits requests to the division G1 to implement the brigade commander's replacement priorities. [AN] 
(8) Reconfigures status charts to reflect new structures and cross attachments based on reorganization or reconstitution. [AN]

d) The brigade S4:

(1) Initiates request to the division rear CP for WSRO.

(2) Coordinates with the brigade S3 for allocation of systems.

(3) Supervises the movement, reception, and processing of incoming WSRO crews/vehicles from division or higher headquarters.

(4) Coordinates for assembly areas for WSRO activities in the $\mathrm{BSA}$ near the division rear $\mathrm{CP}$.

(5) When in the assembly areas and prior to movement to subordinate units, coordinates the following functions:

(a) Shelter and sleeping areas for new crews.

(b) Personnel actions with the brigade S1.

(c) Resupply of Classes III and V.

(d) Maintenance checks of equipment.

(e) Vehicle and personnel pre-combat inspections.

(f) Individual weapons issue and zeroing.

(g) Conduct of map or physical reconnaissance of local area for vehicle commanders and key personnel.

(h) Task units with local security missions.

(i) Initiate training and equipment familiarity programs.

(6) Develops and publishes controlled supply rates for classes of supply.

(7) Specifies maintenance standards and requirements. 
(8) Determines requirements for mortuary affairs support and takes appropriate actions.

(9) Determines brigade transportation needs and takes appropriate actions.

c. The brigade commander confirms that the brigade is prepared to continue the mission. Confirmation criteria include: [AN]

1) All brigade elements report successful completion of reorganization and consolidation.

2) The brigade $\mathrm{XO}$ reports all brigade $\mathrm{C} 3$ facilities, $\mathrm{CPs}$, and systems are fully operational.

3) The brigade $S 2$ reports that all intelligence systems are fully operational.

4) The brigade FSCOORD reports that all fire support systems are fully operational and FA assets are mission capable.

5) The brigade engineer reports that all engineer systems and assets are fully mission capable.

6) The brigade $\mathrm{ADO}$ reports that all air defense coverage is in place and that air defense systems are fully operational.

7) The FSB commander reports that the BSA is operational and all CSS units are operational.

8) The brigade surgeon reports that the brigade casualty treatment and evacuation system will support future operations.

9) The brigade S1 reports that the brigade strength is adequate to continue successful mission accomplishment.

10) The brigade $S 4$ reports that the maintenance and supply systems and status will support future operations. 


\section{TASKS ORGANIZED BY OUTCOMES}

This component links the tasks with the outcomes the task performance supports. Each outcome is linked with all appropriate tasks. This component is used for two purposes. The first is to ensure that each BF outcome is sufficiently supported by all tasks necessary to achieve the outcome. The second is to verify that the outcomes selected support the BF purpose and that they are complete in that no additional outcomes are required to define the $\mathrm{BF}$. This component can be used by trainers to facilitate assessment of training proficiency and to plan training.

\section{Outcome 1}

Brigade command posts (CPs) maintain continuous communications with higher, adjacent, and subordinate headquarters.

\section{Task Elements}

1. The brigade commander directs and leads subordinate forces. [FM 71-3, pp. 3-2 - 3-4; FM 101-5, pp. 1-4 - 1-5; Battle Command Techniques and Procedures, Chap 1, 2, 4; Battle Command, pp. 12-14, 34-37]

a. The brigade commander directs subordinate forces. [FM 71-3, p. 3-4; FM 101-5, pp. 1-4 - 1-5]

2) The brigade commander positions himself where he can best direct and lead, observe the battlefield, and synchronize operations: [FM 71-3, pp. 3-2 - 34; FM 101-5, Chap 1, 2, 3; FM 7-20; Battle Command Techniques and Procedures, Chap 2, 3, 4; ST 22-102, pp. 4-14 - 4-15]

b) Selects positions that enable communications with:

(1) Division commander and assistant division commander for maneuver (ADC-M).

(2) Brigade subordinate commanders.

(3) Main CP.

(4) Adjacent units (main CP may be given this task).

5. Brigade command posts manage and maintain command, control, and communications. [FM 71-123, pp. 1-43 - 1-46; FM 71-3, Chap 3; FM 101-5, Chap 5, 7, App B, Battle Command Techniques and Procedures, Chap 4]

a. The brigade $\mathrm{XO}$ manages the means of communicating information for all brigade CPs. [FM 71-3, Chap 3, 8; FM 71-123, Chap 1; FM 101-5, Chap 6, App B, L] 
5) Radio net operators at all brigade CPs eavesdrop on lower and adjacent unit command and O\&I nets for information. [FN-NTC O/C]

7) The radio net operators at all brigade CPs communicate routine information per brigade SOP. [FM 101-5, p. 6-5]

8) The brigade $\mathrm{S} 3$ manages communications for the command group and $\mathrm{TAC}$ CP and: [FM 71-3, Chap 3; FM 71-123, Chap 1]

a) Facilitates control and coordination for the commander through communication with subordinate, adjacent, and supporting elements.

b) Passes processed information and keeps the commander updated on new information through concise, consolidated updates.

c) Operates and monitors communications nets.

(1) Brigade command.

(2) Brigade O\&I.

(3) Division command.

(4) Division O\&I.

(5) Fire support nets (digital and voice).

(6) Division and brigade high frequency (HF) voice nets (on call).

(7) Air Force coordination nets (frequency modulated [FM], HF, ultra high frequency [UHF], very high frequency [VHF]).

d) The brigade commander communicates with:

(1) Division commander and the $\mathrm{ADCs}(\mathrm{O}$ and $\mathrm{M})$.

(2) Subordinate battalion/TF's commander, XO, or S3.

(3) Brigade XO.

(4) Brigade FSCOORD.

(5) Brigade engineer. 
(6) Brigade ALO.

e) The brigade $\mathrm{S3}$ communicates with:

(1) Brigade commander if not at the TAC CP.

(2) Brigade main CP.

(3) Subordinate battalions.

(4) Division G3.

9) The brigade $\mathrm{XO}$ at the main $\mathrm{CP}$ manages communications and: [FM 71-3, Chap 3; FM 71-123, Chap 1; ARTEP 71-3 MTP, Task 71-3-0001]

a) Maintains communications with the brigade command group and TAC.

b) Manages communications networks and maintains communications linking the brigade main CP to division CP, adjacent headquarters, and brigade subordinate units.

c) Maintains communications between the brigade main CP, the BSA, base clusters, or other units in support of rear area operations.

d) Manages communications networks in support of counter reconnaissance and $\mathrm{R} \& S$ operations in order to maintain reporting linkages for critical sources of information.

e) Maintains a digitized LAN and wide-area network (WAN) to support battlefield computer systems.

f) Ensures that main CP staff members operate and monitor communications nets.

(1) Brigade command net control station (NCS).

(a) Communicates to subordinates the commander cannot reach.

(b) Disseminates critical new information quickly to the commander, staff, and subordinate/supporting headquarters. 
(2) Division command.

(3) Fire support nets (digital and voice).

(4) Brigade O\&I ( NCS).

(5) Division O\&I.

(6) Brigade $\mathrm{A} / \mathrm{L}$.

(7) USAF coordination nets.

(8) Division early warning net and air defense data.

(9) Engineer net.

(10) MCS.

(11) Division EW net.

(12) Air defense battery net.

e) The brigade $\mathrm{S} 3$ section at the brigade main $\mathrm{CP}$ communicates and coordinates with:

(1) Division headquarters.

(2) Adjacent units.

f) The brigade $\mathrm{S} 2$ and $\mathrm{S} 2$ section communicates with: [ARTEP 71-3 MTP, Task 71-3-2006; FM 101-5, App A]

(1) Brigade commander.

(2) Division G2.

(3) Subordinate/supporting unit S2s.

(4) Brigade TAC CP.

(5) Brigade rear $\mathrm{CP}$.

(6) Adjacent unit headquarters in support of their collection efforts. 
(7) ASAS.

(8) DS MI company.

g) The brigade $\mathrm{S} 3$ and $\mathrm{S} 3$ section communicate with: [ARTEP 71-3

MTP, Tasks 71-3-3003/3c, 3008/4; FM 101-5, App A]

(1) Brigade XO.

(2) Brigade staff.

(3) Subordinate and supporting units.

(4) Brigade rear $\mathrm{CP}$.

(5) Division main CP.

(6) Division TAC CP.

h) The brigade $\mathrm{S} 3 \mathrm{Air}$, as $\mathrm{A} 2 \mathrm{C} 2$ team chief, communicates with:

(1) Members of $\mathrm{A} 2 \mathrm{C} 2$ team.

(2) Brigade TAC.

(3) Division G3 (A2C2 section).

i) The brigade NBC section communicates with: [AN]

(1) Division CMLO.

(2) Brigade subordinate commanders and leaders.

(3) Supporting NBC units (e.g., decontamination, reconnaissance).

(4) TF CMLOs.

(5) Brigade staff officers who need the information.

(6) NBC section manages the NBCWRS for the brigade through coordination and communication with external headquarters (division, and adjacent units). 
j) The brigade $\mathrm{ABE}$ section communicates with: [FM 101-5, App A; AN]

(1) Engineer brigade commander.

(2) Assistant division engineer.

(3) Brigade staff officers who need the information.

(4) Adjacent units.

(5) Engineer battalion main CP.

(6) Brigade TAC.

k) The brigade AVLO communicates with: [FM 101-5, App A; AN]

(1) Division G3 (A2C2 section).

(2) Aviation brigade main CP.

(3) Battalion and brigade ALOs (re. Army aviation integration with USAF operations).

(4) Brigade subordinate commanders and leaders.

(5) Brigade FSO.

(6) Brigade S3 and S3 Air.

(7) Other members of brigade $\mathrm{A} 2 \mathrm{C} 2$ element.

(8) Brigade staff officers who need the information.

1) The brigade FSO and FSE section communicate with:

(1) Brigade engineer.

(2) Brigade S2.

(3) Brigade S3.

(4) Division artillery.

(5) Division FSE. 
(6) DS FA battalion S3.

(7) Subordinate TF FSOs.

(8) ALO and AVLO.

(9) FSB Cdr (for rear operations).

(10) Brigade staff officers who need the information.

(11) Brigade NGLO.

(12) FSCOORD.

(13) COLTs.

m) The USAF ALO communicates with: [FM 101-5, App A; AN]

(1) USAF headquarters.

(2) Division ALO.

(3) Subordinate commanders and their ALOs.

(4) Brigade FSO.

(5) Brigade S3 and S3 Air.

(6) Other members of brigade $\mathrm{A} 2 \mathrm{C} 2$ element.

(7) Brigade staff officers who need the information.

(8) Tactical air control party (TACP).

(9) Marine air officer.

n) The brigade air and naval gunfire liaison team (Marine air officer and NGLO) communicates with: [AN]

(1) The division NGO (Division main fire support call) and NALO (Division TACP).

(2) Subordinate SALT teams. 
(3) Brigade FSO and FSE, and TF FSEs.

(4) Brigade ALO and TACP.

(5) Supporting ships providing NSF.

(6) Navy/Marine aircraft.

o) The ADALO communicates with: [FM 101-5, App A; AN]

(1) Air defense battalion commander.

(2) Brigade subordinate commanders and leaders.

(3) $\mathrm{ADA}$ battery commander and subordinate $\mathrm{ADA}$ platoon leaders.

(4) Other members of brigade $\mathrm{A} 2 \mathrm{C} 2$ element.

(5) Brigade staff officers who need the information.

(6) ADALO maintains air defense early warning net with division and higher air defense headquarters, $\mathrm{AD}$ units/teams/weapons within the brigade combat team, and all subordinate units.

p) The MP platoon leader communicates with: [FM 101-5, App A; AN]

(1) MP company commander.

(2) FSB commander.

(3) Brigade staff officers who need the information.

(4) Brigade $\mathrm{XO}$ and brigade $\mathrm{S} 3$.

q) The brigade communications section communicates with: [FM 1015, App A; AN]

(1) Assistant division signal officer.

(2) Signal battalion commander. 
(3) Brigade subordinate commanders and leaders.

(4) Brigade staff officers who need the information.

r) The brigade S5 communicates with: [FM 101-5, App A]

(1) The division G5.

(2) Brigade subordinate commanders and leaders.

(3) Brigade staff officers who need the information.

s) The Brigade HHC commander communicates with:

(1) Brigade XO.

(2) Bde SO.

(3) MP platoon leader.

(4) Brigade rear $\mathrm{CP}$.

(5) Brigade $\mathrm{S} 3$ section.

(6) Brigade CSM.

10) The brigade S1/S4 section ensures that the rear command post: [FM 71-3, Chap 3, 8; ARTEP 71-3 MTP, Tasks 71-3-1012; 4004; FM 101-5, App A; $\mathrm{AN}]$

a) Collocates with the FSB command post in the BSA.

b) Monitors the tactical situation and maintains communications capability to ensure that the rear $\mathrm{CP}$ is prepared to assume duties of the brigade main $\mathrm{CP}$.

c) Maintains communications with the brigade main $\mathrm{CP}$, the FSB CP, and the division rear $\mathrm{CP}$.

d) Acts as NCS for the brigade admin/log net.

e) Operates on and monitors communications nets: 
(1) Brigade command.

(2) Brigade admin/log.

(3) Division admin/log.

(4) FSB - if not collocated.

(5) Expands communications when/if it becomes the main $\mathrm{CP}$ in an emergency.

f) Manages CSS information required to:

(1) Sustain current deep, close, and rear operations.

(2) Forecast future CSS requirements.

(3) Conduct detailed CSS planning.

g) The brigade S1 communicates and coordinates with:

(1) Brigade XO.

(2) Brigade support cell.

(3) Brigade S3 (if necessary).

(4) Brigade current operations and plans cells.

(5) Division G1/AG, SJA, and surgeon.

(6) Brigade FSB CP.

(7) Rear area security units.

(8) TF S1s.

h) The brigade S4 communicates and coordinates with:

(1) Brigade XO.

(2) Brigade support cell.

(3) Division G4. 
(4) DISCOM and MSB staffs.

(5) FSB, support operations section.

(6) TF S4s.

(7) Brigade S3 (if necessary).

(8) $\mathrm{ADC}(\mathrm{S})$.

(9) Brigade subordinate and supporting commanders and leaders.

(10) Brigade staff officers who need the information.

(11) Brigade HHC commander.

(12) Brigade commander or brigade $\mathrm{S} 3$ in the TAC CP.

(13) Brigade CSM.

(14) ADO.

(15) Adjacent units.

b. The information manager at each of the brigade CPs maintains command, control, and communications throughout the battle. [FM 101-5, pp. 5-1 - 5-14; AN]

1) The brigade commander or $\mathrm{S} 3$ repositions $\mathrm{TAC} C \mathrm{CP}$ as necessary to maintain C3 with brigade subordinate leaders, division command group, commanders of adjacent units, and main $\mathrm{CP}$.

2) The brigade $\mathrm{XO}$ repositions the brigade main $\mathrm{CP}$ as necessary to:

a) Maintain $\mathrm{C} 3$ with brigade command group and TAC CP, brigade subordinate units' $\mathrm{CPs}$, division main $\mathrm{CP}$, and adjacent units' $\mathrm{CPs}$.

b) Preclude destruction of main CP C3 capabilities.

3) The brigade $\mathrm{S} 1$ or $\mathrm{S} 4$ repositions the rear $\mathrm{CP}$ in order to:

a) Maintain continuity of CSS support for the brigade forces.

b) Preclude destruction of CSS C3 capabilities. 
c) Maintain collocation and operational capability with the FSB.

c. The brigade reestablishes $\mathrm{C} 3$ operations in the event of $\mathrm{CP}$ loss or destruction. [FM 101-5, Chap 5, App B; FM 71-3, Chap 3, App H; Battle Command Techniques and Procedures, Chap 4]

\section{Outcome 2}

The brigade commander, staff, and other key individuals within the heavy brigade receive, evaluate, and process timely and accurate battlefield information.

\section{Task Elements}

1. The brigade commander directs and leads subordinate forces. [FM 71-3, pp. 3-2 - 3-4; FM 101-5, pp. 1-4 - 1-5; Battle Command Techniques and Procedures, Chap 1, 2, 4; Battle Command, pp. 12-14, 34-37]

a. The brigade commander directs subordinate forces. [FM 71-3, p. 3-4; FM 101-5, pp. 1-4 - 1-5]

1) The brigade commander takes actions to ensure that subordinate leaders have a clear understanding of his intent and concept. Actions include: [FM 101-5, Chap 1, 4; Battle Command Techniques and Procedures, Chap 2, 4; Battle Command, pp. 10-32]

a) Meeting with subordinate commanders and leaders to receive information and issue directions. [FM 101-5, pp. 4-53, 4-59 - 4-60]

b) Listening to cross-talk on brigade command nets.

4) The brigade commander uses his staff to assist him in directing and monitoring the battlefield. [FM 101-5, Chap 1, 3; FM 71-3, Chap 1, 2, 3; Battle Command Techniques and Procedures, Chap 2, 4]

2. Brigade command posts support synchronization by acquiring, evaluating, and communicating information. [FM 101-5, pp. 5-5 - 5-15]

a. The brigade CPs acquire information. [TRADOC Pam 11-9, Chap 7, App D; FM 71-3, Chap 2; FM 34-130, Chap 2; FM 101-5, p. 3-84, Chap 4, 6, App A, C; Battle Command Techniques and Procedures, Chap 2, 3, 4, 5]

1) The brigade staff members, operating out of $\mathrm{CPs}$, directed by the brigade commander or brigade SOP, obtain information during the execution of the battle that: [FM 101-5, p. 3-84] 
a) Is critical in assisting the brigade commander to synchronize the execution of the brigade battle. [FM 101-5, pp. 6-33, 6-34]

b) Provides information that focuses on critical information requirements (CCIR, other) for the commander. [LL- Combat Training Centers (CTCs) Bulletin No. 94-1, p. 5; FM 101-5, pp. 6-8, 6-11, 6-16, and C-4]

3) The brigade $\mathrm{XO}$ manages the acquisition, flow, and exchange of information to, from, and within the brigade main CP. [FM 101-5, pp. 6-2, 6-11, 6-34; ARTEP 71-3 MTP, Task 71-3-0001]

4) The $\mathrm{S} 2$ section obtains intelligence information. [FM 101-5, pp. C-7, C-8; FM 34-130, Chap 2]

b) The brigade $\mathrm{S} 2$ coordinates information concerns related to synchronizing the execution of the battle to include:

(1) Information related to NAIs and TAIs.

(2) Information related to the enemy, terrain, and weather: [ARTEP 71-3 MTP, Tasks 71-3-2003; 2005/2; 2006/3]

(a) PIR.

(b) Dispositions (confirmed and suspected).

(c) Composition.

(d) Activity in deep, close, and rear areas.

(e) Intentions.

(f) Reactions to friendly battle techniques.

(g) Actions triggered by friendly actions or events.

(h) Adherence to or deviation from postulated enemy COA.

(i) Losses based on observer reports, other sources.

(j) Use of EW.

(k) Use of NBC. 


\section{(l) Capabilities.}

(m) Enemy prisoners of war.

(3) Information related to the brigade's capability to continue collection of intelligence information:

(a) Status of NAI coverage.

(b) Strength, location, and capability of brigade and TF R\&S elements.

(c) Status of requests for aerial reconnaissance and other external support.

(d) ASAS status.

(e) DS MI company strength, location, and capability to continue support.

(f) Updating of MCOO.

5) The brigade $S 3$ section obtains operations information (e.g., changes to METT-T and unit status). [FM 101-5, pp. C-8, C-9; ARTEP 71-3 MTP, Task 71-3-3001/1]

b) The brigade $\mathrm{S} 3$ section in conjunction with the brigade $\mathrm{XO}$, and the brigade $\mathrm{S} 3$ in the TAC CP, coordinate information concerns related to synchronizing the execution of the battle to include: [ARTEP 713 MTP, Tasks 71-3-3003/1, 2, 3; 3014/1; 3003/2, 3; FM 101-5, App A]

(1) Direction from the brigade commander.

(a) Changes to mission concept or details of the plan.

(b) Requirements for information to assist him in synchronizing the battle.

(2) FRAGOs/WARNOs from division headquarters.

(3) Changes to division or adjacent unit situations which necessitate changes to brigade OPSEC posture. 
(4) Division and corps units and systems operating within and requiring terrain in the brigade $\mathrm{AO}$.

(5) Information relating to determining effectiveness of brigade OPSEC measures.

(6) Subordinate units' situation reports (SITREPs) and graphics.

(a) Enemy contact.

(b) Current and projected strength and combat power.

(c) Status of task organization.

(d) OPSEC reports.

(e) Results of security operations.

(7) Requests for resources from subordinate units based on synchronization requirements.

(8) Recommendations from subordinate commanders (TFs, DS FA, engineer, FSB, ADA battery) on changes to the brigade scheme of maneuver based on their current and projected operational status.

(9) Information about adjusted maneuver plans from subordinate units.

(10) Information required for confirming, refining, or changing the DST.

(11) Updates from the brigade S1 and S4.

(a) Personnel status.

(b) Vehicle, weapons systems, and equipment status.

(c) Status of supply (Classes I, III and V).

(d) Casualty evacuation.

(e) Capability for emergency resupply. 
(f) Status of key leaders and critical military occupational specialties (MOSs).

(12) Updates from the brigade $\mathrm{S} 5$ on $\mathrm{CMO}$ information.

(a) Civilian population movement on brigade lines of communication (LOCs).

(b) Civilian population centers.

(c) ROE.

(13) Updates from the brigade FSCOORD on employment and status of fire support assets.

(14) Updates from the brigade engineer on status of mobility/ counter-mobility/survivability (M/CM/S) actions and unit status.

(15) Updates from the brigade ALO on CAS employment and status of CAS requests.

(16) Updates from the brigade AVLO on status and employment of attack, assault, and cargo helicopter units.

(17) Updates from the brigade SO on the status of brigade communications links and systems.

(18) Updates from the brigade CMLO on the status and employment of chemical units.

(19) Updates from the brigade ADALO on the status and employment of $\mathrm{AD}$ assets.

(20) Information necessary to deconflict terrain requirements and projected locations for external and/or supporting units operating in the brigade area. [FM 101-5, Chap 3]

(21) Updates from the brigade $\mathrm{S} 2$ on:

(a) The enemy situation to include update BDA on enemy.

(b) Implementation of the R\&S plan and confirmation of NAIs. [AN] 
(c) Status of intelligence collection assets.

(22) Updates on status of FSB operations.

(a) Critical problems with support.

(b) Integrity of brigade support area (BSA) and rear area security.

6) The brigade $\mathrm{S} 3 \mathrm{Air}$, as chief of the $\mathrm{A} 2 \mathrm{C} 2$ element, obtains information from the S2, FSE, ADO, AVLO, NGLO, and Marine air officer concerning airspace use. [ARTEP 71-3 MTP, Task 71-3-3012]

a) The brigade S3 Air obtains information from:

(1) The brigade $\mathrm{S} 2$.

(2) The brigade FSE.

(3) The brigade ADO.

(4) The brigade AVLO.

(5) The brigade ALO.

(6) The brigade NGLO.

b) The brigade $\mathrm{S} 3 \mathrm{Air}$ coordinates $\mathrm{A} 2 \mathrm{C} 2$ information necessary to synchronize the execution of the battle to include:

(1) Changes to $\mathrm{A} 2 \mathrm{C} 2$ measures.

(2) Division use of brigade airspace.

(3) Adequacy of airspace control authority (ACA).

7) The brigade NBC section obtains information concerning friendly and enemy NBC status. [ARTEP 71-3 MTP, Tasks 71-3-0001; 0002, 0005/1]

a) The brigade NBC section obtains information from:

(1) Subordinate units.

(2) Brigade S4. 
(3) Division CMLO.

(4) Brigade S2.

(5) Brigade targeting team.

(6) Brigade commander.

(7) Subordinate units' CMLOs.

(8) Brigade AVLO.

(9) Brigade ALO.

(10) Brigade NGLO.

(11) Brigade ADO.

(12) Brigade ABE.

(13) Brigade S3 Air.

(14) NBC reconnaissance elements.

b) The brigade NBC section coordinates NBC information concerns related to synchronizing the execution of the battle to include:

(1) Division NBC warning and reporting system (WRS) updates.

(2) Changes from the brigade commander's guidance and mission concept and, requirements for information.

(3) Status and location of decontamination and reconnaissance assets.

(4) Reports from NBC reconnaissance elements.

(5) NBC monitoring and surveillance reports.

(6) Information from the brigade S2 and intelligence section which confirms or refutes estimate of NBC threat and requirements. 
(7) Changes to brigade, supporting, and subordinate units' operations in terms of decontamination requirements and timelines.

8) The brigade engineer, $\mathrm{ABE}$, and $\mathrm{ABE}$ section obtain mobility, countermobility and survivability mission information. [FM 5-71-3, Chap 2; ARTEP 71-3 MTP, Tasks 1-3-8001/1, 2; 8003]

a) The brigade engineer, $\mathrm{ABE}$, and $\mathrm{ABE}$ section obtain information from:

(1) Division engineer.

(2) Engineer brigade main CP.

(3) Brigade S2.

(4) Brigade CMLO.

(5) Brigade commander and S3 in the TAC CP.

(6) Subordinate units.

(a) Engineer companies supporting TFs.

(b) TFs.

(c) Attached combat, combat service (CS), and CSS units.

(d) FSO or fire support teams (FISTs) assigned to the engineer battalion.

(7) Brigade $\mathrm{XO}$, brigade $\mathrm{FSO}$, and brigade targeting team.

(8) Brigade S1/S4, FSB support operations officer in the brigade rear CP.

(9) Engineer battalion TOC.

b) The brigade ABE section coordinates mobility, countermobility, and survivability information concerns related to synchronizing the execution of the battle to include: 
(1) Changes from the brigade commander to guidance and mission concept and requirements for information.

(2) Reports from the engineer battalion representative or TF engineer about regarding status of equipment.

(a) Armed combat earthmovers (ACEs) and other digging assets.

(b) Armed vehicle launched bridges (AVLBs).

(c) Mine clearing line charges (MICLICs).

(d) Mine clearing blades and rollers.

(e) Cleared lanes marking systems (CLAMS).

(f) Grizzly.

(3) Countermobility status:

(a) Obstacle/barrier status to include engineer capability to achieve its purpose against the enemy, with obstacle/barrier coverage by fires and responsibilities clearly defined.

(b) Status on Class IV and V materials and special equipment.

(c) Updates on capability to emplace obstacles to include number, classification by type of obstacle, and time requirements.

(d) Updates on readiness to employ FASCAM from the brigade FSO. [ARTEP 71-3 MTP, Task 71-3-8003]

(e) Updates on the capability of maneuver task forces to emplace obstacles and barriers. [AN]

(f) Updates status of security and control of obstacles from maneuver TFs. [AN]

(4) Survivability position status: 
(a) Survivability position construction status and adherence timelines from engineers and subordinate units.

(b) Status of receipt of survivability materials from TF S4s.

(5) Mobility status:

(a) Updates on availability of engineer materials from engineer battalion $\mathrm{S} 4$.

(b) Updates on availability of engineer systems from engineer companies.

(c) Updates on availability of mobility equipment organic to brigade maneuver units (e.g., plows, rollers, breach kits) from TF S4s.

(d) Reports from engineer reconnaissance units and TF scouts on terrain and enemy obstacles.

(6) Task organization status from engineer and TFs, including adherence to directed timelines.

(7) Intelligence information on weather, terrain, and other information which confirms or refutes estimates of engineer requirements.

(8) Changes to brigade and TF maneuver operations in terms of $\mathrm{M} / \mathrm{CM} / \mathrm{S}$ :

(a) FASCAM targets.

(b) Completion of obstacles.

(c) Previously unreported obstacles.

(d) Status of $\mathrm{M} / \mathrm{CM} / \mathrm{S}$ capabilities.

(9) Monitors close operations and posts key activities and locations to engineer journal and situation map (SITMAP). [AN] 
(10) Provides additional engineer support to the close fight from the engineer battalion resources, as directed by the command group. [AN]

(11) Monitors engineer tasks begin done in support of the brigade rear area and posts the status to the engineer journal and SITMAP. [AN]

(12) Assists the brigade staff in the main $\mathrm{CP}$ with the execution of countermobility support to planned brigade deep operations. [AN]

(13) Identifies options for SCATMINE employment not previously planned and coordinates with the brigade FSO and brigade $\mathrm{S} 2$ to determine suitability, feasibility, and acceptability. [AN]

9) The brigade AVLO obtains information about friendly air capabilities and plans. [ARTEP 71-3 MTP, Task 71-3-7001; ARTEP 1-100 MTP, Tasks 01$4-1311 ; 1322]$

a) The brigade AVLO acquires information from:

(1) Division ALO.

(2) Brigade FSO/FSE.

(3) Brigade $\mathbf{2}$.

(4) Brigade targeting and $\mathrm{A} 2 \mathrm{C} 2$ teams.

(5) Brigade commander.

(6) Subordinate units' ALOs/forward air controllers (FACs).

(7) Subordinate units' S3 Air/S3s.

(8) Brigade ALO.

(9) Brigade NGLO.

(10) Brigade S3.

(11) Brigade S3 Air. 
(12) Brigade ADO.

(13) Aviation brigade S3.

(14) Brigade ABE.

(15) DS FA battalion S3.

b) The brigade AVLO coordinates air information concerns related to synchronizing the execution of the battle to include:

(1) Changes from the brigade commander to guidance and mission concept and requirements for information.

(2) Updated status from the aviation brigade on helicopter availability, support capability, and plans.

(3) Intelligence information.

(a) Enemy ADA weapons and electronics capabilities.

(b) Enemy ground to air capability.

(c) Enemy air to air capability.

(d) Confirmation or refutation of predicted weather constraints.

(4) Information from the brigade FSO on SEAD, ACAs, fires, and laser support required for Army aviation operations.

(5) Information from the brigade S3 and S3 Air on the concept for employment of Army aviation and desired effects.

(6) Updates from the division $\mathrm{CP}$ or aviation brigade on aviation activities in the brigade sector (e.g., ingress or egress routes and times of use before/after a deep attack).

(7) Status from the ALO on CAS flight operations.

(a) Times.

(b) Locations. 
(c) Routes.

(8) Changes to brigade, supporting, and subordinate units' plans in terms of target locations and timelines.

(9) Integration of information during targeting and $\mathrm{A} 2 \mathrm{C} 2$ team meetings. [AN]

10) The FSCOORD, brigade FSO, brigade targeting officer, and FSE section obtain fire support information. [FM 6-20, pp. 2-22, 2-23; FM 6-20-40, Chap 4; ARTEP 71-3 MTP, Task 71-3-9002/1b, 3; 9003/1a; 9004/1a]

a) The brigade FSO/FSE monitors calls-for-fire from TF FSOs and retransmits the requests, if necessary, to support execution of the scheme of maneuver.

b) The brigade FSCOORD, FSO, and FSE section obtain information from:

(1) Division FSE.

(2) Division artillery TOC.

(3) Brigade S2, DS MI company targeting officer.

(4) Brigade targeting and $\mathrm{A} 2 \mathrm{C} 2$ teams.

(5) Brigade commander.

(6) Subordinate unit FSOs, FISTs, combat observation lasing teams (COLTs), and supporting arms liaison teams (SALTs) (if assigned).

(7) DS FA battalion S3.

(8) Brigade ALO.

(9) Brigade NGLO (if assigned).

(10) Brigade AVLO.

(11) Brigade ADO.

(12) Brigade ABE. 


\section{(13) Brigade S3 Air.}

c) The brigade FSCOORD, FSO, targeting officer, and FSE coordinate fire support information concerns related to synchronizing the execution of the battle to include:

(1) Enemy capabilities to attack the brigade with indirect fires.

(2) Status of field artillery from the DS FA battalion S3 and mortars from TF S3(s).

(a) Current and projected locations of units.

(b) Current and projected unit weapons status.

(c) Current and projected ammunition status.

(d) Planned repositioning of artillery and mortar units in terms of locations and time.

(3) Status of target acquisition assets and current operations.

(4) Status of field artillery units from division artillery/division FSE.

(a) Organization for combat (including GS, general support -reinforcing [GSR] FA).

(b) Locations and status of GS and GSR batteries, and platoons.

(c) Status and locations of counter fire radars.

(d) Status and timing of meteorological support.

(e) Division or corps directed FSCMs.

(f) SALTs.

(5) Status of task organization, personnel, and equipment from TF FSOs.

(a) COLTs. 


\section{(b) FISTs, SALTs.}

(c) Mortars.

(6) Bottom-up target refinements from TF FSOs for:

(a) Maneuver TFs, to include scout platoons, COLTs, and other observers; obstacle locations.

(b) Final protective fires.

(c) Fire support coordination and control measures.

(7) Information from ALO and AVLO.

(a) Timing of operations and status for Army aviation (from AVLO).

(b) Availability of and times for CAS support.

(c) Status of availability, capability of TACP to coordinate and execute CAS from ALO.

(d) Suppression of enemy air defenses (SEAD) requirements in terms of times, locations, and control measures to support brigade operations or division directed operations in brigade sector.

(8) Availability and locations of EW assets from the brigade S2 and DS MI company commander.

(9) Information necessary to refine indirect fires coverage of obstacles, and adjustments to FASCAM employment from the brigade engineer or $\mathrm{ABE}$.

(10) Fire support requirements from the brigade $\mathrm{S} 4$ and FSB commander to support the BSA and rear area operations.

(11) $\mathrm{A} 2 \mathrm{C} 2$ information from the brigade $\mathrm{S} 3 \mathrm{Air}$ and $\mathrm{A} 2 \mathrm{C} 2$ team meetings.

(12) BDA on enemy, particularly about HPT.

(13) Intelligence or operational information on the TACFIRE nets. 
(14) Reports changes in FSCMs to division artillery. [AN]

(15) Reports changes in FSCMs to the division FSE. [AN]

(16) Coordinates planning and implementation of suppression of enemy air defense. [AN]

(17) Coordinates with the task force FSOs in SEAD zone to plan mortar targets. [AN]

(18) Disseminates FRAGOs to artillery units. [AN]

11) The ALO obtains information about friendly air capabilities and plans. [FM 6-20-40, Chap 2, p. A-9; FM 6-20-50, p. C-7; FM 71-3, Chap 3]

a) The brigade $\mathrm{ALO}$ acquires and receives information from:

(1) Division TACP.

(2) Brigade FSO/FSE.

(3) Brigade $\mathrm{S}$.

(4) Brigade targeting team.

(5) Brigade commander.

(6) Subordinate unit ALOs/TACP, SALTs.

(7) Marine air officer from brigade air/NGF platoon, ANGLICO (if assigned).

(8) Subordinate unit S3s.

(9) Corps air support operations center (ASOC).

(10) Brigade TACP liaison team.

(11) Brigade S3.

(12) Brigade ABE.

(13) Brigade ADO. 
(14) Aviation brigade $\mathrm{CP}$.

(15) Brigade S3 Air.

b) The brigade ALO coordinates CAS information concerns related to synchronizing the execution of the battle to include:

(1) Updated ATO information from the division ALO concerning CAS support status (e.g., times, routes).

(2) Capabilities of Marine/Navy air (CAS) from the Marine air officer, brigade air/NGF platoon, ANGLICO.

(3) Changes to the brigade commander's guidance and mission concept and, requirements or information.

(4) Intelligence information from ALO and ANGLICO channels.

(a) Enemy ADA weapons capabilities and electronics signatures.

(b) Enemy ground to air threat.

(c) Enemy air to air threat.

(d) Enemy ground activities.

(5) Information from the brigade $\mathrm{S} 2$ and intelligence section which confirms or refutes estimate of weather constraints and enemy ADA capabilities.

(6) Information from the brigade FSO on SEAD, ACAs, fires, and lazing support requirements for CAS operations.

(7) Status from the brigade S3, brigade S3 Air, and AVLO on concept for employment of JAAT and desired effects.

(8) Status from the AVLO on helicopter operations.

(9) Changes to brigade, supporting, and subordinate units' plans in terms of projected locations and timelines. 
12) The NGLO obtains information about requirements for NSF and capabilities of ships that provide NSF. [FM 71-3, pp. 7-13 - 7-14; FM 6-20-40, p. A-26; FM 6-20-50, pp. C-25 - C-28]

a) The brigade NGLO acquires and receives information from:

(1) Division naval gunfire officer (NGO).

(2) Brigade FSO/FSE.

(3) Brigade $\mathbf{S}$.

(4) Brigade targeting team.

(5) Brigade commander and $\mathrm{S} 3$ in the TAC CP.

(6) Subordinate unit ALOs/TACP.

(7) Subordinate unit S3s.

(8) Brigade ALO, Marine air officer.

(9) SALT.

(10) US Navy ships in DS.

(11) Brigade $\mathrm{S} 3$ section in the main CP.

(12) Brigade ABE.

(13) Brigade ADO.

(14) Aviation brigade CP.

(15) Brigade S3 Air (A2C2 team).

b) The brigade NGLO coordinates information concerns related to synchronizing the execution of the battle to include:

(1) Status of ships in DS role, and availability and times for GS NSFs from the division NGLO.

(2) Targeting information from the brigade FSE and TF SALT teams. 
(3) Mission timelines from the brigade FSE.

(4) Fire support coordination and control measures from the brigade FSE.

(5) $\mathrm{A} 2 \mathrm{C} 2$ information from the brigade $\mathrm{A} 2 \mathrm{C} 2$ team.

13) The brigade $A D O$ obtains information on air defense requirements and resources. [ARTEP 71-3 MTP, Task 71-3-6001/1]

a) The brigade $\mathrm{ADO}$ obtains information from:

(1) Division CPs.

(2) Brigade AVLO.

(3) Brigade $\mathbf{S}$.

(4) Brigade targeting and $\mathrm{A} 2 \mathrm{C} 2$ teams.

(5) Brigade commander or brigade $\mathrm{S} 3$ in the TAC CP.

(6) Subordinate unit FSOs.

(7) Brigade S3 Air.

(8) Brigade ALO, Marine air officer.

(10) ADA battalion commander and S3.

(11) ADA platoons under TFs' control.

(12) Adjacent units.

b) The brigade ADO coordinates air defense information concerns related to synchronizing the execution of the battle to include:

(1) Disposition of ADA assets from the ADA battalion commander and battalion ADA elements.

(2) Changes from the brigade commander to guidance and mission concept and requirements for information. 
(3) $\mathrm{ADA}$ weapons systems and ammunition status from supporting ADA elements.

(4) Intelligence information which confirms or refutes estimate of $\mathrm{ADA}$ requirements.

(5) Weapons control status from the area air defense commander.

(6) Air defense warning system updates from the ADA battalion and division $\mathrm{CP}$.

(7) Changes or additions to tactical aircraft or Army aviation routes and schedules through the brigade sector.

(8) $\mathrm{A} 2 \mathrm{C} 2$ updates from the division $\mathrm{G} 3 \mathrm{~A} 2 \mathrm{C} 2$ section.

(9) Changes in positions or priorities of designated brigade assets to be defended.

(10) Changes to brigade, supporting, and subordinate units' operations based on $\mathrm{AD}$ capabilities and timelines.

(11) Warns brigade staff and command of imminent enemy air attacks. [AN]

(12) Logs engagement reports and decrement missile counts that includes: [AN]

(a) Type of aircraft engaged.

1 Location.

$2 \quad$ Time.

(b) Type of damage inflicted.

(c) Unit engaging.

(d) Type and number of weapons expended.

14) The MP platoon leader obtains information: [ARTEP 71-3 MTP, Task 713-1201/1] 
a) The MP platoon leader acquires and receives information from:

(1) Brigade $\mathrm{XO}$ and $\mathrm{S} 3$ section in the main $\mathrm{CP}$.

(2) MP company commander.

(3) Brigade S2.

(4) Brigade S5.

(5) FSB support operations officer.

(6) Brigade S1/S4 in the rear CP.

(7) Brigade $\mathrm{S} 3$ in the TAC CP.

b) The brigade MP platoon leader coordinates information concerns related to synchronizing the execution of the battle to include:

(1) Changes from brigade commander to guidance, mission concept, and requirements for information.

(2) Status of supporting MP units.

(3) Intelligence information from the brigade S2 and intelligence section regarding expected EPW numbers.

(4) Information from the brigade S4 about logistical support for EPW holding areas (transportation, supplies, equipment, and medical).

(5) Information from brigade $\mathrm{S} 5$ about $\mathrm{HN}$ military and civilian requirements and status.

(6) Changes from brigade $\mathrm{S} 3$ or brigade $\mathrm{XO}$ regarding priorities for MP support for:

(a) Straggler and refugee control.

(b) Traffic control.

(c) EPW operations.

(d) Security operations. 
15) The Bde SO and communications section obtain information concerning brigade communications requirements and capabilities. [ARTEP 71-3 MTP, Tasks 71-3-1101/1; 1102/1, 4]

a) The Bde SO and communications section obtain information from:

(1) Assistant division signal officer.

(2) Division signal battalion CP.

(3) Brigade $\mathbf{S}$.

(4) Brigade CPs.

(5) Brigade commander and brigade $\mathrm{S} 3$ in the TAC CP.

(6) Subordinate unit:
(a) CPs.

(b) Signal officers.

(7) Brigade S3 Air.

(8) Brigade S3 section.

(9) Brigade HHC commander.

b) The Bde $\mathrm{SO}$ and communications section coordinate communications and electronics (CE) information concerns related to synchronizing the execution of the battle to include:

(1) Status of communications links from brigade $\mathrm{CP}$ s to division and other MSC CPs.

(2) Changes from the brigade commander to guidance and mission concept and requirements for information.

(3) Disposition and status of communications assets from the assistant division signal officer and signal battalion S3.

(4) Updates from subordinate units on communications status.

(a) Status of communications links from brigade CPs. 
(b) Equipment (secure and non-secure).

(c) SOIs.

(d) Availability of subordinate unit communications personnel and equipment.

(5) Intelligence information:

(a) Which updates estimate of communications requirements.

(b) Updates enemy electronic and communication capabilities.

(6) Status reports from retransmission stations.

(a) Positioning.

(b) Equipment serviceability and capability.

(c) Communication ranges and dead spaces.

(7) Information from the brigade $\mathrm{XO}, \mathrm{S} 4$, and $\mathrm{S} 3$ about changes to proposed brigade $\mathrm{CP}$ locations and projected timelines.

(8) Changes to brigade, supporting, and subordinate units' plans in terms of projected locations and timelines.

16) The brigade $\mathrm{S} 1$ section obtains personnel information. [ARTEP 71-3 MTP, Tasks 71-3-1001/1, 2; 1002/1, 3, 4; 1004/1; 1008/1; FM 101-5, pp. C-5; FM 71-3, pp. 8-5, 8-6, 8-17, 8-24; Chap 8]

a) The brigade $\mathrm{S} 1$ section obtains information from:

(1) Division G1/adjutant general (AG).

(2) Brigade commander and $\mathrm{S} 3$ in the TAC CP.

(3) Subordinate units:

(a) Maneuver TFs.

(b) Supporting engineer, artillery, and FSBs. 
(c) MP platoon.

(d) Air defense battery.

(e) Brigade HHC commander.

(4) Adjacent units.

(5) Brigade S5.

(6) FSB medical company.

(7) Brigade surgeon.

(8) MP platoon leader.

(9) Division JAG.

(10) Division PM.

(11) Division inspector general (IG).

(12) Rear CP liaison officer to the brigade main $\mathrm{CP}$.

(13) Brigade, subordinate, and adjacent units' communications nets (eavesdropping).

b) The brigade S1 section coordinates personnel information concerns related to synchronizing the execution of the battle to include:

(1) Changes from the brigade commander to guidance, mission concept, priorities, and requirements for information.

(2) Information from the brigade S2 and S2 section which confirms or refutes estimates of personnel situation and casualty estimates.

(3) Personnel status from subordinate and supporting units.

(a) PSRs.

(b) Critical MOS/grade shortages.

(c) AWOLs. 
(d) Casualty feeder reports.

(e) Key leader and MOS status.

(4) Personnel information from division G1/AG.

(a) Availability of replacements and replacement operations (WSRO).

(b) Postal services.

(c) Morale, welfare, recreation (MWR) support.

(5) Morale and discipline indicators from division and brigade special staff officers.

(a) Disciplinary rates from Staff Judge Advocate (SJA).

(b) Straggler and crime rates from PM.

(c) Sick call and stress casualties from brigade surgeon.

(d) Complaints information from the IG.

(e) Leader and soldier concerns from the chaplain.

(6) FSB support capabilities from the FSB support operations center.

(7) Information from the MP platoon leader concerning EPW processing and evacuation requirements.

(8) Information from the brigade $\mathrm{S} 5$ concerning CMO support requirements.

(9) Changes to brigade, supporting, and subordinate unit plans in terms of projected locations and times.

(10) Continually tracks the tactical situation to focus attention on the forces in contact. [AN]

(11) Monitors the administrative and logistics net for casualty reports from task force S1s. [AN] 
(12) Informs the brigade command and operations group when task force combat strength or total brigade combat strength or total brigade combat power falls below benchmark.

$[\mathrm{AN}]$

(13) Updates personnel status to division G1 routinely or when total brigade strength falls below benchmark. [AN]

(14) Monitors MEDEVACs and number of brigade casualties at each echelon of medical support through division. [AN]

(15) Monitors mass casualty plans requirement. [AN]

(16) Continually tracks EPW (numbers and locations, back through the brigade support area). [AN]

17) The brigade $S 4$ and $S 4$ section obtain logistics information. [ARTEP 71-3 MTP, Tasks 71-3-4001/1, 3; 4002; 4003; FM 101-5, p. C-9; FM 71-3, pp. 8$5,8-17,8-24]$

a) The brigade $\mathrm{S} 4$ section acquires and receives information from:

(1) Division G4.

(2) Brigade commander and CSM.

(3) Subordinate units:

(a) Maneuver TFs.

(b) Supporting engineer, artillery and FSMs.

(c) MP platoon.

(d) Air defense battery.

(e) Bde HHC Cdr.

(4) Adjacent units.

(5) Brigade S5. 
(6) MP platoon leader.

(7) DISCOM.

(8) Brigade $\mathrm{S} 2$.

(9) Brigade S3 section and S3 Air.

(10) Rear CP liaison officer to the brigade main CP.

(11) Brigade, subordinate, and adjacent units' communications nets (eavesdropping).

(12) Brigade XO.

b) The brigade $\mathrm{S} 4$ coordinates logistics information concerns related to synchronizing the execution of the battle to include:

(1) Changes from the brigade commander to guidance, mission concept, priorities, and information requirements.

(2) Intelligence information from the brigade $\mathrm{S} 2$ and $\mathrm{S} 2$ section which confirms or refutes estimates of the logistical situation.

(3) Logistics reports from subordinate and supporting units.

(a) Status of supplies by class.

(b) Equipment readiness.

(c) Task organization and status of CSS elements:

1 FSB.

2 Field trains command post (FTCPs).

3 Combat trains command post (CTCPs).

$4 \quad$ Status of critical CSS personnel.

(d) Prestocked/cached supplies status. 
(4) Maintenance, transportation and supply updates from the division G4 and FSB support operations center (including plans for WSRO).

(5) Availability of air transportation assets from the brigade S3 Air.

(6) Information from the MP platoon leader concerning EPW status and support requirements.

(7) Information from the S5 concerning availability of host nation assets and CMO support requirements.

(8) Changes to brigade, supporting, and subordinate unit plans in terms of projected locations and times of displacement.

(9) Coordinates the execution of refuel requirements by exchanging information regarding who, what, where, and when with the FSB commander and task forces. [AN]

(10) Reacts to critical losses by cross-leveling critical personnel replacement and personnel. [AN]

(11) Performs a situational CSS estimate and presents an information summary when friendly losses start to impact on combat effectiveness. [AN]

(12) Coordinates with the brigade S1 and FSB commander to determine brigade's combat strength. [AN]

18) The brigade surgeon obtains information. [ARTEP 71-3 MTP, Tasks 71-3$1301 / 2,3 ; 1302 / 1 \mathrm{~b}]$

a) The brigade surgeon obtains information from:

(1) Division medical supply officer.

(2) Division surgeon.

(3) Brigade commander and S3 at the TAC CP.

(4) Brigade XO or brigade S4. 
(5) Brigade S2.

(6) TF medical platoon leaders.

(7) FSB staff.

(8) Main support battalion (MSB).

(9) Division medical operations center (DMOC).

b) The brigade surgeon coordinates medical information concerns related to synchronizing the execution of the battle to include:

(1) Information from the brigade S2 and S2 section which confirms or refutes estimates of projected casualties.

(2) Changes from the brigade commander to guidance, mission concept, priorities, and information requirements.

(3) Medical updates and aerial medical evacuation capabilities from the division surgeon.

(4) Class VIII supply updates from the division medical supply officer.

(5) Additional medical support capability from the MSB and corps.

(6) Subordinate and supporting unit medical support status.

(a) Positioning and readiness of medical assets.

(b) Capability to receive, triage, and evacuate casualties.

(c) Requirements for support.

(7) Changes to brigade, subordinate, and supporting unit plans in terms of projected locations and times of displacement.

19) The brigade $S 5$ (or designated substitute) obtains information about the CMO situation related to synchronizing the battle. [FM 101-5, p. C-9; ARTEP 71-3 MTP, Task 71-3-5001, 5003, 5004] 
a) The brigade $\mathrm{S} 5$ obtains information on $\mathrm{CMO}$ requirements and resources, from: [ARTEP 71-3 MTP, Task 71-3-5001/1, 2; 5003/1; $5004 / 1]$

(1) Higher headquarters.

(2) Brigade commander.

(3) Civilian authorities.

(4) MP units.

(5) Adjacent units.

(6) Brigade $\mathrm{XO}$ and brigade S4.

b) The brigade $\mathrm{S} 5$ coordinates $\mathrm{CMO}$ information concerns related to synchronizing the execution of the battle to include:

(1) Status of CMO support required for current brigade operations.

(2) Information from subordinate commanders on whether the situation with civilians will interfere with military operations in their sectors.

(3) Status of and potential problems with refugees and civilians on critical brigade LOCs.

20) The FSB commander and support operations center obtain CSS information: [FM 63-20, Chap 3, 5, 6; FM 71-3, pp. 8-5, 8-6, 8-17, 8-18, 8-25]

a) The FSB commander and staff obtain information from:

(1) Division G4.

(2) Brigade commander and $\mathrm{S} 3$ in the TAC CP.

(3) Brigade units:

(a) Maneuver TFs.

(b) Supporting engineer and artillery battalions.

(c) MP platoon. 
(d) Air defense battery.

(e) Brigade HHC commander.

(4) FSB companies.

(5) Adjacent units.

(6) Brigade S5.

(7) Division material management center (DMMC).

(8) DISCOM commander.

(9) Division medical operations center (DMOC).

(10) Brigade S2.

(11) Brigade S3 Air.

(12) MSB.

(13) Brigade S1 and S4.

(14) Brigade XO.

(15) Brigade, subordinate, and adjacent units' communications nets (eavesdropping).

b) The FSB commander and staff coordinate CSS information concerns related to synchronizing the execution of battle to include:

(1) Changes from the brigade commander to guidance, mission, concept, priorities, and information requirements.

(2) Information from the brigade S2 and S2 section which confirms or refutes estimates of the CSS situation.

(3) Changes to guidance, priorities, and requirements from the DISCOM commander.

(a) CSS task organization. 
(b) Tasks to provide CSS support to division and corps units.

(4) Information from the MSB regarding backup CSS support.

(5) Information from the DMMC concerning supply and maintenance management support.

(6) Information from supported units regarding their requirements.

(a) Maintenance and recovery of weapons systems and equipment.

(b) Resupply requirements.

(7) Information from all organizations in the BSA (for defense and terrain management).

21) The brigade HHC commander obtains information necessary to support the main and tactical CPs. [ARTEP 71-3 MTP, Task 71-3-1501]

a) The brigade $\mathrm{HHC}$ commander obtains information from:

(1) Brigade commander and CSM.

(2) Brigade XO.

(3) Brigade S1/S4.

(4) Brigade S3.

(5) Brigade S2.

(6) Brigade CPs.

b) The brigade HHC commander coordinates information concerns related to synchronizing the execution of the battle to include:

(1) Obtains information from the brigade S2 and S2 section which confirms or refutes enemy threat to the main $\mathrm{CP}$.

(2) Obtains changes to brigade commander guidance, mission concept and information requirements from the brigade XO. 
(3) Obtains anticipated movement times and projected locations for the main and TAC CPs from the brigade XO and S3.

(4) Obtains information from attachments/supporting agencies concerning space, supply, and support requirements.

b. The brigade $\mathrm{CPs}$ and staff sections evaluate acquired information, update products, and maintain status. [FM 63-20, Chap 3, 6; FM 101-5, Chap 6]

3) The brigade $S 2$ section evaluates intelligence information and updates products: [ARTEP 71-3 MTP, Tasks 71-3-2002, 2003, 2005, 2006]

a) The $\mathrm{S} 2$ section evaluates intelligence information: [ARTEP 71-3 MTP, Tasks 71-3-2002/1; 2003/1, 2; 2004/1; 2005]

(1) Impact of changes to guidance/direction and information.

(2) Comparison of desired brigade endstates with current intelligence situation, trends, and intelligence preparation of the battlefield (IPB).

(3) Information which:

(a) Identifies answers to brigade commander's CCIR, PIR, and information requirements (IR).

(b) Confirms or refutes IPB information relative to achieving the commander's intent (e.g., NAIs and TAIs).

(c) Identifies enemy:

1 Composition.

2 Disposition.

3 Location.

$4 \quad$ Strength (losses) and present capabilities.

5 Indications of possible enemy intent.

6 Enemy reaction to friendly operations. 
1 Adherence to or deviation from postulated enemy COA.

(d) Permits comparison of known enemy activity with previously projected enemy COAs.

(e) Permits development of BDAs.

(4) Determines whether R\&S plan/operations continue to meet brigade commander's intent.

(a) Positioning of assets to collect PIR and IR.

(b) Positioning of assets to maintain constant observation of NAIs and TAIs.

(c) Positioning of assets to detect and track HPTs, provide observation for attack of HPTs, and provide BDA on HPT following attack.

(5) Indicators of enemy intentions:

(a) NBC weapons usage or activity as prelude to offensive operations.

(b) Presence of reconnaissance forces as prelude to attack.

(c) Presence and massing of maneuver forces as indicator of initiation of offensive operations.

(d) Increase in fighter activity and massing of transport fixed wing aircraft as indicators of airborne assault or start of offensive operations.

(e) Meaconing, interference, jamming, interception (MIJ) and other changes in enemy electromagnetic activity as prelude to offensive operations.

(f) Conduct of counter-reconnaissance operations as an indicator of defense.

(g) Field artillery and rocket unit activity.

1 Offensive indicators. 
2 Defensive indicators.

(h) Presence and nature of activity of engineer units.

1 Offensive indicators.

2 Defensive indicators.

(i) Increase of enemy helicopter activity as indication of air assault operations.

(6) The brigade $\mathrm{S} 2$ and the intelligence cell:

(a) Identify changes to current projections of enemy COAs.

(b) Perform BDA.

(c) Deduce possible future enemy COAs.

(d) Conduct a hasty analysis of enemy intentions with the intelligence analyst at the TAC CP.

b) The brigade $S 2$ evaluates changes in situation which should lead to convening the targeting and/or $\mathrm{A} 2 \mathrm{C} 2$ teams and recommends to the brigade $\mathrm{XO}$ or brigade $\mathrm{S} 3$ Air that the teams meet if necessary.

c) The brigade $\mathrm{S} 2$ section updates intelligence products, including: [ARTEP 71-3 MTP, Tasks 71-3-2003/2; 2006/2, 3]

(1) Revised intelligence estimate (may or may not be in written form).

(2) Situation template (SIT TEMP).

(3) Event template.

(4) Modified combined obstacle overlay (MCOO), in coordination with the brigade $\mathrm{S} 3$, brigade engineer section and NBC section.

(5) Intelligence portion of the DST.

(6) R\&S plan. 
(7) Intelligence database.

(8) Intelligence overlays and graphics.

(9) Enemy order of battle (OB).

(10) Brigade intelligence summaries (INTSUMs).

(11) Intelligence journal/log.

4) The brigade $\mathrm{S} 3$ operating in the TAC $\mathrm{CP}$ and the brigade $\mathrm{S} 3$ section evaluate operational information and update products: [ARTEP 71-3 MTP, Task 713-3003]

a) The $\mathrm{S} 3$ and $\mathrm{S} 3$ section evaluate operations information to ensure synchronization. [ARTEP 71-3 MTP, Task 71-3-3003/1, 3]

(1) Changes to guidance/direction and information.

(2) Information which confirms or refutes IPB information which may affect achieving the commander's intent.

(3) Desired brigade endstates with what is possible based on current brigade operations, maneuver plan, and trends.

(a) Maneuver units status.

(b) Fire support status.

(c) $\quad \mathrm{M} / \mathrm{CM} / \mathrm{S}$ support status.

(d) CSS status.

(e) Air defense status.

(f) Enemy situation and projected COA.

(4) Impact of changes to the brigade maneuver operations on subordinate units' maneuver operations.

(5) Changes to adjacent unit operations which might affect brigade operations. 
(6) Brigade OPSEC based on information received from division and internal brigade sources.

(7) Changes to $\mathrm{A} 2 \mathrm{C} 2$ plan.

(8) Changes to targeting products.

b) The brigade S3 section evaluates changes in situation which should lead to convening the targeting and/or $\mathrm{A} 2 \mathrm{C} 2$ teams and recommends to the brigade $\mathrm{XO}$ or brigade $\mathrm{S} 3 \mathrm{Air}$ that the teams meet if necessary.

c) The brigade $\mathrm{S} 3$, operating in the TAC CP, and the brigade $\mathrm{S} 3$ section, in coordination with the brigade $\mathrm{XO}$, update operations products. [ARTEP 71-3 MTP, Task 71-3-3003]

(1) Decision tools (e.g., the DST), in conjunction with the brigade $\mathrm{S} 2$, brigade $\mathrm{XO}$, and brigade commander.

(2) Synchronization and execution tools.

(3) The operations overlay for brigade, division, and adjacent units.

(4) Revised operations estimate (may or may not be in written form).

(5) Brigade status boards and charts which record combat power.

(6) Timeline of brigade operations.

(7) Current operations and intelligence map.

(8) NBC map.

(9) SIT TEMP overlay.

(10) Event template overlay.

(11) CSS overlay and support matrix.

(12) Plans map with overlay for future operations.

(13) FSE map with FS overlay and FSEM. 
(14) TACP map and CAS status with assistance of ALO and brigade TACP.

(15) Brigade operations journal/log.

(16) Assists brigade S2 and ABE in updating MCOO.

(17) Updates terrain management plan/overlay.

d) The brigade $\mathrm{S} 3 \mathrm{Air}$, as chief of the $\mathrm{A} 2 \mathrm{C} 2$ team, convenes the brigade $\mathrm{A} 2 \mathrm{C} 2$ team as required to ensure full coordination and integration of $\mathrm{A} 2 \mathrm{C} 2$ related information. [AN]

5) The brigade NBC section evaluates NBC information and updates products. [ARTEP 71-3 MTP, Tasks 71-3-4-0003, 0004, 0007, 0017]

a) The brigade NBC section evaluates information. [ARTEP 71-3 MTP, Tasks 71-3-4-0004, 0007]

(1) Changes to guidance/direction and information.

(2) Desired brigade endstates with what is possible based on current NBC situation and trends.

(3) Information which confirms or refutes IPB information relative to achieving the brigade commander's intent.

(4) Answers to intelligence queries about enemy NBC capabilities.

(5) Brigade decontamination capabilities.

(6) Adjustments to subordinate units operations which affect brigade NBC plans.

(7) Changes to the division's defensive NBC capabilities.

b) The brigade NBC section updates NBC products. [ARTEP 71-3 MTP, Tasks 3-4-0003; 0017]

(1) Revised NBC estimate (may or may not be in written form).

(2) MOPP analysis.

(3) Enemy NBC capabilities. 
(4) NBC equipment and supplies inventories.

(5) NBC overlays and graphics.

(6) Contaminated areas portion of $\mathrm{MCOO}$ (provided to S2).

6) The brigade $\mathrm{ABE}$ section evaluates $\mathrm{M} / \mathrm{CM} / \mathrm{S}$ information and updates products. [ARTEP 71-3 MTP, Tasks 71-3-8001, 8005]

a) The brigade $\mathrm{ABE}$ section evaluates information. [ARTEP 71-3 MTP, Task 71-3-8005]

(1) Changes to guidance/direction.

(2) Desired brigade endstates with what is possible based on current $\mathrm{M} / \mathrm{CM} / \mathrm{S}$ situation and trends.

(3) Progress on engineer tasks compared to timelines and required endstates.

(4) Information which confirms or refutes IPB information relative to achieving the brigade commander's intent.

(5) Answers to intelligence queries which alter initial enemy engineer capabilities and assessment.

(a) Changes to enemy mobility capabilities to determine impact on brigade countermobility and survivability plans.

(b) Changes to enemy countermobility actions or capabilities to determine impact on brigade mobility plan and task organization.

(c) Changes to enemy survivability measures or capabilities to determine impact on brigade mobility, direct fire, and indirect fire plans (through coordination with brigade $\mathrm{S} 3$ and $\mathrm{FSO}$ ).

(6) Changes in operations versus plans by subordinate units.

(7) Estimates of mobility based on differences in terrain from initial IPB or the effect of current weather on the terrain. 
(8) Adequacy of Class IV and V barrier material to support operations.

b) The brigade $\mathrm{ABE}$ determines if evaluated information would require convening the brigade targeting team and recommends to the brigade $\mathrm{XO}$ that the team meets, if necessary.

c) The brigade $\mathrm{ABE}$ section updates engineer products. [ARTEP 71-3 MTP, Task 71-3-8001]

(1) Revised engineer estimate (may or may not be in written form).

(2) Priorities and schedules for engineer effort.

(3) Survivability position and obstacle graphics.

(4) Engineer timelines.

(5) FASCAM employment plan in coordination with the brigade FSO.

(6) $\mathrm{MCOO}$ (ICW brigade $\mathrm{S} 2$, brigade $\mathrm{S} 3$ section and brigade CMLO).

7) The brigade AVLO evaluates aviation information and updates products. [ARTEP 71-3 MTP, Tasks 71-3-7001/3; ARTEP 1-100 MTP, Tasks 01-4$1311,1322]$

a) The brigade AVLO evaluates information. [ARTEP 71-3 MTP, Task 71-3-7001/3; ARTEP 1-100 MTP, Tasks 01-4-1311, 1322]

(1) Changes to guidance/direction and information.

(2) Desired brigade endstates with what is possible based on current aviation situation, trends, and allocated Army aviation support for brigade mission.

(3) Information which confirms or refutes IPB information relative to achieving the brigade commander's intent.

(4) Answers to intelligence queries which alter initial assessment of enemy air and air defense capabilities, objective area or engagement areas, and targets. 
(5) Information which impacts on Army aviation employment, and CAS operations.

(a) Adjustments to fire support plans which affect Army aviation employment plans.

(b) Changes to weather.

(c) Changes to enemy ADA capabilities.

(d) Changes to Army aviation employment under control of the division and the aviation brigade.

b) The brigade AVLO determines if evaluated information would require convening the brigade targeting team and recommends to the brigade $\mathrm{XO}$ that the team meets if necessary.

c) The brigade AVLO updates Army aviation products. [ARTEP 71-3 MTP, Task 71-3-7001/3; ARTEP 1-100 MTP, Tasks 01-4-1311, 1322]

(1) Revised aviation estimate (may or may not be in written form).

(2) Provides input to revision of ACAs.

(3) Army aviation plan.

(4) SEAD and indirect fire support plans (with brigade FSO).

8) The brigade FSCOORD, brigade FSO, brigade targeting officer and brigade FSE section, and NGLO evaluate fire support information and update products. [ARTEP 71-3 MTP, Tasks 71-3-9001, 9002]

a) The brigade FSCOORD, brigade FSO, brigade targeting officer, FSE section, and NGLO evaluate information to determine: [ARTEP 71-3 MTP, Task 71-3-9001/2, 3]

(1) Retargeting requirements. [AN]

(2) Changes to fire support guidance/direction to include AGM, observer plan, target acquisition and surveillance plan, and HPTL. 
(3) Current fire support capability to support brigade operations and implement the FS plan.

(4) Changes to the brigade fire support plan which require synchronization with TFs' fire support plans.

(5) Changes to FA task organization and locations, GS and GSR FA units, or NSF ships.

(6) Required actions based on new information that results from changes in enemy, terrain, or weather.

(7) Changes to FASCAM requirements in coordination with the brigade $\mathrm{ABE}$.

(8) Refinements to the fire support plan based on Army aviation and CAS requirements.

(9) Permissive and restrictive fire measures which may be required.

(10) Effects of indirect fires on enemy; impact on potential future operations.

(11) Availability of CAS and Army aviation; possible targets.

(12) Changes to ACAs.

(13) SEAD plan.

b) The brigade FSCOORD or FSO evaluates changes in situation which should lead to convening the targeting and/or $\mathrm{A} 2 \mathrm{C} 2$ teams and recommends to the brigade XO or brigade S3 Air that the teams meet if necessary.

c) The brigade FSCOORD, FSO, targeting officer, and FSE section update fire support products. [ARTEP 71-3 MTP, Task 71-3-9002]

(1) Revised fire support estimates (may or may not be in written form) to include:

(a) Status of firing elements.

(b) Displacement of artillery units throughout the AO. 
(c) Fire support plan.

(d) Observation plan.

(e) Dispositions, status, and activities of fire support assets under brigade control.

(2) FSEM.

(3) Target lists.

(4) HPT list.

(5) Fire support graphics.

(6) Priority targets.

(7) FSCMs to include ACAs.

(8) SEAD plan.

(9) AGM.

9) The brigade ALO, in conjunction with the Marine air officer, and the brigade TACP, evaluates CAS information and updates products. [FM 1015, p. 6-45]

a) The brigade ALO evaluates information in coordination with the Marine air officer (if assigned) and brigade TACP. [FM 101-5, p. 645]

(1) Changes to guidance/direction and information.

(2) Changes to ATO.

(3) Desired brigade endstates with what is possible based on current CAS situation, trends, and allocated CAS support from the ATO.

(4) Information which confirms or refutes IPB information which may affect achieving the brigade commander's intent. 
(5) Answers to intelligence queries which alter initial assessment of enemy air and air defense capabilities as well as CAS targets.

(6) Information which impacts on planned ACAs, CAS employment, and integration with Army aviation operations.

(7) Changes to weather.

(8) Changes to enemy ADA capabilities.

(9) Adjustments to the brigade plan and the Army aviation employment.

(10) Availability of CAS.

(11) Changes to SEAD plans.

b) The brigade ALO evaluates changes in situation which should lead to convening the targeting and/or $\mathrm{A} 2 \mathrm{C} 2$ teams and recommends to the brigade XO or brigade S3 Air that the teams meet if necessary.

c) The brigade ALO, in coordination with the Marine air officer, and brigade TACP, updates CAS products. [FM 6-20-40, Chap 2]

(1) Revised CAS estimate (may or may not be in written form).

(2) Target lists for preplanned CAS.

(3) Updates input for SEAD and indirect fire support plans (with brigade FSO).

10) The brigade ADALO evaluates air defense information and updates products. [ARTEP 71-3 MTP, Tasks 71-3-6001, 6002]

a) The brigade ADALO evaluates information. [ARTEP 71-3 MTP, Task 71-3-6001/1]

(1) Changes to guidance/direction and information.

(2) Desired brigade endstates with what is possible based on current ADA situation and trends.

(3) Information which confirms or refutes IPB and may affect achieving the brigade commander's intent. 
(4) Answers to intelligence queries about enemy air capabilities.

(5) Friendly air (CAS, Army aviation).

(6) Adjustments to subordinate unit operations.

(7) Changes to locations and $\mathrm{AD}$ coverage by divisional $\mathrm{AD}$ assets.

(8) Continually compares the HIMAD coverage with the position of the maneuver faces.

(9) Plots and maintains airspace control measures and effective times within the brigade $\mathrm{AO}:$ [AN]

(a) Restricted operation areas.

(b) Standard-use Army, USAF, USN, USMC aircraft flight routes.

(c) Weapons-free zones.

(d) Planned FA fire support (FS) fires.

(e) Air assault operations.

(f) Major aviation operations.

(10) Changes to the brigade air picture and division early warning statue. [AN]

(11) Coordinates with the brigade $\mathrm{XO}$ and brigade $\mathrm{S} 3$ to adjust air defense coverage by reallocating fire units. [AN]

b) The brigade ADALO evaluates changes in situation which should lead to convening the targeting and/or $\mathrm{A} 2 \mathrm{C} 2$ teams and recommends to the brigade XO or brigade S3 Air that the teams meet if necessary.

c) The brigade ADALO updates air defense products. [ARTEP 71-3 MTP, Task 71-3-6001/3; 6002/1d] 
(1) Revised air defense estimate (may or may not be in written form).

(2) Graphics of air defense high- to medium-altitude air defense (HIMAD) coverage and location of ADA battery assets.

(3) Graphics of friendly air corridors.

(4) Graphics of probable enemy air routes into the brigade area.

(5) Brigade weapons control and air defense warning status.

d) The brigade ADALO monitors air picture and early warning, alerting brigade elements as necessary.

11) The MP platoon leader evaluates information and updates products.

[ARTEP 71-3 MTP, Tasks 71-3-1201/1; 1202/1]

a) The MP platoon leader evaluates information. [ARTEP 71-3 MTP, Tasks 71-3-1201/1; 1202/1]

(1) Changes to guidance/direction and information.

(2) Desired endstates with what is possible based on current MP situation and trends.

(3) Answers to intelligence queries.

(4) Updated status of EPW demands and assessment of capability to continue the mission. [AN]

(5) Assessment to continue to support traffic control mission. [AN]

b) The MP platoon leader updates MP products. [ARTEP 71-3 MTP, Task 71-3-1201/1]

(1) Revised estimates (may or may not be in written form).

(2) Straggler/refugee control plans.

(3) Traffic control plans.

(4) EPW/CI plan. 
12) The brigade communications section evaluates information and updates brigade communication products. [ARTEP 71-3 MTP, Tasks 71-3-1102, $1103]$

a) The brigade communications section evaluates information. [ARTEP 71-3 MTP, Task 71-3-1103/3]

(1) Changes to guidance/direction and information.

(2) Desired brigade endstates with what is possible based on current communication situation and trends.

(3) Information which confirms or refutes IPB information relative to achieving the brigade commander's intent.

(4) Answers to intelligence queries about enemy electronic and communications capabilities.

(5) Adjustments to brigade CPs' locations, and subordinate unit operations and locations.

(6) Results of communications checks.

b) The brigade communications section updates communications products. [ARTEP 71-3 MTP, Task 71-3-1102/2,3]

(1) Revised signal estimates (may or may not be in written form).

(2) Communications network overlay, area coverage overlay, and dead space overlay.

(3) SOIs.

13) All brigade CSS officers (brigade $S 1$, brigade $S 4$, and brigade surgeon) and FSB commander evaluate CSS information and update products. [FM 6320, Chap 3, 6; ARTEP 71-3 MTP, Tasks 71-3-1002; 1003; 1004; 1008; $1009 ; 4001 ; 4002 ; 4003 ; 1301]$

a) The brigade CSS officers and sections evaluate information.

(1) Desired brigade endstate compared with current and projected personnel, maintenance, transportation, medical, and supply status. 
(a) Adequacy of CSS for the brigade main effort.

(b) Adequacy of CSS for the brigade secondary effort.

(2) Information which confirms or refutes EEFI and other IPB information.

(3) Answers to intelligence queries which alter initial assessment of enemy CSS capabilities.

(4) Adjustments to subordinate and supporting units' operations.

(5) Additional requirements for medical treatment and evacuation.

(6) Forecast of future sustainment levels based on known resupply of critical Class III and V requirements.

(7) Requirements for emergency resupply of units engaged in the close battle.

(8). Enemy activity.

(9) Status of the brigade LOCs.

b) The brigade CSS officers update CSS products.

(1) The brigade S1 section updates personnel information. [ARTEP 71-3 MTP, Tasks 71-3-1002/1, 3; 1003/1; 1004/2; $1008 ; 1009]$

(a) Revised personnel services estimate (may or may not be in written form).

(b) Personnel status of subordinate and supported units.

(c) Casualty feeder reports.

(d) Personnel priorities as directed by the brigade commander.

(e) Updates medical evacuation status on administration and logistics operation center (ALOC) map overlay. [AN] 
(2) The brigade S4 section updates logistical information. [ARTEP 71-3 MTP, Tasks 71-3-4001; 4002; 4003]

(a) Maintenance, supply, and transportation portions of revised logistics estimates (may or may not be in written form).

(b) Supply:

1 Percent fill of combat basic loads.

2 Configuration and location of immediate and emergency resupply (Class III and V) loads and push packages.

3 Adequacy of CSS supply assets.

$4 \quad$ Supply priorities as directed by the brigade commander.

$5 \quad$ Establishment and fill of stock piles and caches.

6 Capability for emergency resupply.

(c) Maintenance:

$1 \quad$ Number and type of equipment systems on hand and operational.

2 Systems non-mission capable and repairable.

3 Projections for repair and return of fighting vehicles and other essential equipment.

4 On-hand Class IX, authorized stockage list (ASL) and prescribed load list (PLL) stockage levels.

5 Maintenance priorities and guidelines as directed by the brigade commander.

6 Status of the combat vehicles in the maintenance float pool. [AN] 
(d) Transportation:

$1 \quad$ Schedules and priorities.

2 Status of supplies, equipment, and materials requiring transport.

$3 \quad$ Availability of ground transport assets.

$4 \quad$ Availability of air transport assets.

$5 \quad$ Status of logistics packages (LOGPACs) and refuel-on-the-move (ROM) capability.

6 Transportation recovery and back-haul plans.

7 MSR and ASR traffic and route conditions.

(3) The brigade surgeon updates medical information. [ARTEP 71-3 MTP, Task 71-3-1301/3]

(a) MEDEVAC capabilities.

(b) Class VIII stocks and resupply activities.

(c) Reinforcement and reconstitution of medical assets.

(d) Disposition and capability of brigade medical assets compared to tactical situation and plans.

(e) Medical priorities as directed by the brigade commander.

(4) The FSB commander and FSB support operations center update CSS information. [FM 63-20, Chap 3, 5, 6]

(a) Tasks to subordinate units to support the brigade's current and future operations.

(b) Tasks to subordinate units to support division and corps units operating in the brigade sector.

(c) Rear area security plans:

1 Threat (Levels I, II and III) from brigade S2. 
$2 \quad$ Base and base cluster defense plans integrated with brigade security plans.

3 Forces available for local security operations and reaction force.

$4 \quad$ Aviation and indirect fire support.

$\underline{5}$ Communications capabilities.

(d) Update/validate support matrix and CSS overlay.

14) The brigade $\mathrm{S} 5$ evaluates $\mathrm{CMO}$ information and updates products. [ARTEP 71-3 MTP, Task 71-3-5001]

a) The brigade $\mathrm{S} 5$ evaluates newly obtained information to determine:

(1) Changes to guidance and direction.

(2) The impact of the civilian population on the activities and mission of the brigade.

(3) The impact of enemy activity on the civilian population and resources/facilities.

(4) The impact of brigade combat activities on the civilian population.

(5) Desired brigade endstates compared with what is possible based on the CMO situation and trends.

b) The brigade $\mathrm{S} 5$ determines requirements and actions to assist in the acquisition of local resources, facilities, and support. [ARTEP 713 MTP, Task 71-3-5003]

c) The brigade S5 determines coordination requirements to mitigate local population interference with US military operations. [ARTEP 71-3 MTP, Task 71-3-5004]

d) The brigade S5 updates the CMO plan to provide guidance and direction for dealing with the civilian population on termination of operations. [AN] 
e) The brigade $\mathrm{S} 5$ section updates the $\mathrm{CMO}$ "running estimate" to support the brigade's operations (may or may not be in written form). [AN]

15) The HHC commander evaluates information to determine:

a) Capability to move, secure, and support the main and TAC CPs.

b) Requirements to move, secure, and support the main and TAC CPs.

16) The brigade CPs maintain status. [FM 71-3, pp. 3-20 - 3-25]

a) The brigade commander and brigade $\mathrm{S} 3$ in the command group/TAC CP maintains status and information to include: [FM 71-3, pp. 3-20 $-3-25]$

(1) Information which supports the commander's CCIR.

(2) Current and projected combat power status of subordinate units (e.g., green-amber-red).

(3) Current operations and intelligence map.

(a) Operations overlay (brigade, higher, and adjacent units).

(b) Intelligence overlay.

(c) SIT TEMP overlay.

(d) Event template overlay.

(e) Modified combined obstacle overlay.

(f) Fire support overlay.

(g) Decision support tools (e.g., DST).

(h) Synchronization and execution tools (e.g., matrixes, operations schedule (OPSCHED), checklists).

(4) Status of key communications links.

(5) Information required to serve as alternate main $\mathrm{CP}$. 
b) The brigade $\mathrm{XO}$ ensures that the main $\mathrm{CP}$ maintains status and information including: [FM 71-3, pp. 3-20 -3-25]

(1) Current operations and intelligence map.

(a) Operations overlay (brigade, higher, and adjacent units).

(b) Intelligence overlay.

(c) SIT TEMP overlay.

(d) Event template.

(e) $\mathrm{MCOO}$.

(f) NBC overlay.

(g) CSS overlay.

(h) Terrain management status.

(2) CSS overlays and information per brigade SOP.

(3) Intelligence information from division and higher headquarters.

(4) Disposition of collection assets.

(5) Information on external units conducting R\&S and security operations to prevent fratricide.

(6) Disposition and status of patrols and other R\&S and security forces.

(7) Status of operations so as to ensure compliance with stated mission timelines.

(8) Current and projected combat power status of subordinate units (e.g., green-amber-red).

(9) Status on task organization (into the brigade, within the brigade, and detachments out of the brigade).

(a) $\quad \mathrm{R} \& S$ and security forces. 
(b) TFs.

(c) Fire support systems.

(d) Engineer assets.

(e) GSR and other radar systems.

(f) ADA assets.

(10) Obstacle and survivability position construction and progress as compared to timelines.

(11) Utilization of engineer assets and materials as compared to timelines.

(12) Decision support tools (e.g., DST).

(13) Plans map (with overlays for future operations).

(14) Synchronization and execution tools (e.g., FSEM, OPSCHEDs, checklists).

(15) Journals/logs.

(16) Status of key communications links to include retransmission capability.

c) The brigade $\mathrm{S} 1$ or $\mathrm{S} 4$ at the brigade rear $\mathrm{CP}$ ensures that status is maintained and that information includes: [FM 71-3, pp. 3-20-325]

(1) Current operations and intelligence map.

(a) Operations overlay (brigade, higher, and adjacent units).

(b) Rear operations, security, and threat overlay.

(c) Intelligence overlay.

(d) SIT TEMP overlay.

(e) Event template overlay. 


\section{(f) $\mathrm{MCOO}$.}

(g) Fire support overlay.

(2) Decision support tools (e.g. DST).

(3) CSS SITMAP and overlays.
(a) LOCs, MSR and ASR.
(b) CSS locations, current and projected.
(c) Decontamination sites.

(4) Synchronization and execution tools (e.g., matrixes, OPSCHEDs, checklists).

(5) BSA security plans.

(6) CSS staff journal.

(7) Current and projected personnel and equipment status.

(a) Personnel strength.

(b) Operational equipment strength.

(c) Status of supplies.

(d) Casualties.

(e) Replacement personnel status/location.

(f) Damaged and non-mission-capable vehicles and equipment.

(8) Location and evacuation of EPW and their equipment.

(9) Location and evacuation of displaced persons.

(10) Status of key communications links.

(11) Identification and location of CSS units operating in brigade rear to include non-brigade units/elements. 
3. The brigade commander sees and visualizes the battlefield. [FM 100-5, p. 1-8]

a. The brigade commander updates his estimate according to his assessment of new information for purpose of more clearly seeing the battlefield, based on what he has observed and what he has been told. The updated estimate is based on information related to: [FM 101-5, Chap 1, 3, 4; Battle Command Techniques and Procedures, Chap 2, 4; Battle Command, pp. 10-14 and pp. 22-24; FM 34-130, Chap 1, 2, 4; FM 71-100, Chap 1, 3, App 4]

1) Friendly situation:

a) The present friendly situation based on his personal observation.

b) The present friendly situation based upon reports from:

(1) Division commanding general (CG), ADC-M, or G3.

(2) TF and other subordinate commanders.

(3) Brigade XO and brigade staff officers.

(4) Brigade S3, FSCOORD, and ALO.

c) The present friendly situation in terms of:

(1) The brigade commander's CCIR. [FM 101-5, pp. 4-47/48, 6-8/9]

(2) The brigade commander's need for information based on his visualization of current and future desired endstates.

(3) Anticipated flow of the battle (e.g., changes in battle phasing).

(4) Changes in location of brigade combat power.

(5) The impact of past activities on brigade units, particularly those fighting the close battle.

(6) The current operations of brigade units and their ability to modify or change their plans.

(7) Changes in combat power of brigade units relative to the accomplishment of current and future missions relative to: 
(a) Capabilities, strengths, and weaknesses of subordinate commanders.

(b) Capabilities, strengths, and weaknesses of subordinate units in terms of:

1 Weapon systems and equipment.

2 Personnel.

$3 \quad$ Supplies.

(8) Status of brigade reserve.

(9) Adjacent units.

(a) Situation:

1 Locations.

$2 \quad$ Activities

3 Combat power.

(b) Intentions and future plans.

(10) Status of training.

d) Time:

(1) The amount of time available and the amount of time required for:

(a) The brigade and its subordinate units to move or accomplish all assigned tasks.

(b) A planned event or required action to occur.

(2) The amount of time available and the amount of time required to plan and coordinate missions.

2) Mission:

a) The division and corps commander's intentions and concepts. 
b) The brigade mission, in terms of:

(1) Present concept of operation (maneuver and fires).

(2) Comparison of the present plan to the current situation.

3) Characteristics of the $\mathrm{AO}$ :

a) Weather:

(1) Visibility (fog and cloud cover).

(2) Light data.

(3) Precipitation.

(4) Temperature and humidity.

(5) Wind speed.

b) Terrain:

(1) The impact on the brigade units, the enemy's ability to maneuver, and the capability to apply combat power relating to the brigade mission.

(2) The effects of terrain in relation to:

(a) Observation and fire.

(b) Enemy and friendly obstacles.

(c) Obscurants (smoke, etc.).

(d) Electromagnetic measures.

c) Other pertinent factors:

(1) Safety and accident prevention.

(2) Civilian infrastructures that affect brigade operations, such as communications, or transportation systems, noncombatant locations, or activity.

4) Enemy situation: 
a) Dispositions.

b) Composition.

c) Strength, to include committed forces, reinforcements, artillery, air, EW, air defense, anti-tank, and NBC.

d) Capabilities.

e) Recent and present activities.

f) Peculiarities and weaknesses.

g) Enemy capabilities, apparent intentions, and possible COAs.

5) Combat power relevant to the enemy:

a) Maneuver units.

b) Supporting fires.

c) Leadership.

6) The battlefield operating systems (BOSs):

a) Intelligence.

(1) Is the $R \& S$ plan still valid?

(2) Are brigade collection assets still capable of providing required information about the enemy?

(3) Are PIR/IR still valid?

b) Maneuver.

(1) Does the brigade have the combat power to accomplish the mission in accordance with commander's intent?

(2) Does repositioning criteria and planned movement ensure that the mission can be achieved as designated?

(3) Are in-depth and on-order defensive positions prepared and do they meet the plan requirements and commander's intent? 
(4) Does the scheme of maneuver gain the positional advantages to achieve this intent and the designated endstate (including contingencies, branches and sequels)?

(5) Does the employment criteria and events for the use of reserves achieve the mission?

(6) Have reconnaissance and back-briefs confirmed the initial decision on where the brigade will accept decisive engagement?

(7) Is the main effort properly resourced to accomplish the mission?

c) Fire support.

(1) Have fire plans been adjusted based on new enemy and terrain information?

(2) Have fire plans and sector sketches been developed and modified to ensure that fires can be massed as designated by the commander?

(3) Have direct and indirect fire coordination measures been disseminated and confirmed by subordinate commanders?

(4) Have boundaries and other control measures been disseminated and confirmed by subordinate commanders?

(5) Are direct and indirect fire plans synchronized and integrated with all other combat multipliers, including physical tie-in between brigade units and units on the brigade's flanks?

(6) Do fire support priorities adequately weight the main effort?

(7) Do fires adequately support brigade $R \& S$ and counterreconnaissance forces?

(8) Are target acquisition assets in place or projected to be in place in time?

(9) Have target lists been updated by the brigade FSO and TF FSOs, and are they synchronized with changes to the brigade or TF scheme of maneuver? 
(10) Are fire support assets positioned and prepared to support the operation?

(11) Has responsibility been assigned for firing critical targets and are observers in position?

d) Command and control.

(1) Are key communications links within the brigade operational?

(2) Do current and projected locations of CPs provide for continuous command and control?

(3) Are CCIR being adequately answered?

(4) Are leaders and units motivated and capable of continued operations?

(5) Is the succession of command clear and ready to be implemented?

(6) Have risk factors been accurately identified and understood?

e) Mobility and survivability.

(1) Are obstacles in place or projected to be in place in time?

(2) Are obstacles observed and covered by fires and responsibility properly assigned?

(3) Do the obstacles shape the battlefield in accordance with commander's intent?

(4) Are plans for clearing lanes in friendly obstacles adequate to support brigade maneuver?

(5) Can the brigade conduct obstacle breaching as designated in the plan?

(6) Is there new information which might require changes to the point of penetration or breach? 
(7) Are there sufficient mobility assets (mine plows/blades) for the breach element?

(8) Are fighting and survivability positions adequate to ensure mission accomplishment?

(9) Is there adequate construction material and is it being delivered on time?

(10) Are there any modifications to FASCAM employment plans required by the engineer and FSCOORD/brigade FSO based on new information?

f) Air defense.

(1) Does ADA coverage ensure support of adjusted priorities, concept of the operation, and commander's intent?

(2) Have modifications to the weapons control status been made based on changes to the enemy air threat?

(3) Are air defense assets adequate and positioned and capable of protecting the brigade now and during mission execution?

g) Combat service support.

(1) Is there a need to adjust CSS priorities based on new information?

(2) Are supplies adequate to support the operation and are they being delivered to brigade unit's on time?

(3) Are prestocked cache positions secured?

(4) Are there sufficient transportation assets available and operational to support the operation?

(5) Does the status of personnel fill enable brigade units to accomplish their missions and tasks?

(6) Does the state of morale in the brigade support mission accomplishment? 
(7) Is the current and projected state of maintenance of equipment in the brigade adequate to support mission accomplishment?

(8) Are medical personnel, supplies, and equipment available and positioned to support the concept of the operation?

5. Brigade command posts manage and maintain command, control, and communications. [FM 71-123, pp. 1-43 - 1-46; FM 71-3, Chap 3; FM 101-5, Chap 5, 7, App B, Battle Command Techniques and Procedures, Chap 4]

a. The brigade $\mathrm{XO}$ manages the means of communicating information for all brigade CPs. [FM 71-3, Chap 3, 8; FM 71-123, Chap 1; FM 101-5, Chap 6, App B, L]

1) The brigade commander appoints an "information manager" from the staff (usually the brigade XO) to: [FM 101-5, 6-2, App B]

a) Facilitate the flow of information and communication of information from staff members and subordinate units.

b) Outline and monitor the performance and responsibilities of the staff in processing mission information, preparation status, and the commander's information requirements.

c) Ensure that the brigade CCIR is used to focus the staff as it manages all information.

d) Establish and enforce timelines.

2) The brigade commander or XO employs a "battle captain" to manage the operations of the main $\mathrm{CP}$ and the operations section when the $\mathrm{XO}$ is not available. [LL-CTC Bulletin No. 94-1, p. 5]

a) Coordinates and integrates staff activities for short periods.

b) Initiates staff action as directed by the commander, $\mathrm{XO}$, and $\mathrm{S} 3$.

c) Performs as brigade operations OIC.

3) The brigade XO directs staff meetings to: [ARTEP 71-3 MTP, Task 71-30001]

a) Ensure that each staff officer disseminates information which is relevant to the entire staff. 
b) Appraise completeness of information.

c) Identify information gaps and directs actions to fill them.

d) Initiate staff planning as part of an accelerated decision process.

e) Coordinate brigade targeting team's actions.

4) The brigade $X O$ ensures that LNOs provide information to the brigade commander and staff and to the HQ they represent. [FM 101-5, App L]

a) Responses to specific questions asked of LNO.

b) Unit locations, activities, capabilities, status, and intentions.

c) Coordination problems.

(1) Inability to reach/meet with specific people or staff positions.

(2) Receipt of information which invalidates or should change estimates and plans.

5) Radio net operators at all brigade CPs eavesdrop on lower and adjacent unit command and O\&I nets for information. [FN-NTC O/C]

6) The information manager at each brigade $\mathrm{CP}$ ensures that information on the situation is communicated between staff officers during shift changes. [FM 101-5, pp. 5-7 - 5-8; AN]

a) Enemy activities.

b) Status of subordinate units.

c) On-going staff actions which must be monitored, tracked, and completed.

d) Timelines and suspenses which must be met.

e) Planning for future missions.

7) The radio net operators at all brigade CPs communicate routine information per brigade SOP. [FM 101-5, p. 6-5]

\section{Outcome 3}


Tactically sound recommendations are developed and critical information is communicated by the heavy brigade staff and others within the brigade.

\section{Task Elements}

1. The brigade commander directs and leads subordinate forces. [FM 71-3, pp. 3-2 - 3-4; FM 101-5, pp. 1-4 - 1-5; Battle Command Techniques and Procedures, Chap 1, 2, 4; Battle Command, pp. 12-14, 34-37]

a. The brigade commander directs subordinate forces. [FM 71-3, p. 3-4; FM 101-5, pp. 1-4 - 1-5]

4) The brigade commander uses his staff to assist him in directing and monitoring the battlefield. [FM 101-5, Chap 1, 3; FM 71-3, Chap 1, 2, 3; Battle Command Techniques and Procedures, Chap 2, 4]

a) Directs the brigade $\mathrm{XO}$ to function as the brigade information manager.

b) Directs the brigade $\mathrm{XO}$ to act as supervisor of the brigade main $\mathrm{CP}$.

c) Specifies the composition of the TAC CP.

d) Provides the brigade $\mathrm{S3}$ guidance as to the manner in which the S3 will operate in conjunction with the commander to direct tactical operations.

e) Provides guidance to staff officers if they are to operate in a manner other than governed by SOP or usual practices.

f) Provides guidance to the brigade FSCOORD and the engineer battalion commander on how to operate in conjunction with the brigade commander to synchronize and direct the brigade battle.

g) Exchanges information with the brigade staff.

h) Takes steps to identify indicators of diminishing effectiveness of the brigade staff. [LL-CALL Newsletter No. 90-8, p. 25]

d. The brigade commander synchronizes tactical operations. [FM 101-5, Chap 1, 5, 6; Battle Command, pp. 42-45, Battle Command Techniques and Procedures, Chap 2, 4; FM 71-123, Chap 3, 4, 5, 6; ST 22-102, p. 4-10 - 4-12]

1) The brigade commander synchronizes tactical operations by using the following techniques to employ maneuver and fires at required times or 
places in order to accomplish the commander's intent and concept of operations.

d) Continuously monitoring and using decision support aids:

(1) Using the decision support template (DST) and synchronization matrix to aid timing of maneuver.

(2) Using the DST and synchronization matrix to order execution of fires, movement, and/or maneuver of subordinate elements.

(3) Using the DST to execute pre-planned tactical decisions to shift fires and/or forces.

(4) Using the FSEM to aid in the execution of fire support.

(5) Using the FSEM, DST, and synchronization matrix to aid in timing and target selection.

(6) Ordering resupply based on critical events reflected on the synchronization matrix.

2. Brigade command posts support synchronization by acquiring, evaluating, and communicating information. [FM 101-5, pp. 5-5 - 5-15]

c. The brigade $\mathrm{CPs}$ and staff communicate information necessary to conduct a synchronized brigade battle. [FM 6-20-40, p. 26; FM 6-20-50, App C; FM 71-3, Chap 3, 8, App H; FM 71-123, Chap 1; FM 101-5, Chap 5, 6, App A, B, L; ARTEP 1-100 MTP; ARTEP 3-117-40 MTP; ARTEP 71-3 MTP; FN-NTC]

1) All CPs and staff members disseminate information. [FM 71-3, pp. 3-20 3-25]

a) Timely recommendations to the commander on critical synchronization actions.

b) Critical information needed to:

(1) Coordinate brigade synchronization.

(2) Monitor the situation.

(3) Keep higher and adjacent headquarters informed. 
(4) Influence their areas of responsibility.

c) All staff officers remain alert for and ensure that critical information they receive is passed as soon as it is received to other staff officers who require the information.

2) The brigade $S 2$ and $S 2$ section assist the brigade commander to synchronize the battle by communicating the enemy's situation, evaluations of enemy capabilities, BDA, and analyses of PIR, IR, and routine information.

3) The brigade $\mathrm{S} 3$ in the TAC CP and $\mathrm{S} 3$ section assist the brigade commander to synchronize the battle by communicating: [ARTEP 71-3 MTP, Tasks 713-3003/2, 3; LL-CALL Bulletin No. 95-4, Chap 1]

a) Updated products, e.g.:

(1) WARNOs/FRAGOs.

(2) Coordinating instructions.

(3) Reports of the brigade situation.

(4) Evaluations of brigade status.

(5) DST information.

(6) Synchronization/execution matrix.

b) Information regarding requirements for use of terrain in the brigade area that will impact on current operations.

c) Information to adjacent units to coordinate: [ARTEP 71-3 MTP, Task $71-3-3003 / 3 c]$

(1) Zones of attack or axes of advance, objectives, bypass criteria, and actions on contact.

(2) Battle handover location, criteria, and time or event at which handover is complete.

(3) Checkpoints, coordination points, phase lines, and contact points.

(4) Direct and indirect fire plans, control measures, and restrictive fire lines. 
d) Mission information from other staff members (internal and external) which impacts on the concept of operation and synchronization of combat power.

(1) Disposition and location of brigade combat power.

(2) Brigade activities.

(3) Brigade capabilities.

(4) Status of personnel and equipment.

(5) Intentions of the brigade.

(6) Unit boundaries.

(7) Current situation.

e) Information on future operations.

f) Significant changes to enemy situation.

g) Answers to CCIR.

h) Recommendations to the brigade $\mathrm{S} 3$ (from $\mathrm{S} 3$ section), $\mathrm{XO}$, or commander concerning shifts of main effort and synchronization of combat power.

4) The brigade CMLO and NBC section assist the brigade commander to synchronize the battle by communicating: [FM 101-5, App A; ARTEP 3117-40 MTP, Tasks 3-4-0007; 0009; 0016]

a) The brigade NBC situation and analysis of CCIR, IR, and critical information.

b) The brigade CMLO coordinates with the division CMLO and supporting decontamination units to confirm and organize deliberate decontamination plans and preparations. [ARTEP 3-117-40 MTP, Task 3-4-0005]

c) Recommendations to the brigade $\mathrm{S} 3, \mathrm{XO}$, or commander concerning critical NBC related actions. 
5) The $\mathrm{ABE}$ section assists the brigade commander to synchronize the battle by communicating: [FM 101-5, App A; ARTEP 71-3 MTP, Task 71-3-8005/2]

a) The brigade engineer situation, analysis of CCIR, IR, and critical information to other brigade staff sections and external headquarters/staff officers.

b) Current status of M/CM/S operations. [ARTEP 71-3 MTP, Task 713-8005/1]

(1) Mobility operations. [ARTEP 71-3 MTP, Task 71-3-8005/1]

(a) Sufficient engineer obstacle (natural and man-made) breaching equipment has been allocated to and coordinated with maneuver forces to ensure maintaining brigade momentum.

(b) Smoke and suppressive fires have been planned at critical breaching sites.

(c) MSRs and ASRs can be maintained allowing the brigade to sustain combat operations.

(2) Countermobility operations: [ARTEP 71-3 MTP, Task 71-3$8002 / 2]$

(a) Obstacles support the brigade scheme of maneuver and subordinate unit tactical plans, reinforce engagement areas, and are tied in to other obstacles and terrain.

(b) All obstacles are covered by observation, direct fires, and indirect fires.

(c) Control measures are established.

(d) Existing obstacle locations and types are recorded, including lanes and passage points.

(e) Obstacle security is maintained by the unit responsible for the obstacle.

(f) Obstacles will not conflict or inhibit future mobility requirements for brigade operations. [AN] 
(g) Criteria for FASCAM employment is accurate and understood.

(3) Current status of types and locations of required survivability positions: [ARTEP 71-3 MTP, Task 71-3-8002]

(a) Position construction is based on priority (including positions for security force units).

(b) Locations are jointly sited by:

1 Maneuver commanders (responsible for site selection).

$2 \quad$ Engineer leader (responsible for providing equipment, material, expertise, and for preparation to standard of vehicle positions).

c) The $\mathrm{ABE}$ section coordinates with brigade units, $\mathrm{TF}$ engineers, and engineer battalion (as applicable) to ensure that $\mathrm{M} / \mathrm{CM} / \mathrm{S}$ operations are in accordance with the brigade order. [ARTEP 71-3 MTP, Task $71-3-8005 / 1]$

d) The brigade engineer section communicates with adjacent units and the assistant division engineer. [ARTEP 71-3 MTP, Task 71-3$8005 / 1]$

(1) To exchange information on obstacle status, type, and location.

(2) To ensure that division-directed obstacle requirements are satisfied.

(3) To exchange information on mobility plans (brigade, division).

e) Recommendations to the brigade $\mathrm{S} 3, \mathrm{XO}$, or commander concerning critical mobility, countermobility, and survivability actions.

6) The AVLO assists the brigade commander to synchronize the battle by communicating: [ARTEP 71-3 MTP, Task 71-3-7001/3; ARTEP 1-100 MTP, Tasks 01-4-1311, 1322]

a) The Army aviation situation to other brigade staff sections and external headquarters/staff officers. 
b) Time on station for attack helicopters for specific missions.

c) Recommendations to the brigade $\mathrm{S} 3, \mathrm{XO}$, or commander concerning employment of Army aviation assets.

7) The brigade FSCOORD, FSO, targeting officer, FSE, and NGLO assist the brigade commander to synchronize the battle by communicating: [FM 1015, App A; ARTEP 71-3 MTP, Task 71-3-9002/2, 3; FM 71-3, pp. 7-13 - 714; FM 6-20-40, p. A-26; FM 6-20-50, pp. C-25 - C-28]

a) Brigade fire support situation and analysis of CCIR, IR, and routine information.

b) Brigade FSO and FSE section communicate with adjacent and higher FSEs and DS FA battalion headquarters (and NGLO communicates with DS and GS NSF ships) to: [ARTEP 71-3 MTP, Task 71-3-9002/2]

(1) Ensure that planned brigade fire support will not interfere with other fire support systems, will not disrupt adjacent unit operations, and will not jeopardize troop safety.

(2) Ensure that fire support information and products (target lists, FSEM, CAS requests, and ATO) are exchanged and refined.

c) The brigade FSO and FSE section communicate with the brigade S3 and TF FSOs to verify: [ARTEP 71-3 MTP, Task 71-3-3001/2]

(1) Control measures delineating mutual boundaries.

(a) Directed by division.

(b) Internal boundaries (TFs, scouts, security forces).

(2) Air space control measures.

(3) FSCMs.

(4) Signals and conditions under which restrictive measures will be emplaced or lifted.

(5) Locations. 
d) Intelligence information received through artillery or naval channels.

e) The targeting team communicates results of attacks on targets, assessments of results, and recommendations of changes to the fire support plan and attack means.

f) Recommendations to the brigade $\mathrm{S} 3, \mathrm{XO}$, or commander concerning critical fire support matters.

8) The ALO, Marine air officer, and brigade TACP assist the brigade commander to synchronize the battle by communicating: [FM 101-5, App A]

a) CAS situation and routine information to other brigade staff sections and external headquarters/staff officers.

b) Time on station for CAS sorties in support of specific targets.

c) Intelligence information received through air operations channels.

d) Recommendations to the brigade $\mathrm{S} 3$, XO, or commander concerning CAS employment.

9) The Marine air officer and NGLO assist the brigade commander to synchronize the battle by communicating naval air and NSF situation to brigade staff sections and external (to include maritime) headquarters/staff officers and make recommendations to the brigade $\mathrm{S} 3, \mathrm{XO}$, or commander as necessary concerning naval air support and NSF. [FM 101-5, App A; ARTEP 71-3 MTP, Task 71-3-9002/2, 3]

10) The $\mathrm{ADO}$ assists the brigade commander to synchronize the battle by communicating: [FM 101-5, App A; ARTEP 71-3 MTP, Task 71-3-6001/1, 6002]

a) Changes in HIMAD coverage to the brigade $\mathrm{XO}$ and brigade $\mathrm{S} 3$.

b) The brigade air picture, ADA situation and analysis of CCIR, IR, and routine information.

c) The $\mathrm{ADO}$ communicates with adjacent units and ADA battalion headquarters. [ARTEP 71-3 MTP, Task 71-3-6002/2, 3] 
(1) To confirm scheme of maneuver, identification, friend or foe (IFF) codes, and AD weapons area coverage.

(2) To confirm weapons control status with higher and adjacent units.

(3) To confirm events and reporting systems which will cause the brigade to upgrade weapons control status.

d) Warning of imminent enemy air attacks (early warning).

e) Updates the brigade S2 and air defense battalion S2 on: [AN]

(1) Type of aircraft engaged.

(a) Location.

(b) Time.

(2) Type of damage inflicted.

(3) Routes, tactics used by enemy air.

f) Recommendations to the brigade $\mathrm{S} 3, \mathrm{XO}$, or commander concerning air defense matters.

11) The MP platoon leader assists the brigade commander to synchronize the battle by communicating brigade MP situation and critical information to other brigade staff sections and external headquarters and makes recommendations to the brigade $\mathrm{S} 3, \mathrm{XO}$, or commander as necessary about traffic control, handling of EPW, and other assigned missions. [FM 101-5, App A; ARTEP 71-3 MTP, Task 71-3-1201/1]

12) The Bde $\mathrm{SO}$ and section assists the brigade commander to synchronize the battle by communicating: [FM 101-5, App A; ARTEP 71-3 MTP, Task 713-1102/4]

a) Brigade communications situation and critical information to other brigade staff sections and external headquarters.

b) The brigade communications section communicates with adjacent units and signal battalion headquarters. [ARTEP 71-3 MTP, Task $71-3-1102 / 4]$ 
(1) To confirm allocation and locations of signal assets and capabilities.

(2) To acquire signal equipment to supplement brigade CPs and subordinate units which require special communications equipment.

c) Recommendations to the brigade S3, XO, or commander concerning critical communication actions.

13) The brigade rear $\mathrm{CP}$ ( $\mathrm{S} 1$ and $\mathrm{S} 4$ officers and sections), FSB commander, and support operations officer assist the brigade commander to synchronize the battle by communicating: [FM 101-5, App A]

a) Critical Class III, IV, and V supplies status that will affect the current battle.

b) Brigade CSS staff communicates with brigade staff and brigade units:

(1) To identify additional requests for support.

(a) Transportation assets.

(b) Medical augmentation.

(c) Maintenance support for vehicles and weapons systems and for recovery of damaged vehicles or return of repaired vehicles.

(2) To coordinate the transportation of supplies and cargo to brigade units.

(3) To coordinate routine, emergency, and critical resupply operations (e.g., delivery times, types and quantities of supplies required).

(4) For receiving and processing replacements.

(5) To track evacuation of personnel and casualties.

(6) To process awards, decorations, promotions, and legal actions. 
(7) For security and protection of CSS units operating forward.

c) Inform the brigade $\mathrm{S} 3, \mathrm{XO}$, or commander of serious capability losses and provide recommendations for provision of CSS. [AN]

d) Inform higher headquarters (G4, WSRO officer) when combat personnel or equipment losses reach a point where assistance is needed. [AN]

14) The brigade $\mathrm{S} 5$ assists the brigade commander to synchronize the battle by communicating: [FM 101-5, App A; ARTEP 71-3 MTP, Task 71-3-5001/2]

a) CMO situation and analysis of CCIR, IR, and routine information.

b) Civilian activity impact on LOC congestion that will affect synchronization.

c) Recommendations to the brigade S3, XO, or commander concerning operational actions based on $\mathrm{CMO}$ situation.

3. The brigade commander sees and visualizes the battlefield. [FM 100-5, p. 1-8]

d. The brigade commander informs the division commander of the results of his brigade assessment. [AN]

1) The brigade commander's projection of the current battle indicates that the division commander's intent cannot be met.

2) The brigade must receive additional combat power to achieve the division commander's intent.

3) The brigade can accomplish the mission.

\section{Outcome 4}

Sound (feasible, suitable, acceptable) decisions are made by the brigade commander and others within the heavy brigade.

\section{Task Elements}

1. The brigade commander directs and leads subordinate forces. [FM 71-3, pp. 3-2 - 3-4; FM 101-5, pp. 1-4 - 1-5; Battle Command Techniques and Procedures, Chap 1, 2, 4; Battle Command, pp. 12-14, 34-37] 
d. The brigade commander synchronizes tactical operations. [FM 101-5, Chap 1, 5, 6; Battle Command, pp. 42-45, Battle Command Techniques and Procedures, Chap 2, 4; FM 71-123, Chap 3, 4, 5, 6; ST 22-102, p. 4-10 - 4-12]

1) The brigade commander synchronizes tactical operations by using the following techniques to employ maneuver and fires at required times or places in order to accomplish the commander's intent and concept of operations.

a) Maintaining a current revised estimate of the situation.

3. The brigade commander sees and visualizes the battlefield. [FM 100-5, p. 1-8]

a. The brigade commander updates his estimate according to his assessment of new information for purpose of more clearly seeing the battlefield, based on what he has observed and what he has been told. The updated estimate is based on information related to: [FM 101-5, Chap 1, 3, 4; Battle Command Techniques and Procedures, Chap 2, 4; Battle Command, pp. 10-14 and pp. 22-24; FM 34-130, Chap 1, 2, 4; FM 71-100, Chap 1, 3, App 4]

1) Friendly situation:

a) The present friendly situation based on his personal observation.

b) The present friendly situation based upon reports from:

(1) Division commanding general (CG), ADC-M, or G3.

(2) TF and other subordinate commanders.

(3) Brigade $\mathrm{XO}$ and brigade staff officers.

(4) Brigade S3, FSCOORD, and ALO.

c) The present friendly situation in terms of:

(1) The brigade commander's CCIR. [FM 101-5, pp. 4-47/48, 6-8/9]

(2) The brigade commander's need for information based on his visualization of current and future desired endstates.

(3) Anticipated flow of the battle (e.g., changes in battle phasing). 
(4) Changes in location of brigade combat power.

(5) The impact of past activities on brigade units, particularly those fighting the close battle.

(6) The current operations of brigade units and their ability to modify or change their plans.

(7) Changes in combat power of brigade units relative to the accomplishment of current and future missions relative to:

(a) Capabilities, strengths, and weaknesses of subordinate commanders.

(b) Capabilities, strengths, and weaknesses of subordinate units in terms of:

1 Weapon systems and equipment.

2 Personnel.

$3 \quad$ Supplies.

(8) Status of brigade reserve.

(9) Adjacent units.

(a) Situation:

1 Locations.

$2 \quad$ Activities

3 Combat power.

(b) Intentions and future plans.

(10) Status of training.

d) Time:

(1) The amount of time available and the amount of time required for:

(a) The brigade and its subordinate units to move or accomplish all assigned tasks. 
(b) A planned event or required action to occur.

(2) The amount of time available and the amount of time required to plan and coordinate missions.

2) Mission:

a) The division and corps commander's intentions and concepts.

b) The brigade mission, in terms of:

(1) Present concept of operation (maneuver and fires).

(2) Comparison of the present plan to the current situation.

3) Characteristics of the $\mathrm{AO}$ :

a) Weather:

(1) Visibility (fog and cloud cover).

(2) Light data.

(3) Precipitation.

(4) Temperature and humidity.

(5) Wind speed.

b) Terrain:

(1) The impact on the brigade units, the enemy's ability to maneuver, and the capability to apply combat power relating to the brigade mission.

(2) The effects of terrain in relation to:

(a) Observation and fire.

(b) Enemy and friendly obstacles.

(c) Obscurants (smoke, etc.).

(d) Electromagnetic measures. 
c) Other pertinent factors:

(1) Safety and accident prevention.

(2) Civilian infrastructures that affect brigade operations, such as communications, or transportation systems, noncombatant locations, or activity.

4) Enemy situation:

a) Dispositions.

b) Composition.

c) Strength, to include committed forces, reinforcements, artillery, air, $\mathrm{EW}$, air defense, anti-tank, and NBC.

d) Capabilities.

e) Recent and present activities.

f) Peculiarities and weaknesses.

g) Enemy capabilities, apparent intentions, and possible COAs.

5) Combat power relevant to the enemy:

a) Maneuver units.

b) Supporting fires.

c) Leadership.

b. The brigade commander projects current battle endstates now necessary to achieve his intent based on his evaluation of the current plan and brigade situation by considering factors associated with each BOS: [FM 101-5, Chap 4; FM 34-130, Chap 1, 2, 3; Battle Command Techniques and Procedures, Chap 2, 4; Battle Command, pp. 38-45; FM 34-8, Chap 1, 2, App C]

1) Intelligence:

a) Disposition of enemy forces, to include follow-on, reserve, or uncommitted forces. 
b) Composition and combat strength of enemy forces.

c) "Will to fight" of enemy forces.

d) Enemy's capabilities and possible COAs.

e) Enemy's capability to continue operations at the conclusion of the current battle.

f) Enemy's limitations and exploitable weaknesses.

g) Terrain conditions and considerations.

h) Weather conditions.

i) Capability of brigade reconnaissance elements to provide continuous R\&S for the force.

j) Availability, position, and mission of brigade, division or higher headquarters intelligence collection assets.

2) Maneuver:

a) Combat strength of the brigade's maneuver forces.

b) Location of brigade maneuver forces including follow-on, reserve, or uncommitted units.

c) The terrain responsibility and orientation of subordinate units.

d) Brigade task organization.

e) Force ratios and combat power in comparison to the enemy.

f) Capabilities of division elements and adjacent units.

3) Command and control:

a) Status of unit morale, cohesion, and capability to continue operations.

b) Status and effectiveness of the brigade command, control, and communications (C3) system. 
c) Status of brigade C2 capability to achieve and maintain initiative, agility, flexibility, and depth.

d) Status of synchronization and "progress" of current battle.

e) Adequacy of CCIR.

4) Fire support:

a) Strength, availability, and positions of all fire support assets:

(1) Artillery.

(2) Mortars.

(3) CAS, TACP.

(4) EW.

(5) NSFs.

(6) FIST, FSO, COLTs, SALTs.

(7) Radars.

b) FS units' capabilities to support brigade operations.

c) Priorities.

5) Air defense:

a) Brigade friendly air status.

b) Enemy air threat.

c) Strength, availability, and position of $\mathrm{AD}$ assets.

d) Status of the air defense C2 system.

e) Status of early warning system.

f) Priorities.

6) Mobility/countermobility/survivability: 
a) Engineer assets and CL IV/V supplies available to support $\mathrm{M} / \mathrm{MCM} / \mathrm{S}$ operations.

b) Task organization of engineer assets as compared to maneuver units.

c) Engineer unit capabilities, positions, and missions.

d) Location and status of task force organic M/CM/S equipment.

e) Capability and disposition of supporting NBC reconnaissance, smoke and decontamination units.

7) Combat service support:

a) Operational capability of the subordinate units' CSS system.

b) Availability of all classes of supply.

c) Operational and support capability of the FSB.

d) Capability of the medical support system.

c. The brigade commander anticipates requirements and actions based on his projection of the outcome of the current battle. [FM 101-5, Chap 1, 2, 4, 5, App C, D, E; Battle Command Techniques and Procedures, Chap 2, 4]

1) The brigade commander bases anticipated future requirements and actions on:

a) The brigade on order or be prepared mission(s).

b) His understanding of the higher commander's intent.

c) His projection of the outcome of the current battle.

d) His assessment of what the enemy will do at the end of the current battle.

e) His assessment of risk.

f) Subordinate units' capabilities.

g) Existing brigade contingency plans or war gamed branches and sequels to the current operation. 
2) The brigade commander develops information to assist him in determining future requirements and actions by:

a) Communicating with his higher headquarters to ensure that he knows and understands future division plans.

b) Soliciting input from the senior leadership within the brigade, e.g., brigade $\mathrm{XO}$ and $\mathrm{S} 3$, subordinate $\mathrm{TF}$, and battalion commanders.

3) The brigade commander defines requirements and actions based on BOS factors:

a) Intelligence BOS:

(1) Adjustments necessary to the PIR.

(2) Additional intelligence collection assets needed.

(3) Mission changes required for intelligence collection assets.

b) Maneuver BOS:

(1) Missions appropriate for all maneuver forces.

(2) Repositioning or reorientation required for maneuver units at the end of the current battle.

(3) Mission changes required for the brigade maneuver reserve.

(4) Direction or guidance given to subordinate commanders to reduce ambiguity for future operations.

(5) Changes necessary in the maneuver scheme to shape the current battle so as to be better postured for the on order mission.

(6) Impact of adjacent unit dispositions, strength, activities, capabilities, and missions on projected brigade operations.

(7) Additional maneuver combat power required.

c) Fire support BOS:

(1) Changes required to the fire support priorities and plan. 
(2) Additional fire support assets needed.

(3) Requirements to reposition fire support assets.

(4) Adjacent units' capabilities to support.

(5) Retargeting of HPT.

d) Command and control BOS:

(1) Required adjustments in brigade C2.

(2) Additional communications capability required.

(3) Impact of time on future actions.

(4) Adjustments necessary to C2 graphics.

(5) Adjustments necessary to the DST and other operational matrices.

(6) Redefined CCIR.

(7) Redefined risk assessment.

e) Air defense BOS:

(1) Adjustments to the $\mathrm{AD}$ priorities.

(2) Repositioning requirements for $\mathrm{AD}$ assets.

(3) Additional $\mathrm{AD}$ assets needed.

f) Mobility and survivability BOS:

(1) Additional $\mathrm{M} / \mathrm{CM} / \mathrm{S}$ assets required.

(2) Adjustments to the mobility tasks required.

(3) Countermobility tasks required.

(4) Survivability tasks required.

(5) MOPP status. 
(6) Decontamination requirement.

(7) Force protection requirements.

g) Combat service support BOS:

(1) Additional CSS units required.

(2) Adjustments necessary in the positioning of logistics support units and nodes.

(3) Additional supplies by class of supply required.

(4) Additional personnel needed by MOS.

(5) Additional equipment, vehicles, and weapons systems required.

e. The brigade commander decides whether the current plan needs to be changed. [FM 101-5, Chap 4, 7, App H, J; Battle Command Techniques and Procedures, Chap 2, $4,5]$

1) The brigade commander uses his staff to test the validity of his ideas. [LLCall Newsletter, No 90-8, p. 24]

2) The brigade commander decides the current plan will achieve his intent and the brigade mission and continues to direct brigade battle execution. [FM 101-5, p. 4-48]

3) The brigade commander decides the plan must be modified. [FM 101-5, p. 4-48]

a) The brigade commander bases his decision to initiate a FRAGO by considering: (See Task 4.b.11 for description of how to develop and issue this FRAGO) [FM 101-5, pp. 1-14 - 1-16]

(1) Whether COAs previously developed can be modified and developed as the new plan.

(2) Time available to develop, coordinate, and implement a new plan.

(3) Subordinate units' time to complete new preparation requirements under the new plan and task organization. 
(4) The brigade staff's ability to continue to monitor and direct current brigade activities while meeting new planning requirements.

(5) Whether the FS assets can support the COA considered.

(6) Reevaluating the present brigade $\mathrm{M} / \mathrm{CM} / \mathrm{S}$ situation and determining what can be done to support the COA considered.

(7) CSS units' capabilities to support the brigade.

(8) Whether the brigade can be supported by available $\mathrm{AD}$ assets.

(9) Preplanned CAS availability and joint air attack team (JAAT) requirements for the contemplated modification.

(10) Whether a new DST and FSEM can be developed to incorporate the modification.

(11) Whether the brigade's communication system can support the modified brigade COA.

(12) Time required to plan and prepare for new mission based on current mission timelines and staff's abilities.

(13) Ability of the brigade to respond to the new situation based on current tactical posture and situation.

(a) Maneuver forces available to respond without impacting brigade ability to perform the current mission.

(b) Availability of CS, CSS, and supplies to support the new situation without impacting on support necessary for the current mission.

(14) Whether staff has time to plan and coordinate new missions.

(15) Impact of diverting key staff members from synchronizing the current mission to planning for a new mission. 
b) The brigade commander determines how to modify the military decision-making process (MDMP) based on complexity, potential probable confusion on the battlefield, and time available. [FM 1015, Chap 4]

(1) The brigade commander determines staff availability, the magnitude of change to the plan, and the amount of time available before execution.

(2) The brigade commander decides where to conduct the decision-making process (DMP) and actions required to produce and disseminate the FRAGO.

4. The brigade commander directs changes to the operation or plan. [FM 71-123, pp. 138; FM 101-5, pp. 1-4 - 1-15]

b. The brigade commander employs the MDMP in a time-constrained environment. (Time available may be as brief as seconds or minutes.) [FM 71-3, App I; FM 1015, pp. 4-41 - 4-60]

1) When planning changes to current orders or planning for a new mission during the execution phase of the current battle, the brigade commander must:

a) Consider use of existing decision products and synchronization tools in use during the current mission as reference points from which modifications are made. Products and tools include:

(1) Weather analysis.

(2) Terrain analysis.

(3) Enemy order of battle and updated IPB products.

(4) Current revised staff estimates.

(a) Brigade capabilities.

(b) Constraints.

(5) PIR, EEFI, and FFIR requested by the commander.

(6) Decision support tools (e.g., DST). 
(7) Synchronization and execution tools (e.g., FSEM, OPSCHEDs, checklists).

b) The brigade commander and staff must simultaneously monitor, plan, and direct all aspects of brigade operations (e.g., execution of the current mission; development of changes to the current plan).

c) Anticipate the outcome of the current fight and begin considering future requirements and actions.

d) Recognize similarities and/or differences between the initial plan and new requirements.

e) Assess friendly force posture, enemy probable actions and postures, and battlespace.

f) Modify existing branches and sequels to meet new requirements.

g) Future requirements for deep, close, and rear battle areas.

h) Key leader and staff availability and location.

i) The amount of time available for planning and rehearsal.

j) Extent of reconnaissance effort necessary to obtain critical information.

2) The brigade commander conducts a quick mission analysis by:

a) Analyzing the division and corps commander's intents.

b) Determining the brigade's stated mission and required endstate to accomplish that mission.

c) Comparing the desired endstate for the brigade to the enemy situation.

d) Deciding whether the brigade has the assets and resources to execute the new mission.

e) Identifying time critical tasks (shifting units, resupply, and requesting additional resources).

f) Conducting a map reconnaissance or if possible a brief physical reconnaissance (by air). 
g) Establishing a time schedule using backward planning.

h) Deciding the brigade task organization.

3) The brigade commander completes an update of his estimate.

a) Mission:

(1) Identifies specified and implied tasks which his brigade must accomplish.

(2) Appraises whether the who, what, where, when, and why of the "new" brigade plan support the corps and division commander's intents.

b) Enemy:

(1) Determines the enemy's strength, location, disposition, activity, equipment, capability, and intentions.

(2) Identifies which limited number of enemy COA the brigade must defeat.

c) Terrain and weather: information on observation and fields of fire, cover and concealment, obstacles, key terrain, avenues of approach (OCOKA), vegetation, soil type, hydrology conditions, visibility, climatic conditions, and visibility.

d) Troops: the commander determines the status of the brigade's and TFs' combat power in terms of capability relative to the mission by considering:

(1) Capabilities, strengths, and weaknesses of subordinate commanders and units.

(2) Weapon systems and equipment.

(3) Disposition.

(4) Supplies.

(5) Troop rest and morale. 
e) Time: the commander determines the time available for planning, preparing, and executing the operation for both enemy and friendly forces.

4) The brigade commander quickly develops a revised concept and/or COA which is based on:

a) His mission analysis.

b) His updated commanders analysis.

c) BOS specific information from selected staff members.

d) Information available in products developed during the initial mission DMP.

5) The brigade commander describes his revised concept and COA to his staff. [FM 101-5, pp. 4-48, 4-49]

a) The commander develops and explicitly expresses:

(1) Brigade commander's intent and desired endstate.

(2) Concept of operations.

(a) Major components of maneuver.

(b) Integration of combat multipliers.

(c) Critical points and center of gravity.

(d) Sketch of the initial concept of the operation. [LLCALL Newsletter No. 93-3, p. 9]

(3) Enemy $\mathrm{COA}(\mathrm{s})$ to be considered.

(4) CCIR.

(5) Limitations.

(6) Risks.

b) If time is available, the brigade staff:

(1) Develops details on COA provided by the commander. 
(2) Develops branches and sequels to the selected COA which adhere to the commander's guidance.

6) The brigade commander performs a brief, but comprehensive, analysis of selected COA. The commander performs the analysis by himself or with staff assistance. [FM 71-3, App I; FM 101-5, pp. 4-51]

a) Suitability factors:

(1) New concept accomplishes the brigade mission.

(2) New concept meets the division and corps commander's intents.

(3) The plan accomplishes his intent for the brigade's endstate relative to the intended endstate for the enemy.

(4) The brigade can maintain the initiative by forcing the enemy to react to the new brigade COA.

b) Feasibility factors:

(1) There is time available to execute the plan(s) as designed.

(a) Duration of events.

(b) Time and distance factors for maneuver and fires.

(2) There is sufficient ground and air space to accomplish the plan(s) as designed.

(a) Roads and terrain support the plan.

(b) Depth of action.

(3) The brigade has the means to execute the plan(s) as designed.

(a) Brigade combat power versus the enemy (force ratios).

(b) Special equipment and personnel to accomplish the mission (e.g., bridging equipment, mine clearing, Army aviation, CAS).

(4) Impact on on-going actions. 
(5) Impact on subordinate units and combat multipliers.

(6) Requirements to alter task organization.

c) Acceptability: can be conducted within acceptable costs/risks.

7) The brigade commander quickly compares COA (if more than one).

8) The brigade commander selects a COA and:

a) Announces his decision to key brigade staff members.

b) Ensures that he or a staff member documents the selected COA for use in preparing and issuing orders.

9) The brigade commander conducts mission risk assessment to ensure that conditions most likely to cause mission failure and accidents (including fratricide) have been mitigated.

a) Brigade units have not been tasked beyond their capabilities.

b) Procedural and positive risk-reduction control measures have been implemented, for example:

(1) Situation is understood by brigade members.

(2) Procedures governing destruction or engagement of targets are clear.

(3) Target identification and responsibilities are clear.

(4) SOPs are consistent with doctrine and are adhered to.

(5) Control measures are flexible enough to not interfere with operations and are firm enough to prevent fratricide, civilian casualties, and collateral damage.

(6) Doctrinally correct terminology is applied to all control measures (e.g., fire support coordination lines [FSCLs], and restrictive fire lines [RFLs]).

(7) ROE are clear.

\section{Outcome 5}


Affected units and personnel receive relevant direction, change, and refinements to the plan in time to perform troop leading procedures and execute coordinated and synchronized actions.

\section{Task Elements}

1. The brigade commander directs and leads subordinate forces. [FM 71-3, pp. 3-2 - 3-4; FM 101-5, pp. 1-4 - 1-5; Battle Command Techniques and Procedures, Chap 1, 2, 4; Battle Command, pp. 12-14, 34-37]

a. The brigade commander directs subordinate forces. [FM 71-3, p. 3-4; FM 101-5, pp. 1-4 - 1-5]

1) The brigade commander takes actions to ensure that subordinate leaders have a clear understanding of his intent and concept. Actions include: [FM 101-5, Chap 1, 4; Battle Command Techniques and Procedures, Chap 2, 4; Battle Command, pp. 10-32]

a) Meeting with subordinate commanders and leaders to receive information and issue directions. [FM 101-5, pp. 4-53, 4-59 - 4-60]

b) Listening to cross-talk on brigade command nets.

c) Evaluating reports from subordinates for understanding of his intent, concept of operations, and their missions.

d) Confirmation briefs and backbriefs by subordinate commanders. [AN]

e) Rehearsals. [AN]

2) The brigade commander positions himself where he can best direct and lead, observe the battlefield, and synchronize operations: [FM 71-3, pp. 3-2 - 34; FM 101-5, Chap 1, 2, 3; FM 7-20; Battle Command Techniques and Procedures, Chap 2, 3, 4; ST 22-102, pp. 4-14 - 4-15]

a) Ensures that people and equipment needed for him to move about the battlefield are organized and prepared to move on short notice.

b) Selects positions that enable communications with:

(1) Division commander and assistant division commander for maneuver (ADC-M).

(2) Brigade subordinate commanders. 


\section{(3) Main CP.}

(4) Adjacent units (main CP may be given this task).

c) Selects positions that provide protection for the brigade commander and the tactical (TAC) CP against direct and indirect fires.

d) Selects positions that minimize chance that he will become decisively engaged and lose freedom of movement.

e) Selects locations at decisive points in the battle using as criteria:

(1) Proximity to the main effort.

(2) Event or location where the brigade can exploit enemy weaknesses.

(3) Proximity to places that he anticipates his personal intervention, at a precise time, will be necessary to synchronize maneuver and/or indirect fires or other elements of combat power.

(4) Capability to command through the depth of the battlefield (close, deep, and rear battles).

(5) Capability to see the battlefield and enhance overall visualization of the battle.

(6) Non-interference with the exercise of initiative, judgment, and efforts of subordinates.

(7) Enhance capability to conduct necessary face-to-face coordination and guidance in the operational area.

(8) Enhance the capability for redundant $\mathrm{C} 2$ in high risk situations.

(9) Non-interference of brigade command, control, communications, and intelligence (C3I) activities of the brigade CSM, S3, or other key leaders.

3) The brigade commander directs the execution of the battle: [FM 71-3, Chap 3, 4, 5, FM 101-5, Chap 1, 4, App D, E; Battle Command Techniques and Procedures, Chap 3, 4; Battle Command, pp. 10-16, 32-37; FM 71-123, Chap 3, 4, 5, 6] 
a) Allows plan to be executed unless there is significant change to mission, enemy, terrain, troops, and time available (METT-T).

b) Issues timely FRAGOs (refer to Task 4) to:

(1) Modify OPORD or create new OPORD.

(2) Change priorities:

(a) Main effort.

(b) Fire support.

(c) CSS.

(d) ADA support.

(e) Engineer support.

(3) Commit reserve.

(4) Reorganize task forces.

c) Intervenes personally if required to:

(1) Direct maneuver.

(2) Coordinate fires with the FSCOORD or brigade targeting team.

d) Diverts, in coordination with the brigade targeting team, CAS from a preplanned target to a more critical target.

e) Requests additional resources and assets from division.

f) Provides guidance as appropriate to commanders and to brigade staff.

g) Ensures continuous mutual support among units.

h) Ensures continuity of command throughout the brigade.

3. The brigade commander sees and visualizes the battlefield. [FM 100-5, p. 1-8] 
e. The brigade commander decides whether the current plan needs to be changed. [FM 101-5, Chap 4, 7, App H, J; Battle Command Techniques and Procedures, Chap 2, $4,5]$

2) The brigade commander decides the current plan will achieve his intent and the brigade mission and continues to direct brigade battle execution. [FM $101-5$, p. 4-48]

3) The brigade commander decides the plan must be modified. [FM 101-5, p. 4-48]

a) The brigade commander bases his decision to initiate a FRAGO by considering: (See Task 4.b.11 for description of how to develop and issue this FRAGO) [FM 101-5, pp. 1-14 - 1-16]

(1) Whether COAs previously developed can be modified and developed as the new plan.

(2) Time available to develop, coordinate, and implement a new plan.

(3) Subordinate units' time to complete new preparation requirements under the new plan and task organization.

(13) Ability of the brigade to respond to the new situation based on current tactical posture and situation.

(a) Maneuver forces available to respond without impacting brigade ability to perform the current mission.

(b) Availability of CS, CSS, and supplies to support the new situation without impacting on support necessary for the current mission.

(14) Whether staff has time to plan and coordinate new missions.

(15) Impact of diverting key staff members from synchronizing the current mission to planning for a new mission.

b) The brigade commander determines how to modify the military decision-making process (MDMP) based on complexity, potential probable confusion on the battlefield, and time available. [FM 1015, Chap 4] 
(1) The brigade commander determines staff availability, the magnitude of change to the plan, and the amount of time available before execution.

(2) The brigade commander decides where to conduct the decision-making process (DMP) and actions required to produce and disseminate the FRAGO.

4. The brigade commander directs changes to the operation or plan. [FM 71-123, pp. 138; FM 101-5, pp. 1-4 - 1-15]

a. The brigade commander and/or staff issue WARNOs to alert staff members and subordinate elements that the plan will be changed. WARNOs may include: [FM 101-5, p. 4-55; LL-CALL Newsletter No. 93-3, p. 3]

1) The enemy situation and events.

2) The corps and/or division mission(s).

3) The corps and/or division commander's intent(s).

4) The earliest time of movement or degree of notice the commander can provide to the main body.

5) Orders for repositioning units, preliminary direct action against the enemy (e.g., fires, reconnaissance, surveillance, and observation).

6) Service support instructions, any special equipment necessary, regrouping of transportation, or preliminary moves to assembly areas.

7) The rendezvous point or time for assembly of an orders group; whether commanders or representatives are to attend; and time needed for issuing written orders.

b. The brigade commander employs the MDMP in a time-constrained environment. (Time available may be as brief as seconds or minutes.) [FM 71-3, App I; FM 1015, pp. 4-41 - 4-60]

2) The brigade commander conducts a quick mission analysis.

3) The brigade commander completes an update of his estimate.

e) Time: the commander determines the time available for planning, preparing, and executing the operation for both enemy and friendly forces. 
11) The brigade commander prepares or directs preparation of a FRAGO. [FM 101-5, App H; ARTEP 71-3 MTP, Task 71-3-3010]

a) The brigade commander, during battle execution, may prepare the FRAGO himself.

(1) The FRAGO must be documented by the main $\mathrm{CP}$ so that the staff can conduct necessary coordination and integration activities, and for recording the FRAGO in the brigade operations journal/log.

(2) The brigade staff members collocated with the brigade commander, (e.g., at the TAC CP) may assist in FRAGO preparation.

b) The brigade commander may direct the FRAGO be prepared by the brigade staff.

(1) The brigade XO manages and supervises internal and external coordination by the staff to prepare a synchronized FRAGO. [ARTEP 71-3 MTP, Task 71-3-0001]

(2) The brigade XO directs the brigade staff backbriefs to the brigade commander based on his guidance and: [LL-CALL Newsletter No 93-3, p. 9]

(a) The brigade $\mathrm{XO}$ develops a preparation timeline. [LL-CALL Newsletter No. 93-3, p. 12]

(b) The brigade $\mathrm{XO}$ refines the timeline by listing tasks to be accomplished during preparation and the person responsible to complete the task. [LL-CALL Newsletter No. 93-3, p. 12]

(c) The brigade $\mathrm{XO}$ ensures that the brigade staff uses the timeline to track the progression of preparation. [LL-CALL Newsletter No. 93-3, p. 12]

(d) The brigade $\mathrm{S} 3$ section organizes reproduction by centralizing collection of the portions of the order and its production. [LL-CALL Newsletter No. 93-3, p. 27] 
(e) The brigade XO selects an area to reproduce the order that will not interfere with the staff's work. [LL-CALL Newsletter No. 93-3, p. 27]

(f) The brigade $\mathrm{S} 3$ section uses a mimeograph or a photocopier to speed reproduction of order text. [LLCALL Newsletter No. 93-3, p. 27]

(g) The brigade $\mathrm{S} 3$ section uses a photocopier to reproduce graphics. [LL-CALL Newsletter No. 93-3, p. 27]

(3) The brigade $\mathrm{XO}$ directs the brigade staff as it takes prompt action to accomplish the guidance given by the commander. Actions include:

(a) Publish refinements to orders, annexes, and synchronization products.

(b) Initiate requests to higher and adjacent units for additional support.

(c) Coordinate receipt of additional support.

(4) The brigade $\mathrm{XO}$ directs the brigade staff in preparing FRAGOs reflecting changes to the current plan for the brigade commander's approval. FRAGO preparations include: [FM 101-5, App H; ARTEP 71-3 MTP, Task 71-33010]

(a) Graphics and control measures for the operation.

(b) DST and synchronization matrix.

(c) Fire support plan, FSEM, FSCM, AGM, and quick fire plan.

(d) Communications plan.

(e) CSS plan with support matrix.

12) The brigade commander approves and directs issuance of the FRAGO. [FM 101-5, p. 4-49, 4-59 - 4-60; App H; ARTEP 71-3 MTP, Task 71-3-3010] 
a) The brigade commander will normally, in the execution phase, approve and issue the FRAGO from the TAC CP (personally or by the S3).

\section{(1) Oral.}

(2) Other.

b) If the FRAGO has been prepared by the staff at the main $\mathrm{CP}$, the brigade commander may direct the brigade $\mathrm{XO}$ to approve and issue the FRAGO.

c) Mandatory elements of the FRAGO are:

(1) 1. Situation. (Include any changes to the existing order.)

(2) Mission. (List the new mission.)

(3) 3. Execution:

(a) Intent:

(b) a. Concept of operations.

(c) b. Tasks to subordinate units.

(d) c. Coordinating instructions. (Include the statement, "The current overlay remains in effect" or, "See change one to Annex C, Operations Overlay.") (Mark any changes to control measures on the overlay.) (As time permits, issue a new overlay.)

(4) 4. Service support. (Include any changes to existing order or the statement, "no change to OPORD xx.")

(5) 5. Command and signal. (Include any changes to existing order or the statement, "no change to OPORD xx.")

13) As soon as possible, and as needed, appropriate supporting plans and decisions are developed and distributed, including:

a) DST and synchronization matrix.

b) Fire support plan, FSEM, FSCM. 
c. The brigade XO directs the brigade staff as it coordinates internally and with higher, adjacent, and supporting elements to coordinate the FRAGO. [FM 101-5, App B]

1) The brigade $\mathrm{XO}$ directs the brigade staff to inform brigade elements of outdated/preempted orders, execution products and annexes containing information that has been superseded by the current FRAGO.

2) The brigade $\mathrm{XO}$, at the main $\mathrm{CP}$, analyzes the current FRAGO in light of current division, adjacent, and supporting unit OPORDs to preclude conflict.

3) The brigade XO ensures that the brigade staff understands how the commander wants to synchronize the battle; staff members perform necessary coordination. (See brigade BF 20, Task 2. a, b and c; Task 4. b. 11) b) (1) and (2)).

4) The brigade XO directs LNOs to communicate the FRAGO and the brigade commander's intent to their respective headquarters.

d. The brigade XO supervises the staff actions necessary to assist the brigade commander to synchronize the current battle. (See brigade BF 20, Task 2. a, b and c).

\section{Outcome 6}

The brigade staff ensures that the brigade commander's guidance and orders are executed and that all relevant actions are coordinated with higher, adjacent, and subordinate headquarters.

\section{Task Elements}

1. The brigade commander directs and leads subordinate forces. [FM 71-3, pp. 3-2 - 3-4; FM 101-5, pp. 1-4 - 1-5; Battle Command Techniques and Procedures, Chap 1, 2, 4; Battle Command, pp. 12-14, 34-37]

d. The brigade commander synchronizes tactical operations. [FM 101-5, Chap 1, 5, 6; Battle Command, pp. 42-45, Battle Command Techniques and Procedures, Chap 2, 4; FM 71-123, Chap 3, 4, 5, 6; ST 22-102, p. 4-10 - 4-12]

2) The brigade commander, assisted by the brigade staff, integrates and coordinates combat power, considering factors associated with each battlefield operating system; factors include: [TRADOC Pamphlet 11-9, Chap 7, App D; FM 101-5, Chap 1, 3, 4, App A, B, C, D, E, F, J; Battle 
Command Techniques and Procedures, Chap 1, 2, 3, 4, 6; Battle Command, pp. 10-39]

a) Maneuver: [Battle Command Techniques and Procedures, Chap 3;

FM 71-3, Chap 4, 5, 6; FM 71-123, Chap 2, 3, 4, 5, 6, App A]

(1) Movement:

(a) Brigade movements are conducted in accordance with the order (e.g., checkpoints are met on time) so that units are on time and at the right place to achieve intended results.

(b) Units are required to maintain orientation, security, and mutual support.

(2) Maneuver:

(a) Depth is achieved by the disposition of forces, obstacles, and fires.

(b) The battlefield is shaped to mass fires on the enemy.

(c) Agility is achieved by the rapid shifting of combat power to a place where it can be most effectively employed against the enemy force.

(d) Initiative is achieved by forcing the enemy into a continuous reactive state.

(e) Synchronization is achieved by integrating and massing friendly combat power at the right place and time to achieve the intended purpose.

(f) With the brigade S2 and brigade S3, reviews the DST to ensure that decisions can be made in a timely manner.

(g) Brigade reserve is committed as necessary to gain/retain initiative and accomplish commander's intent.

(h) Commitment of attack helicopter assists is synchronized with fire support and maneuver to achieve brigade commander's intent. 
b) Fire support: [FM 6-20; Battle Command Techniques and Procedures, Chap 6; FM 6-71; FM 71-123, Chap 2, 3, 4, 5, 6]

(1) Manages, in conjunction with the brigade FSCOORD, execution of fire support by exception.

(2) Monitors, in conjunction with the brigade FSCOORD, fire support, ensuring that it is executed according to plan and that it achieves the desired results.

(3) In conjunction with brigade ALO, directs diversion of immediate CAS attack based on requirements to influence the current battle.

(4) Exercises overall control of fire support through FRAGOs to change priorities and missions/tasks for supporting fire support systems.

(5) As required, orders massing and shifting of fires to support the brigade's maneuver.

(6) Monitors, in conjunction with the brigade FSCOORD, repositioning of DS FA battalion elements and determines alternative means to compensate for unavailable means of fire support.

(7) Monitors BDA to appraise results of the fire support plan in terms of achieving the desired effects.

(8) Determines deep attack requirements.

(9) Monitors establishment and implementation of ACAs.

(10) Monitors SEAD in support of operations.

2. Brigade command posts support synchronization by acquiring, evaluating, and communicating information. [FM 101-5, pp. 5-5 - 5-15]

a. The brigade CPs acquire information. [TRADOC Pam 11-9, Chap 7, App D; FM 71-3, Chap 2; FM 34-130, Chap 2; FM 101-5, p. 3-84, Chap 4, 6, App A, C; Battle Command Techniques and Procedures, Chap 2, 3, 4, 5] 
1) The brigade staff members, operating out of CPs, directed by the brigade commander or brigade SOP, obtain information during the execution of the battle that: [FM 101-5, p. 3-84]

a) Is critical in assisting the brigade commander to synchronize the execution of the brigade battle. [FM 101-5, pp. 6-33, 6-34]

b. The brigade CPs and staff sections evaluate acquired information, update products, and maintain status. [FM 63-20, Chap 3, 6; FM 101-5, Chap 6]

16) The brigade CPs maintain status. [FM 71-3, pp. 3-20 - 3-25]

b) The brigade $\mathrm{XO}$ ensures that the main $\mathrm{CP}$ maintains status and information including: [FM 71-3, pp. 3-20-3-25]

(1) Current operations and intelligence map.

(a) Operations overlay (brigade, higher, and adjacent units).

(b) Intelligence overlay.

(c) SIT TEMP overlay.

(d) Event template.

(e) MCOO.

(f) NBC overlay.

(g) CSS overlay.

(h) Terrain management status.

(2) CSS overlays and information per brigade SOP.

(3) Intelligence information from division and higher headquarters.

(4) Disposition of collection assets.

(5) Information on external units conducting R\&S and security operations to prevent fratricide. 
(6) Disposition and status of patrols and other R\&S and security forces.

(7) Status of operations so as to ensure compliance with stated mission timelines.

(8) Current and projected combat power status of subordinate units (e.g., green-amber-red).

(9) Status on task organization (into the brigade, within the brigade, and detachments out of the brigade).

(a) R\&S and security forces.

(b) TFs.

(c) Fire support systems.

(d) Engineer assets.

(e) GSR and other radar systems.

(f) ADA assets.

(10) Obstacle and survivability position construction and progress as compared to timelines.

(11) Utilization of engineer assets and materials as compared to timelines.

(12) Decision support tools (e.g., DST).

(13) Plans map (with overlays for future operations).

(14) Synchronization and execution tools (e.g., FSEM, OPSCHEDs, checklists).

(15) Journals/logs.

(16) Status of key communications links to include retransmission capability.

c. The brigade $\mathrm{CPs}$ and staff communicate information necessary to conduct a synchronized brigade battle. [FM 6-20-40, p. 26; FM 6-20-50, App C; FM 71-3, 
Chap 3, 8, App H; FM 71-123, Chap 1; FM 101-5, Chap 5, 6, App A, B, L; ARTEP 1-100 MTP; ARTEP 3-117-40 MTP; ARTEP 71-3 MTP; FN-NTC]

1) All CPs and staff members disseminate information. [FM 71-3, pp. 3-20 3-25]

a) Timely recommendations to the commander on critical synchronization actions.

b) Critical information needed to:

(1) Coordinate brigade synchronization.

(2) Monitor the situation.

(3) Keep higher and adjacent headquarters informed.

(4) Influence their areas of responsibility.

c) All staff officers remain alert for and ensure that critical information they receive is passed as soon as it is received to other staff officers who require the information.

2) The brigade $S 2$ and $S 2$ section assist the brigade commander to synchronize the battle by communicating the enemy's situation, evaluations of enemy capabilities, BDA, and analyses of PIR, IR, and routine information.

3) The brigade $\mathrm{S} 3$ in the TAC CP and $\mathrm{S} 3$ section assist the brigade commander to synchronize the battle by communicating: [ARTEP 71-3 MTP, Tasks 713-3003/2, 3; LL-CALL Bulletin No. 95-4, Chap 1]

a) Updated products, e.g.:

(1) WARNOs/FRAGOs.

(2) Coordinating instructions.

(3) Reports of the brigade situation.

(4) Evaluations of brigade status.

(5) DST information.

(6) Synchronization/execution matrix. 
b) Information regarding requirements for use of terrain in the brigade area that will impact on current operations.

c) Information to adjacent units to coordinate: [ARTEP 71-3 MTP, Task 71-3-3003/3c]

(1) Zones of attack or axes of advance, objectives, bypass criteria, and actions on contact.

(2) Battle handover location, criteria, and time or event at which handover is complete.

(3) Checkpoints, coordination points, phase lines, and contact points.

(4) Direct and indirect fire plans, control measures, and restrictive fire lines.

d) Mission information from other staff members (internal and external) which impacts on the concept of operation and synchronization of combat power.

(1) Disposition and location of brigade combat power.

(2) Brigade activities.

(3) Brigade capabilities.

(4) Status of personnel and equipment.

(5) Intentions of the brigade.

(6) Unit boundaries.

(7) Current situation.

e) Information on future operations.

f) Significant changes to enemy situation.

g) Answers to CCIR. 
h) Recommendations to the brigade $\mathrm{S} 3$ (from $\mathrm{S} 3$ section), XO, or commander concerning shifts of main effort and synchronization of combat power.

4) The brigade CMLO and NBC section assist the brigade commander to synchronize the battle by communicating: [FM 101-5, App A; ARTEP 3117-40 MTP, Tasks 3-4-0007; 0009; 0016]

a) The brigade NBC situation and analysis of CCIR, IR, and critical information.

b) The brigade CMLO coordinates with the division CMLO and supporting decontamination units to confirm and organize deliberate decontamination plans and preparations. [ARTEP 3-117-40 MTP, Task 3-4-0005]

c) Recommendations to the brigade $\mathrm{S} 3, \mathrm{XO}$, or commander concerning critical NBC related actions.

5) The $\mathrm{ABE}$ section assists the brigade commander to synchronize the battle by communicating: [FM 101-5, App A; ARTEP 71-3 MTP, Task 71-3-8005/2]

a) The brigade engineer situation, analysis of CCIR, IR, and critical information to other brigade staff sections and external headquarters/staff officers.

b) Current status of M/CM/S operations. [ARTEP 71-3 MTP, Task 71$3-8005 / 1]$

(1) Mobility operations. [ARTEP 71-3 MTP, Task 71-3-8005/1]

(a) Sufficient engineer obstacle (natural and man-made) breaching equipment has been allocated to and coordinated with maneuver forces to ensure maintaining brigade momentum.

(b) Smoke and suppressive fires have been planned at critical breaching sites.

(c) MSRs and ASRs can be maintained allowing the brigade to sustain combat operations.

(2) Countermobility operations: [ARTEP 71-3 MTP, Task 71-3$8002 / 2]$ 
(a) Obstacles support the brigade scheme of maneuver and subordinate unit tactical plans, reinforce engagement areas, and are tied in to other obstacles and terrain.

(b) All obstacles are covered by observation, direct fires, and indirect fires.

(c) Control measures are established.

(d) Existing obstacle locations and types are recorded, including lanes and passage points.

(e) Obstacle security is maintained by the unit responsible for the obstacle.

(f) Obstacles will not conflict or inhibit future mobility requirements for brigade operations. [AN]

(g) Criteria for FASCAM employment is accurate and understood.

(3) Current status of types and locations of required survivability positions: [ARTEP 71-3 MTP, Task 71-3-8002]

(a) Position construction is based on priority (including positions for security force units).

(b) Locations are jointly sited by:

1 Maneuver commanders (responsible for site selection).

$2 \quad$ Engineer leader (responsible for providing equipment, material, expertise, and for preparation to standard of vehicle positions).

c) The ABE section coordinates with brigade units, TF engineers, and engineer battalion (as applicable) to ensure that $\mathrm{M} / \mathrm{CM} / \mathrm{S}$ operations are in accordance with the brigade order. [ARTEP 71-3 MTP, Task 71-3-8005/1]

d) The brigade engineer section communicates with adjacent units and the assistant division engineer. [ARTEP 71-3 MTP, Task 71-38005/1] 
(1) To exchange information on obstacle status, type, and location.

(2) To ensure that division-directed obstacle requirements are satisfied.

(3) To exchange information on mobility plans (brigade, division).

e) Recommendations to the brigade $\mathrm{S} 3$, XO or commander concerning critical mobility, countermobility, and survivability actions.

6) The AVLO assists the brigade commander to synchronize the battle by communicating: [ARTEP 71-3 MTP, Task 71-3-7001/3; ARTEP 1-100 MTP, Tasks 01-4-1311, 1322]

a) The Army aviation situation to other brigade staff sections and external headquarters/staff officers.

b) Time on station for attack helicopters for specific missions.

c) Recommendations to the brigade $\mathrm{S} 3$, $\mathrm{XO}$, or commander concerning employment of Army aviation assets.

7) The brigade FSCOORD, FSO, targeting officer, FSE, and NGLO assist the brigade commander to synchronize the battle by communicating: [FM 1015, App A; ARTEP 71-3 MTP, Task 71-3-9002/2, 3; FM 71-3, pp. 7-13 - 714; FM 6-20-40, p. A-26; FM 6-20-50, pp. C-25 - C-28]

a) Brigade fire support situation and analysis of CCIR, IR, and routine information.

b) Brigade FSO and FSE section communicate with adjacent and higher FSEs and DS FA battalion headquarters (and NGLO communicates with DS and GS NSF ships) to: [ARTEP 71-3 MTP, Task 71-3-9002/2]

(1) Ensure that planned brigade fire support will not interfere with other fire support systems, will not disrupt adjacent unit operations, and will not jeopardize troop safety.

(2) Ensure that fire support information and products (target lists, FSEM, CAS requests, and ATO) are exchanged and refined. 
c) The brigade FSO and FSE section communicate with the brigade S3 and TF FSOs to verify: [ARTEP 71-3 MTP, Task 71-3-3001/2]

(1) Control measures delineating mutual boundaries.

(a) Directed by division.

(b) Internal boundaries (TFs, scouts, security forces).

(2) Air space control measures.

(3) FSCMs.

(4) Signals and conditions under which restrictive measures will be emplaced or lifted.

(5) Locations.

d) Intelligence information received through artillery or naval channels.

e) The targeting team communicates results of attacks on targets, assessments of results, and recommendations of changes to the fire support plan and attack means.

f) Recommendations to the brigade $\mathrm{S} 3, \mathrm{XO}$, or commander concerning critical fire support matters.

8) The ALO, Marine air officer, and brigade TACP assist the brigade commander to synchronize the battle by communicating: [FM 101-5, App

A]

a) CAS situation and routine information to other brigade staff sections and external headquarters/staff officers.

b) Time on station for CAS sorties in support of specific targets.

c) Intelligence information received through air operations channels.

d) Recommendations to the brigade $\mathrm{S} 3, \mathrm{XO}$ or commander concerning CAS employment.

9) The Marine air officer and NGLO assist the brigade commander to synchronize the battle by communicating naval air and NSF situation to brigade staff sections and external (to include maritime) headquarters/staff 
officers and make recommendations to the brigade $\mathrm{S} 3, \mathrm{XO}$, or commander as necessary concerning naval air support and NSF. [FM 101-5, App A; ARTEP 71-3 MTP, Task 71-3-9002/2, 3]

10) The $\mathrm{ADO}$ assists the brigade commander to synchronize the battle by communicating: [FM 101-5, App A; ARTEP 71-3 MTP, Task 71-3-6001/1, 6002]

a) Changes in HIMAD coverage to the brigade $\mathrm{XO}$ and brigade $\mathrm{S} 3$.

b) The brigade air picture, ADA situation and analysis of CCIR, IR, and routine information.

c) The $\mathrm{ADO}$ communicates with adjacent units and $\mathrm{ADA}$ battalion headquarters. [ARTEP 71-3 MTP, Task 71-3-6002/2, 3]

(1) To confirm scheme of maneuver, identification, friend or foe (IFF) codes, and $\mathrm{AD}$ weapons area coverage.

(2) To confirm weapons control status with higher and adjacent units.

(3) To confirm events and reporting systems which will cause the brigade to upgrade weapons control status.

d) Warning of imminent enemy air attacks (early warning).

e) Updates the brigade $\mathrm{S} 2$ and air defense battalion $\mathrm{S} 2$ on: [AN]

(1) Type of aircraft engaged.

(a) Location.

(b) Time.

(2) Type of damage inflicted.

(3) Routes, tactics used by enemy air.

f) Recommendations to the brigade $\mathrm{S} 3$, $\mathrm{XO}$, or commander concerning air defense matters. 
11) The MP platoon leader assists the brigade commander to synchronize the battle by communicating brigade MP situation and critical information to other brigade staff sections and external headquarters and makes recommendations to the brigade $\mathrm{S} 3, \mathrm{XO}$, or commander as necessary about traffic control, handling of EPW, and other assigned missions. [FM 101-5, App A; ARTEP 71-3 MTP, Task 71-3-1201/1]

12) The $\mathrm{Bde} \mathrm{SO}$ and section assists the brigade commander to synchronize the battle by communicating: [FM 101-5, App A; ARTEP 71-3 MTP, Task 71$3-1102 / 4]$

a) Brigade communications situation and critical information to other brigade staff sections and external headquarters.

b) The brigade communications section communicates with adjacent units and signal battalion headquarters. [ARTEP 71-3 MTP, Task 71-3-1102/4]

(1) To confirm allocation and locations of signal assets and capabilities.

(2) To acquire signal equipment to supplement brigade CPs and subordinate units which require special communications equipment.

c) Recommendations to the brigade $\mathrm{S} 3, \mathrm{XO}$, or commander concerning critical communication actions.

13) The brigade rear $\mathrm{CP}$ (S1 and S4 officers and sections), FSB commander, and support operations officer assist the brigade commander to synchronize the battle by communicating: [FM 101-5, App A]

a) Critical Class III, IV, and V supplies status that will affect the current battle.

b) Brigade CSS staff communicates with brigade staff and brigade units:

(1) To identify additional requests for support.

(a) Transportation assets.

(b) Medical augmentation. 
(c) Maintenance support for vehicles and weapons systems and for recovery of damaged vehicles or return of repaired vehicles.

(2) To coordinate the transportation of supplies and cargo to brigade units.

(3) To coordinate routine, emergency, and critical resupply operations (e.g., delivery times, types and quantities of supplies required).

(4) For receiving and processing replacements.

(5) To track evacuation of personnel and casualties.

(6) To process awards, decorations, promotions, and legal actions.

(7) For security and protection of CSS units operating forward.

c) Inform the brigade S3, XO, or commander of serious capability losses and provide recommendations for provision of CSS. [AN]

d) Inform higher headquarters (G4, WSRO officer) when combat personnel or equipment losses reach a point where assistance is needed. [AN]

14) The brigade $\mathrm{S} 5$ assists the brigade commander to synchronize the battle by communicating: [FM 101-5, App A; ARTEP 71-3 MTP, Task 71-3-5001/2]

a) CMO situation and analysis of CCIR, IR, and routine information.

b) Civilian activity impact on LOC congestion that will affect synchronization.

c) Recommendations to the brigade $\mathrm{S} 3, \mathrm{XO}$, or commander concerning operational actions based on CMO situation.

4. The brigade commander directs changes to the operation or plan. [FM 71-123, pp. 138; FM 101-5, pp. 1-4 - 1-15]

b. The brigade commander employs the MDMP in a time-constrained environment.

(Time available may be as brief as seconds or minutes.) [FM 71-3, App I; FM 101-
5, pp. 4-41 - 4-60] 
11) The brigade commander prepares or directs preparation of a FRAGO. [FM 101-5, App H; ARTEP 71-3 MTP, Task 71-3-3010]

b) The brigade commander may direct the FRAGO be prepared by the brigade staff.

(1) The brigade XO manages and supervises internal and external coordination by the staff to prepare a synchronized FRAGO. [ARTEP 71-3 MTP, Task 71-3-0001]

(2) The brigade XO directs the brigade staff backbriefs to the brigade commander based on his guidance and: [LL-CALL Newsletter No 93-3, p. 9]

(a) The brigade $\mathrm{XO}$ develops a preparation timeline. [LL-CALL Newsletter No. 93-3, p. 12]

(b) The brigade $\mathrm{XO}$ refines the timeline by listing tasks to be accomplished during preparation and the person responsible to complete the task. [LL-CALL Newsletter No. 93-3, p. 12]

(c) The brigade $\mathrm{XO}$ ensures that the brigade staff uses the timeline to track the progression of preparation. [LL-CALL Newsletter No. 93-3, p. 12]

(3) The brigade XO directs the brigade staff as it takes prompt action to accomplish the guidance given by the commander. Actions include:

(a) Publishes refinements to orders, annexes, and synchronization products.

(b) Initiates requests to higher and adjacent units for additional support.

(c) The staff at the main $\mathrm{CP}$ facilitates planning for future operations and coordinates additional support from division.

(4) The brigade $\mathrm{XO}$ directs the brigade staff in preparing FRAGOs reflecting changes to the current plan for the brigade commander's approval. FRAGO preparations include: [FM 101-5, App H; ARTEP 71-3 MTP, Task 71-33010] 
(a) Graphics and control measures for the operation.

(b) DST and synchronization matrix.

(c) Fire support plan, FSEM, FSCM, AGM, and quick fire plan.

(d) Communications plan.

(e) CSS plan with support matrix.

c. The brigade $\mathrm{XO}$ directs the brigade staff as it coordinates internally and with higher, adjacent, and supporting elements to coordinate the FRAGO. [FM 101-5, App B]

1) The brigade $\mathrm{XO}$ directs the brigade staff to inform brigade elements of outdated/preempted orders, execution products and annexes containing information that has been superseded by the current FRAGO.

2) The brigade $\mathrm{XO}$, at the main $\mathrm{CP}$, analyzes the current $\mathrm{FRAGO}$ in light of current division, adjacent, and supporting unit OPORDs to preclude conflict.

3) The brigade $\mathrm{XO}$ ensures that the brigade staff understands how the commander wants to synchronize the battle; staff members perform necessary coordination. (See brigade BF 20, Task 2. a, b and c; Task 4. b. 11) b) (1) and (2)).

4) The brigade $\mathrm{XO}$ directs $\mathrm{LNO}$ to communicate the FRAGO and the brigade commander's intent to their respective headquarters.

d. The brigade XO supervises the staff actions necessary to assist the brigade commander to synchronize the current battle. (See brigade BF 20, Task 2. a, b and c).

\section{Outcome 7}

Subordinate leaders demonstrate an understanding of the critical elements of their own mission and mission-essential tasks, the brigade mission, and the brigade commander's intent.

\section{Task Element}

1. The brigade commander directs and leads subordinate forces. [FM 71-3, pp. 3-2 - 3-4; FM 101-5, pp. 1-4 - 1-5; Battle Command Techniques and Procedures, Chap 1, 2, 4; Battle Command, pp. 12-14, 34-37] 
a. The brigade commander directs subordinate forces. [FM 71-3, p. 3-4; FM 101-5, pp. 1-4 - 1-5]

1) The brigade commander takes actions to ensure that subordinate leaders have a clear understanding of his intent and concept. Actions include: [FM 101-5, Chap 1, 4; Battle Command Techniques and Procedures, Chap 2, 4; Battle Command, pp. 10-32]

a) Meeting with subordinate commanders and leaders to receive information and issue directions. [FM 101-5, pp. 4-53, 4-59 - 4-60]

b) Listening to cross-talk on brigade command nets.

c) Evaluating reports from subordinates for understanding of his intent, concept of operations, and their missions.

d) Confirmation briefs and backbriefs by subordinate commanders. [AN]

e) Rehearsals. [AN]

4. The brigade commander directs changes to the operation or plan. [FM 71-123, pp. 138; FM 101-5, pp. 1-4 - 1-15]

b. The brigade commander employs the MDMP in a time-constrained environment. (Time available may be as brief as seconds or minutes.) [FM 71-3, App I; FM 1015, pp. 4-41 - 4-60]

9) The brigade commander conducts mission risk assessment to ensure that conditions most likely to cause mission failure and accidents (including fratricide) have been mitigated.

b) Procedural and positive risk-reduction control measures have been implemented, for example:

(1) Situation is understood by brigade members.

14) The brigade commander conducts a confirmation brief in person or by electronic means with key brigade leaders. [LL-CALL Newsletter No. 90-8, p. 25]

15) The brigade $X O$ conducts a confirmation brief with the brigade staff at the main and rear CPs. [LL-CALL Newsletter No. 90-8, p. 25] 
16) Brigade key leaders and all subordinate commanders, if possible, are able to hear each others' confirmation briefs. This ensures:

a) Common understanding of the entire plan and the roles of each unit.

b) Agility in execution; i.e., the ability to react quicker than the enemy.

c) Direct personal coordination, which enhances synchronization of the plan.

d) Continuity of command, so that if the brigade commander becomes combat ineffective, the subordinate commanders will share the same view of the commander's intent.

\section{Outcome 8}

Soldiers and units are motivated, disciplined, and maintain unit cohesion.

\section{Task Elements}

1. The brigade commander directs and leads subordinate forces. [FM 71-3, pp. 3-2 - 3-4; FM 101-5, pp. 1-4 - 1-5; Battle Command Techniques and Procedures, Chap 1, 2, 4; Battle Command, pp. 12-14, 34-37]

b. The brigade commander exercises leadership during the execution of the brigade battle by: [FM 101-5, Chap 1, 4; FM 71-3, Chap 3; Battle Command Techniques and Procedures, Chap 1, 2, 3, 4; Battle Command, pp. 10-13, 32-37]

1) Being professionally competent.

2) Inspiring soldiers with the will to win.

3) Sharing the hardships and dangers of his soldiers.

4) Demonstrating both mental and physical stamina.

5) Displaying physical and moral courage (making the difficult choices and decisions).

c. The brigade commander maintains unit discipline and morale by: [FM 101-5, Chap 1; Battle Command Techniques and Procedures, Chap 4; Battle Command, pp. 1013; ST 22-102, Chap 4]

1) Keeping the soldiers informed of the current situation. 
2) Making personal contact with soldiers.

3) Sharing the hardships and dangers that his soldiers face.

4) Reassuring subordinates in a calm manner.

5) Ensuring that soldiers have the opportunity to rest, eat, and otherwise refit as conditions permit.

6) Acting decisively.

7) Giving precise, simple, easy-to-understand orders.

8) Checking to see that his orders are carried out.

2. Brigade command posts support synchronization by acquiring, evaluating, and communicating information. [FM 101-5, pp. 5-5 - 5-15]

a. The brigade CPs acquire information. [TRADOC Pam 11-9, Chap 7, App D; FM 71-3, Chap 2; FM 34-130, Chap 2; FM 101-5, p. 3-84, Chap 4, 6, App A, C; Battle Command Techniques and Procedures, Chap 2, 3, 4, 5]

2) The brigade CSM obtains information on matters such as: [FM 71-3, pp. 35 - 3-6; FM 101-5, pp. 3-70 - 3-71]

a) Morale, discipline, and adherence to standards by brigade soldiers.

d) Welfare of brigade soldiers.

16) The brigade $\mathrm{S} 1$ section obtains personnel information. [ARTEP 71-3 MTP, Tasks 71-3-1001/1, 2; 1002/1, 3, 4; 1004/1; 1008/1; FM 101-5, pp. C-5; FM 71-3, pp. 8-5, 8-6, 8-17, 8-24; FM 71-3, Chap 8]

b) The brigade $\mathrm{S} 1$ section coordinates personnel information concerns related to synchronizing the execution of the battle to include:

(3) Personnel status from subordinate and supporting units.

(a) PSRs.

(b) Critical MOS/grade shortages.

(c) AWOLs.

(d) Casualty feeder reports. 
(e) Key leader and MOS status.

(5) Morale and discipline indicators from division and brigade special staff officers.

(a) Disciplinary rates from Staff Judge Advocate (SJA).

(b) Straggler and crime rates from PM.

(c) Sick call and stress casualties from brigade surgeon.

(d) Complaints information from the IG.

(e) Leader and soldier concerns from the chaplain.

\section{Outcome 9}

The brigade command and control capability is effective, survives, and is prepared for the next mission.

\section{Task Elements}

1. The brigade commander directs and leads subordinate forces. [FM 71-3, pp. 3-2 - 3-4; FM 101-5, pp. 1-4 - 1-5; Battle Command Techniques and Procedures, Chap 1, 2, 4; Battle Command, pp. 12-14, 34-37]

a. The brigade commander directs subordinate forces. [FM 71-3, p. 3-4; FM 101-5, pp. 1-4 - 1-5]

2) The brigade commander positions himself where he can best direct and lead, observe the battlefield, and synchronize operations: [FM 71-3,pp. 3-2 - 34; FM 101-5, Chap 1, 2, 3; FM 7-20; Battle Command Techniques and Procedures, Chap 2, 3, 4; ST 22-102, pp. 4-14 - 4-15]

a) Ensures that people and equipment needed for him to move about the battlefield are organized and prepared to move on short notice.

b) Selects positions that enable communications with:

(1) Division commander and assistant division commander for maneuver (ADC-M).

(2) Brigade subordinate commanders. 
(3) Main CP.

(4) Adjacent units (main CP may be given this task).

c) Selects positions that provide protection for the brigade commander and the tactical (TAC) CP against direct and indirect fires.

d) Selects positions that minimize chance that he will become decisively engaged and lose freedom of movement.

e) Selects locations at decisive points in the battle using as criteria:

(1) Proximity to the main effort.

(2) Event or location where the brigade can exploit enemy weaknesses.

(3) Vicinity to places that he anticipates his personal intervention, at a precise time, will be necessary to synchronize maneuver and/or indirect fires or other elements of combat power.

(4) Capability to command through the depth of the battlefield (close, deep, and rear battles).

(5) Capability to see the battlefield and enhance overall visualization of the battle.

(6) Non-interference with the exercise of initiative, judgment, and efforts of subordinates.

(7) Enhance capability to conduct necessary face-to-face coordination and guidance in the operational area.

(8) Enhance the capability for redundant C2 in high risk situations.

(9) Non-interference of brigade command, control, communications, and intelligence (C3I) activities of the brigade CSM, S3, or other key leaders.

4. The brigade commander directs changes to the operation or plan. [FM 71-123, pp. 138; FM 101-5, pp. 1-4 - 1-15] 
b. The brigade commander employs the MDMP in a time-constrained environment. (Time available may be as brief as seconds or minutes.) [FM 71-3, App I; FM 1015, pp. 4-41 - 4-60]

16) Brigade key leaders and all subordinate commanders, if possible, are able to hear each other's confirmation briefs. This ensures:
a) Common understanding of the entire plan and the roles of each unit.
b) Agility in execution; i.e., the ability to react quicker than the enemy.
c) Direct personal coordination, which enhances synchronization of the plan.
d) Continuity of command, so that if the brigade commander becomes combat ineffective, the subordinate commanders will share the same view of the commander's intent.

5. Brigade command posts manage and maintain command, control, and communications. [FM 71-123, pp. 1-43 - 1-46; FM 71-3, Chap 3; FM 101-5, Chap 5, 7, App B, Battle Command Techniques and Procedures, Chap 4]

b. The information managers at each of the brigade CPs maintain command, control, and communications throughout the battle. [FM 101-5, pp. 5-1 - 5-14; AN]

2) The brigade $\mathrm{XO}$ repositions the brigade main $\mathrm{CP}$ as necessary to:
a) Maintain $\mathrm{C} 3$ with brigade command group and TAC CP, brigade subordinate units' $\mathrm{CPs}$, division main $\mathrm{CP}$, and adjacent units' $\mathrm{CPs}$.
b) Preclude destruction of main CP C3 capabilities.

3) The brigade $\mathrm{S} 1$ or $\mathrm{S} 4$ repositions the rear $\mathrm{CP}$ in order to:
a) Maintain continuity of CSS support for the brigade forces.
b) Preclude destruction of CSS C3 capabilities.
c) Maintain collocation and operational capability with the FSB.

c. The brigade reestablishes $\mathrm{C} 3$ operations in the event of $\mathrm{CP}$ loss or destruction. [FM 101-5, Chap 5, App B; FM 71-3, Chap 3, App H; Battle Command Techniques and Procedures, Chap 4] 
1) The brigade $\mathrm{XO}$ reestablishes $\mathrm{C} 3$ operations in the event of the loss of the brigade TAC CP: [FM 71-3, Chap 3; FM 71-123, Chap 1; Battle Command Techniques and Procedures, Chap 4]

e) The brigade $\mathrm{XO}$ at the brigade main $\mathrm{CP}$ assumes control of the close battle by:

(1) Maintaining communications with forward elements.

(2) Synchronizing combat, CS, and CSS activities in support of the close battle.

(3) Maintaining the current situation of the entire brigade battle area.

(4) Informing the division main $\mathrm{CP}$ of the loss of the brigade TAC CP and the status of the brigade commander and key brigade staff members who were at the TAC CP.

(5) Notifying all brigade elements that the main $\mathrm{CP}$ or a preselected TF CP is now controlling the entire brigade battle area.

(6) Ensuring that all brigade units send all reports to the brigade main $\mathrm{CP}$.

(7) Notifying all adjacent units that the brigade main is now in charge of all brigade activities and to send all message traffic to the main.

g) The brigade commander, should he survive or is not at the TAC CP when it is destroyed, may elect to:

(1) Establish a small assault $\mathrm{CP}$ with the communication equipment and personnel available and retain control to fight the close battle.

(2) Move to the closest TF CP and establish a new TAC CP and continue to fight the close battle.

(3) Move back to the brigade main CP and fight the close battle from that location.

2) The brigade commander or brigade $S 3$ ensures that appropriate actions are taken in the event of the loss of the brigade main CP: [FM 71-3, Chap 3, 
App H; FM 71-123, Chap 1; Battle Command Techniques and Procedures, Chap 4]

c) The brigade commander or brigade $\mathrm{S} 3$ ensures, upon confirmation that the main $\mathrm{CP}$ is out of action, that functions are transferred. Function transfer might include:

(1) The brigade TAC CP, which continues to fight the close battle and assumes the main $\mathrm{CP}$ functions of:

(a) Fighting the deep battle.

(b) Developing intelligence.

(c) Monitoring and coordinating the rear battle.

(d) Serving as the synchronization point for the entire brigade battlefield.

(e) Allocating brigade resources.

(f) Maintaining continuous communication with the forward elements, the brigade rear $\mathrm{CP}$, division, or other higher headquarters.

(g) Performs A2C2 functions for the entire brigade battle area.

(h) Requesting additional personnel from the brigade $\mathrm{S} 1$ at the rear $\mathrm{CP}$.

(i) Planning for future operations.

(2) The CP designated in the brigade TSOP assumes the following main $\mathrm{CP}$ responsibilities:

(a) The brigade command center and maintenance of communications with division and adjacent units.

(b) Liaison with:

1 Brigade subordinate and supporting units.

$\underline{2}$ Division and adjacent units. 
(c) Synchronization of CS and CSS for the close and rear battle areas.

(d) Fighting the rear battle.

(e) Monitoring the close battle.

(f) Providing situation reports to division main CP.

(g) Ensures that all main CP functions are quickly assumed by the rear $\mathrm{CP}$.

(h) Reconstitutes main CP functional cells of headquarters, current operations, plans, intelligence, FS, and CSS from assets within the brigade or with help from division.

3) The brigade $\mathrm{XO}$ ensures that appropriate actions are taken if the brigade rear CP is lost: [FM 71-3, Chap 3, App H; FM 71-123, Chap 1; Battle Command Techniques and Procedures, Chap 4]

a) The $\mathrm{CP}$ designated in the brigade TSOP assumes the functions of the brigade rear $\mathrm{CP}$ to include:

(1) Sustainment of all brigade units with priority to those units fighting the close battle.

(2) Transportation support of all brigade units with priority to forward elements.

(3) Protection of support facilities and LOCs.

(4) Management of terrain in the BSA.

b) The brigade XO takes measures to reconstitute and reestablish the brigade rear $\mathrm{CP}$ by requesting replacement personnel and equipment.

d. The brigade commander or brigade $\mathrm{XO}$ ensures that the brigade succession of command is implemented in accordance with the brigade plan or TSOP. [FM 1015, Chap 5; FM 71-3, App H; Battle Command Techniques and Procedures, Chap 4; CTC Bulletin No 94-1, p. 19]

6. The brigade consolidates and reorganizes. [FM 71-3, pp. 8-23 - 8-26; FM 7-30, p. 9-6, App H; FM 71-123, Chap 2, 5; FM 100-9, Chap 4; FM 71-100, Chap 1, App A; Battle Command Techniques and Procedures, Chap 3; FM 101-5, Chap 4] 
a. The brigade commander directs the brigade consolidation. [FM 101-5, Chap 4; FM 71-3, Chap 8, App H; Battle Command Techniques and Procedures]

2) The brigade commander directs the brigade staff to assist in the brigade consolidation: [FM 101-5, Chap 4; Battle Command Techniques and Procedures, Chap 2, 3; FM 71-3, App H]

b) The brigade $\mathrm{XO}$ directs the brigade coordinating and special staff in accomplishing the following:

(1) The brigade XO:

(a) Alerts the brigade staff to start preparing for the consolidation and reorganization brief by: $[\mathrm{AN}]$

1 Directing staff estimates of the brigade's post-battle situation.

2 Obtains current disposition and locations of brigade units.

3 Obtains estimate of strength and equipment status and capabilities of units.

$4 \quad$ Obtains current intelligence and estimate of enemy intent from the division G-2.

(b) Supervises the staff preparation of orders for follow on missions.

(c) Directs and supervises the refurbishment of brigade units in preparation of the next mission.

(d) Keeps the commander informed on the activities of adjacent units.

(e) Ensures that the command has the current CCIR.

(f) Continues to monitor all activities in the brigade deep battle area and supervises the activities in the brigade rear battle area. 
b. The brigade commander directs brigade reorganization. [FM 71-123, Chap 2, 8; FM 71-3, Chap 1, 2, 7, 8, App H; Battle Command Techniques and Procedures, Chap 3, 9]

1) The brigade commander directs reorganization of brigade units: [FM 71123, Chap 2, 6; FM 71-3, Chap 8, App H; Battle Command Techniques and Procedures, Chap 3, 9]

a) Refit of $\mathrm{C} 3 \mathrm{I}$ equipment.

b) Cross leveling or replacement of personnel.

c) Replacement of personnel, supplies, and equipment based upon command priorities, references, and resources.

d) Conduct of essential training.

e) Reallocation of terrain responsibilities.

2) The brigade commander directs the brigade staff under the supervision of the brigade XO to prepare a FRAGO that includes: [FM 101-5, Chap 4; FM 71-3, Chap 8, App H; Battle Command Techniques and Procedures, Chap 9]

a) Personnel replacement (brigade $\mathrm{S} 1$ ).

b) Intelligence collection efforts (brigade S2).

c) Maneuver plan (brigade $\mathrm{S} 2$, brigade $\mathrm{S} 3$, brigade engineer, brigade FSO, brigade $\mathrm{ADO}$, brigade $\mathrm{S} 4$, brigade FSB commander, and brigade ALO and brigade AVLO).

d) Security and reconnaissance (brigade S2, brigade S3, brigade FSO).

e) Fire support (brigade S3, brigade FSO, brigade ALO, brigade ADO).

f) Engineer support (brigade S2, brigade S3, brigade ABE).

g) Air defense support (ADO/ADALO).

h) Supply (brigade S4, brigade FSB commander).

i) Medical support (brigade S1, brigade S4, brigade surgeon).

j) Maintenance support (brigade S4, brigade FSB commander, brigade maintenance officer). 
k) Guidance on minimum manning levels for major weapon systems.

c. The brigade commander confirms that the brigade is prepared to continue the mission. Confirmation criteria include: $[\mathrm{AN}]$

1) All brigade elements report successful completion of reorganization and consolidation.

2) The brigade $\mathrm{XO}$ reports all brigade $\mathrm{C} 3$ facilities, $\mathrm{CPs}$, and systems are fully operational. 


\section{LESSONS LEARNED}

This component identifies the lessons learned extracted from the U.S. Army Center for Army Lessons Learned (CALL) publications relevant to performing this battlefield function (BF). The lessons learned are organized and listed by the appropriate task in the $\mathrm{BF}$ task list. Where appropriate to address the absence of a task in an Army Training and Evaluation Program - Mission Training Plan (ARTEP-MTP), the lessons learned have been structured as tasks and are included in the detailed task list as subtasks. The purpose of the lessons learned component is to provide the user with the most recent tactics, techniques and procedures (TTP) associated with the performance of the tasks in this BF.

\section{The brigade commander directs subordinate forces.}

LL - Command information programs which provide the soldier realistic capabilities, information, and solutions are required. TC 90-16 (Armor/Antiarmor Operations on the Integrated Battlefield) is one source which provides capabilities and solutions. Soldiers need to know! Explaining why certain TTPs are required during training is another method of providing the soldier with the information. Tying the capability to TTP reinforces the information. An especially effective technique used on North Africa was for all soldiers to fire their weapons at enemy vehicles and equipment on training ranges to gain confidence in the weapons and to see first hand the effects of the weapons on the enemy vehicles and equipment. [The Center for Army Lessons Learned (CALL) Newsletter No. 90-8: Special Edition: Winning in the Desert II, p. 22]

LL - Commanders often seek to maximize their control of the situation under stress. This may result in detailed orders to subordinates that stifle their initiative and reduce the flexibility to respond to contingencies. [The Center for Army Lessons Learned (CALL) Newsletter No. 90-8: Special Edition: Winning in the Desert II, p. 25]

LL - Good communication is always difficult, but stress and fatigue will greatly increase misunderstandings. Just because something is very clear to you, do not assume that it is clear to everyone else. Double-check communication. Use backbriefs and rehearsals. Staff visits and follow ups also foster good communications and can keep problems from recurring. [The Center for Army Lessons Learned (CALL) Newsletter No. 90-8: Special Edition: Winning in the Desert II, p. 25]

LL - The mental abilities required for effective $\mathrm{C} 2$ are those which first and foremost suffer from sleep loss. Sleep loss has been proven to decrease performance on tasks requiring calculations, creativity, anticipation, and planning ahead. While we all can recognize the physical signs of fatigue in us and others, we seldom recognize mental lapses. Do not judge your level of degradation by how well you can still perform physically. Although there is the temptation to remain awake through intense planning sessions and engagements, adequate sleep discipline is fundamental for maintaining the abilities to develop and adjust plans. Three to four 
hours of uninterrupted sleep each day will maintain mental performance only for five to six days. Less sleep will lead to rapid declines. [The Center for Army Lessons Learned (CALL) Newsletter No. 90-8: Special Edition: Winning in the Desert II, p. 25]

LL - Widespread agreement among the staff is not necessarily a healthy sign. It could mean that the desire to find agreement is overriding critical thinking. In times of stress there will be a natural desire to reduce that stress by increasing group harmony and ignoring problems. Be alert for group think and when you suspect it is occurring, take a devil's advocate position and actively find the flaws that everyone is missing. [The Center for Army Lessons Learned (CALL) Newsletter No. 90-8: Special Edition: Winning in the Desert II, p. 25]

LL - Do not let stress make the situation appear worse than it is. Be calm and confident during the fight. It is inevitable that you will make mistakes. And some may be costly. Let your mistakes make you a better soldier instead of a worse one. [The Center for Army Lessons Learned (CALL) Newsletter No. 90-8: Special Edition: Winning in the Desert II, p. 26]

LL - The commander must plan and rehearse his own position and movement on the battlefield as carefully as is done for the overall TF plan. He must be forward to personally see critical points in the battle, yet protected in order to survive. [CALL Compendium, Vol. 1: Heavy Forces, Fall 88]

LL - Commanders must demand that key leaders discipline themselves to obtain a minimum level of rest. [CALL 89-1: Non-Mechanized Forces, Spring 89]

LL - On the battlefield the CSM can position himself where leadership is most needed. [CALL 89-1: Non-Mechanized Forces, Spring 89]

LL - NCOs must help set priorities of work by clarifying through the chain of command what must be done. [CALL: NCO Lessons Learned, Oct 89]

LL - The troops must be kept informed and the NCO must do it. [CALL: NCO Lessons Learned, Oct 89]

LL - The NCO must know and understand the commander's intent if he is to be effective and accomplish the unit's mission. [CALL: NCO Lessons Learned, Oct 89]

LL - The CSM is a vital source of information to the commander and is a key leader in dealing with NCOs. [CALL: NCO Lessons Learned, Oct 89]

LL - The command sergeant major has a tremendous impact on the soldier's performance, team cohesion, and unit effectiveness. He looks out for the welfare of 
their men and can foster a positive command climate. [CALL: NCO Lessons Learned, Oct 89]

LL - The CSM can greatly assist by:

* Identifying, correcting, and bringing to the commander's attention NCO leadership problems.

* Moving with the commander to assess unit morale and logistics problems. [CALL: NCO Lessons Learned, Oct 89]

LL - Doing all oneself simply will not work. There may be short-term success; but in the long run only disaster will result. Give subordinates responsibilities, train them to standard, give them authority, and hold them accountable. [CALL 90-6: The Musicians of Mars]

\section{Brigade command posts support synchronization by acquiring, evaluating, and} communicating information.

LL - The commander and XO should ensure that the tracking of enemy events related to the commander's intent during the battle is coordinated. [Combat Training Centers (CTCs) Bulletin No. 93-4, p. 27]

LL - Of major concern, battle tracking continues to cause problems for brigade staffs. [Combat Training Centers (CTCs) Bulletin No. 94-1, p. 5]

LL - Commanders do not always have a clear vision of the battlefield because reports are either untimely or staff members do not seek and compile the critical information the commander needs to make his assessment. Battle tracking is an integrated staff effort at the command post. The key person in charge of the shift, the battle captain, must be able to manage the information flow in the command post and integrate all elements to track the battle. Units will succeed in this task if they take the time to establish an SOP for what information is required, and how it is received, tracked within the command post, and then distributed. If units establish a battle-tracking system that corresponds with critical information requirements for the commander, chances of mission success will greatly improve. [Combat Training Centers (CTCs) Bulletin No. 94-1, p. 5]

LL - * Minimum critical information (MCI) that should be tracked in the battalion TOC (both friendly and enemy forces) includes: relative combat power, unit locations, obstacle overlay, execution matrix, task organization, and personnel status.

* Information boards need to be updated (at a minimum) every four hours. 
* Have a designated individual track minimum critical information (MCI).

* Conduct formal shift change briefs in the TOC. This process forces information updates and sharing.

* Logs and journals (DA 1594s) are excellent tools for details and historical purposes. However, consider adding a "significant activities" board in the TOC to share information. This should display significant activities of all the battlefield operating systems in the TOC. [The Center for Army Lessons Learned, News from the Front!]

LL - Situation assessment is not something you do just during mission analysis. It must be a continuous activity to avoid delays in comprehending important changes and events and to maintain the ability to respond rapidly. A good understanding of the situation is a start point for all staff operations. [The Center for Army Lessons Learned (CALL) Newsletter No. 90-8: Special Edition: Winning in the Desert II, p. 24]

LL - All uncertainties as to enemy status and responses, friendly capabilities and successes, terrain conditions, etc., should be resolved or reduced if possible, given the time available. If they cannot be resolved, then they must be treated as uncertainties -- not assumed away -- and contingencies considered for the most likely branches. [The Center for Army Lessons Learned (CALL) Newsletter No. 90-8: Special Edition: Winning in the Desert II, p. 25]

LL - Under stress we revert to doing the things that are easiest and that we know best. Try to recognize when you are spending too much time doing simple tasks such as collating or sending messages. Make sure you are not focusing on simple, rote tasks to avoid difficult, but more important thinking tasks. Do not limit solutions to your branch specialty. Maintain a combined arms perspective and remember that staff coordination is essential to battlefield synchronization. [The Center for Army Lessons Learned (CALL) Newsletter No. 90-8: Special Edition: Winning in the Desert II, p. 25]

LL - Good communication is always difficult, but stress and fatigue will greatly increase misunderstandings. Just because something is very clear to you, do not assume that it is clear to everyone else. Double-check communication. Use backbriefs and rehearsals. Staff visits and follow ups also foster good communications and can keep problems from recurring. [The Center for Army Lessons Learned (CALL) Newsletter No. 90-8: Special Edition: Winning in the Desert II, p. 25]

LL - There is a human tendency to listen only to information that confirms our own beliefs and ignore or minimize information that is contrary. This appears to be especially true in stressful situations. Commanders and staffs must remain open to opposing opinions and assure that they have good reasons for rejecting contrary 
information. [The Center for Army Lessons Learned (CALL) Newsletter No. 90-8: Special Edition: Winning in the Desert II, p. 26]

LL - Battles are won and lost on the basis of errors. Commanders and staffs must be on the constant lookout for flaws in concepts, omissions in synchronization, and errors in critical estimates. Follow these guidelines for eliminating errors:

* Reflect on what is being done and why.

* Make a rough first guess for comparison to calculations.

* Have others check critical work.

* Check for consistency in estimates, concepts, and orders.

* Make sure that your message is understood.

* $\quad$ Follow good sleep discipline.

* Watch for waning concentration and automatic behavior. [The Center for Army Lessons Learned (CALL) Newsletter No. 90-8: Special Edition: Winning in the Desert II, p. 26]

LL - The 24 hours a day war demands that TOC personnel be trained in all aspects of the TOC operation. [CALL Bulletin No 1-86, Jul 86]

LL - Shift changeovers can cause a loss of continuity during an operation. No matter how good the changeover briefing is, there will be something lost. The shift schedules also gets disrupted because of TOC displacements which should occur frequently. [CALL Bulletin No 1-86]

LL - All TOC personnel must understand the commander's concept and intent and what is supposed to happen at TAIs and NAIs. Supervisory personnel must be able to make basic tactical decisions, based on the situation, in the absence (for whatever the reason) of key leaders. [CALL Bulletin No 1-86]

LL - The task force S2 section must continuously anticipate "tomorrow's battle" requirements to facilitate future planning. [CALL Bulletin No 3]

LL - The BICC performs the preliminary analysis for future operations. The S2 receives, analyzes, and disseminates current battle information to the commander. The next battle is an extension of the current operation. The BICC continues to develop the IPB to support the next operation. [CALL Bulletin No 3] 
LL - Offensive IPB enables the commander and his staff to maintain the initiative with all available combat power by focusing the reconnaissance and surveillance effort. [NTC Lessons Learned, CALL Bulletin No 4: Command and Control System]

LL - Proper reporting and dissemination of collected combat information is essential to success of the reconnaissance effort. [NTC Lessons Learned, CALL Bulletin No 4: Command and Control System]

LL - The task force commander must have an effective TOC to react to the fast pace on the AirLand battlefield. [NTC Lessons Learned, CALL Bulletin No 4: Command and Control System]

LL - The TOC should analyze all sources of information and make recommendations to the task force commander. The TOC must keep abreast of adjacent units and advise the commander, companies, and separate platoons accordingly. The TOC should be able to plan for the next battle and direct functions for the commander which he is too busy to personally direct. [NTC Lessons Learned, CALL Bulletin No 4: Command and Control System]

LL - TOCs should:

* Track the battle. This consists of monitoring current location, activity, and combat power of task force elements; monitoring the progress of adjacent and supporting units, and updating templates.

* Analyze data. The TOC must analyze all incoming reports from the company/teams, other task force elements, higher headquarters, adjacent units and supporting units. After the TOC analyzes these reports, they pass the results to the task force commander and recommend any changes to the present course of action.

* Plan for future operations. The significant activity in adjacent and higher units or receipt of the warning order initiates planning. The TOC staff must immediately begin to consider possible courses of actions, probable enemy actions, support requirements, etc. The TOC must also initiate a task force warning order and ensure that the S1-S4 are immediately brought in on the planning.

* Disseminate information. The TOC should keep the battalion/task force informed of any action or development that might influence the battle. One technique is to provide an intel summary from analyzed reports off the O\&I net. This summary should be concise and given periodically over the battalion net. This summary could also be used to inform higher headquarters. 
* The TOC must be able to break-down, move, and set-up quickly and with the minimum disruption to its operation.

* The TOC must be able to write and produce overlays in the field under all conditions. [NTC Lessons Learned, CALL Bulletin No. 4: Command and Control System]

3. The brigade commander sees and visualizes the battlefield.

LL - Do not underestimate your opponent. At the outbreak of conflicts, there is a common tendency to underestimate the opponent's military abilities. At the beginning of the U.S. Civil War, both soldiers thought they could win quickly and easily. In many training exercises, U.S. planners seem to assume that because the opponent is culturally different, not a world power, or technologically inferior, he will be easy to defeat. After the enemy is more successful than anticipated, then it is common to overestimate his capabilities. Maintain a realistic, balanced perspective on enemy capabilities. Plan ahead. The reality of violent combat can cause commanders and staffs to concentrate on just the immediate battle. This is especially true if operations do not go exactly as planned. Yet most of our potential adversaries fight in echelons, and, in a fast-paced battle, we must be preparing to meet the second echelon while fighting the first. Eliminate future surprises by planning for the next battle during the current fight. See the entire battlefield. Under stress it is more comfortable to narrow your focus to your immediate control and within your own boundaries. What is happening on your flanks and rear is critical to accomplishing your mission. The support you might get from the flanks and from higher command could be critical to accomplishing your mission. Commanders and staffs must consider the bigger picture when planning and conducting their operations. [The Center for Army Lessons Learned (CALL) Newsletter No. 90-8: Special Edition: Winning in the Desert II, p. 23]

LL - Some leaders try to analyze and decide by themselves. They isolate themselves from open discussion of their ideas and plans. Under stress, individuals' judgment is typically degraded, and it becomes more crucial than ever for leaders to use their senior staff to test the validity of their ideas. [The Center for Army Lessons Learned (CALL) Newsletter No. 90-8: Special Edition: Winning in the Desert II, p. 24]

LL - Situation assessment is not something you do just during mission analysis. It must be a continuous activity to avoid delays in comprehending important changes and events and to maintain the ability to respond rapidly. A good understanding of the situation is a start point for all staff operations. [The Center for Army Lessons Learned (CALL) Newsletter No. 90-8: Special Edition: Winning in the Desert II, p. 24] 
LL - All uncertainties as to enemy status and responses, friendly capabilities and successes, terrain conditions, etc., should be resolved or reduced if possible, given the time available. If they cannot be resolved, then they must be treated as uncertainties -- not assumed away -- and contingencies considered for the most likely branches. [The Center for Army Lessons Learned (CALL) Newsletter No. 90-8: Special Edition: Winning in the Desert II, p. 25]

LL - Commanders must visualize the battlefield:

* Study enemy order of battle, doctrine, and tactics. A thorough knowledge of the enemy will allow the commander to visualize enemy actions as certain cues are seen or reported.

* A thorough IPB to include verification of the situation template by recon assets will add to the mental picture.

* Detailed, yet concise, reports from trusted agents or subordinates regarding both friendly and enemy movements or activities throughout the course of the battle is a necessity.

* The unit tactical operations center must forward concise reports to the commander on information gained from higher and adjacent units. This must include both friendly and enemy activities.

* Personal reconnaissance of the battlefield must be done for each new mission regardless of previous familiarity with the terrain. [CALL Compendium, Vol. 1: Heavy Forces, Fall 88]

\section{The brigade commander directs changes to the operation or plan.}

LL - The following procedures warrant special consideration:

* Warning orders enjoy greater emphasis.

* Units must routinely move without the presence of commanders. They must train to this requirement.

* To the maximum degree possible, commanders and staffs should go forward to issue orders. This buys critical time for subordinate commanders.

* Don't drive when you can fly. Maximum use should be made of aviation assets to buy commanders time. This is true at all levels of command. [The Center for Army Lessons Learned (CALL) Newsletter No. 90-8: Special Edition: Winning in the Desert II, p. 23] 
LL - Mission-type orders are more effective in fast-paced modern warfare with all its uncertainties. However, the opposite extreme should be avoided. Commanders should clearly specify intent and provide sufficient control measures to ensure unity of purpose. [The Center for Army Lessons Learned (CALL) Newsletter No. 90-8: Special Edition: Winning in the Desert II, p. 25]

LL - Good communication is always difficult, but stress and fatigue will greatly increase misunderstandings. Just because something is very clear to you, do not assume that it is clear to everyone else. Double-check communication. Use backbriefs and rehearsals. Staff visits and follow ups also foster good communications and can keep problems from recurring. [The Center for Army Lessons Learned (CALL) Newsletter No. 90-8: Special Edition: Winning in the Desert II, p. 25]

LL - Send multiple warning orders to maximize subordinate planning and preparation time. [CALL Newsletter No. 93-3: The Battalion and Brigade Battle Staff, p. 3]

LL - Conduct parallel planning by providing subordinate commanders the concept of the operation and specified tasks when they are developed. [CALL Newsletter No. 933: The Battalion and Brigade Battle Staff, p. 3]

LL - Determine the necessary information required to complete the commander's METTT analysis. [CALL Newsletter No. 93-3: The Battalion and Brigade Battle Staff, p. 4]

LL - Assist the commander by identifying and listing constraints, restrictions, and specified and implied tasks. [CALL Newsletter No. 93-3: The Battalion and Brigade Battle Staff, p. 6]

LL - Analyze the mission completely by accomplishing the following:

* Review the commander's intent of the two higher echelons.

* Identify the unit's constraints and restrictions.

* Identify the unit's specified and implied tasks.

* Derive the essential tasks from the specified and implied tasks. [CALL Newsletter No. 93-3: The Battalion and Brigade Battle Staff, p. 6]

LL - Commander: determine the amount of planning guidance the staff requires to develop the plan. [CALL Newsletter No. 93-3: The Battalion and Brigade Battle Staff, p. 9]

LL - Commander: sketch the initial concept of the operation for the staff. [CALL Newsletter No. 93-3: The Battalion and Brigade Battle Staff, p. 9] 
LL - Staff: take notes on the commander's guidance. [CALL Newsletter No. 93-3: The Battalion and Brigade Battle Staff, p. 9]

LL - Commander: have the staff backbrief you on your guidance. [CALL Newsletter No. 93-3: The Battalion and Brigade Battle Staff, p. 9]

LL - Commander: preserve subordinate commander's time. [CALL Newsletter No. 933: The Battalion and Brigade Battle Staff, p. 12]

LL - Commander and staff: develop a planning and preparation timeline. [CALL Newsletter No. 93-3: The Battalion and Brigade Battle Staff, p. 12]

LL - Commander and staff: refine the timeline by listing tasks to be accomplished during planning and preparation and the person responsible to complete the task. [CALL Newsletter No. 93-3: The Battalion and Brigade Battle Staff, p. 12]

LL - Commander and staff: use the timeline to track the progression of preparation. [CALL Newsletter No. 93-3: The Battalion and Brigade Battle Staff, p. 12]

LL - Staff: develop courses of action together to integrate all battlefield operating systems. [CALL Newsletter No. 93-3: The Battalion and Brigade Battle Staff, p. 16]

LL - Staff: ensure that the course of action is complete, consistent with doctrine, complies with the commander's guidance, feasible, and unique. [CALL Newsletter No. 93-3: The Battalion and Brigade Battle Staff, p. 16]

LL - Staff: develop courses of action that identify what, when, where, how, and why the unit will execute. [CALL Newsletter No. 93-3: The Battalion and Brigade Battle Staff, p. 16]

LL - Commander: if time is short, remain with the staff and have it assist you in courseof-action development. [CALL Newsletter No. 93-3: The Battalion and Brigade Battle Staff, p. 16]

LL - Commander and staff: use the war-gaming sequence to develop and begin synchronizing the operation. [CALL Newsletter No. 93-3: The Battalion and Brigade Battle Staff, p. 22]

LL - Staff: conduct a detailed analysis with the entire staff to determine the recommended course of action. [CALL Newsletter No. 93-3: The Battalion and Brigade Battle Staff, p. 23] 
LL - Staff: use a decision matrix with criteria developed from commander's guidance, critical events, and other significant factors pertaining to the mission to analyze the courses of action. [CALL Newsletter No. 93-3: The Battalion and Brigade Battle Staff, p. 23]

LL - Staff: quantify each course of action by ranking them for each criterion. [CALL Newsletter No. 93-3: The Battalion and Brigade Battle Staff, p. 23]

LL - Commander: specify through guidance the type of order to issue (written five paragraph, oral, overlay, or matrix). [CALL Newsletter No. 93-3: The Battalion and Brigade Battle Staff, p. 27]

LL - Staff: develop a preformatted order to use for written orders. [CALL Newsletter No. 93-3: The Battalion and Brigade Battle Staff, p. 27]

LL - Staff: organize reproduction by centralizing collection of the portions of the order and its production. [CALL Newsletter No. 93-3: The Battalion and Brigade Battle Staff, p. 27]

LL - Staff: select an area to reproduce the order that will not interfere with the staff's work. [CALL Newsletter No. 93-3: The Battalion and Brigade Battle Staff, p. 27]

LL - Staff: use a mimeograph or a photocopier to speed reproduction of order text. [CALL Newsletter No. 93-3: The Battalion and Brigade Battle Staff, p. 27]

LL - Staff: use a photocopier to reproduce graphics. [CALL Newsletter No. 93-3: The Battalion and Brigade Battle Staff, p. 27]

LL - Commander: provide clear and detailed planning guidance, and remain close to the staff during the MDMP. [CALL Newsletter No. 93-3: The Battalion and Brigade Battle Staff, p. 28]

LL - Commander: allocate time to review and approve the order before it is reproduced and briefed. [CALL Newsletter No. 93-3: The Battalion and Brigade Battle Staff, p. 28]

LL - Staff: organize the briefing to follow the written order format. [CALL Newsletter No. 93-3: The Battalion and Brigade Battle Staff, p. 31]

LL - Commander: control the briefing to stop distractions. [CALL Newsletter No. 93-3: The Battalion and Brigade Battle Staff, p. 31] 
LL - Commander: review your intent and address each subordinate directly to ensure that he understands how his mission relates to your intent. [CALL Newsletter No. 93-3: The Battalion and Brigade Battle Staff, p. 31]

LL - Staff: use graphic aids to better present the order. [CALL Newsletter No. 93-3: The Battalion and Brigade Battle Staff, p. 31]

LL - Commander: conduct confirmation briefs and backbriefs with subordinates. [CALL Newsletter No. 93-3: The Battalion and Brigade Battle Staff, p. 34]

LL - Frequent changes in task organization should be avoided. The teamwork advantage is often far more important than a slightly more desirable mix of forces. Also, the timing of a change requires careful analysis. The significant advantage of a daylight link-up and the time required to receive the OPORD and to coordinate SOPs and LOGPACs must be considered. [NTC Commander's Memorandum]

LL - Adhere to a disciplined system of time management. Someone must establish a timed critical list based on each mission and enforce it. The 1/3-2/3 rule is a guide but METT-T dependent. [CALL Compendium, Vol. 1: Heavy Forces, Fall 88]

LL - One of the best forms of commander's guidance is rough maneuver and fire support graphics drawn by the commander and given to the staff to focus staff planning. [CALL Compendium, Vol. 1: Heavy Forces, Fall 88]

LL - Employ clear/concise written orders:

* Clear written orders greatly reduce the fog of war to tired leaders. They provide a checklist for exhausted leaders to remind themselves what their mission and the commander's intent really is.

* The limiting factor on the conciseness of the order is how well the unit understands the commander's intent. [CALL Compendium, Vol. 1: Heavy Forces, Fall 88]

LL - Immediately after the commander issues the order, his subordinates backbrief the commander on their tentative concepts of operations. If these are in line with the commander's intent, his subordinates understand the order. If not, the commander clarifies the plan. Ensure that all slice elements backbrief. [CALL Compendium, Vol. 1: Heavy Forces, Fall 88]

LL - Leaders must give the greatest amount of available time to subordinate leaders. Use no more than $1 / 3$ of the available time for planning and preparation of the order. Provide no less than $2 / 3$ of the available time for subordinate units to prepare for 
combat. Prioritize critical tasks and use available time to concentrate on those tasks. [CALL 89-1: Non-Mechanized Forces, Spring 89]

LL - Time available dictates the amount of detail allowed in planning. [CALL 89-1: Non-Mechanized Forces, Spring 89]

LL - Reverse planning is an indispensable technique for time management. Begin with the time an event must take place (i.e., line of departure [LD] time) and estimate the time each prior event will take. [CALL 89-1: Non-Mechanized Forces, Spring 89]

LL - A brief order that clearly defines the intent of the commander requires less effort to execute. It is better to provide a good plan quickly and refine it later, than to delay preparation until the best plan is completed and time is limited. [CALL 89-2: Heavy-Light Lessons Learned]

LL - Control of FRAGOs and warning orders. Many units are running into difficulty when the TAC, rear, and the main issue FRAGOs and warning orders, especially when duplicate numbers are issued. [CALL: Corps-Division Lessons Learned]

LL - Hard copy follow-up on verbal orders/decisions. Many decisions are made in faceto-face discussions between commanders. Sometimes problems arise when these discussions are away from the CP. This causes problems for the staff in synchronizing the various aspects of the operation as well as keeping the other players informed. Hard copy backup needs to be generated to assist in this process. [CALL: Corps-Division Lessons Learned, Nov 89]

\section{Brigade command posts manage and maintain command, control, and communications.}

LL - * Ensure that the succession of command is specified by SOP or OPORD; identify the primary location on the battlefield of the second in command.

* Ensure that the unit knows the priority for command succession.

* $\quad$ Ensure that personnel identified in the succession of command are thoroughly familiar with the mission and the commander's intent through use of backbriefs and rehearsals.

* Continue to develop junior leaders through effective training. [Combat Training Centers (CTCs) Bulletin No. 94-1, p. 19]

LL - The admin/log center (ALC) assumes TOC operations when the TOC is destroyed or incapacitated, and continues until the TOC becomes operational or a replacement headquarters assumes control of task force operations. Criteria for assumption of 
this on-order mission must be specified in the unit tactical SOP. [NTC Lessons Learned, CALL Bulletin No 4: Command and Control System]

LL - Destruction of the TOC, while a catastrophic loss, must not prevent the task force from continuing its mission. [NTC Lessons Learned, CALL Bulletin No 4: Command and Control System]

LL - Staff personnel from the ALC must be cross-trained to perform TOC functions with minimal loss of continuity of command and control. [NTC Lessons Learned, CALL Bulletin No 4: Command and Control System]

LL - Situation maps and unit status boards reflecting the current tactical status of each company/team are examples of the equipment that must be available in the ALC for immediate use upon assumption of the TOC mission. [NTC Lessons Learned, CALL Bulletin No 4: Command and Control System]

LL - ALC personnel must track the battle and keep abreast of the current tactical situation at all times. [NTC Lessons Learned, CALL Bulletin No 4: Command and Control System]

LL - At a minimum, the ALC must have all friendly situation information posted, the most recent intelligence preparation of the battlefield (IPB) update, the most current doctrinal and situational templates of suspected enemy locations, and known enemy locations. Both the obstacle plan and target overlay must be posted and kept current. [NTC Lessons Learned, CALL Bulletin No 4: Command and Control System]

LL - Communications equipment must be available to provide the ALC with an equivalent capability to exercise command and control over subordinate elements as well as communicate with higher headquarters (brigade) and attached or supporting elements. [NTC Lessons Learned, CALL Bulletin No 4: Command and Control System]

LL - All the NCOs, and even some of the more experienced soldiers of lower rank, must stay aware of the tactical situation and be prepared mentally to take charge. [CALL: NCO Lessons Learned]

LL - NCOs must help set priorities of work by clarifying through the chain of command what must be done. [CALL: NCO Lessons Learned]

LL - The troops must be kept informed and the NCO must do it. [CALL: NCO Lessons Learned]

\section{The brigade consolidates and reorganizes.}


LL - All the NCOs, and even some of the more experienced soldiers of lower rank, must stay aware of the tactical situation and be prepared mentally to take charge. [CALL: NCO Lessons Learned, Oct 89]

LL - NCOs must help set priorities of work by clarifying through the chain of command what must be done. [CALL: NCO Lessons Learned, Oct 89]

LL - The troops must be kept informed and the NCO must do it. [CALL: NCO Lessons Learned, Oct 89] 


\section{GATE TASKS}

This component identifies critical individual or collective tasks upon which each BF task identified in the task list is dependent. In order to ensure efficient and safe training of the major task, the participants should have achieved a level of proficiency or understanding in these gate tasks.

\section{TASK}

1. The brigade commander directs and leads subordinate forces.

\section{INDIVIDUAL/COLLECTIVE PROFICIENCIES}

Bde Cdr

[STP 21-II-MQS, Common Tasks]

- Establish a positive command climate. [03-9001.11-0002]

- Motivate subordinates to accomplish unit missions. [03-9001.14-0002]

- Apply the ethical decision-making process as a commander or staff officer. [03-9001.10-0004]

- Communicate effectively as a commander or staff officer. [03-9001.12-0003]

\section{Bde CSM}

[STP 21-24-MCT, Common Tasks]

- Inspect personnel/equipment. [071-328-5301]

- Conduct OPSEC procedures. [113-573-0002]

- Integrate risk management into mission. [850-001-4001]

\section{Bde FSCOORD/FSO}

[STP 21-II-MQS, Common Tasks]

- Establish a positive command climate. [03-9001.11-0002]

- Motivate subordinates to accomplish unit missions. [03-9001.14-0002]

- Apply the ethical decision-making process as a commander or staff officer. [03-9001.10-0004]

- Communicate effectively as a commander or staff officer. [03-9001.12-0003]

Bde Engr Bn Cdr/Bde Engr [STP 21-II-MQS, Common Tasks]

- Establish a positive command climate. [03-9001.11-0002]

- Motivate subordinates to accomplish unit missions. [03-9001.14-0002] 
- Apply the ethical decision-making process as a commander or staff officer.

[03-9001.10-0004]

- Communicate effectively as a commander or staff officer. [03-9001.12-0003]

Bde ADA Battery Commander/Coordinator (ADO) [STP 21-II-MQS, Common Tasks]

- Establish a positive command climate. [03-9001.11-0002]

- Motivate subordinates to accomplish unit missions. [03-9001.14-0002]

- Apply the ethical decision-making process as a commander or staff officer. [03-9001.10-0004]

- Communicate effectively as a commander or staff officer. [03-9001.12-0003]

\section{TF Cdrs}

[STP 21-II-MQS, Common Tasks]

- Establish a positive command climate. [03-9001.11-0002]

- Motivate subordinates to accomplish unit missions. [03-9001.14-0002]

- Apply the ethical decision-making process as a commander or staff officer. [03-9001.10-0004]

- Communicate effectively as a commander or staff officer. [03-9001.12-0003]

Officer Common Tasks for: Bde XO, Bde S3, Bde S3 Air, Bde S2, Bde S4, Bde USAF ALO, Bde CMLO [STP 21-II-MQS, Common Tasks]

- Apply the ethical decision-making process as a commander or staff officer. [03-9001.10-0004]

- Communicate effectively as a commander or staff officer. [03-9001.12-0003]

2. Brigade command posts support synchronization by acquiring, evaluating, and communicating information.

\section{Bde Cdr}

[STP 21-II-MQS, Common Tasks]

- Communicate effectively as a commander or staff officer. [03-9001.12-0003]

- Implement OPSEC. [03-3711.12-0001]

\section{Bde CSM}

[STP 21-24-MCT, Common Tasks]

- Conduct OPSEC procedures. [113-573-0002] 
[ARTEP-71-3-MTP]

- Maintain the current situation. [71-3-3003]

\section{Bde XO}

[STP 21-II-MQS, Common Tasks]

- Communicate effectively as a commander or staff officer. [03-9001.12-0003]

- Brief to inform, persuade, or direct. [01-9007.01-0250]

- Implement OPSEC. [03-3711.12-0001]

Bde S1 section

[STP 21-II-MQS, Common Tasks]

- Communicate effectively as a commander or staff officer. [03-9001.12-0003]

- Brief to inform, persuade, or direct. [01-9007.01-0250]

- Implement OPSEC. [03-3711.12-0001]

- Report casualties. [121-030-3534]

- Perform wartime strength accounting. [03-0170.01-1005]

\section{Bde S2 section/DS MI Co}

[STP 21-II-MQS, Common Tasks]

- Communicate effectively as a commander or staff officer. [03-9001.12-0003]

- Brief to inform, persuade, or direct. [01-9007.01-0250]

- Implement OPSEC. [03-3711.12-0001]

[STP 17-12-II-MQS, Armor]

- $\quad$ Plan the IPB. [01-3353.02-0090]

[STP 34-35-II-MQS, Intelligence]

- Conduct intelligence liaison. [01-3381.166-5001]

- Participate in the development of intelligence requirements. [01-3381.01-5001]

- Direct the intelligence portion of the IPB process. [01-3381.01-5002]

- Conduct battlefield area evaluation. [01-3381.01-4012]

- Conduct terrain and weather analysis. 
[01-3381.01-4013]

- Conduct threat evaluation. [01-3381.01-4014]

- Participate in the threat integration process. [01-3381.01-4015]

- Conduct situation development. [01-3381.01-4016]

- Conduct target development. [01-3381.01-4017]

- Prepare OB studies. [01-3381.41-4015]

- Produce finished intelligence products from allsource information. [01-3381.41-5003]

- Conduct all-source intelligence analysis. [01-3381.41-4014]

- Analyze intelligence and combat information. [01-3381.39-4004]

- Direct recording and evaluation of information. [01-3381.41-5001]

- Recommend force protection countermeasures. [01-3381.16-5003]

[STP 34-96B14-M-G, Intelligence Analyst]

- Review current intelligence holdings to identify gaps. [301-336-2004]

- Supervise organization and maintenance of order of battle information. [301-336-2001]

- Coordinate targeting function. [301-336-4100]

- Develop doctrinal templates. [301-336-2200]

- Develop situation templates for each avenue of avenue of approach. [301-33602250]

- Develop event templates based on situation templates. [301-336-2251]

- Develop event analysis matrix for each mobility corridor. [301-336-2252]

- Prioritize threat probable COAs. [301-336-3250]

- Develop DST. [301-336-2100]

- Prepare intelligence reports and summaries. [301-336-3105]

- Supervise preparation of intelligence reports and summarizes. [301-336-4050]

- Disseminate intelligence and combat information. [01-3381.39-4005]

- Record intelligence and combat information. [01-3381.39-4003]

- Direct analysis and dissemination of information. [01-3381.41-5002]

- Supervise preparation of written analysis of the 
battlefield area. [301-336-3100]

- Supervise receipt/transfer/storage of classified material. [301-336-3201]

- Disseminate intelligence reports and summaries. [301-336-3106]

- Present intelligence briefings. [301-336-3101]

[ARTEP 34-245-10-DRILL, Intelligence Section]

- Recording intelligence information. [Drill 1]

- Perform IPB. [Drill 2]

- Briefing/transmitting by radio. [Drill 5a]

Bde S3 section/Bde S3 Air/Bde Army Air Command and Control (A2C2) Element

[STP 21-II-MQS, Common Tasks]

- Communicate effectively as a commander or staff officer. [03-9001.12-0003]

- Brief to inform, persuade, or direct. [01-9007.01-0250]

- Implement OPSEC. [03-3711.12-0001]

Bde S4 section/FSB Support Operations section [STP 21-II-MQS, Common Tasks]

- Communicate effectively as a commander or staff officer. [03-9001.12-0003]

- Brief to inform, persuade, or direct. [01-9007.01-0250]

- Implement OPSEC. [03-3711.12-0001]

- Report casualties. [121-030-3534]

[STP 10-92ABDII-MQS, Quartermaster]

- Determine Class V (conventional) requirements. [O1-4000.11-1111]

- Determine and verify water requirements for a unit. [O1-5103.00-0030]

- Assess unit capabilities to support proposed operations. [S3-5101.00-0229]

[STP 10-76Z5-M-G, Senior Supply Sgt]

- Review road movement graphs and tables. [101-522-5503]

[STP 9-91 BCII-MQS, Ordinance]

- Evaluate Class IX performance. [01-4716.26-0002] 
[STP 55-88 II-MQS, Transportation]

- Determine aircraft requirements to move cargo, equipment, and personnel. [ 01-7320.70-0460]

- Request host-nation (HN) transportation support. [01-7320.70-0480]

\section{Bde S5}

[STP 21-II-MQS, Common Tasks]

- Communicate effectively as a commander or staff officer. [03-9001.12-0003]

- Brief to inform, persuade, or direct. [01-9007.01-0250]

- Implement OPSEC. [03-3711.12-0001]

\section{Bde FSCOORD/FSO/FSE/Bde Targeting Officer}

[STP 21-II-MQS, Common Tasks]

- Communicate effectively as a commander or staff officer. [03-9001.12-0003]

- Brief to inform, persuade, or direct. [01-9007.01-0250]

- Implement OPSEC. [03-3711.12-0001]

- Report casualties. [121-030-3534]

[STP 6-13-II-MQS, Artillery]

- Explain employment considerations of FA special munitions. [01-2660.00-2005]

- Advise the maneuver Cdr on employment of COLTs. [01-2840.00-2039]

- Advise maneuver commander on employment of available fire support assets. [01-2999.94-0106]

- Advise the Cdr on the capabilities of available tgt acq assets. [01-3020.00-7002]

- Direct the evaluation and dissemination of intel reports using TACFIRE. [01-2770.01-0114]

- Direct the establishment of and verify Cdr's criteria. [01-2770.01-0115]

[STP 6-13F14-M-G, Artillery]

- Retrieve artillery tgt intel using VFMED. [061-277-4020]

- Analyze the formations of threat forces. [061-284-4000]

- Post information on a SIT MAP/overlay. 
[061-284-1011]

- $\quad$ Produce an HPTL. [061-284-4245]

- Establish FSE commo. [061-284-4021]

\section{Bde Engineer section}

[STP 21-II-MQS, Common Tasks]

- Communicate effectively as a commander or staff officer. [03-9001.12-0003]

- $\quad$ Brief to inform, persuade, or direct. [01-9007.01-0250]

- Implement OPSEC. [03-3711.12-0001]

- Report casualties. [121-030-3534]

[STP 5-21-II-MQS, Engineer]

- Establish intelligence production requirements and essential elements of terrain or engineer information. [01-2250.20-1004]

- Provide input to intelligence preparation of the battlefield. [01-2250.20-1006]

- Evaluate engineer intelligence for dissemination. [01-2250.20-1005]

\section{Bde Signal Support section}

[STP 21-II-MQS, Common Tasks]

- Communicate effectively as a commander or staff officer. [03-9001.12-0003]

- Brief to inform, persuade, or direct. [01-9007.01-0250]

- Implement OPSEC. [03-3711.12-0001]

- Report casualties. [121-030-3534]

[STP 11-25-II-MQS, Signal]

- $\quad$ Provide communications support using FM voice communications. [01-5704.04-9001]

- Manage secure voice communications system. [01-5735.04-0001]

- Direct a net control station operation. [01-5704.04-0003]

- Analyze battlefield spectrum management. [01-5701.07-0003]

- Employ communications system of a maneuver brigade or battalion. [01-5841.07.0001]

- Implement displacement of communications nodes. [01-5754.04-0002] 
- Implement communications system control element operations. [01-5753.07-002]

- Manage network traffic routing. [01-5710.07-002]

- Perform distribution management of communications variables for combat radio operations using battlefield CEOI system. [01-5880.07-001]

- Employ communications system of a maneuver brigade or battalion. [01-5841.07-001]

- Identify the data communications techniques used with tactical communications systems. [01-5769.04-0001]

\section{Bde NBC section}

[STP 21-II-MQS, Common Tasks]

- Communicate effectively as a commander or staff officer. [03-9001.12-0003]

- Brief to inform, persuade, or direct. [01-9007.01-0250]

- Implement OPSEC. [03-3711.12-0001]

- Report casualties. [121-030-3534]

[STP 3-74-II-MQS, Chemical]

- Identify operation and functions of chemical units and staffs. [S1-5060.02-2138]

- Direct CP and TOC internal security operations. [01-3761.00-1103]

\section{Bde Surgeon}

[STP 21-II-MQS, Common Tasks]

- Communicate effectively as a commander or staff officer. [03-9001.12-0003]

- Brief to inform, persuade, or direct. [01-9007.01-0250]

- Implement OPSEC. [03-3711.12-0001]

- Report casualties. [121-030-3534]

[STP 10-92ABDII-MQS, Quartermaster]

- Analyze division medical supply system. [S1-8310.00-6006]

\section{Bde ALO}

- Communicate effectively as a commander or staff 
officer. [03-9001.12-0003]

- Brief to inform, persuade, or direct.

[01-9007.01-0250]

- Implement OPSEC. [03-3711.12-0001]

- Report casualties. [121-030-3534]

\section{Bde AVLO}

[STP 21-II-MQS, Common Tasks]

- Communicate effectively as a commander or staff officer. [03-9001.12-0003]

- Brief to inform, persuade, or direct. [01-9007.01-0250]

- Implement OPSEC. [03-3711.12-0001]

- Report casualties. [121-030-3534]

\section{Bde NGLO}

[STP 21-II-MQS, Common Tasks]

- Communicate effectively as a commander or staff officer. [03-9001.12-0003]

- Brief to inform, persuade, or direct. [01-9007.01-0250]

- Implement OPSEC. [03-3711.12-0001]

- Report casualties. [121-030-3534]

\section{Bde ADO}

[STP 21-II-MQS, Common Tasks]

- Communicate effectively as a commander or staff officer. [03-9001.12-0003]

- Brief to inform, persuade, or direct. [01-9007.01-0250]

- Implement OPSEC. [03-3711.12-0001]

- Report casualties. [121-030-3534]

[STP 44-14-II-MQS, ADA]

- Perform as ADALO. [01-0401.31-0019]

- Analyze ADA perspective of terrain. [01-0401.21-0002]

- Coordinate ADA activities with battery/battalion staff. [01-0401.21-0003]

\section{Bde MP Platoon Ldr}

[STP 21-II-MQS, Common Tasks]

- Communicate effectively as a commander or staff officer. [03-9001.12-0003] 
- Brief to inform, persuade, or direct. [01-9007.01-0250]

- Implement OPSEC. [03-3711.12-0001]

- Report casualties. [121-030-3534]

- Process captured material. [03-3711.13-0001]

\section{Bde HHC Cdr}

[STP 21-II-MQS, Common Tasks]

- Communicate effectively as a commander or staff officer. [03-9001.12-0003]

- Brief to inform, persuade, or direct. [01-9007.01-0250]

- Implement OPSEC. [03-3711.12-0001]

- Report casualties. [121-030-3534]

NCO Common Tasks for: All Primary and Special Staff NCOs

[STO 21-24-SMCTM Common Tasks]

- Prepare SITREP. [071-332-5022]

- Conduct OPSEC procedures. [113-573-0002]

[ARTEP 71-3-MTP]

- Perform duties in a TOC or admin/log CP. [7-1-3904/3036]

- Advise and assist on elements of BOS that support/impact their staff function. [71-3-0001]

- Maintain the current situation. [71-3-3003]

3. The brigade commander sees and visualizes the battlefield.

\section{Bde Cdr}

[STP 21-II-MQS, Common Tasks]

- Solve problems using the military problem-solving process. [03-9001.13-0001]

[STP 17-12-II-MQS, Armor]

- Perform a map reconnaissance. [01-1250.00-0002]

- Plan the IPB. [01-3353.02-0090]

Officer Common Tasks for: Bde XO, Bde S1 section, Bde S2 section, Bde S3 section, Bde S4 section, Bde S5, Bde FSCOORD/FSO/FSE section, Bde Engr section, Bde Signal Support section, Bde NBC section, Bde ALO, Bde Avlo, Bde ADO, TF Cdrs [STP 21-II-MQS, Common Tasks]

- Apply the ethical decision-making process as a 
4. The brigade commander directs changes to the operation or plan. commander or staff officer. [03-9001.10-0004]

- Communicate effectively as a commander or staff officer. [03-9001.12-0003]

\section{Bde Cdr}

[STP 21-II-MQS, Common Tasks]

- Solve problems using the military problem-solving process. [03-9001.13-0001]

- Communicate effectively as a commander or staff officer. [03-9001.12-0003]

- Brief to inform, persuade, or direct. [01-9007.01-0250]

\section{Bde XO}

[STP 21-II-MQS, Common Tasks]

- Solve problems using the military problem-solving process. [03-9001.13-0001]

- Communicate effectively as a commander or staff officer. [03-9001.12-0003]

- Brief to inform, persuade, or direct. [01-9007.01-0250]

\section{Bde S2}

[STP 21-II-MQS, Common Tasks]

- Solve problems using the military problem-solving process. [03-9001.13-0001]

- Communicate effectively as a commander or staff officer. [03-9001.12-0003]

- Brief to inform, persuade, or direct. [01-9007.01-0250]

[ARTEP 71-3-MTP]

- Advise and assist staff on elements of BOS that support/impact their staff function. [71-3-0001]

[STP 34-35-II-MQS, Intelligence]

- Prepare the intelligence estimate. [01-3381.41-4004]

- Prepare intelligence taskings. [01-3381.39-4002]

- Prepare R\&S plan. [01-3381.06-4011]

- Select intelligence and electronic warfare (IEW) operational sites. [01-3381.04-4005]

- Develop an IEW scheme of maneuver. [01-3381.04-5001] 
- $\quad$ Plan employment of IEW assets.

[01-3381.04-5002]

- Plan reconnaissance operations. [01-3381.44-5001]

- Participate in the development of the DST. [01-3381.01-5003]

- Assist in preparing the intelligence annex. [01-3381.41-4001]

- Direct asset management. [01-3381.06-5001]

- Direct collection management operations. [01-3381.06-5001]

[STP 34-96B14-M-G, Intelligence Analyst]

- Supervise preparation of intelligence estimate. [301-336-3104]

- Recommend area of interest and operation based on METT. [301-336-4000]

- Recommend PIR/IR. [301-336-3006]

- Prioritize avenues of approach according to size/directness/length. [301-336-2300]

- Determine air avenues of approach. [301-336-2301]

- Extract from collection plan information to be incorporated into the intelligence annex.

- Draft intelligence estimate. [301-336-2003]

- Prepare draft orders/request to support collection effort. [301-336-2002]

- Supervise preparation of written analysis of the battlefield area. [301-336-3100]

- Prepare intelligence annex to operations plan/operations order. [301-336-3103]

[ARTEP 34-245-10-DRILL, Intelligence Section]

- Intelligence annex to the OPORD. [Drill 3]

- Brigade R\&S planning. [Drill 4b]

\section{Bde S3}

[STP 21-II-MQS, Common Tasks]

- Solve problems using the military problem-solving process. [03-9001.13-0001]

- Communicate effectively as a commander or staff officer. [03-9001.12-0003]

- Brief to inform, persuade, or direct. [01-9007.01-0250] 
[STP 17-12-II-MQS, Armor]

- Perform a map reconnaissance. [01-1250.00-0002]

[STP 21-24-MCT, Common Tasks]

- Prepare a strip map. [551-721-3359]

- Prepare an operation overlay.

[071-332-5000/ 71-3-3002(2) MTP 71-3]

[ARTEP 71-2-MTP/ARTEP 71-3-MTP]

- Prepare plans/orders/annexes IAW FM's 71-2 and 101-5. [7-1-3904(9)/71-3-3002]

\section{[ARTEP 71-3-MTP]}

- Advise and assist staff on elements of BOS that support/impact their staff function. [71-3-0001]

\section{Bde S4/FSB Commander}

[STP 21-II-MQS, Common Tasks]

- Solve problems using the military problem-solving process. [03-9001.13-0001]

- Communicate effectively as a commander or staff officer. [03-9001.12-0003]

- Brief to inform, persuade, or direct. [01-9007.01-0250]

[ARTEP 71-3-MTP]

- Advise and assist staff on elements of BOS that support/impact their staff function. [71-3-0001]

[STP 10-92-ABIDE-MQS, Quartermaster]

- Determine field locations for combat service support units. [01-9253.00-0003]

- Plan for airdrop of supplies. [03-5102.02-0001]

- Plan transport by helicopter. [01-7310.95-0415]

- Prepare command logistics plans, estimates, and orders. [O3-5106.00-0166]

[STP 10-76Z5-M-G, Senior Supply Sgt]

- Provide logistics input for the administrative or logistics order. [101-522-5403]

[STP 9-91 BCII-MQS, Ordinance]

- Develop a concept of support for a brigade level combat operation. [01-9253.00-001] 
[STP 55-88 II-MQS, TRANSPORTATION]

- Plan logistics support for maintenance operations. [01-4720.26-0001]

- Plan evacuation of equipment. [01-4999-26-0001]

- Plan convoy operations. [01-7300.75-0500]

- Plan use of HN assets. [01-7320.70-0435]

- Plan highway net use. [01-7320.75-0535]

Bde S1

[STP 21-II-MQS, Common Tasks]

- Solve problems using the military problem-solving process. [03-9001.13-0001]

- Communicate effectively as a commander or staff officer. [03-9001.12-0003]

- Brief to inform, persuade, or direct. [01-9007.01-0250]

[ARTEP 71-3-MTP]

- Advise and assist staff on elements of BOS that support/impact their staff function. [71-3-0001]

\section{Bde S5}

[STP 21-II-MQS, Common Tasks]

- $\quad$ Solve problems using the military problem-solving process. [03-9001.13-0001]

- Communicate effectively as a commander or staff officer. [03-9001.12-0003]

- Brief to inform, persuade, or direct. [01-9007.01-0250]

[ARTEP 71-3-MTP]

- Advise and assist staff on elements of BOS that support/impact their staff function. [71-3-0001]

\section{Bde FSO}

[STP 21-II-MQS, Common Tasks]

- Solve problems using the military problem-solving process. [03-9001.13-0001]

- Communicate effectively as a commander or staff officer. [03-9001.12-0003]

- Brief to inform, persuade, or direct. [01-9007.01-0250] 
[ARTEP 71-3-MTP]

- Advise and assist staff on elements of BOS that support/impact their staff function. [71-3-0001]

[STP 6-13-II-MQS, Artillery]

- Advise maneuver commander on employment of available of fire support assets. [01-2999.94-0106]

- Plan field artillery support of maneuver units. [01-2999.94-0100]

- Recommend FSCMs. [01-299.94.0101]

- Develop an FS plan to support an offensive OPN. [01-2660.00-2008]

- Develop an FS plan to support a defensive OPN. [01-2660.00-2009]

- Direct the establishment of a fire plan in the TACFIRE computer. [01-2770.01-0115]

- Produce an AGM. [01-2840.00-2038]

- Produce an HPT matrix. [01-2840.00-2044]

[STP 6-13F14-M-G, Artillery]

- Advise supported units of friendly fire support capabilities and limitations. [061-284-3004]

- Recommend and disseminate FSCMs. [061-284-4040]

- Plan and coordinate FS to suppress enemy AD. [061-284-4209]

- Advise maneuver Cdr on employment of tgt acq assets. [061-284-4211]

- Plan FS for Bn or Bde Off Opns. [061-284-4229]

- Plan for employment of smart weapons and special munitions. [061-384-4243]

- Enter, modify, and delete Cdr's criteria by using the VFMED. [061-277-4020]

- Establish and maintain a FASCAM fire plan by using the VFMED. [061-277-4026]

- Write the fires paragraph of maneuver OPORD. [061-284-4244]

- Produce an HPTL. [061-284-4245]

- Write the fire support plan. [061-284-4247]

- Produce an AGM. [061-284-4246]

- Advise maneuver Cdr on employment of tgt acq assets. [061-284-4211]

- Pass fire support information of lower, adjacent, and higher field artillery elements. [061-284-3046] 


\section{Bde ABE}

[STP 21-II-MQS, Common Tasks]

- Solve problems using the military problem-solving process. [03-9001.13-0001]

- Communicate effectively as a commander or staff officer. [03-9001.12-0003]

- Brief to inform, persuade, or direct. [01-9007.01-0250]

[ARTEP 71-3-MTP]

- Advise and assist staff on elements of BOS that support/impact their staff function. [71-3-0001]

[STP 50-1-II-MQS, Engineer]

- Advise the commander on the use of terrain for combat operations. [01-2250.20-1008]

- Advise supported units on engineer capabilities and employment. [01-2250.10-1002]

- Advise the commander on the use of terrain for combat operations. [01-2250.20-1008]

- Plan engineer support for river-crossing operations. [O1-2080.20-1001]

- Prepare engineer annexes. [O1-2250.20-1002]

- Prepare engineer estimates. [O1-2250.20-1001]

\section{Bde ALO}

[STP 21-II-MQS, Common Tasks]

- Solve problems using the military problem-solving process. [03-9001.13-0001]

- Communicate effectively as a commander or staff officer. [03-9001.12-0003]

- Brief to inform, persuade, or direct. [01-9007.01-0250].

\section{[ARTEP 71-3-MTP]}

- Advise and assist staff on elements of BOS that support/impact their staff function. [71-3-0001]

\section{Bde AVLO}

[STP 21-II-MQS, Common Tasks]

- Solve problems using the military problem-solving process. [03-9001.13-0001]

- Communicate effectively as a commander or staff 
officer. [03-9001.12-0003]

- Brief to inform, persuade, or direct. [01-9007.01-0250]

[ARTEP 71-3-MTP]

- Advise and assist staff on elements of BOS that support/impact their staff function. [71-3-0001]

\section{Bde ADO}

[STP 21-II-MQS, Common Tasks]

- Solve problems using the military problem-solving process. [03-9001.13-0001]

- Communicate effectively as a commander or staff officer. [03-9001.12-0003]

- Brief to inform, persuade, or direct. [01-9007.01-0250]

\section{[ARTEP 71-3-MTP]}

- Assist in coordinating air defense operations. [71-3-6001]

- Advise and assist staff on elements of BOS that support/impact their staff function. [71-3-0001]

5. Brigade command posts manage and maintain command, control, and communications.

\section{Bde Cdr}

[STP 21-II-MQS, Common Tasks]

- Communicate effectively as a commander or staff officer. [03-9001.12-0003]

- Brief to inform, persuade, or direct. [01-9007.01-0250]

- Implement OPSEC. [03-3711.12-0001]

- Implement MOPP. [04-5030.00-2013]

- Prepare for an NBC attack. [04-5030.00-2017]

- Supervise unit response to chemical or biological attack. [04-5030.00-2006]

- Supervise NBC decontamination. [04-5030.00-2020]

- Report casualties. [121-030-3534]

[ARTEP 71-3-MTP]

- Assist in site selection for command and control facilities to include splitting of CPs. [71-3-1501]

[ARTEP 71-2-MTP]

- Assist in planning for establishment/ occupy/depart 
of assembly areas. [7-1-3002]

- Assist in and execute plan for medical assistance and evacuation for unit and staff personnel. [7-1-3912(8)]

\section{Bde XO}

[STP 21-II-MQS, Common Tasks]

- Communicate effectively as a commander or staff officer. [03-9001.12-0003]

- Brief to inform, persuade, or direct. [01-9007.01-0250]

- Implement OPSEC. [03-3711.12-0001]

- Implement MOPP. [04-5030.00-2013]

- Prepare for an NBC attack. [04-5030.00-2017]

- Supervise unit response to chemical or biological attack. [04-5030.00-2006]

- Supervise NBC decontamination. [04-5030.00-2020]

- Report casualties. [121-030-3534]

[ARTEP 71-3-MTP]

- Assist in site selection for command and control facilities to include splitting of CPs. [71-3-1501]

- Maintain the current situation. [71-3-3003]

[ARTEP 71-2-MTP]

- Assist in planning for establishment/ occupy/depart of assembly areas. [7-1-3002]

- Assist in and execute plan for medical assistance and evacuation for unit and staff personnel. [7-1-3912(8)]

\section{Bde Signal Support section}

[STP 21-II-MQS, Common Tasks]

- Communicate effectively as a commander or staff officer. [03-9001.12-0003]

- Brief to inform, persuade, or direct. [01-9007.01-0250]

- Implement OPSEC. [03-3711.12-0001]

- Implement MOPP. [04-5030.00-2013]

- Prepare for an NBC attack. [04-5030.00-2017]

- Supervise unit response to chemical or biological attack. [04-5030.00-2006]

- Supervise NBC decontamination. 
[04-5030.00-2020]

- Report casualties. [121-030-3534]

[ARTEP 71-3-MTP]

- Assist in site selection for command and control facilities to include splitting of CPs. [71-3-1501]

- Maintain the current situation. [71-3-3003]

[ARTEP 71-2-MTP]

- Assist in planning for establishment/occupy/depart of assembly areas. [7-1-3002]

- Assist in and execute plan for medical assistance and evacuation for unit and staff personnel. [7-1-3912(8)]

[STP 11-25-II-MQS, Signal]

- Provide communications support using FM voice communications. [01-5704.04-9001]

- Manage secure voice communications system. [01-5735.04-0001]

- Direct a net control station operation. [01-5704.04-0003]

- Analyze battlefield spectrum management. [01-5701.07-0003]

- Employ communications system of a maneuver brigade or battalion. [01-5841.07.0001]

- Implement displacement of communications nodes. [01-5754.04-0002]

- Implement communications system control element operations. [01-5753.07-002]

- Manage network traffic routing. [O1-5710.07-002]

- Perform distribution management of communications variables for combat radio operations using battlefield CEOI system. [O1-5880.07-001]

- Identify the data communications techniques used with tactical communications systems. [O1-5769.04-0001]

\section{Bde HHC Cdr}

[STP 21-II-MQS, Common Tasks]

- Communicate effectively as a commander or staff officer. [03-9001.12-0003]

- $\quad$ Brief to inform, persuade, or direct. 
[01-9007.01-0250]

- Implement OPSEC. [03-3711.12-0001]

- Implement MOPP. [04-5030.00-2013]

- Prepare for an NBC attack. [04-5030.00-2017]

- Supervise unit response to chemical or biological attack. [04-5030.00-2006]

- Supervise NBC decontamination. [04-5030.00-2020]

- Report casualties. [121-030-3534]

[ARTEP 71-3-MTP]

- Assist in site selection for command and control facilities to include splitting of CPs. [71-3-1501]

- Maintain the current situation. [71-3-3003]

[STP 17-12-II-MQS, Armor]

- Plan and direct combat service support operations at company level. [3-1270.00-0002]

Officer Common Tasks for: Bde S1 section, Bde S3 section, Bde S4 section, Bde S5, Bde FSE section, Bde ABE section, Bde NBC section, FSB support operations section, Bde ALO, Bde AVLO, Bde NGLO, Bde ADALO, Bde MP PIt Ldr, liaison officers (LNOs), Bde battle captains, Bde CPs' information managers.

[STP 21-II-MQS, Common Tasks]

- Communicate effectively as a commander or staff officer. [03-9001.12-0003]

- Brief to inform, persuade, or direct. [01-9007.01-0250]

- Implement OPSEC. [03-3711.12-0001]

- Implement MOPP. [04-5030.00-2013]

- Prepare for an NBC attack. [04-5030.00-2017]

- Supervise unit response to chemical or biological attack. [04-5030.00-2006]

- Supervise NBC decontamination. [04-5030.00-2020]

- Report casualties. [121-030-3534]

[ARTEP 71-3-MTP]

- Assist in site selection for command and control facilities to include splitting of CPs. [71-3-1501]

- Maintain the current situation. [71-3-3003] 
[ARTEP 71-2-MTP]

- Assist in planning for establishment/occupy/depart of assembly areas. [7-1-3002]

- Assist in and execute plan for medical assistance and evacuation for unit and staff personnel. [7-1-3912(8)]

6. The brigade consolidates and reorganizes.

\section{Bde Cdr}

[STP 21-II-MQS, Common Tasks]

- Communicate effectively as a commander or staff officer. [03-9001.12-0003]

- Solve problems using the military problem-solving process. [03-9001.13-0001]

- Brief to inform, persuade, or direct. [01-9007.01-0250]

- Supervise the management of accident risk in unit operations. [03-9003.02-0001]

- Implement OPSEC. [03-3711.12-0001]

[STP 21-24-MCT, Common Tasks]

- Prepare SITREP. [071-332-5022]

\section{Bde XO}

[STP 21-II-MQS, Common Tasks]

- Communicate effectively as a commander or staff officer. [03-9001.12-0003]

- Solve problems using the military problem-solving process. [03-9001.13-0001]

- Brief to inform, persuade, or direct. [01-9007.01-0250]

- Supervise the management of accident risk in unit operations. [03-9003.02-0001]

- Implement OPSEC. [03-3711.12-0001]

[STP 21-24-MCT, Common Tasks]

- Prepare SITREP. [071-332-5022]

\section{Bde CSM}

[STP 21-24-MCT, Common Tasks]

- Supervise PMCS. [091-309-0710]

- Inspect personnel/equipment. [071-328-5301]

- Prepare SITREP. [071-332-5022]

- Supervise unit preventive medicine and field 
sanitation procedures. [081-831-0102]

- Conduct OPSEC procedures. [113-573-0002]

- Supervise handling of enemy personnel and equipment. [191-379-4450]

[ARTEP 71-3-MTP]

- Assist in site selection for command and control facilities to include splitting of CPs. [71-3-1501]

[ARTEP 71-2-MTP]

- Assist in and execute plan for medical assistance and evacuation for unit and staff personnel. [7-1-3912[8]]

- Assist in planning for establishment/occupy/depart of assembly areas. [7-1-3002]

\section{Bde $\mathrm{S3}$ section}

[STP 21-II-MQS, Common Tasks]

- Communicate effectively as a commander or staff officer. [03-9001.12-0003]

- Solve problems using the military problem-solving process. [03-9001.13-0001]

- Brief to inform, persuade, or direct. [01-9007.01-0250]

- Supervise the management of accident risk in unit operations. [03-9003.02-0001]

- Implement OPSEC. [03-3711.12-0001]

[STP 21-24-MCT, Common Tasks]

- Prepare SITREP. [071-332-5022]

[ARTEP 71-3-MTP]

- Advise and assist staff on elements of BOS that support/impact their staff function. [71-3-0001]

- Assist in site selection for command and control facilities to include splitting of CPs. [71-3-1501]

[ARTEP 71-2-MTP]

- Assist in planning for establishment/ occupy/depart of assembly areas. [7-1-3002]

\section{Bde $\mathbf{S 2}$ section}

[STP 21-II-MQS, Common Tasks]

- Communicate effectively as a commander or staff 
officer. [03-9001.12-0003]

- Solve problems using the military problem-solving process. [03-9001.13-0001]

- Brief to inform, persuade, or direct. [01-9007.01-0250]

- Supervise the management of accident risk in unit operations. [03-9003.02-0001]

- Implement OPSEC. [03-3711.12-0001]

- Process captured material. [03-3711.13-0001]

[ARTEP 71-3-MTP]

- Advise and assist staff on elements of BOS that support/impact their staff function. [71-3-0001]

[STP 21-24-MCT, Common Tasks]

- Prepare SITREP. [071-332-5022]

\section{Bde S1 section}

[STP 21-II-MQS, Common Tasks]

- Communicate effectively as a commander or staff officer. [03-9001.12-0003]

- Solve problems using the military problem-solving process. [03-9001.13-0001]

- Brief to inform, persuade, or direct. [01-9007.01-0250]

- Supervise the management of accident risk in unit operations. [03-9003.02-0001]

- Implement OPSEC. [03-3711.12-0001]

- Perform wartime strength accounting. [03-0170.01-1005]

[STP 21-24-MCT, Common Tasks]

- Prepare SITREP. [071-332-5022]

[ARTEP 71-3-MTP]

- Assist in site selection for command and control facilities to include splitting of CPs. [71-3-1501]

- $\quad$ Advise and assist staff on elements of BOS that support/impact their staff function. [71-3-0001]

- Perform strength management. [71-3-1002]

- Assist in conduct of replacement operations. [71-3-1003]

- Conduct by-name casualty reporting. [71-3-1004]

- Perform essential personnel actions. [71-3-1005] 
- Coordinate essential financial service. [71-3-1006]

- Provide essential administration service support. [71-3-1007]

- Manage the awards and decorations program. [71-3-1011]

- Assist in the establishment of rear CP. [71-3-1012]

[ARTEP 71-2-MTP]

- Assist in and execute plan for medical assistance and evacuation for unit and staff personnel. [7-1-3912(8)]

\section{Bde S4 section}

[STP 21-II-MQS, Common Tasks]

- Communicate effectively as a commander or staff officer. [03-9001.12-0003]

- Solve problems using the military problem-solving process. [03-9001.13-0001]

- Brief to inform, persuade, or direct. [01-9007.01-0250]

- Supervise the management of accident risk in unit operations. [03-9003.02-0001]

- Implement OPSEC. [03-3711.12-0001]

- Supervise unit maintenance operations. [01-4965.90-0001]

- Supervise PMCS. [03-4966.90-0010]

[STP 21-24-MCT, Common Tasks]

- Prepare SITREP. [071-332-5022]

[ARTEP 71-3-MTP]

- Maintain current status of maintenance and supplies. [71-3-4003]

- Advise and assist staff on elements of BOS that support/impact their staff function. [71-3-0001]

[STP 10-92ABDII-MQS, Quartermaster]

- Determine field locations for combat service support units. [01-9253.00-0003]

- Analyze division medical supply system. [S1-8310.00-6006]

- Determine Class V (conventional) requirements. [01-4000.11-1111] 
- Assess unit capabilities to support proposed operations. [S3-5101.00-0229]

[STP 9-91 BCII-MQS, Ordinance]

- Develop a concept of support for a brigade level combat operation. [01-9253.00-001]

- Evaluate Class IX performance. [01-4716.26-0002]

[STP 55-88 II-MQS, Transportation]

- Determine aircraft requirements to move cargo, equipment, and personnel. [01-7320.70-0460]

- Plan logistics support for maintenance operations. [01-4720.26-0001]

- Plan evacuation of equipment. [01-4999-26-0001]

- Plan convoy operations. [01-7300.75-0500]

- Plan use of HN assets. [01-7320.70-0435]

- Plan highway net use. [01-7320.75-0535]

- Request $\mathrm{HN}$ transportation support. [01-7320.70-0480]

\section{Bde Surgeon}

[STP 21-II-MQS, Common Tasks]

- Communicate effectively as a commander or staff officer. [03-9001.12-0003]

- Solve problems using the military problem-solving process. [03-9001.13-0001]

- Brief to inform, persuade, or direct. [01-9007.01-0250]

- Supervise the management of accident risk in unit operations. [03-9003.02-0001]

- Implement OPSEC. [03-3711.12-0001]

[STP 21-24-MCT, Common Tasks]

- Prepare SITREP. [071-332-5022]

[STP 21-24-MCT, Common Tasks]

- Supervise unit preventive medicine and field sanitation procedures. [081-831-0102]

\section{[ARTEP 71-3-MTP]}

- Advise and assist staff on elements of BOS that support/impact their staff function. [71-3-0001] 
[ARTEP 71-2-MTP]

- Assist in and execute plan for medical assistance and evacuation for unit and staff personnel. [7-1-3912(8)]

[STP 10-92ABDII-MQS, Quartermaster]

- Analyze division medical supply system. [S1-8310.00-6006]

FSB Commander/Support Operations section [STP 21-II-MQS, Common Tasks]

- Communicate effectively as a commander or staff officer. [03-9001.12-0003]

- Solve problems using the military problem-solving process. [03-9001.13-0001]

- Brief to inform, persuade, or direct. [01-9007.01-0250]

- Supervise the management of accident risk in unit operations. [03-9003.02-0001]

- Implement OPSEC. [03-3711.12-0001]

- Supervise unit maintenance operations. [01-4965.90-0001]

- Supervise PMCS. [03-4966.90-0010]

[STP 21-24-SMCT, Common Tasks]

- Prepare SITREP. [071-332-5022]

[ARTEP 71-3-MTP]

- Maintain current status of maintenance and supplies. [71-3-4003]

- Advise and assist staff on elements of BOS that support/impact their staff function. [71-3-0001]

[STP 10-92ABDII-MQS, Quartermaster]

- Determine field locations for combat service support units. [01-9253.00-0003]

- Analyze division medical supply system. [S1-8310.00-6006]

- Determine Class V (conventional) requirements. [01-4000.11-1111]

- Assess unit capabilities to support proposed operations. [S3-5101.00-0229] 
[STP 9-91 BCII-MQS, Ordinance]

- Develop a concept of support for a brigade level combat operation. [01-9253.00-001]

- Evaluate Class IX performance. [01-4716.26-0002]

[STP 55-88 II-MQS, Transportation]

- Determine aircraft requirements to move cargo, equipment, and personnel. [01-7320.70-0460]

- Plan logistics support for maintenance operations. [01-4720.26-0001]

- Plan evacuation of equipment. [01-4999-26-0001]

- Plan convoy operations. [01-7300.75-0500]

- Plan use of HN assets. [01-7320.70-0435]

- Plan highway net use. [01-7320.75-0535]

- Request HN transportation support. [01-7320.70-0480]

\section{Bde SO}

[STP 21-II-MQS, Common Tasks]

- Communicate effectively as a commander or staff officer. [03-9001.12-0003]

- Solve problems using the military problem-solving process. [03-9001.13-0001]

- Brief to inform, persuade, or direct. [01-9007.01-0250]

- Supervise the management of accident risk in unit operations. [03-9003.02-0001]

- Implement OPSEC. [03-3711.12-0001]

[STP 21-24-SMCT, Common Tasks]

- Prepare SITREP. [071-332-5022]

[ARTEP 71-3-MTP]

- Advise and assist staff on elements of BOS that support/impact their staff function. [71-3-0001]

[STP 11-25-II-MQS, Signal]

- Employ communications system of a maneuver brigade or battalion. [01-5841.07-001]

- Manage network traffic routing. [01-5710.07-002]

Bde HHC Cdr and Subordinate and Supporting Unit Cdrs and staffs 
[STP 21-II-MQS, Common Tasks]

- Communicate effectively as a commander or staff officer. [03-9001.12-0003]

- Solve problems using the military problem-solving process. [03-9001.13-0001]

- Brief to inform, persuade, or direct. [01-9007.01-0250]

- Supervise the management of accident risk in unit operations. [03-9003.02-0001]

- Implement OPSEC. [03-3711.12-0001]

- Supervise unit maintenance operations. [01-4965.90-0001]

- Supervise PMCS. [03-4966.90-0010]

- Perform wartime strength accounting. [03-0170.01-1005]

[STP 21-24-SMCT, Common Tasks]

- Prepare SITREP. [071-332-5022]

- Inspect personnel/equipment. [071-328-5301]

- Supervise unit preventive medicine and field sanitation procedures. [081-831-0102]

[ARTEP 71-3-MTP]

- Assist in site selection for command and control facilities to include splitting of CPs. [71-3-1501]

[ARTEP 71-2-MTP]

- Assist in planning for establishment/occupy/depart of assembly areas. [7-1-3002]

- Assist in and execute plan for medical assistance and evacuation for unit and staff personnel. [7-1-3912(8)]

[STP 17-12-II-MQS, Armor]

- Plan and direct combat service support operations at company level. [3-1270.00-0002]

Officer Common Tasks for: Bde S5, Bde FSCOORD/FSO/FSE section, Bde ABE section, Bde ADO, Bde NBC section, Bde ALO, Bde AVLO, Bde NGLO [STP 21-II-MQS, Common Tasks]

- Communicate effectively as a commander or staff officer. [03-9001.12-0003] 
- Solve problems using the military problem-solving process. [03-9001.13-0001]

- Brief to inform, persuade, or direct. [01-9007.01-0250]

- Supervise the management of accident risk in unit operations. [03-9003.02-0001]

- Implement OPSEC. [03-3711.12-0001]

[STP 21-24-MCT, Common Tasks]

- Prepare SITREP. [071-332-5022]

[ARTEP 71-3-MTP]

- Advise and assist staff on elements of BOS that support/impact their staff function. [71-3-0001] 


\section{REFERENCES}

This component identifies the references and sources used by the author to develop the battlefield function (BF) task list. This component provides users with sources for further information.

\section{Field Manuals (FMs)}

6-20 Fire Support in the Airland Battle, May 1988

6-20-40 Fire Support for Brigade Operations (Heavy), January 1990

6-20-50 Fire Support for Brigade Operations (Light), January 1990

6-71 Tactics, Techniques, and Procedures for the Combined Arms Commander, September 1994

7-20 The Infantry Battalion, April 1992

7-30 The Infantry Brigade, October 1995

34-8 Combat Commanders Handbook on Intelligence, September 1992

34-130 Intelligence Preparation of the Battlefield, July 1994

63-20 Forward Support Battalion, February 1990

71-3 Armored and Mechanized Infantry Brigade, January 1996

71-123 Tactics, Techniques, and Procedures for Combined Arms Heavy Forces: Armored and Mechanized Infantry Brigade, Battalion/Task Force, and Company/Team, September 1992

71-100 Division Operations, June 1990

100-5 Operations, June 1993

101-5 Command and Control for Commanders and Staff, August 1993

100-9 Reconstitution, January 1992

Army Training and Evaluation Program (ARTEPs)

1-100-MTP MTP for the Aviation Brigade and Battalion, June 1990 
3-117-40-MTP MTP for Chemical Section and NBC Center, September 1994

71-3-MTP MTP for the Heavy Brigade Command Group and Staff, October 1988

Soldier Training Publication (STP)

3-74II-MQS Military Qualification Standards II, Chemical Branch (74), Company Grade Officer's Manual, March 1991

5-21II-MQS Military Qualification Standards II, Engineer (21), Company Grade Officer's Manual, March 1991

6-13II-MQS Military Qualification Standards II, Field Artillery Branch (13), Company Grade Officer's Manual, March 1991

$6-13 \mathrm{~F} 14$

9-91II-MQS

$10-76 \mathrm{Z} 5$

10-92ABDII-MQS

11-25II-MQS

17-12II-MQS

21-II-MQS

21-24-MCT

34-35II-MQS

34-96B 14

34-245-10-DRILL
Soldier's Manual of Fire Support Tasks, Skill Level 1-4

Military Qualification Standards II, Ordnance Branch (91), Company Grade Officer's Manual

Soldier's Manual of Senior Supply Sergeant Tasks

Military Qualification Standards II, Quartermaster (92AB), Company Grade Officers Manual, March 1991

Military Qualifications Standards II, Signal Corps (25), Company Grade Officer's Manual, August 1991

Military Qualification Standards II, Armor Branch (12), Company Grade Officer's Manual, February 1991

Military Qualification Standards II Manual of Common Tasks for Lieutenants and Captains, January 1991

Soldier's Manual of Common Tasks, Skill Levels 2-4, October 1992

Military Qualification Standards II, Military Intelligence Branch (35), Company Grade Officer's Manual, September 1991

Soldier's Manual of Intelligence Tasks, Skill Level 1-4

Drill Intelligence Section, December 1987 
44-14II-MQS Military Qualification Standards II, Air Defense Artillery Branch (14), Company Grade Officer's Manual, June 1991

55-88II-MQS Military Qualification Standards II, Transportation Branch (88), Company Grade Officer's Manual

\section{U.S. Army Training and Doctrine Command (TRADOC) Pamphlet (PAM)}

\section{Center for Army Lessons Learned (CALL) Publications}

CALL Bulletin No. 1-86, July 86 (need title)

CALL Bulletin 90-6, "News From the Front," April 1994

CALL Bulletin No. 3, Sep 86

NTC Commander's Memorandum, Nov 85

NTC Lessons Learned, CALL Bulletin No. 4: Command and Control System, Feb 87

CALL Bulletin, "News From the Front," January-February 1995

CALL Newsletter No. 90-8, Special Edition, "Winning in the Desert, Tactics, Techniques and Procedures for Maneuver Commanders," September 1990

CALL Newsletter 95-6, "National Training Center’s Fighting with Fires", 1995

CALL 89-1: Non-Mechanized Forces, Spring 89

CALL 89-2: Heavy-Light Lessons Learned, Aug 89

CALL: Corps -Division Lessons Learned, Nov 89

CALL Compendium, Vol. 1: Heavy Forces, Fall 88

CALL: NCO Lessons Learned, Oct 90

CALL CTC Bulletin No. 93-4, July 1993

CALL Newsletter No. 93-3, "The Battalion Staff," July 1993

CALL CTC Bulletin No. 94-1, "Lessons and Information," March 1994 


\section{Other References}

\section{U.S. Army Command General Staff College (CGSC) Student Texts (ST)}

22-102 Command, January 1995

\section{Battle Command Battle Laboratory Publications:}

Battle Command: Leadership and Decision Making for War and Operations Other than War, Battle Command Laboratory, Fort Leavenworth, KS, April 1994

Battle Command Techniques and Procedures: A Commander's Guide for the Coordination and Execution of Battlefield Operating Systems, Battle Command Battle Laboratory, Fort Leavenworth, KS, April 1995

\section{Battlefield Functions:}

BF 15 Task Analysis for Coordinate, Synchronize, and Integrate Fire Support as Accomplished by a Brigade Combat Team, Bartholomew J. Mcllroy, Jr., William J. Mullen, III, J. Douglas Dressel, and Franklin L. Moses, August 1996

BF 20 Direct and Lead Units in Execution of Battle as Accomplished by an Engineer Battalion Supporting a Heavy Brigade, Martin S. Anderson and Robert A. Clagg, In Press 


\section{Appendix A}

\section{INDEX of \\ BRIGADE COMBAT TEAM BATTLEFIELD FUNCTIONS \\ Grouped By Battlefield Operating System (BOS)}

This component lists the thirty-nine (39) battlefield functions (BFs) for each battlefield operating system (BOS) which have been identified as relevant to U.S. Army tactical echelon units. These BFs were identified based on an analysis of Training and Doctrine Command (TRADOC) Pamphlet 11-9, "Blueprint of the Battlefield." The purpose of this component is to depict the BOS and the BF which define each BOS.

$\begin{array}{ll}\text { INTELLIGENCE } & \text { (1) Conduct intelligence planning. } \\ & \text { (2) Collect information. } \\ & \text { (3) Process information. } \\ & \text { (4) Disseminate intelligence. }\end{array}$

MANEUVER (5) Conduct tactical movement.

(6) Engage enemy with direct fire and maneuver.

AIR DEFENSE

FIRE SUPPORT

MOBILITY AND SURVIVABILITY
(16) Take active air defense measures.

(17) Take passive air defense measures.

(7) Employ mortars.

(8) Employ field artillery.

(9) Employ close air support.

(10) Conduct electronic collection and electronic attack.

(11) Conduct battlefield psychological operations.

(12) Employ hical ${ }^{1}$

(13) Conduct counter target acquisition operations.

(14) Employ naval surface fires.

(15) Coordinate, synchronize, and integrate fire support.

(21) Overcome obstacles.

(22) Enhance movement.

(23) Provide countermobility.

(24) Enhance physical protection.

(25) Provide operations security.

(26) Conduct deception operations.

(27) Provide NBC defense.

\footnotetext{
${ }^{1}$ Although U.S. national policy has renounced the use of chemical weapons, this BF is retained because it is a function which might be performed by other nations.
} 
COMMAND AND

CONTROL

COMBAT SERVICE SUPPORT
(18) Plan for combat operations.

(19) Direct and lead units during preparation for the battle.

(20) Direct and lead units in execution of battle.

(28) Provide transport services.

(29) Conduct supply operations.

(30) Provide personnel services.

(31) Maintain weapons systems and equipment.

(32) Provide health services.

(33) Treat and evacuate battlefield casualties.

(34) Conduct enemy prisoners of war (EPW) operations.

(35) Conduct law and order operations.

(36) Conduct civil affairs operations.

(37) Provide sustainment engineering.

(38) Evacuate non-combatants from area of operations.

(39) Provide field services. 


\section{Appendix B}

\section{STRUCTURE OF BATTLEFIELD FUNCTIONS (BFs) RELEVANT TO BRIGADE OPERATIONS}

This component provides a description of each BF and the battlefield operating system (BOS) with which it is aligned. Included with each BF definition is a listing of major doctrinal topics and aspects addressed by the BF. These definitions provide the necessary framework required to understand the focus of each $\mathrm{BF}$. Under most circumstances, heavy brigades will be involved in the accomplishment of some or all aspects of the BF. The involvement can vary from extensive, wherein the $\mathrm{BF}$ is a major focus, to minor, wherein the brigade headquarters only furnishes information. In the latter instances, the involvement may not be sufficient to warrant incorporation into a brigade's training program, although the brigade's responsibilities for the function are likely addressed in its SOP for tactical operations (TACSOP). BF definitions were extrapolated from TRADOC Pam 350-7 "Blueprint of the Battlefield," as well as other doctrinal publications relevant to the applicable BF or BOS.

1. Intelligence BOS - The ways and means of acquiring, analyzing, and using knowledge of the enemy, weather, and terrain required by a commander in planning, preparing, and conducting combat operations. These BFs are continuous throughout the planning, preparation, and execution phases of the battle.

a. BF (1) Conduct Intelligence Planning - The developing and coordinating of information relative to the enemy, weather, and terrain prior to and during the development of the unit OPORD; the planning to collect information from battlefield sources and to acquire intelligence from other headquarters. Focus of this BF is the intelligence preparation of the battlefield (IPB). This BF addresses:

1) Reconnaissance and surveillance plan (R\&S Plan).

2) Integrated threat templates (e.g., doctrinal, event, input to DST).

3) Terrain and weather analysis.

b. BF (2) Collect Information - Obtaining information in any manner from the heavy brigade's elements and from sources outside the heavy brigade (e.g., higher headquarters and adjacent units). This BF includes the tasks associated with managing the processes and activities necessary to collect battlefield information which may eventually be used to provide intelligence relative to the enemy, terrain, and weather. This BF addresses:

1) Information collected as a result of the R \& S Plan.

2) Continuous information collection and acquisition from all sources. 
c. BF (3) Process Information - Converting information into intelligence through collation, evaluation, analysis, integration, and interpretation in a continual process. This $\mathrm{BF}$ addresses:

1) Evaluation of threat information.

2) Evaluation of physical environment information.

3) Integration of intelligence information.

4) Development of enemy intentions.

5) Development of targeting information.

6) Preparation of intelligence reports.

7) Update of situational template.

8) Provision of battlefield area reports.

d. BF (4) Disseminate Intelligence - Transmitting of information by any means (verbal, written, electronic, etc.), from one person or place to another to provide timely dissemination of critical intelligence to all appropriate members of the combined arms team. This BF addresses:

1) The sending of processed intelligence in a timely manner to those on the combined arms team who can, by its receipt, take appropriate actions to accomplish the mission. This includes intelligence on the enemy, terrain, and weather.

2) The sending of raw intelligence directly from those responsible for reconnaissance and surveillance to the commander should that raw intelligence be time sensitive (and not be subject to receipt and processing by intelligence analysts).

3) Dissemination of battlefield reports.

2. Maneuver BOS - The employment of direct fire weapons, platforms, and systems through movement and fire and maneuver to achieve a position of advantage in respect to enemy ground forces, in order to accomplish the mission. The direct fire weapons are tank guns, BFV 25mm, anti-tank guns and rockets, attack helicopter guns and rockets, small arms, crew-served weapons, and directed energy weapons systems.

a. BF (5) Conduct Tactical Movement - Planning for and directing the positioning of direct fire weapons systems relative to the enemy to secure or retain positional advantage, making full use of terrain and formations. Tactical movement occurs when 
contact with the enemy is likely or imminent but direct fire engagement has not yet occurred. Units supporting maneuver units are included. This BF addresses:

1) Subordinate element $O P O R D$ preparation and dissemination.

2) Preparation for movement.

3) Movement, both mounted and dismounted, and on and off road.

4) Closure of movement to tactical assembly area or tactical positions.

5) Navigation.

6) Air movement.

b. BF (6) Engage Enemy with Direct Fire and Maneuver - Planning for and directing elements in ground combat with the enemy using direct fire and/or close combat in order to destroy the enemy or cause him to withdraw. This BF relates only to those direct fire weapons systems associated with the maneuver BOS. This BF addresses:

1) Preparation of engagement areas.

2) Rehearsals of battle plans.

3) Prevention of fratricide.

4) Conduct of close combat.

5) Integration of direct fire with maneuver.

6) Control of terrain.

7) Consolidation and reorganization.

3. Fire Support BOS - The collective, coordinated, and synchronized use of target acquisition data, indirect fire weapons, armed aircraft (less attack helicopters) and other lethal and nonlethal means against ground targets in support of maneuver force operations and to achieve the commander's intent and scheme of maneuver. The fire support BOS addresses these weapons: mortars, field artillery, close air support, electronic measures, and naval surface fires.

a. BF (7) Employ Mortars - Planning for and employment of mortars by the maneuver unit to place fires on the enemy or terrain to support the commander's concept and intent. 
b. BF (8) Employ Field Artillery - Planning for and directing of indirect artillery fires to be placed on the enemy or terrain to support the commander's concept and intent. The fire support coordination tasks necessary to integrate the field artillery and the maneuver units are the primary focus. This BF does not address those field artillery tasks associated directly with those actions taken by the batteries of the artillery battalion in the conduct of their support mission such as FDC operations, gun operations, etc. This $\mathrm{BF}$ addresses:

1) Fire support - maneuver unit rehearsals.

2) FSE operations during the preparation and execution phases of the battle.

3) Positioning and movement within the maneuver unit sector or zone.

4) Indirect fire missions in support of maneuver commander's concept and intent.

c. BF (9) Employ Close Air Support - Planning for, requesting, and employing armed aircraft (less attack helicopters) in coordination with other fire support (lethal and nonlethal) against ground targets in support of the brigade commander's concept and intent. This BF addresses:

1) Air-ground attack requests.

2) Air space coordination and management.

3) Air liaison officer, forward air controller; other Army fire support coordination officers, USN/USMC brigade team commander, SALT and FCT tasks that enable air-to-ground attacks.

d. BF (10) Conduct Electronic Collection and Jamming ${ }^{1}$ - Planning for and directing actions taken to deny the enemy effective command, control, and communications of his own tactical force in support of maneuver commander's concept and intent. This BF includes jamming, deception, and collection.

e. BF (11) Conduct Battlefield Psychological Operations - Planning for and directing the conduct or support of psychological operations (when psychological operations units are available) as an integral part of combat operations to bring psychological pressure to bear on enemy forces and civilians under enemy control in the battle area, to assist in the achievement of tactical objectives in support of the brigade commander's concept and intent.

\footnotetext{
${ }^{1}$ Title and structure change to "Conduct electronic collection and electronic attack" are presently under consideration.
} 
f. BF (12) Employ Chemieal ${ }^{2}$ - Employing chemical agents or other means to degrade enemy capabilities in support of the brigade commander's concept and intent.

g. BF (13) Conduct Counter Target Acquisition Operations - Planning for and directing the suppression (e.g., using smoke or dazzling illumination) to degrade enemy direct observation, optics, radar, sensors, electronic DF equipment, and imaging systems in support of the commander's concept and intent.

h. BF (14) Employ Naval Surface Fires - Planning for and directing naval gunfire in support of the maneuver commander's concept and intent.

i. BF (15) Coordinate, Synchronize, and Integrate Fire Support - Coordinating all fire support means in support of the maneuver commanders' concepts and intents. The BF integrates BF 7-14.

4. Air Defense BOS - The means and measures organic or assigned to the maneuver commander which, when employed successfully, will nullify or reduce the effectiveness of attack by hostile aircraft or missiles after they are airborne.

a. BF (16) Take Active Air Defense Measures - Planning for and directing the application of firepower to destroy enemy air targets. This BF encompasses the coordinating tasks which enable the commander to successfully employ any attached or assigned air defense weapons system, as well as the tasks necessary to employ all organic weapons systems against enemy air targets. This BF addresses:

1) Employment of air defense artillery guns and missiles.

2) Employment of maneuver unit weapons systems such as small arms, automatic weapons, BFV $25 \mathrm{~mm}$ and TOW missiles, and tank main gun against enemy air.

3) Airspace management.

4) Early warning.

b. BF (17) Take Passive Air Defense Measures - Planning for and directing the protection of the unit from enemy air by means other than weapons. This BF addresses:

1) Early warning.

2) Dispersion.

2 Although U.S. national policy has renounced the use of chemical weapons, this BF is retained because it is a function which might be performed by other nations. 


\section{3) Deception.}

5. Command and Control BOS - The ways and means a commander exercises authority and direction over organic and assigned combat power in the accomplishment of the mission.

a. BF (18) Plan for Combat Operations - The integration of all members of the unit in the coordinated development of an operations order which will guide the activities of the unit in conducting combat operations to accomplish assigned missions. The product/outcome of this $\mathrm{BF}$ is a briefed, understood OPORD. This BF addresses:

1) Receipt and analysis of higher HQ OPORD.

2) Issuance of warning order.

3) Restated mission statement.

4) Commander's estimate process/troop leading procedures.

5) Commander's guidance.

6) Mission analysis (includes course of action development).

7) Decision brief to commander.

8) Development of a synchronized OPORD.

9) Reproduction and distribution of OPORD to all participants.

10) Briefing of OPORD; understanding of order by participants.

11) FRAGO planning and issue.

b. BF (19) Direct and Lead Unit during Preparation for the Battle - The ways and means to prepare the unit so that it is ready to support the commander's concept and intent. This BF addresses:

1) Commander's actions and decisions.

2) Directing preparation for the battle.

3) Issuing orders.

4) Communicating information. 
5) Confirmation briefs and backbriefs.

6) Rehearsals.

7) Maintaining and updating information and force status.

8) Decisions to act or change ongoing actions.

9) Confirming IPB through the reconnaissance effort.

10) Determining actions to implement decisions.

11) Synchronizing preparation (e.g., management of time).

12) TOC operations (e.g., staff integration).

13) Second in command (2IC) responsibilities.

14) Continuous and sustained operations.

15) Communications (e.g., planning, installation and operation of system, management, site election).

c. BF (20) Direct and Lead Units in Execution of Battle - The ways and means to command and control the unit's execution of the battle plan to accomplish the commander's concept and intent. This BF addresses:

1) Commander's actions and decisions.

2) Directing the conduct of the battle.

3) Issuing orders.

4) Information distribution.

5) Synchronizing tactical operations (e.g., use of DST).

6) TOC operations (includes $\mathrm{CP}$ displacement, security, survivability, battle tracking).

7) Continuity of command (e.g., C2 redundancy).

8) Second in command (2IC) responsibilities.

9) Continuous and sustained operations. 
10) Consolidation and reorganization.

6. Mobility and Survivability BOS - The ways and means that permit freedom of movement, relative to the enemy, while retaining the force's ability to fulfill its primary mission, as well as the measures the force takes to remain viable and functional by protection from the effects of enemy weapons systems and natural occurrences.

a. BF (21) Overcome Obstacles - Planning for and directing actions to remove or clear/reduce natural and man-made obstacles.

b. BF (22) Enhance movement - Planning for and coordinating elements providing mobility for the unit in its area of operations. This BF addresses:

1) Construction and repair of combat roads and trails.*

2) Facilitating movement on routes. (This includes control of road traffic and control of refugees and stragglers.)*

3) Tracking status of routes.*

4) Host nation support.*

c. BF (23) Provide Countermobility - Planning for and directing actions to delay, channel, or stop enemy offensive movement consistent with the commander's concept and intent by enhancing the effectiveness of friendly direct and indirect weapons systems.

d. BF (24) Enhance Physical Protection - Planning for and directing actions that provide protection of friendly forces on the battlefield by enhancing the physical protection of personnel, equipment and weapons systems, and supplies.

e. BF (25) Provide Operations Security - Planning for and directing action to deny information to the enemy about friendly capabilities and intentions by identifying, controlling, and protecting indicators associated with planning and conducting military operations. This BF addresses:

1) Analysis to determine key assets and threats to them.

2) Monitoring of implementation of OPSEC measures.

3) Physical security measures.

\footnotetext{
* Normally accomplished by units supporting the division.
} 
4) Signal security.

5) Electronic security.

f. BF (26) Conduct Deception Operations - Taking actions in accordance with the division's or corps' deception plan to mask the objectives of tactical operations in order to delay effective enemy reaction. This BF addresses:

1) Physical deception.

2) Electronic deception.

g. BF (27) Provide NBC Defense - The avoidance of contamination; the protection of people, objects or areas from chemical or biological agents by absorbing, destroying, neutralizing, or otherwise rendering harmless or removing such agents; and the removal of radioactive material. This $\mathrm{BF}$ addresses:

1) Decontamination of individual soldiers and equipment.

2) Decontamination of weapon systems and supplies.

3) Hasty and deliberate decontamination.

4) Avoidance of contaminated areas.

5) NBC reconnaissance.

6) NBC defensive measures.

7) NBC warning.

7. Combat Service Support BOS - The support, assistance, and service provided to sustain forces, primarily in the area of logistics, personnel services, and health services.

a. BF (28) Provide Transport Services - Planning for and directing provision or coordination for transportation which will assure sustainment support operations in support of the unit. This BF addresses:

1) Movement of cargo, equipment, and personnel by surface or air.

2) Loading, transloading, and unloading material and supplies.

3) Reporting status. 
b. BF (29) Conduct Supply Operations - Planning for and directing provision of the items necessary to equip, maintain, and operate the force during the preparation and execution phases of the battle. This BF addresses:

1) Requesting, receiving, procuring, storing, protecting, relocating, and issuing supplies to the specific elements of the force.

2) Providing munitions to weapons systems.

3) Providing fuel and petroleum products to equipment and weapons systems.

4) Reporting status.

c. BF (30) Provide Personnel Services - Planning for and directing all personnel-related matters to sustain the force. This BF addresses:

1) Personnel administrative services.

a) Replacement, casualty reporting.

b) Awards and decorations.

c) Postal operations.

d) Promotions, reductions.

2) Financial services.

3) Unit ministry team operations.

4) Legal services.

5) Public affairs services.

6) Preservation of the force through safety.

7) Management of stress.

8) Reporting status.

d. BF (31) Maintain Weapons Systems and Equipment - Planning for and directing preservation and repair of weapons systems and equipment. This BF includes the provision of repair parts and end items to all members of the unit before, during and 
after the battle. Included also is doctrinal echeloning of maintenance (organization, DS, GS). This BF addresses:

1) Recovery.

2) Diagnosis, substitution, exchange, repair and return of equipment and weapons systems to the combined arms force.

3) Reporting status.

e. BF (32) Provide Health Services -Planning for, directing and coordinating health services regardless of location, to promote, improve, conserve or restore the mental or physical well-being of individuals or groups. This BF addresses:

1) Preventive medicine.

2) Field sanitation.

3) Mental health.

f. BF (33) Treat and Evacuate Battlefield Casualties - Planning for and directing the application of medical procedures on battlefield casualties beginning with "buddy aid" through treatment by trained medical personnel. The BF includes movement of casualties from the forward edge of the battlefield back to division-level medical facilities. This BF addresses:

1) Triage of battlefield casualties.

2) Treatment and movement of casualties to rear (MEDEVAC).

3) Evacuation.

4) Handling and processing the remains of soldiers who have died of wounds.

5) Reporting status.

g. BF (34) Conduct Enemy Prisoners of War (EPW) Operations - Planning for and directing the collection, processing, evacuation, and safeguarding of enemy prisoners of war. This BF addresses:

1) Collecting and evacuating EPW.

2) Searching, segregating, safeguarding, silencing, and rapid rearward movement of EPW. 
h. BF (35) Conduct Law and Order Operations - Enforcing laws and regulations and maintaining of unit and personnel discipline.

i. BF (36) Conduct Civil Affairs Operations - Planning for, directing, and/or coordinating assigned tasks to conduct activities which encompass the relationship between the military forces and civil authorities and the citizens in a friendly or occupied country or area when U.S. military forces are present.

j. BF (37) Provide Sustainment Engineering - Planning for and coordinating the actions of elements (when in the unit area), providing repair and construction of facilities and lines of communication. This BF addresses:

1) Rear area restoration.*

2) Construction and maintenance of lines of communication (roads, railroads, ports, airfields).*

3) Construction support:

a) Marshaling, distribution and storage facilities.*

b) Pipelines.*

c) Fixed facilities.*

d) Well drilling.*

e) Dismantlement of fortifications.*

k. BF (38) Evacuate Non-combatants from Area of Operations - Planning for and directing the unit's participation in actions to use available military and host-nation resources for the evacuation of US forces, dependents, US government civilian employees, and private citizens (US and other). This BF addresses:

1) Medical support.

2) Transportation.

3) Security.

4) Preparation of temporary shelters.

* Normally accomplished by units supporting the division. 
5) Operation of clothing exchange facilities.

6) Operation of bathing facilities.

7) Graves registration.

8) Laundry.

9) Feeding.

1. BF (39) Provide Field Services - Planning for and coordinating the provision of service logistics functions by CSS elements*. This BF addresses:

1) Clothing exchange.

2) Shower facilities.

3) Graves registration.

4) Laundry and clothes renovation.

5) Bakeries.

6) Feeding (rations supply, kitchens).

7) Salvage.

* Normally accomplished by units supporting the division. 


\section{Appendix C}

\section{BFs LISTED BY ECHELON}

This component depicts the identification of BFs to the echelon/type unit based on previous research and analysis.

\begin{tabular}{|cl|c|c|c|c|c|c|}
\hline & INTELLIGENCE BOS & $\begin{array}{c}\mathrm{Bn} \\
\text { TF }\end{array}$ & Bde & $\begin{array}{c}\text { FA } \\
\mathrm{Bn}\end{array}$ & $\begin{array}{c}\text { Eng } \\
\mathrm{Bn}\end{array}$ & $\begin{array}{c}\text { FS } \\
\mathrm{Bn}\end{array}$ & $\begin{array}{c}\text { ADA } \\
\text { Btry }\end{array}$ \\
\hline$(1)$ & Conduct Intelligence Planning & $\mathrm{X}$ & $\mathrm{X}$ & $\mathrm{X}$ & $\mathrm{X}$ & $\mathrm{X}$ & \\
\hline$(2)$ & Collect Information & $\mathrm{X}$ & $\mathrm{X}$ & $\mathrm{X}$ & $\mathrm{X}$ & $\mathrm{X}$ & $\mathrm{X}$ \\
\hline$(3)$ & Process Information & $\mathrm{X}$ & $\mathrm{X}$ & $\mathrm{X}$ & $\mathrm{X}$ & $\mathrm{X}$ & $\mathrm{X}$ \\
\hline$(4)$ & Disseminate Information & $\mathrm{X}$ & $\mathrm{X}$ & $\mathrm{X}$ & $\mathrm{X}$ & $\mathrm{X}$ & $\mathrm{X}$ \\
\hline
\end{tabular}

\begin{tabular}{|ll|c|c|c|c|c|c|}
\hline \multicolumn{1}{|c|}{ MANEUVER BOS } & $\begin{array}{c}\text { Bn } \\
\text { TF }\end{array}$ & Bde & $\begin{array}{c}\text { FA } \\
\mathrm{Bn}\end{array}$ & $\begin{array}{c}\text { Eng } \\
\mathrm{Bn}\end{array}$ & $\begin{array}{c}\text { FS } \\
\mathrm{Bn}\end{array}$ & $\begin{array}{c}\text { ADA } \\
\text { Btry }\end{array}$ \\
\hline (5) & Conduct Tactical Movement & $\mathrm{X}$ & $\mathrm{X}$ & $\mathrm{X}$ & $\mathrm{X}$ & $\mathrm{X}$ & $\mathrm{X}$ \\
\hline (6) & $\begin{array}{l}\text { Engage the Enemy with Direct Fire and } \\
\text { Maneuver }\end{array}$ & $\mathrm{X}$ & $\mathrm{X}^{1}$ & & & & \\
\hline
\end{tabular}

\begin{tabular}{|cl|c|c|c|c|c|c|}
\hline & FIRE SUPPORT BOS & Bn & Bde & FA & Eng & FS & ADA \\
TF & & Bn & Btry \\
\hline$(7)$ & Employ Mortars & $\mathrm{X}$ & $\mathrm{X}$ & & & & \\
\hline$(8)$ & Employ Field Artillery & $\mathrm{X}$ & $\mathrm{X}$ & $\mathrm{X}$ & $\mathrm{X}$ & $\mathrm{X}$ & $\mathrm{X}$ \\
\hline$(9)$ & Employ Close Air Support & $\mathrm{X}$ & $\mathrm{X}$ & & & & \\
\hline
\end{tabular}

\footnotetext{
${ }^{1} \mathrm{BF} 6$, as defined, concerns how units will engage the enemy through maneuver and direct fires. The function is performed by the element directly controlling the direct fire systems. Initial analysis indicates that this is accomplished by maneuver battalions, such as a mechanized infantry or armor $\mathrm{Bn} \mathrm{TF}$, and attack helicopter battalions. The brigade commander and brigade staff's involvement in the engagement of the enemy is through direction of the subordinate battalions. Hence, the brigade's control is not direct to the systems involved. Therefore, the brigade involvement is described within the context of BF 18, 19, and 20. Further analysis is required.
} 


\begin{tabular}{|ll|c|c|c|c|c|c|}
\hline FIRE SUPPORT BOS (cont.) & $\begin{array}{c}\text { Bn } \\
\text { TF }\end{array}$ & Bde & $\begin{array}{c}\text { FA } \\
\mathrm{Bn}\end{array}$ & $\begin{array}{c}\text { Eng } \\
\mathrm{Bn}\end{array}$ & $\begin{array}{c}\text { FS } \\
\mathrm{Bn}\end{array}$ & $\begin{array}{c}\text { ADA } \\
\text { Btry }\end{array}$ \\
\hline (10) & $\begin{array}{l}\text { Conduct Electronic Collection and } \\
\text { Jamming }^{2}\end{array}$ & & & & & & \\
\hline (11) & $\begin{array}{l}\text { Conduct Battlefield Psychological } \\
\text { Operations }\end{array}$ & & & & & & \\
\hline$(12) \quad$ Employ Chemical Weapons & & & & & & \\
\hline (13) & $\begin{array}{l}\text { Conduct Counter Target Acquisition } \\
\text { Operations }\end{array}$ & & & $\mathrm{X}$ & & & \\
\hline (14) & Employ Naval Surface Fires & $\mathrm{X}$ & $\mathrm{X}$ & & & & \\
\hline (15) & $\begin{array}{l}\text { Coordinate, Synchronize, and Integrate } \\
\text { Fire Support }\end{array}$ & $\mathrm{X}$ & $\mathrm{X}$ & $\mathrm{X}$ & $\mathrm{X}$ & $\mathrm{X}$ & \\
\hline
\end{tabular}

\begin{tabular}{|cc|c|c|c|c|c|c|}
\hline \multicolumn{1}{|c|}{ AIR DEFENSE BOS } & $\begin{array}{c}\mathrm{Bn} \\
\mathrm{TF}\end{array}$ & $\mathrm{Bde}$ & $\begin{array}{c}\text { FA } \\
\mathrm{Bn}\end{array}$ & $\begin{array}{c}\text { Eng } \\
\mathrm{Bn}\end{array}$ & $\begin{array}{c}\text { FS } \\
\mathrm{Bn}\end{array}$ & $\begin{array}{c}\text { ADA } \\
\text { Btry }\end{array}$ \\
\hline (16) & Take Active Air Defense Measures & $\mathrm{X}$ & $\mathrm{X}$ & & & & $\mathrm{X}$ \\
\hline (17) & Take Passive Air Defense Measures & $\mathrm{X}$ & $\mathrm{X}$ & $\mathrm{X}$ & $\mathrm{X}$ & $\mathrm{X}$ & $\mathrm{X}$ \\
\hline
\end{tabular}

\begin{tabular}{|ll|c|c|c|c|c|c|}
\hline & COMMAND AND CONTROL BOS & $\begin{array}{c}\mathrm{Bn} \\
\mathrm{TF}\end{array}$ & $\mathrm{Bde}$ & $\begin{array}{c}\mathrm{FA} \\
\mathrm{Bn}\end{array}$ & $\begin{array}{c}\text { Eng } \\
\mathrm{Bn}\end{array}$ & $\begin{array}{c}\mathrm{FS} \\
\mathrm{Bn}\end{array}$ & $\begin{array}{c}\text { ADA } \\
\mathrm{Btry}^{4}\end{array}$ \\
\hline (18) & Plan for Combat Operations & $\mathrm{X}$ & $\mathrm{X}$ & $\mathrm{X}$ & $\mathrm{X}$ & $\mathrm{X}$ & \\
\hline$(19)$ & $\begin{array}{l}\text { Direct and Lead Units During Preparation } \\
\text { for Battle }\end{array}$ & $\mathrm{X}$ & $\mathrm{X}$ & $\mathrm{X}$ & $\mathrm{X}$ & $\mathrm{X}$ & \\
\hline$(20)$ & $\begin{array}{l}\text { Direct and Lead Units in Execution of } \\
\text { Battle }\end{array}$ & $\mathrm{X}$ & $\mathrm{X}$ & $\mathrm{X}$ & $\mathrm{X}$ & $\mathrm{X}$ & \\
\hline
\end{tabular}

2 Title and focus change to "Conduct electronic collection and electronic attack" are presently under consideration.

${ }^{3}$ Although U.S. national policy has renounced the use of chemical weapons, this BF is retained because it is a function which could be performed by other nations.

${ }^{4}$ The battle phases of plan, prepare, and execute are inherent to the ADA battery's performance of BF 16, Take Active Air Defense Measures. 


\begin{tabular}{|ll|c|c|c|c|c|c|}
\hline MOBILITY AND SURVIVABILITY BOS & $\begin{array}{c}\text { Bn } \\
\text { TF }\end{array}$ & Bde & $\begin{array}{c}\text { FA } \\
\text { Bn }\end{array}$ & $\begin{array}{c}\text { Eng } \\
\text { Bn }\end{array}$ & $\begin{array}{c}\text { FS } \\
\text { Bn }\end{array}$ & $\begin{array}{c}\text { ADA } \\
\text { Btry }\end{array}$ \\
\hline (21) & Overcome Obstacles & $\mathrm{X}$ & $\mathrm{X}$ & & $\mathrm{X}$ & & \\
\hline$(22)$ & Enhance Movement & & & & $\mathrm{X}$ & & \\
\hline$(23)$ & Provide Countermobility & $\mathrm{X}$ & $\mathrm{X}$ & & $\mathrm{X}$ & & \\
\hline$(24)$ & Enhance Physical Protection & $\mathrm{X}$ & $\mathrm{X}$ & $\mathrm{X}$ & $\mathrm{X}$ & $\mathrm{X}$ & $\mathrm{X}$ \\
\hline$(25)$ & Provide Operations Security & $\mathrm{X}$ & $\mathrm{X}$ & $\mathrm{X}$ & $\mathrm{X}$ & $\mathrm{X}$ & $\mathrm{X}$ \\
\hline$(26)$ & Conduct Deception Operations & & & & & & \\
\hline$(27)$ & Provide NBC Defense & $\mathrm{X}$ & $\mathrm{X}$ & $\mathrm{X}$ & $\mathrm{X}$ & $\mathrm{X}$ & $\mathrm{X}$ \\
\hline
\end{tabular}

\begin{tabular}{|ll|c|c|c|c|c|c|}
\hline COMBAT SERVICE SUPPORT BOS & $\mathrm{Bn}$ & $\mathrm{Bde}$ & $\mathrm{FA}$ & $\begin{array}{c}\text { Eng } \\
\mathrm{BF}\end{array}$ & $\begin{array}{c}\text { FS } \\
\mathrm{Bn}\end{array}$ & $\begin{array}{c}\text { ADA } \\
\text { Btry }\end{array}$ \\
\hline (28) & Provide Transport Services & $\mathrm{X}$ & $\mathrm{X}$ & $\mathrm{X}$ & $\mathrm{X}$ & $\mathrm{X}$ & \\
\hline (29) & Conduct Supply Operations & $\mathrm{X}$ & $\mathrm{X}$ & $\mathrm{X}$ & $\mathrm{X}$ & $\mathrm{X}$ & $\mathrm{X}$ \\
\hline (30) & Provide Personnel Services & $\mathrm{X}$ & $\mathrm{X}$ & $\mathrm{X}$ & $\mathrm{X}$ & $\mathrm{X}$ & \\
\hline (31) & $\begin{array}{l}\text { Maintain Weapons Systems and } \\
\text { Equipment }\end{array}$ & $\mathrm{X}$ & $\mathrm{X}$ & $\mathrm{X}$ & $\mathrm{X}$ & $\mathrm{X}$ & $\mathrm{X}$ \\
\hline (32) & Provide.Health Services & & $\mathrm{X}$ & & & $\mathrm{X}$ & \\
\hline (33) & Treat and Evacuate Battlefield Casualties & $\mathrm{X}$ & $\mathrm{X}$ & $\mathrm{X}$ & $\mathrm{X}$ & $\mathrm{X}$ & $\mathrm{X}$ \\
\hline (34) & $\begin{array}{l}\text { Conduct Enemy Prisoner of War } \\
\text { Operations }\end{array}$ & & $\mathrm{X}$ & & & $\mathrm{X}$ & \\
\hline (35) & Conduct Law and Order Operations & & & & & & \\
\hline (36) & Conduct Civil Affairs Operations & & & & & & \\
\hline (37) & Provide Sustainment Engineering & & & & & & \\
\hline (38) & $\begin{array}{l}\text { Evacuate Non-combatants from Area of } \\
\text { Operations }\end{array}$ & & & & & & \\
\hline (39) & Provide Field Services & & & & & $\mathrm{X}$ & \\
\hline
\end{tabular}




\section{Appendix D}

\section{USER'S GUIDE}

This component is designed to facilitate use of the function analysis. The examples are based on the function analysis (FA) of BF 18--Plan for Combat Operations--as performed by the heavy brigade.

\section{Section 1 - Background on Functional Approach to Training and Battlefield Functions}

Given the task-based nature of Army training, the tools for identifying, structuring, and organizing tasks critical for combat effectiveness are essential to realizing goals of Army training for the 21st century. Providing such tools has been a persistent effort in structuring assessment and planning of collective training. Army Training and Evaluation Program Mission Training Plans (ARTEP-MTPs), which list tasks by mission, represent one approach to provide that structure. A complementary approach has emerged in the use of functional areas.

Several initiatives have considered tasks in relation to functional areas rather than missions. One such approach was adopted at the Combat Training Centers (CTCs). The specific approach developed in the mid-1970s used Battlefield Operating Systems (BOSs) as the framework for after action reviews (AARs) and take home packages. The BOSs are seven functional areas which encompass tactical operations.

In addition, to enhance the utility of the BOS structure, the U.S. Army Training and Doctrine Command (TRADOC) developed the Blueprint of the Battlefield. That work used the BOS structure as a framework to describe the tactical level of war in terms of operating systems, functions, and generic tasks. While the functional hierarchy in the Blueprint of the Battlefield provided finer granularity than the BOS, the Blueprint of the Battlefield did not represent battlefield processes, critical sequences of events, procedural steps, and many of the tasks that must be accomplished.

This research product is part of an effort to improve further the functional structure for planning and assessing collective training through the identification and analysis of Battlefield Functions (BFs). Like the Blueprint of the Battlefield, the BFs orient on functions (activities and processes that occur over time) while retaining granularity that supports task-based training. The $\mathrm{BF}$ analyses extend the Blueprint of the Battlefield in two ways:

- Identify relationships among BOSs, tasks, echelons, and people required to achieve identified outcomes, thus improving representation of battlefield processes and sequences of events.

- Provide explicit ties to tasks derived from ARTEP-MTPs and doctrine, tactics, techniques, and procedures described in doctrinal manuals, applied at CTCs, or identified by experienced field commanders, thus improving representation of procedural steps and tasks that must be accomplished. 
FAs of BFs have been conducted at a level of detail that supports a functional approach to training. The functional approach uses battlefield functions performed by units as the basis for assessing proficiency and planning training. The BF FAs provide content and a framework to apply the functional approach to training. Thirty-nine (39) BFs (Appendix A) are relevant to tactical operations at echelons from battalion through corps. Association of specific BFs to particular type units indicates that those BFs are germane to the unit's training program.

\section{Section 2 - Overview of Components to a BF Function Analysis}

The BF FA conducted as part of this project (Innovative Tools and Techniques for Brigade and Below Staff Training (TTTBBST)) contains seventeen (17) components including this User's Guide. The components allow BF FA users the capability to use the BF FA for a variety of purposes, some of which are described in Section 3 below. The title and a brief description of each BF FA component follow.

Overview: Information is provided concerning the presentation of the BF FA components, the table of organization and equipment (TO\&E) of the type unit for which the BF FA is relevant, and the context in which the FA was developed. The information provides an overview of the analytical approach used for the FA.

Purpose and Outcomes: The overall end result which the BF is supposed to accomplish, termed the purpose, is identified. This component also identifies the endstates or bottom line results necessary to achieve the purpose, termed outcomes.

Flow Charts: This graphical description portrays the sequence of BF tasks within the framework of tactical battle phases (i.e., planning, preparation, execution). This component describes the flow of tasks during each battle phase, the vertical task linkages (to higher and lower echelon units), and horizontal linkages to other BFs for the echelon being analyzed. It also depicts information flow which affects the tasks.

Task Linkages to Other BFs/Units: Tasks performed in other BFs or by other units are described as they relate (i.e., are linked) to the tasks of the BF being analyzed. These descriptions provide verbal details of the relationships portrayed graphically by the Flow Charts. The purpose of this component is to allow the user to incorporate related tasks and participants into a training exercise for this BF. Tasks which link to this analysis have been extracted for BFs or units for which FAs have been accomplished and extrapolated for FAs which have not yet been developed.

Key Participants by Task: The participants required to perform the tasks are identified. Identification is based on the appropriate echelon/type unit TO\&E. It includes special staff members who are critical for task accomplishment. 
Key Inputs and Outputs: The critical information required and generated by participants to successfully accomplish the $\mathrm{BF}$ is identified. Where information results from the performance of the BF tasks, BF information output is identified. One BF's information output normally is provided as another BF's input. Critical input and output are organized by the specific part of the doctrinal product or means used to communicate it. The source of critical information is specific only to the BF echelon and function being analyzed, and is not intended to reflect all the information the product may contain. The linkages of inputs and outputs to specific tasks are depicted in the Flow Charts component.

Task List Summary: The tasks which are described in detail in the Task List are summarized and numbered. The numbers allow cross referencing among BF FA components.

Task Lists: Tasks and supporting tasks necessary to perform the function are listed by battle phase. Normally, the task identifies the primary participants responsible for performing the tasks. The tasks have been extracted from the appropriate ARTEP-MTPs, echelon and functional area field manuals (FMs), and proponent school special texts. The specific sources of references for each task and subtask are shown in brackets [] following the task. Tasks derived from ARTEP-MTPs are referenced with the ARTEP-MTP number and task number, such as [ARTEP 5-145-MTP, Task 05-1-0002/1]. Tasks derived from FMs are referenced with the FM number and page number, such as [FM 5-71-3, p. 2-11]. Tasks identified during interviews with TRADOC school proponent subject matter experts (SMEs), CTC Operations Groups, and Army Forces Command units are referenced as field notes (FN) and the source is reflected, such as [FN-NTC CSS OCs]. Tasks derived from the Center for Army Lessons Learned (CALL) are referenced with the notation LL for lessons learned; the CALL publication number and page number are included, such as [LLCALL Newsletter 95-6, p. 16]. In some cases, the analysis of the BF resulted in identification of tasks for which no doctrinal references could be identified. Such tasks were selected based on author experience and relevant doctrine. These tasks are referenced as author notes [AN]. The references facilitate review of original source material for further detail and context.

Tasks Organized by Outcomes: Tasks and supporting tasks necessary to perform the function are listed by outcome. The component supports analysis of performance related to outcomes to identify tasks for sustainment or remediation training.

Lessons Learned: The lessons learned extracted from the CALL publications relevant to performing this $\mathrm{BF}$ are identified. They are organized and listed by the appropriate task from the Task List component. The purpose of this component is to provide the user with recent tactics, techniques, and procedures (TTP) associated with the performance of the tasks in this BF. 
Gate Tasks: Critical individual or collective tasks which BF participants must be able to perform prior to engaging in the identified BF tasks are listed so that the training can be conducted efficiently and safely.

References: The references and sources used by the analyst are identified.

Index of Brigade Combat Team Battlefield Functions: The thirty-nine (39) BFs relevant to Army tactical echelon units, organized by the BOS they compose, as derived from TRADOC Pamphlet 11-9, Blueprint of the Battlefield, are identified.

Structure of Battlefield Functions Relevant to Brigade Operations: Definitions for the 39 BFs and BOSs they compose are provided.

BFs Listed by Echelon: The occurrences of BFs relevant to training according to echelon/type units are listed. This list is subject to change as research into the relevance of functions continues.

User's Guide: Descriptions are provided of the background of BFs and the Functional Approach to training (Section 1), the components of a BF FA (in this section), and approaches to exploit the flexibility of the BF FA to support multiple Army uses and users (Section 3).

Acronyms and Abbreviations: The acronyms and abbreviations used in the analysis are listed. The acronyms and abbreviations were taken from relevant doctrinal references.

\section{Section 3 - Use of the BF Function Analysis}

The analysis of a function contained in each BF FA can support a variety of purposes. General purposes and information needs will be suggested for force developers, materiel developers, doctrine developers, training developers, and unit commanders.

- $\quad$ Force Developers: Develop personnel systems and organizational structures to support the force. Purpose and Outcomes and Task Lists components, for example, could support identification of required capabilities and tasks that a particular unit or organization must be able to perform. The Flow Charts component could support delineation of a new organizational design.

- Materiel Developers: Develop requirements for new systems to ease performance activities of soldiers and to accomplish new battlefield requirements. Through the identification of requirements, new technologies and processes can be applied to support force needs. The Flow Charts component, for example, could be used to illustrate opportunities to revise procedures to take advantage of enhancements in areas such as information dissemination. 
- Doctrine Developers: Develop new and modify existing doctrine to integrate emerging technologies and to implement changing Army missions and priorities. TTP will evolve to meet new battlefield conditions and requirements as well as to guide combined arms, joint service, and multinational operations. The emphasis in BF FAs on interrelationships can identify gaps in task coverage which should be addressed through revisions to publications such as ARTEP-MTPs.

Training Developers: Develop new and modify existing training programs to support new doctrine, emerging technologies, changes in organization, and reduced resources and training environments. Potential uses of a BF FA to support areas such as development of training support packages (TSP) and development of training aids, devices, simulators, and simulations (TADSS) are discussed in Section 4.

- Unit Commanders: Assess training effectiveness, develop training plans, and execute training. BF FA support for training assessment and planning training events is discussed in Section 4.

Developers and commanders often begin by performing or examining one or more front end analyses (FEAs) to gain an understanding of a relevant issue. Whether they perform FEAs themselves or draw from available analyses (like the BF FAs), information is sought on many topics. Likely topics include the following (with relevant BF FA components):

- What are the objectives/missions of the system? (Purpose and Outcomes)

- What are the vertical and horizontal linkages between elements, and what are the information inputs and outputs associated with these? (Flow Charts, Tasks Linked to Other $\mathrm{BFs} /$ Units, and Key Inputs and Outputs)

- What are the processes and tasks being performed within each element? (Task Lists, Tasks Organized by Outcomes, and Flow Charts)

- Who are the players and/or target audience? (Key Participants by Task)

- What enabling and objective knowledge and skills are required? (Gate Tasks) 
- Are there any experiences and lessons learned that would be helpful? (Task Lists and Lessons Learned Integrated into the Task List)

Two detailed examples of BF FA usage are presented in Section 4 below. These examples demonstrate, first, how unit commanders and, second, how training developers can use BF FAs. The examples should serve as a guide for potential BF FA users in that generic information within the BF FAs is transferable to the other applications.

\section{Section 4 - Unit Commander and Training Developer Use of a BF Task Analysis}

\section{Unit Commanders}

Unit commanders use published Army doctrine as contained in FM 25-100, Training the Force (November 1988), and FM 25-101, Battle Focused Training (September 1990) to assess training effectiveness and to plan training events. The BF FAs provide relevant information for assessment and planning within the intent of those documents. The added information supports functional training which uses proficiency related to functions as the basis for identifying tasks to be trained and structuring training on those tasks. The BF FAs supplement the training and assessment systems and processes already in use by commanders.

\section{Conduct Training Assessment}

The commander assesses the mission essential task list (METL) to identify functions that require attention, to select outcomes for training focus, and to provide specific guidance for training. This functional training assessment allows the commander to perform an analysis across several layers with a successively narrow focus:
a. METL tasks.
b. Each BOS for each METL task that requires remediation or sustainment.
c. Relevant BFs for each BOS that requires remediation or sustainment.
d. Relevant outcomes for each BF that requires remediation or sustainment.

The commander assesses BF performance in the context of the unit METL and the BOS by using the Purpose and Outcomes component. To support the assessment, commanders could develop and complete a worksheet which relates BFs and the outcomes to the METL and BOS, as depicted in Figure D-1, which presents a completed assessment worksheet for BF 18. 
BF 18 Outcomes (extracted from the function analysis):

1. Complete, concise, feasible, suitable, acceptable, and tactically sound brigade orders that conform to doctrinal standards are issued.

2. Brigade orders are received in no more than $1 / 3$ of the available time and understood by key participants and subordinates.

3. Sufficient hard copies of the brigade order and all key accompanying documents are provided to key personnel in accordance with TSOP.

4. Brigade operations, command, and control continue during planning process.

\begin{tabular}{|c|c|c|c|c|c|c|}
\hline \multirow{4}{*}{$\begin{array}{l}\text { Mission Essential } \\
\text { Tasks }\end{array}$} & \multicolumn{5}{|c|}{ CURRENT TRAINING STATUS } & \multirow{4}{*}{$\begin{array}{l}\text { Overall METL } \\
\text { Status }\end{array}$} \\
\hline & \multicolumn{5}{|c|}{ BOS: Command and Control } & \\
\hline & \multicolumn{5}{|c|}{ BF: 18-Plan for Combat Operations } & \\
\hline & \multirow[t]{2}{*}{ Outcomes } & 1 & 2 & 3 & 4 & \\
\hline \multirow[b]{2}{*}{ Defend } & & $P$ & $P$ & $T$ & $P$ & $P$ \\
\hline & \multicolumn{6}{|c|}{$\begin{array}{l}\text { Outcome 1: OPORD generally very good; need more detail on control } \\
\text { measures (excessive risk of fratricide). } \\
\text { Outcome 2: Too slow getting information to supporting battalions--FSB } \\
\text { especially needs support requirements earlier. } \\
\text { Outcome 3: Dissemination is very smooth. } \\
\text { Outcome 4: Weak communications between main CP and adjacent units. }\end{array}$} \\
\hline \multirow{2}{*}{$\begin{array}{l}\text { Attack; Movement to } \\
\text { Contact }\end{array}$} & & $P$ & $U$ & $T$ & $P$ & $P$ \\
\hline & \multicolumn{6}{|c|}{$\begin{array}{l}\text { Outcome 1: Accuracy of graphics questionable--MCOO inaccurate or } \\
\text { unclear--not sure which, may be both. } \\
\text { Outcome 2: Adjacent units never received initial WARNO. } \\
\text { Outcome 3: OPORD distribution continued to be a strength. } \\
\text { Outcome 4: Rear CP: SITMAP and information displays of tactical } \\
\text { situation were not current. }\end{array}$} \\
\hline \multicolumn{4}{|c|}{ Overall BF Status: BF $18=P$} & \multicolumn{3}{|c|}{ BOS Status $=P$} \\
\hline
\end{tabular}

Note: Italics indicate entries made by hypothetical commander.

Figure D-1. Assessment worksheet for heavy brigade performance of BF 18. 


\section{Plan Training Events}

The BF FA supports four steps related to planning a training event. The use of BF FAs to perform each of these tasks is described below.

\section{a. $\quad$ Selecting Tasks and Supporting Tasks To Be Trained}

1) Selection of tasks by outcome or battle phase. When the training assessment identifies outcomes to be achieved, trainers can focus their attention on particular tasks that support the outcome. This process can be streamlined by referring to the Tasks Organized by Outcomes component of a BF FA. The tasks relevant to each outcomes for the BF 18 FA are shown in Figure D-2. While many of the tasks are required by more than one outcome, the supporting tasks will usually vary between the outcomes.

If trainers have no basis for identifying an outcome within the BF or if the training is to focus on a single battle phase, they can select tasks from the Task List Summary component. For most BFs, this component is organized by the battle phases--plan, prepare, and execute--supported by the Flow Chart. The exceptions to that organization are BFs 1 through 4, which cover the Intelligence BOS, and BFs 18 through 20 , which cover the command and control BOS by battle phase. The Intelligence BFs reflect the continuous nature of the intelligence cycle.

\section{BF 18 Outcomes (OC):}

1. Complete, concise, feasible, suitable, acceptable, and tactically sound brigade orders that conform to doctrinal standards are issued.

2. Brigade orders are received in no more than $1 / 3$ of the available time and understood by key participants and subordinates.

3. Sufficient hard copies of the brigade order and all key accompanying documents are provided to key personnel in accordance with TSOP.

4. Brigade operations, command, and control continue during planning process.

\begin{tabular}{|l|l|l|l|l|}
\hline Tasks (from the Task List) & OC 1 & OC 2 & OC 3 & OC 4 \\
\hline $\begin{array}{l}\text { 1. The brigade commander and staff direct and lead the brigade } \\
\text { during planning for the battle. }\end{array}$ & & & $\mathrm{X}$ \\
\hline $\begin{array}{l}\text { 2. The brigade receives an order initiating a new mission from } \\
\text { higher headquarters. }\end{array}$ & $\mathrm{X}$ & $\mathrm{X}$ & & \\
\hline 3. The brigade commander and staff conduct mission analysis. & $\mathrm{X}$ & $\mathrm{X}$ & & \\
\hline $\begin{array}{l}\text { 4. The brigade executive officer directs the staff in the } \\
\text { preparation and issuance of a brigade warning order. }\end{array}$ & $\mathrm{X}$ & & & \\
\hline 5. The brigade commander issues initial planning guidance. & $\mathrm{X}$ & $\mathrm{X}$ & & \\
\hline 6. The brigade commander and staff prepare estimates. & $\mathrm{X}$ & & & \\
\hline 7. The brigade commander and staff develop course(s) of action. & $\mathrm{X}$ & & & \\
\hline 8. The brigade commander and staff analyze course(s) of action. & $\mathrm{X}$ & & & \\
\hline 9. The brigade staff compares course(s) of action. & $\mathrm{X}$ & & & \\
\hline 10. The brigade commander announces decision. & $\mathrm{X}$ & & & \\
\hline 11. The brigade staff prepares the operations order. & $\mathrm{X}$ & $\mathrm{X}$ & $\mathrm{X}$ & \\
\hline 12. The brigade commander and staff issue the operations order. & $\mathrm{X}$ & $\mathrm{X}$ & $\mathrm{X}$ & \\
\hline
\end{tabular}

Figure D-2. Overview of tasks by outcomes for BF 18 FA. 
2) Selection of supporting tasks. Trainers must also select supporting tasks. Supporting tasks are blocks of performance required by the task. Each task and supporting task is structured to describe actions to be performed (e.g., steps) or the end states of the task (i.e., aspects of the standard). The detailed description for each task and supporting task is contained in the Task List component. An excerpt from that component of the BF 18 FA is shown in Figure D-3.

5. The brigade commander issues initial planning guidance. [FM 101-5, Chap 4, p. 4-15]

a. The brigade commander develops planning guidance: [FM 101-5, p. 4-16; FM 71-3, p. 3-3]

1) Using the results of his own mission analysis and his METT-T assessment. [FM 101-5, p. 4-16]

2) Using the results of the brigade staff's mission analysis. [FM 6-20-40, p. 2-1; FM 6-20-50, p. 2-1; FM 6-20-10, p. 1-5; FN-JRTC; FN-194 AR]

b. The brigade XO prepares the brigade staff to receive the brigade commander's guidance. [FM 101-5, p. 4-15; ARTEP 71-3 MTP, Task 71-3-0001/2]

1) Determines who must be present at the commander's guidance briefing, if not SOP (e.g., engineer battalion Cdr, FSCOORD, MP platoon leader).

2) Ensures staff is prepared to take notes on guidance issued (depending on the level of detail and specificity of guidance).

c. The brigade commander issues planning guidance to the brigade staff, which may include: [FM 101-5, p. 4-17; FM 6-20-40, p. 2-1, 2-3; FM 6-20-50, p. 2-1, 2-3; FM 620-10, p. 1-7; ARTEP 71-3 MTP, Task 71-3-0001/3]

1) Enemy COA. [FM 101-5, p. 4-17]

2) Restated mission. [FM 101-5, p. 4-18]

Figure D-3. Example of supporting tasks extracted from the Task List of BF 18 FA.

3) Identification of references. As Figure D-3 also illustrates, the doctrinal source (publication number and task number or page number), in brackets, is included with the listing of each task and supporting task. Trainers can refer to the References component to determine the doctrinal publication title and publication date. They can then refer to doctrinal source material for further detail and context, if desired. Figure D-4 provides examples taken from the References component of BF 18.
Field Manuals (FMs)
6-20-40 Tactics, Techniques, and Procedures for Fire Support for Brigade Operations (Heavy)
6-20-50 Tactics, Techniques, and Procedures for Fire Support for Brigade Operations (Light)
71-3 The Armored and Mechanized Infantry Brigade
101-5 Command and Control for Commanders and Staff (Draft)
Army Training and Evaluation Program (ARTEPs)
71-3 MTP Mission Training Plan for the Heavy Brigade Command Group and Staff

Figure D-4. Excerpt from References component of BF 18 FA. 
4) Identification of techniques and useful training information. As part of the task selection process and the planning of the training event, trainers can refer to the Lessons Learned component. This component identifies lessons learned extracted from the CALL publications. This component also provides information not necessarily contained in the applicable doctrinal references but determined to be relevant to training of the function based on performance history of brigades at the CTCs. In other cases, lessons learned at CTCs may provide a clearer definition of how tasks should be performed and the conditions under which they must be performed. An excerpt from that component of the BF 18 FA is shown in Figure D-5.

\begin{tabular}{|l} 
5. The brigade commander issues initial planning guidance. \\
LL - $\begin{array}{l}\text { Determine the amount of planning guidance the staff requires to develop the plan. } \\
\text { [CALL Newsletter No. 93-3: The Battalion and Brigade Battle Staff, p. 9] }\end{array}$ \\
LL - $\begin{array}{l}\text { Do not suppress the staff's ability to plan by providing excessive planning } \\
\text { guidance. [CALL Newsletter No. 93-3: The Battalion and Brigade Battle Staff, p. } \\
\text { 9] }\end{array}$ \\
LL - \\
Sketch the initial concept of the operation for the staff. [CALL Newsletter No. \\
93-3: The Battalion and Brigade Battle Staff, p. 9]
\end{tabular}

Figure D-5. Excerpt from Lessons Learned Integrated into the Task List component of BF 18 FA.

b. Selecting the Training Audience. After determining which tasks must be trained, trainers should next identify the training audience. The Key Participants by Task component of the BF FA supports that analysis. This component, based on the unit's TO\&E, specifies the participants required to perform the tasks selected for training. One potential result of this review is that trainers may have to coordinate (through the appropriate commanders) with external units to have a specific special staff member participate in the training event. Figure D-6 depicts an example of that component of the BF $18 \mathrm{FA}$.

\section{Tasks}

5. The brigade commander issues initial planning guidance.

\section{Participants}

Bde Cdr, Bde XO, Bde CSM, Bde S2, DS MI Co Cdr, Bde S3, Bde S3-Air, Bde S3 Opns Sgt, CMLO, FSCOORD, FSO, Engr Bn Cdr, ABE, ADLO, AVLO, ALO, Bde S1, Bde Chaplain, Bde Surgeon, MP Plt Ldr, Bde S4, BSO, Bde HQ Co Cmdt, Bde S5 (if assigned)

Figure D-6. Excerpt from Key Participants by Task component of BF 18.

c. Identifying Task Training Sequences and Products To Support Training. Unit trainers must also decide which products and information sources must be replicated or emulated to introduce external stimuli to the training events. The Flow Charts and Key Inputs and Outputs components help determine that information. 
The flow charts are used to determine: (a) the flow of tasks during each battle phase; (b) vertical task linkages (to higher and lower echelon units); (c) horizontal task linkages (to tasks in other BFs for the echelon being analyzed); and (d) information input and output which affect relevant tasks. The flow charts provide a graphical description of tasks as they are sequenced within the framework of the battle phases. Although the sequencing of tasks throughout each battle phase is intended to reflect the flow of tasks, tasks may be performed concurrently or may interact with preceding or subsequent tasks.

The Inputs section of the Key Inputs and Outputs component contains critical information, organized by the doctrinal product or means used to communicate it, required by participants to achieve the purpose of the BF. The information and products described must be replicated to drive training events. The Lessons Learned Integrated into the Task List component can also support identification of conditions to be replicated.

The Outputs section of the Key Inputs and Outputs component describes information which results from the performance of the BF tasks. The Outputs should be covered by performance standards and should usually be covered during the after action review (AAR). An excerpt from the Key Inputs and Outputs component of the BF 18 FA is shown in Figure D-7. 
KEY INPUTS

D - 4 GUIDANCE AND INFORMATION FROM THE DIVISION COMMANDER AND STAFF.

a. Division commanders verbal or written guidance.

b. Operational situation reports (OPSITREPs).

c. Periodic personnel report (PPREPT).

d. Periodic intelligence report (PERINTREP).

e. Periodic operation report (PEROPRPT).

f. Periodic logistics report (PERLOGRPT).

g. Periodic civil affairs report (PERCARPT).

h. Engineer reports.

i. Field artillery reports.

j. Air defense artillery reports.

k. Other reports of planning or critical combat information of interest to the brigades.

\section{KEY OUTPUTS}

\section{Bde - 3 BRIGADE WARNING ORDER}

a. Mission, intent, and CCIR of brigade commander.

b. Graphics.

c. Types of fire support munitions available, including CSR and RSR.

d. Enemy situation.

e. Assets available for collection of information and intelligence.

f. Task organization.

Figure D-7. Excerpt from Key Inputs and Outputs component of BF 18 FA.

d. Determining Prerequisite Training Tasks. If units are to obtain full benefit from training, participants must have previously achieved a level of proficiency in the individual and collective tasks required to enable safe and effective training of the selected tasks. Identification of such prerequisite tasks is accomplished by analyzing the Gate Tasks component. Trainers use this information to provide focus for individual training, subordinate echelon collective training, and staff training. An excerpt from the Gate Tasks component for the BF 1 FA contained in this research product is shown in Figure D-9. 


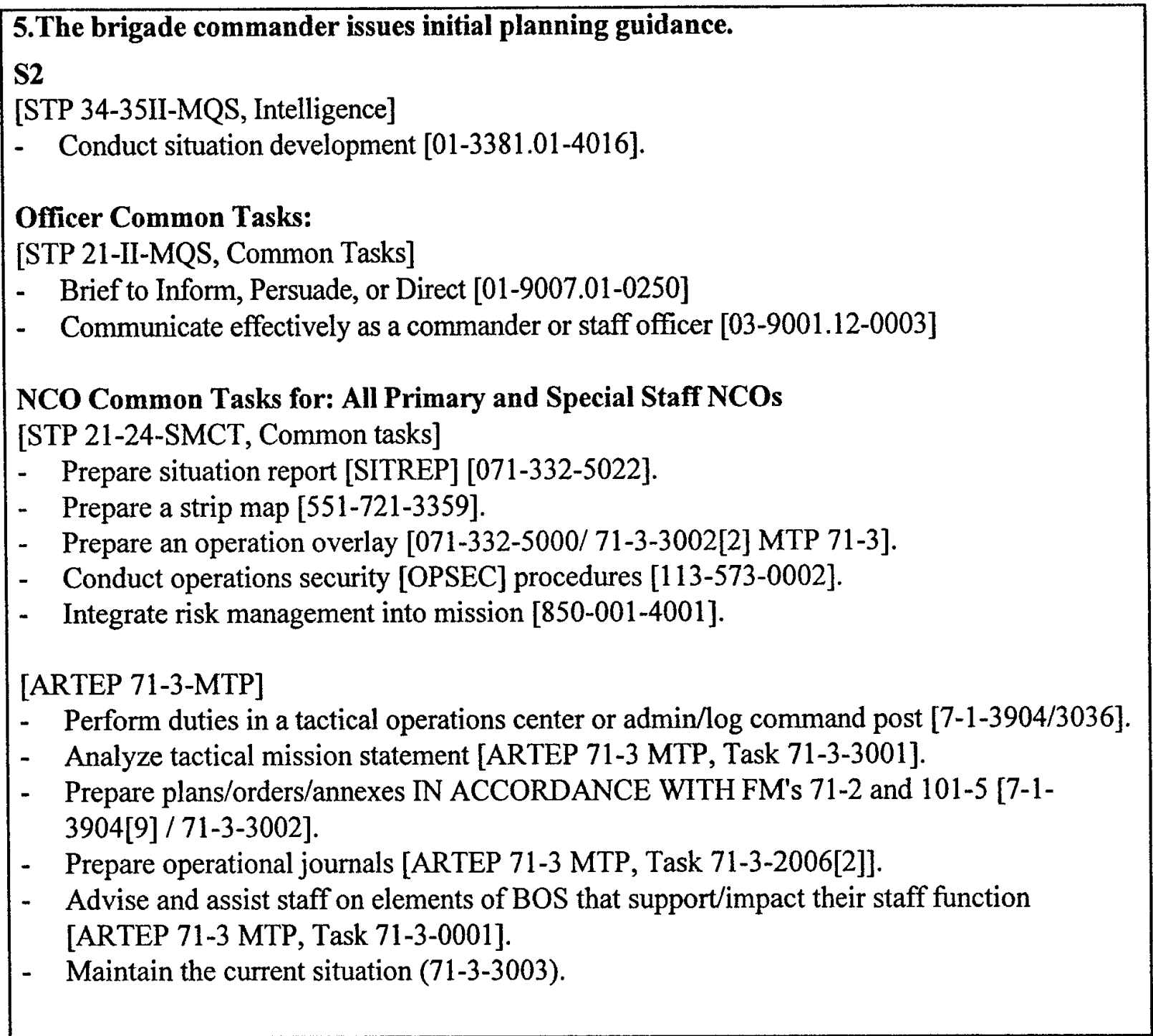

Figure D-8. Excerpt from Gate Tasks component of BF 18 FA.

\section{Training Developers}

The TRADOC service schools (proponents) develop training materials to guide individual and collective training. Training development is conducted within the framework of the systems approach to training. The BF FAs support the systems approach for collective training by identifying not only the tasks for each type of unit, but also horizontal and vertical relationships within each BOS, relationships among BOS, and relevant details about the relationships. The descriptions of interrelationships, which describe the scope of required synchronization plus details about tasks and supporting tasks, provide training developers with information about the content of training which they are supporting. 
Within TRADOC, current training development supports Force XXI. The BF FAs are especially germane to the WARFIGHTER XXI (collective) emphasis. The information in each BF FA can be applied within each of the five WARFIGHTER XXI components:

- $\quad$ Standard Army Training System (SATS)

- TSPS

- TADSS

- Standard After Action Review System (STAARS)

- $\quad$ Army Training Digital Library (ATDL)

\section{Standard Army Training System}

SATS is a computer-based software system that automates training management doctrine. The most direct connection of BF FAs to SATS is through the Combined Arms Training Strategy (CATS). This is the mechanism for establishing long-range and short-range unit training strategies. Each CATS identifies tasks, drills and exercises, TADSS, and resources to support training for each unit type. BF FA components help developers identify tasks to be addressed by the strategy; the FAs are especially useful for identifying staff tasks that are not currently included in ARTEP. MTPs. In addition, BF FAs directly support two elements of the CATS--Training Unit Audience and Prerequisite Training Gates. Training developers can extract information about the audience for training from the Key Participants by Task component. They can find prerequisites for the tasks in the Gate Tasks component. Figure D-9 shows extracts from the CATS for the Armor Battalion Task Force that were based on the BF FAs for the battalion task force.

\begin{tabular}{|l|l|}
\hline Training Unit Audience & Prerequisite Training Gates \\
\hline MOVEMENT TO CONTACT \\
\hline $\begin{array}{l}\text { Full TF, including Slice } \\
\text { (includes FSO/FSE, CEWI }\end{array}$ & $\begin{array}{l}\text { TF Command Posts, Staff and Slice (Attached units, staff } \\
\text { elements, and LNOs) - Assessed at "T" level task proficiency in } \\
\text { Assets, Engineer, ADA, } \\
\text { the performance of BOS functions and supporting tasks: } \\
\text { Trains (BSA)) }\end{array}$ \\
\hline
\end{tabular}

Figure D-9. Extract from CATS for battalion task force.

\section{Training Support Packages}

A TSP for collective training integrates training products, materials, and information necessary to train one or more tasks. BF FAs support development of unit preparation materials, 
tactical materials, and trainer materials. Examples of how the components can contribute to development of TSPs include:

- The Task Lists component or Tasks Organized by Outcomes component can be a useful first draft for a training and evaluation outline. Since both lists may include tasks that are not explicitly described in ARTEP-MTPs, they are especially valuable in designing staff training.

- Training developers can augment the training and evaluation outline by providing tactics, techniques, and procedures drawn from Lessons Learned Integrated into the Task List component.

- Several components work together to specify conditions that must be replicated for realistic training. The Flow Charts and Key Participants by Task components show the type of horizontal and vertical interactions that should be built into the scenario. The Task Lists and Key Inputs and Outputs components describe the scope of those interactions. The inputs and outputs can be especially useful in packaging required information to train particular tasks.

- In addition to setting out the conditions, the Purpose and Outcomes and Key Inputs and Outputs components can be the basis for building "A Way" demonstrations of how the various units, sections, and individuals are synchronized during the operation and what results the event/exercise should produce.

- The Purpose and Outcomes component can be a guide for organizing an AAR. Once an OC identifies an outcome to be sustained or improved, the Tasks Organized by Outcomes component can be used to identify particular tasks and supporting tasks to address in the AAR.

\section{Training Aids, Devices, Simulators, and Simulations}

BF FAs support TADSS development by defining requirements in terms of tasks which should be performed. In other words, the BF FAs describe the "what" of training so that TADSS developers can develop the "how." The FAs are especially valuable for specifying interactions between echelons and among units. Three components give such information: Flow Charts, Tasks Linked to Other BFs/Units, and Key Participants by Task.

\section{Standard After Action Review System}

STAARS will be linked to live, virtual, and constructive exercises and operations with the intent of translating lessons learned into leader development and collective training concepts, methods, and strategies. Since BF FAs structure assessments at successively precise levels (mission, BOS, BF, outcome, and task), they would be well suited to an automated feedback system. The BF FAs can also provide a useful level for aggregating CTC-based lessons learned 
between the task and BOS levels. In the same way that the Purpose and Outcomes component can facilitate AARs by CTC OCs, the information in that component can structure lessons learned.

\section{Army Training Digital Library}

The ATDL is a repository of digital information related to training. BF FAs are compatible with ATDL formats and some FAs have been partially formatted into the Automated Systems Approach to Training. ATDL makes it possible to share the information from BF FA components with commanders in the field through the interactive electronic "library without walls" that provides digitized access to training information. In addition, the BF and outcome structure could be useful in organizing task-related information within ATDL. 


\section{Appendix E}

\section{ACRONYMS AND ABBREVIATIONS}

This component identifies the acronyms used by the authors in the function analysis. Acronyms were derived from relevant doctrinal publications.
A $\quad \mathrm{A} 2 \mathrm{C} 2$
Army airspace command and control
$\mathrm{ABCS}$
Army battle command system
$\mathrm{ABE}$
assistant brigade engineer
ACA
airspace control authority
ACA
airspace coordination area
ACE
armored combat earthmover
AD
air defense
ADA
air defense artillery
ADALO
assistant division air defense officer
ADC
assistant division commander
ADC-M
assistant division commander for maneuver
ADO
air defense officer
$\mathrm{ADW}$
air defense warning
AFATDS
advanced field artillery tactical data system
$\mathrm{AG}$
adjutant general
AGM
attack-guidance matrix
AI
air interdiction
$\mathrm{A} / \mathrm{L}$
administrative/logistics
ALO
air liaison officer 
ALOC

ANGLICO

ARI

ARTEP

ASAS

ASL

ASOC

ASP

ASR

ATO

ATP

AVLB

AVLO

B $\mathrm{BCC}$

BDA

Bde

BF

$\mathrm{Bn}$

BOS

BSA

C $\quad \mathrm{C} 2$ administration and logistics operation center

air and naval gunfire liaison company

Army Research Institute

Army Training and Evaluation Program

all source analysis system

authorized stockage list

air support operations center

ammunition supply point

available supply rate

air tasking order

ammunition transfer point

armored vehicle launched bridge

aviation liaison officer

battlefield circulation control

battle damage assessment

brigade

Battlefield function

battalion

battlefield operating system(s)

brigade support area

command and control 
$\mathrm{C} 2 \mathrm{~W}$

C3

C3I

CALL

CAS

CCF

CCIR

$\mathrm{Cdr}$

CE

CEB

CEWI

CG

CHS

CI

CLAMS

CL I

CL III

CL IV

CL V

CL VIII

CL IX

CMLO command and control warfare

command, control, and communications

command, control, communications, and intelligence

Center for Army Lessons Learned

close air support

critical combat function(s)

commander's critical information requirements

commander

communications and electronics

clothing exchange and bath

combat electronic warfare and intelligence

commanding general

combat health support

counterintelligence

cleared lane marking system

subsistence items

petroleum, oils, lubricants

construction and barrier material

ammunition

medical material

repair parts and components

chemical officer 
CMO

Co

COA

COLT

COSCOM

CP

CSM

CSR

CSS

CTC

CTCP

D DISCOM

Div

DIVARTY

DMMC

DMOC

DMP

DS

DST

DTDD

DTTP civil-military operations

company

course of action

combat observation lasing team

corps support command

command post

command sergeant major

controlled supply rate

combat service support

combat training center

combat trains command post

division support command

division

division artillery

division material management center

division medical operations center

decision-making process

direct support

decision support template

Directorate of Training Development and Doctrine

doctrine, tactics, techniques, and procedures 
E EAC

EC

ECM

EEFI

EMP

Engr

EPW

EW

F

FA

FAC

FASCAM

FFIR

FIST

FM

FM

FRAGO

FS

FSB

FSCL

FSCM

FSCOORD

FSE echelons above corps

electronic combat

electronic countermeasures

essential elements of friendly information

electro-magnetic pulse

engineer

enemy prisoner(s) of war

electronic warfare

function analysis

forward air controller

family of scatterable mines

friendly forces information requirements

fire support team

field manual

frequency modulated

fragmentary order

fire support

forward support battalion

fire support coordination line

fire support coordinating measure

fire support coordinator

fire support element 
FSEM

FSM

FSO

FTCP

G G1

G2

G4

G5

GS

GSR

H HF

HHC

HIMAD

HN

HPT

HPTL

HQ

HSS

I ICW

IFF fire support execution matrix

fire support measures

fire support officer

field trains command post

ACofS, personnel

ACofS, intelligence

ACofS, logistics

ACofS, civil affairs

general support

general support-reinforcing

high frequency

headquarters and headquarters company

high- to medium-altitude air defense

host nation

high payoff targets

high payoff target list

headquarters

health service support

in coordination with

identification, friend, or foe 
IG

INTSUM

IPB

IR

J JAAT

JAG

FRTC

K KIA

L LADW

Idr

LLTR

LNO

LOC

LOGPAC

LRSU

LZ

M $\mathrm{MCI}$

$\mathrm{M} / \mathrm{CM} / \mathrm{S}$

$\mathrm{MCOO}$

MEDEVAC inspector general

intelligence summary

intelligence preparation of the battlefield

information requirements

joint air attack team

Judge Advocate General

Joiint Readiness Training Center

killed in action

local air defense warning

leader

low level transit route

liaison officer

lines of communication

logistics package

long-range surveillance unit

landing zone

minimum critical information

mobility/counter-mobility/survivability

modified combined obstacle overlay

medical evacuation 
METT-T

MI

MIA

MICLIC

MIJI

MOPP

MP

MSB

MSC

MSR

MTP

MWR

N NAI

NBC

NBCWRS

NCS

NGLO

NGO

NSF

NTC

o $\mathrm{OB}$ mission, enemy, terrain, troops, and time available

military intelligence

missing in action

mine clearing line charge

meaconing, intrusion, jamming, and interference

mission-oriented protective posture

military police

main support battalion

major subordinate command

main supply route

mission training plan

morale, welfare, recreation

named area of interest

nuclear, biological, and chemical

NBC warning and reporting system

net control station

naval gunfire liaison officer

naval gunfire officer

naval surface fires

National Training Center

order of battle 
$\mathrm{OC}$

OCOKA

OEG

O\&I

OPSCHED

OPSITREP

P PERINTREP

PEROPRPT

PIR

Plt

PM

PPREPT

PRF

PSR

PSYOP

PZ

R R\&S

RFL

ROE

ROM

$\mathrm{ROZ}$ observer-controller

observation and fields of fire, cover and concealment, obstacles, key terrain, avenues of approach

operational exposure guide

operations and intelligence

operations schedules

operational situation report

periodic intelligence report

periodic operation report

priority intelligence requirements

platoon

provost marshal

periodic personnel report

pulse repetition frequency

personnel strength report

psychological operations

pickup zone

reconnaissance and surveillance

restrictive fire line

rules of engagement

refuel-on-the-move

restricted operations zone 
S

S1

S2

S3

S3 Air

S4

S5

SALT

SCATMINE

SEAD

SITMAP

SITREP

SIT TEMP

SJA

SO

SOF

SOI

SOP

SOR

T TA

TAC CP adjutant/personnel officer, brigade and battalion staff

intelligence officer, brigade and battalion staff

operations and training officer, brigade and battalion staff

operations and training officer - air operations, brigade and battalion staff

supply/logistics officer, brigade and battalion staff

civil-military operations, brigade and battalion staff

supporting arms liaison team

scatterable mine

suppression of enemy air defenses

situation map

situation report

situation template

Staff Judge Advocate

signal officer

special operations forces

signal operating instructions

standing operating procedures

specific orders and requests

target acquisition; task analysis

tactical command post 
TACFIRE

TACP

TAI

TF

TRADOC

TSOP

TSS

TTP

U UAV

UHF

USAF

USMC

USN

V VHF

W WAN

WCS

WIA

WSRO

X XO

Y tactical fire direction system

tactical air control party

targeted area of interest

task force

U.S. Army Training and Doctrine Command

tactical standing operating procedures

target selection standards

tactics, techniques, and procedures

unmanned aerial vehicle

ultra high frequency

United States Air Force

United States Marine Corps

United States Navy

very high frequency

wide area network

weapons control status

wounded in action

weapons system replacement operations

executive officer 
Appendix E for Brigade BF 20

Z

E-12 